On yield gains and yield gaps in wheat-maize intercropping: opportunities for sustainable increases in grain production 


\section{Thesis committee}

\section{Promotor}

Prof. Dr M.K. van Ittersum

Personal chair at the Plant Production Systems group

Wageningen University

\section{Co-promotor}

Dr W. van der Werf

Associate professor, Centre for Crop Systems Analysis

Wageningen University

\section{Other members}

Prof. Dr E. Hoffland, Wageningen University

Prof. Dr J. Olesen, Aarhus University, Denmark

Dr D. Makowski, INRA, Thiverval-Grignon, France

Prof. Dr L.F.M. Marcelis, Wageningen University

This research was conducted under the auspices of the C.T. de Wit Graduate school of Production Ecology and Resource Conservation 


\title{
On yield gains and yield gaps in wheat-maize intercropping: opportunities for sustainable increases in grain production
}

\author{
Fang Gou
}

Thesis

submitted in fulfilment of the requirements for the degree of doctor at Wageningen University

by the authority of the Rector Magnificus

Prof. Dr A.P.J. Mol, in the presence of the

Thesis Committee appointed by the Academic Board

to be defended in public

on Wednesday 11 January 2017

at 4 p.m. in the Aula. 
Gou, F.

On yield gains and yield gaps in wheat-maize intercropping: opportunities for sustainable increases in grain production, 202 pages.

$\mathrm{PhD}$ thesis, Wageningen University, Wageningen, NL (2017)

With references, with summary in English

ISBN: 978-94-6257-981-1

DOI: $10.18174 / 393481$ 


\begin{abstract}
Intercropping is the cultivation of two or more crop species simultaneously in the same field, while relay intercropping means that the growing periods of the crop species are only partially overlapping. Intercropping has advantages with respect to productivity, resource capture, build-up of soil organic matter, and pest and disease suppression. This thesis aims to quantify and explain the yield advantages in wheat-maize relay intercropping and to assess the importance of intercropping for food production and land use efficiency.
\end{abstract}

Wheat-maize intercropping had land equivalent ratios around or above one in two experiments in the Netherlands. Wheat in border rows showed major yield increases, and this yield increase was due to increases in the number of tillers per plant and the number of kernels per ear. The yield advantage of intercropped wheat was associated with a high radiation interception and radiation use efficiency (RUE). Under Dutch growing conditions, maize performance in the intercrop was constrained. Intercropping had a negative effect on the yield per plant and radiation use efficiency of maize. A strip intercrop model was developed, parameterized and tested with data on wheat-maize intercropping in the Netherlands. The model simulates radiation interception and growth in relay-strip intercrops with two species in different planting configurations. The model also allows simulating the consequences of border row effects for total system productivity. Bayesian analysis was applied to calibrate radiation use efficiency of wheat and maize in sole crops and intercrop. Intercropped wheat had higher a RUE than sole wheat, while intercropped maize had a lower RUE than sole maize. Intercropped maize had less favourable leaf traits (e.g. nitrogen content) during the flowering stage than sole maize in 2014, but the leaves in the intercrop had a higher photosynthetic rate than those in the sole crop. Possible explanations for this finding include differences between sole and mixed crops in water acquisition from soil, light distribution in the canopy, nitrogen distribution within the leaf and the contribution of the ear leaf to the growth of the cob. The low radiation use efficiency in intercropped maize may relate to nitrogen deficiency during grain filling. New concepts for potential yield, yield gain and yield gap in intercropping were developed in this thesis. Using crop model simulations and farm survey data, those concepts were operationalized in the context of wheat and maize production in an oasis area (Zhangye city) in northwest China. Wheat-maize intercropping resulted in substantial yield gains under potential and actual growing conditions. A comparison of potential and actual yields indicated a yield gap of $33 \%$ for sole wheat, $49 \%$ 
for sole maize, $15 \%$ for intercropped wheat, and $51 \%$ for intercropped maize. The land use analysis showed that discontinuing the use of intercropping in this region will decrease grain production substantially.

Overall, this thesis studied the growth and productivity of wheat-maize intercropping at organ, plant and cropping system level, and also assessed its contribution to grain production at a regional level. The findings suggest that intercropping of food crops provides opportunities to meet increasing food demands. New technologies are needed to make strip intercropping efficient in terms of labour use and breeding should pay attention to cultivars that are suitable for intercropping.

Key words: Europe, northwest China, intercrop configuration, light interception, radiation use efficiency, intercrop model, leaf traits, photosynthesis, potential yield 


\section{Contents}

Chapter $1 \quad$ General introduction

Chapter 2 Yield and yield components of wheat and maize in wheat-maize 13 intercropping in the Netherlands

Chapter 3 Intercropping wheat and maize increases total radiation interception and wheat RUE but lowers maize RUE

Chapter 4 Simulating potential growth in a relay-strip intercropping system: model description, calibration and testing

Chapter 5 Wheat-maize intercropping lowers leaf nitrogen but increases leaf photosynthesis in maize: a puzzle of plant plasticity and competitive resource acquisition

Chapter 6 On yield gains and yield gaps in intercropping: opportunities for increasing grain production in northwest China

Chapter $7 \quad$ General discussion

References

Appendix A

Appendix B

Appendix C

Summary

Acknowledgements

Publication list

PE\&RC Training and Education Statement

Curriculum vitae

Funding 

Chapter 1

General Introduction 


\section{Chapter 1}

\subsection{Introduction}

The Green Revolution in the twentieth century has remarkably increased global food production and drastically decreased the proportion of the world's people that are hungry. However, the global population is growing beyond 9 billion in 2050 and the grain production must increase $60-70 \%$ to meet the food requirements (FAO, 2009; Alexandratos and Bruinsma, 2012). Meanwhile, the technologies of modern agriculture, particularly the usage of high levels of mineral fertilizers, chemical pesticides and intensive mechanisation in conventional agriculture have caused severe environmental problems, such as the loss of biodiversity, soil erosion and degradation, ground water pollution and greenhouse gas emission (Matson et al., 1997; Gregory et al., 2002). In the future, more sustainable agricultural production methods are required to preserve natural habitats and biodiversity and to protect the climate system (Cassman, 1999; Cassman et al., 2003).

Intercropping is one of the alternative pathways to a more sustainable agriculture (Lithourgidis et al., 2011a; Brooker et al., 2015). It is defined as the cultivation of two or more crop species simultaneously in the same field (Vandermeer, 1989). Compared to sole crops, intercropping systems have distinct advantages with respect to production per unit area (Willey, 1979; Mucheru-Muna et al., 2010; Li et al., 2013) and stability, i.e. reduced crop failure (Rao and Willey, 1980; Clawson, 1985; Horwith, 1985). These advantages are mainly through complementary patterns of resource uptake (light, water, nutrients) between crop species (Trenbath and Francis, 1986) and better nutrient recycling (Lunnan, 1989; AduGyamfi et al., 2007; Rahman et al., 2009), and through suppression of pests (Risch, 1983; Kyamanywa and Tukahirwa, 1988; Andow, 1991), weeds (Baumann et al., 2000; Szumigalski and van Acker, 2005) and diseases (Vilich-Meller, 1992; Zhu et al., 2000). Though intercropping is an ancient agronomic practice and was applied worldwide, it is now mostly used by smallholder farmers in developing countries (Horwith, 1985; Machado, 2009). However, recently it is gaining increasing interest in the context of sustainable agriculture in developed countries, especially for organic agriculture (Bulson et al., 1997; Entz et al., 2001) and for forage production (Carr et al., 2004; Lithourgidis and Dordas, 2010).

The intercropping performance depends on the interactions between different species and between plants and soil, which are all affected by the local climate and crop management. Thus wise choices of species combinations and planting configurations under different 
climate conditions are required, and those characteristics need to be studied before transferring one system from one place to another. In this thesis, I will contribute to this by investigating the plant growth and production of wheat-maize intercropping in two different locations by means of experimentation and crop modelling.
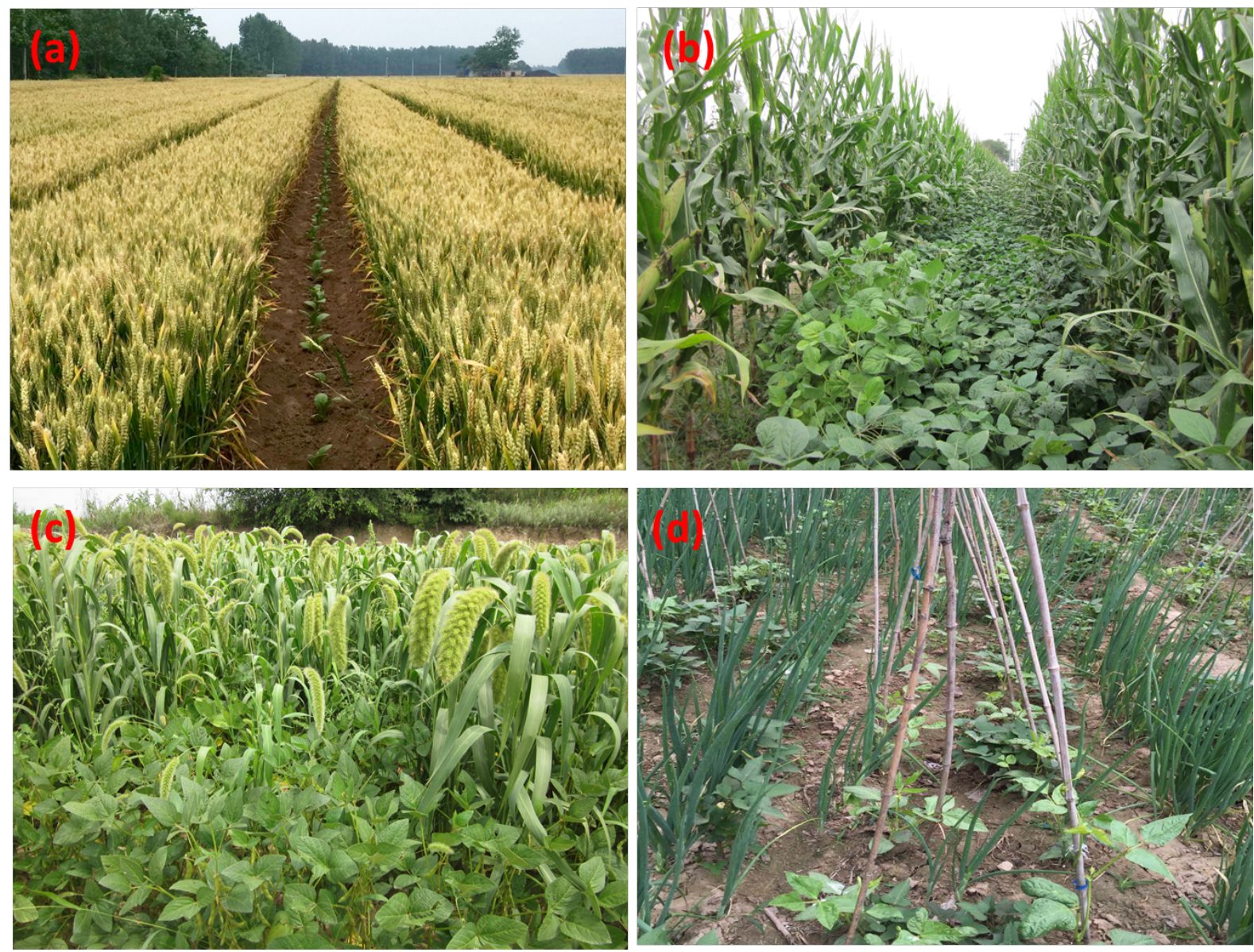

Fig. 1.1 Intercropping systems in farmers' fields in China: (a) strip intercropping of wheat and tobacco; (b) strip intercropping of maize and soybean; (3) mixture of millet and soybean; (d) mixture of leak and cowpea.

\subsection{Wheat-maize relay strip intercropping in China}

In China, the annually sown area of intercropping is estimated at more than 28 million hectares (Li et al., 2007; Liu and Chen, 2005). Knörzer et al. (2009) classified China into four intercropping regions: 1) North Region, where the main systems are annual intercropping of maize with soybean, peanut, potato and millet; 2) Northwest region, where wheat is intercropped with maize, millet, tobacco and soybean; 3) Yellow-Huai River Valley, where the main intercrop systems are wheat-maize, wheat-cotton, maize-soybean in rotation with wheat, and wheat-garlic in rotation with maize; and 4) Southwest Region, where a diversity of 


\section{Chapter 1}

intercropping systems can be found, such as wheat intercropped with all kinds of vegetables in rotation with maize-sweet potato, or maize-sorghum in rotation with wheat. Fig. 1.1 shows four intercropping systems in farmers' fields. They differ in species combinations, planting configurations and sowing time.

In some temperate regions, the number of growing degree days (temperature sum) is not enough to grow two consecutive crops in a growing season but enough to grow two crops that partly overlap in growing season, i.e. relay intercropping. In a relay intercrop, one crop is sown early in the growing season and the second crop is sown or transplanted well after the emergence of the first. Usually, the first crop is harvested before the second. Wheat-maize intercropping is an example of a relay system (Fig. 1.2).
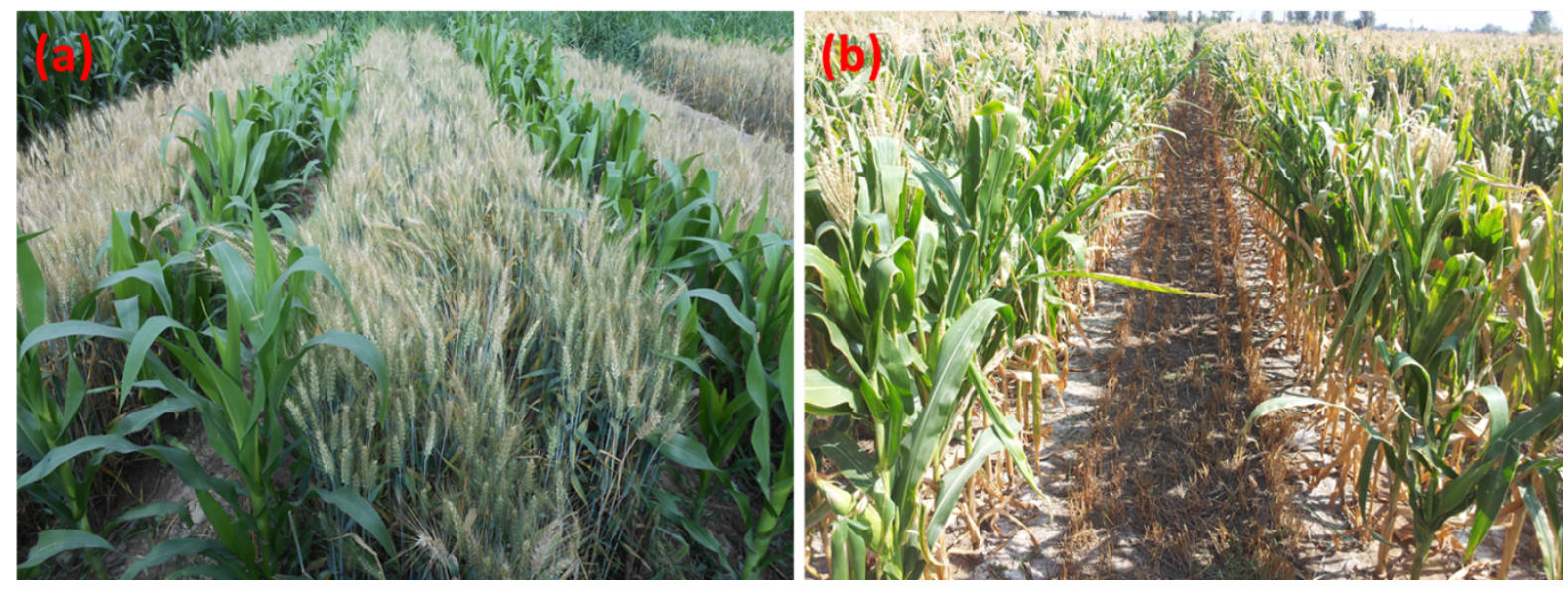

Fig. 1.2 Wheat-maize relay intercrop in farmers' fields in Gansu Province, China, (a) the cogrowth period of wheat and maize in late June, when wheat is at the stage of grain filling, while maize is at the stage of shooting, (b) wheat is harvested in late July, after which maize is grown alone as strips until October.

In the 1960s, wheat-maize relay intercropping was introduced to parts of northwest China (Gansu and Ningxia Province) where the thermal time is not enough to grow two crops in one year, while solar radiation is abundant and irrigation water is available. In this region, wheat is sown in strips of approximately six rows wide in March and harvested in July. Empty space is left between the wheat strips to sow two rows of maize in May in the empty space, while the maize is harvested in September (Fig. 1.2). This relay intercropping system soon spread to 75,100 hectares in Ningxia and 200,000 hectares in Gansu in 1995 (Li et al., 2001b). Wheatmaize intercropping is the focus of this thesis because of the major importance of grain production for global future food security (Fischer et al., 2012), and because of the demonstrated land use advantages of this system. Wheat is a short C3 crop growing in the early 
season, while maize is a tall C4 crop growing later in the season. Their combination has a high potential to increase productivity, due to their physiological properties and the heterogeneous canopy structure. For example, Yu et al. (2015) found that that temporal niche differentiation contributed substantially to high land equivalent ratio (LER) in systems combining a $\mathrm{C} 3$ and $\mathrm{C} 4$ species, while this is not the case in systems based on $\mathrm{C} 3$ species mixtures. However, the wheat-maize system is only practiced by Chinese farmers and not elsewhere. Chinese researchers have actively engaged in quantitative studies on wheat-maize intercrop performance over the last two decades. Studies focused on quantification of yields ( $\mathrm{Li}$ et al., 2001b), radiation use efficiency (Wang et al., 2015) and water use efficiency (Fan et al., 2013), analyses of the soil carbon and nitrogen sequestration in the long term (Cong et al., 2015a; Cong et al., 2015b) and greenhouse gas emission (Hu et al., 2015; Hu et al., 2016), and exploration of belowground root interactions in terms of nutrient mobilization and nutrient transfer between species (Zhang and Li, 2003). Often positive effects were found in those studies, such as higher land use efficiency, higher water use efficiency, greater carbon and nitrogen storage and less greenhouse gas emission per hectare in wheat-maize intercropping compared to sole wheat or sole maize. However, it is unknown whether those advantages will still hold under other climatic conditions. In this thesis, I will test the performance of wheatmaize relay intercropping under Dutch growing conditions, and explore the possible mechanisms underlying performance.

In all wheat-maize intercropping studies, intercropped wheat always shows yield advantage compared to sole wheat, and the yield advantage is mainly from border row effects. For example, Zhu et al. (2016) found that the border row wheat had 141\% higher grain yield per meter row than the sole wheat, and it came from more tillers per plant and a greater number of kernels per ear. In contrast, intercropped maize was negatively affected by intercropping with wheat, especially during its early growth, e.g. lower leaf appearance rate (Zhu et al., 2014), and a lower biomass accumulation per day (Li et al., 2001a). But during the late growth after wheat harvest, a compensatory growth was found, and finally maize yield per plant was higher in the intercrop than in the sole crop. This phenomenon was characterized as a "competition-recovery production principle" by Zhang and Li (2003). The recovery process was partly explained by below ground interactions, that is maize has a greater root space and a longer root life span in an intercrop than in a sole crop (Li et al., 2011). However, no studies have quantified the changes of leaf traits and photosynthetic capacity during the late growing season. This thesis will contribute to filling this knowledge gap. 


\section{Chapter 1}

\subsection{Quantification of intercropping performance in farmers' fields}

In intercropping studies, land equivalent ratio (LER) is the most widely used criterion to compare the performance of intercropping that of to the corresponding sole crops and it is calculated as (Rao and Willey, 1980):

$L E R=L E R_{\mathrm{a}}+L E R_{\mathrm{b}}=\frac{Y_{\mathrm{a}}}{M_{\mathrm{a}}}+\frac{Y_{\mathrm{b}}}{M_{\mathrm{b}}}$

where $Y_{\mathrm{a}}$ and $Y_{\mathrm{b}}$ are the yields for each crop in the intercrop, and $M_{\mathrm{a}}$ and $M_{\mathrm{b}}$ are yields for each species in sole crops, $L E R_{\mathrm{a}}$ and $L E R_{\mathrm{b}}$ are partial land equivalent ratios for each species. A land equivalent ratio of 1.0 indicates the same land productivity for intercropping and sole crops, whereas values greater than 1.0 indicate a land use advantage for intercropping while values smaller than 1.0 indicate a disadvantage for intercropping. An average LER of 1.22 was found by a meta-analysis across 100 intercropping studies ( $\mathrm{Yu}$ et al., 2015), which is equivalent to $22 \%$ more land area being required by sole crops to produce the same yield as in intercrop. To understand this, one example is given here. Song et al. (2006) reported that in year 2004, wheat yield was $6.5 \mathrm{t} \mathrm{ha}^{-1}$ in sole crop and $4.1 \mathrm{t} \mathrm{ha}^{-1}$ in intercrop, maize yield was 11.6 $\mathrm{t} \mathrm{ha}^{-1}$ in sole crop and $8.7 \mathrm{t} \mathrm{ha}^{-1}$ in intercrop in northwest China. The LER is 1.38 according to $E q$. 1.1, and this can be understood as: if we want to produce $4.1 \mathrm{t}$ of wheat and $8.7 \mathrm{t}$ of maize with the productivity of sole crops, then 0.63 ha of land is required to cultivate wheat $(0.63=4.1 / 6.5)$ and 0.75 ha of land is required to cultivate maize $(0.75=8.7 / 11.6)$, the total land area needed to produce the same wheat and maize yield is then 1.38 ha.

As LER is evaluated by comparing the intercrop yields to the sole crop yields, it is difficult to judge the production level by only investigating LER. In addition, this evaluation is only fair when both sole crops and intercrop are grown under the same conditions, for instance wellmanaged field experiments. LER is often used by researchers to compare the productivity of sole crops to intercrop, but it is not an easy term to be understood by farmers and policy makers, thus a new approach is required for the assessment of intercropping performance in farmers' field, in analogy to yield gap analysis in sole crops.

Yield gap is defined as the difference between potential yield and actual yield in sole crops (van Ittersum and Rabbinge, 1997; Lobell et al., 2009; van Ittersum et al., 2013). It is a useful method to examine the actual yields realized in farmers' fields, and to investigate the room for improvement by investing more inputs or using better technologies (Simane et al., 1994; Bell 
et al., 1995; Laborte et al., 2012). Yield gaps have been investigated for rice, wheat and maize grain production in sole crops from regional to global scales (Neumann et al., 2010; Hochman et al., 2012; Mueller et al., 2012; van Ittersum et al., 2013), and a wide range of yield gaps are observed around the world, with average yields ranging from roughly $20 \%$ to $80 \%$ of yield potential (Lobell et al., 2009). The main problems leading to the yields gaps are too high sowing density, untimely sowing, suboptimal variety choice, poor irrigation practice and unbalanced fertilization (Liang et al., 2006). Thus better management practices need to be introduced to improve the current productivity. As intercropping has the potential to produce more yield per unit area than sole crops, the use of intercropping may increase the food production at farm or regional level under current growing conditions and inputs levels. However, the food production difference between the use and non-use of intercropping has not been investigated, while exploiting intercropping could make a critical contribution to food security.

In a sole crop, potential yield is defined as the yield of a crop cultivar when grown with water and nutrients non-limiting and biotic stress effectively controlled (Evans, 1993; van Ittersum and Rabbinge, 1997). However, it is difficult to define potential yield for intercropping systems because there is not one yield, but two, and the balance of productivity between the two species is affected by the planting densities, sowing dates and variety choice. While LER is often used to express the overall yield advantage or disadvantage of intercropping compared to sole crops, the crop combination and planting pattern with the highest LER does not necessarily represent the greatest total yield per unit area of both species. Thus, new methods need to be developed to investigate the potential yields and yield gaps of intercropping.

\subsection{A new intercrop model is required to explore yield potential in intercrop}

Simulating interspecific competition is the core of an intercropping model. Numerous studies have explored the mechanisms of inter-specific competition for radiation (Sinoquet and Bonhomme, 1992; Tsubo and Walker, 2002), water and nutrients (Lafolie et al., 1999; CorreHellou et al., 2009). The partitioning of radiation between species is a key process in determining crop growth and yield formation.

One of the widely adopted strategies for calculating the partitioning of radiation acquisition between plant species in a mixed canopy is to divide the canopy in horizontal strata. This method first calculates the total light interception for each layer using Lambert-Beer's law, and 


\section{Chapter 1}

then computes the share of radiation capture for each species per layer according to its light extinction coefficient and its share in the leaf area (Keating and Carberry, 1993), and finally sums up the radiation interception for all the layers. In this thesis, I call this the horizontally homogenous canopy model (HHC). Many intercrop models have applied this method to simulate the light distribution between species in intercrops, for example: crop-weed competition model INTERCOM (Kropff and van Laar, 1993), celery-leek intercrop (Baumann et al., 2002), pea-barley intercrop (Brisson et al., 2004; Corre-Hellou et al., 2009) and cereal-legume mixture (Tsubo et al., 2005). These models, however, are not suitable to simulate the light competition in relay-strip intercrops, where the border row effect plays an important role in productivity (Zhu et al., 2015; Zhu et al., 2016) and the strength of competition for light depends on the planting configuration (row spacing, sowing density and dates).

A more mechanistic approach to calculate radiation in heterogeneous canopies is functional structural plant modelling (FSPM). However, functional-structural plant models require numerous inputs, such as incident radiation (sun location, diffuse and direct component), canopy structure parameters (plant height, leaf size and leaf inclination and angle distribution) and optical properties of the leaves and the soil surface. Measuring the plant parameters is laborious and parameters are not generally available and may have to be measured again if an intercrop under different conditions is simulated (Sinoquet and Bonhomme, 1992; OzierLafontaine et al., 1997). Recently, a plant architectural model was built based on empirical plant traits data to simulate light capture with and without plant plasticity, providing a very useful approach to investigate how plant plasticity and row configuration contribute to light interception. However, this model is a descriptive model, and does not consider the carbon assimilation process in plant growth (Zhu et al., 2015). Another FSPM intercrop model was built to explore the effect of temporal niche differences on biomass production of a relay intercropping system. This model contains the feedback between light absorption, photosynthesis and the emergence of plant structure and biomass in species mixtures under different conditions of spatial and temporal management. While this model used an ideal plant type with different maximum photosynthetic rate to represent $\mathrm{C} 3$ or $\mathrm{C} 4$ plants, it was not calibrated with real data (Yu, 2016). An FSPM will therefore not be readily suitable for upscaling to regional level, due to the complexity of model parameterization and testing. 
Fortunately, a simple light interception model for row crops was developed by Goudriaan (1977). In this thesis I will call this model as strip-canopy model. This computationally simple model requires few measured inputs describing the LAI, and the width and height of the row structured canopy. It is suitable for calculating the distribution of light in strip intercrops. Zhang et al. (2008) applied this model to calculate light partitioning in a wheat-cotton relay intercrop in which cotton is sown in bare strips in a maturing wheat crop, and where the wheat is harvested seven weeks after cotton emergence. In this case, light interception by wheat was calculated as if it was a sole crop grown in strips interspersed with bare strips, and cotton shading by wheat was considered during the seven weeks-long co-growth period. For wheatmaize relay intercropping, light transfer in the canopy requires more inputs because the period of overlap is longer and their competitive dominance shifts over time. For a proper calculation, the dynamics of plant height and canopy size of two crops during the season must be taken into account. Before maize sowing, wheat light interception can be treated as strip light interception; and from maize emergence until the time that the two crops have the same height, maize shading by wheat is considered and the calculations are similar to the approach in wheat-cotton intercropping; when maize surpasses wheat by height, wheat shading by maize should be taken into account. Quantification of the leaf area, plant height and strip width dynamics are critical to use the strip-canopy model to calculate competitive light capture of two species in an intercrop. In this thesis, I will modify this strip-canopy model to simulate relay-strip intercropping.

Through the combination of the light interception model with the radiation use efficiency (RUE) concept, an intercrop growth model will be developed. The model will be based on the LINTUL model (light interception and utilization). The original LINTUL model was described by Spitters and Schapendonk (1990) and is based on the fact that crop growth rate under favourable conditions is proportional to the amount of light intercepted by the canopy (Monteith, 1977). This model was used to simulate growth and yield of potato (Kooman and Haverkort, 1995; van Delden, 2001), maize (Farré et al., 2000) and winter wheat, winter barley and sugar beet (Angulo et al., 2013). In this thesis, I will calibrate the intercrop model and test it at different locations.

\subsection{Land use studies from farm to regional level}

Though intercropping has been reported to have ecological and economic advantages, a declining trend of intercropping has been reported in North China Plain by Feike et al. (2012). Feike et al. also estimated that only five percent of the arable land in China is currently 


\section{Chapter 1}

cultivated with intercropping systems, based on their observations during field work and travel. The main reasons leading to the decrease of intercropping are presumably the increase of labour price and the migration of rural labour to industry, construction and service sectors in cities, as well as a shift towards more mechanisation in agriculture. Similar trends were also observed in northwest China, where intercropping was widely used by farmers until recently. The main reasons for abandoning intercropping in northwest China are the shortage of water resources and the increasing production of cash crops. For example, in Wuwei city, the farmers are not able to cultivate wheat-maize intercrop under the new irrigation policy, and in Zhangye city, the share of land for grain production is currently much less than that for cash crops (mainly seed crops) (Shi et al., 2014).

Explorative land use studies allow the quantitative analyses of different land use strategies to assess the sustainability of production, and to explore optimal land use strategies subject to different goals (van Ittersum et al., 1998). Such land use studies can be helpful to reveal the role of intercrops in sustainable food systems in regions where intercrops have played or are playing an important role in food security. In this thesis, I will investigate the grain production changes under different land use strategies in northwest China, comparing intercropping to sole crops.

\subsection{Objectives of the thesis}

In this thesis, I aim to quantify and explain the yield advantages in intercropping and to assess the importance of intercropping for local food security and land use. The specific objectives are:

1) to quantify the development and growth, and phenological and morphological characteristics of wheat and maize in an intercropping system as compared to sole crops under Dutch growth conditions;

2) to quantify the radiation interception and radiation use efficiency of wheat-maize intercropping in different row configurations under Dutch growth conditions;

3) to investigate the leaf traits and photosynthesis characteristics of maize in sole crop and in intercrops under Dutch growth conditions; 
4) to develop an intercrop model for potential growing conditions, which can be used for investigating the optimal planting arrangement and yield potential in relay-strip intercropping systems under Dutch growth condition;

5) to calibrate and evaluate the model for Dutch growing conditions and for oasis agriculture in Gansu Province, northwest China;

6) to define and quantify yield gaps in the context of intercropping;

7) to perform a preliminary explorative land use study for northwest China and to assess comparative advantages of intercropping in terms of food production.

\subsection{Outline of the thesis}

The aim of this thesis is to understand and quantify plant growth and yields of wheat and maize intercrops under different growing conditions, including the differences between intercrops and sole crops; the differences between Chinese and Dutch growing conditions; and the differences between potential and actual growing conditions (i.e. in farmers' fields). This thesis consists of seven chapters: a general introduction (Chapter 1), five research chapters (Chapter 2 to 6), and a general discussion (Chapter 7).

Chapter 2 will test the assumption that a similar LER can be obtained in wheat-maize relay intercropping under Dutch growing conditions as in northwest China. In particular, it determines how spatial heterogeneity in planting patterns in an intercrop (e.g. border rows versus inner rows in strips of one species) results in spatial heterogeneity in production. And it will also determine the yield components of wheat and maize to obtain more insight in crop physiological responses underlying the yield response in different planting configurations.

Chapter 3 will determine how row configuration influences radiation interception and productivity in wheat-maize intercropping under Dutch growing conditions. To do so, the strip-canopy light interception model will be modified to use it in relay-strip intercropping, and the performance of the model will be tested with light interception measurements from field experiments. Then, the radiation interception and radiation use efficiency will be analysed in sole wheat, sole maize and wheat-maize intercrop with different row configurations. 


\section{Chapter 1}

Chapter 4 will present an intercrop model for potential growth and production in relay-strip intercropping. The model will be developed based on a sole crop model LINTUL, using the radiation use efficiency concept and a strip-canopy light partitioning module (described in Chapter 3). And the intercrop model will be calibrated and tested with two years of experimental data from the Netherlands. Moreover, results of the strip-canopy model will be compared to those of a horizontally homogenous canopy model (HHC).

Chapter 5 will study the differences in mechanisms of plant growth, yield performance and radiation use efficiency of maize in intercrop and in sole crop from physiological perspective. To achieve this, the leaf traits of maize will be analyzed, including specific leaf area, leaf nitrogen content and leaf chlorophyll content, in sole crop and in intercrop with different row configurations. The photosynthetic rate of those maize leaves during maize grain filling will be investigated.

Chapter 6 will develop new concepts and methods to analyse intercrop performance under potential growing conditions and in farmers' fields in Zhangye city, Gansu Province, northwest China. The difference of grain production between intercrop and sole crops will be quantified (yield gain), both under potential and actual growing conditions; and the difference of grain production between potential and actual growing condition will be investigated (i.e. yield gap), both in sole crop and in intercrop. The potential yields will be simulated by crop models and the actual yields will be collected from a farm survey.

Chapter 7 will synthesize the results of the above chapters and discuss the implications of the results for understanding the mechanisms of growth and yields of wheat-maize intercropping. And the differences of intercrop performances under northwest China and Dutch growing conditions will be compared. Finally, the current state and future prospects of intercropping research and its contribution to future food security will be discussed. 


\title{
Chapter 2
}

\section{Yield and yield components of wheat and maize in wheat-maize intercropping in the Netherlands}

\author{
Fang Gou ${ }^{1,2}$, Martin K. van Ittersum ${ }^{2}$, Guoyu Wang ${ }^{1}$, \\ Peter E.L. van der Putten ${ }^{1}$, Wopke van der Werf $^{1}$ \\ ${ }^{1}$ Centre for Crop Systems Analysis, Wageningen University, P.O. Box 430, 6700 AK \\ Wageningen, The Netherlands \\ ${ }^{2}$ Plant Production Systems group, Wageningen University, P.O. Box 430, 6700 AK \\ Wageningen, The Netherlands
}




\title{
Chapter 2
}

\begin{abstract}
Intercropping is widely used by smallholder farmers in developing countries, and attracting attention in the context of ecological intensification of agriculture in developed countries. There is little experience with intercropping of food crops in Western Europe. Yields in intercrops depend on planting patterns of the mixed species in interaction with local growing conditions. Here we present data of two years' field experimentation on yield and yield components of a wheat-maize intercrop system in different planting configurations in the Netherlands. Treatments included sole crops of wheat (SW) and maize (SM), a replacement intercrop consisting of strips of six wheat rows alternating with two maize rows (6:2WM), as well as subtractive or additive designs, based on skip-row (6:0WM, $0: 2 \mathrm{WM}$ ) and add-row (8:2WM, 6:3WM) configurations. The land equivalent ratio (LER) of intercrops varied from 1.18 to 1.30 in 2013 and from 0.97 to 1.08 in 2014 . Wheat grown in the border rows of wheat strips had higher ear number per meter row, greater kernel number per ear, and greater yield per meter row than wheat in inner rows and sole wheat, indicating reduced competition. Wheat in the border rows in the intercrops had, however, reduced thousand kernel weight and harvest index, indicating that competition in border rows intensified over time. Intercropping negatively affected maize biomass and thousand kernel weight, especially in add-row treatments. This study indicates that there is a potential yield benefit for the wheat-maize intercropping system under Western European growing conditions. However, the LER was affected by yearly variation in weather conditions and significantly greater than one in only one of the two years of the study.
\end{abstract}

Key words: Europe, intercrop configurations, border row effect, LER 


\subsection{Introduction}

Global grain production has more than doubled in the past half-century due to genetic improvements, application of fertilizers and pesticides, and improved water management (Tilman et al., 2002; Valipour et al., 2015). Yet, the world is projected to need $60-70 \%$ more food to feed 9.5 billion people by 2050 (Alexandratos and Bruinsma, 2012), thus further improvement in productivity are crucial for food security in the future (Tilman et al., 2002; Spiertz, 2013). Intercropping is the cultivation of two or more crop species simultaneously in the same field (Vandermeer, 1989), which has potential advantages such as higher overall productivity, better pest and disease control and enhanced ecological services (Malézieux et al., 2009; Lithourgidis et al., 2011a). Intercropping has been used for millennia by smallholder farmers in Asia, Africa and Latin America to increase yields per unit land and exploit species complementarities, and is still widely practiced. Relay intercropping is a special form of intercropping in which two or more crop species overlap only partially in growing period (Vandermeer, 1989). In a relay intercrop, the second crop is sown or planted well after emergence of the first. Usually, the first crop is harvested before the second. Wheatmaize intercropping is an example of a relay system.

Wheat-maize intercropping is practiced in northwest China, notably Gansu province and Ningxia autonomous region ( $\mathrm{Li}$ et al., 2001b). In these regions, the thermal time is not sufficient to grow wheat and maize after each other in one growing season as in the North China Plain (south of Beijing), but the temperature sum is sufficient to grow two species with partially overlapping growing periods as a relay intercrop. In the wheat-maize intercrop, wheat is sown in strips of approximately six rows wide in spring and harvested in midsummer. Empty space is left between the wheat strips to sow maize in the late spring, approximately two to three months before the harvest of wheat. Usually, two maize rows are sown in the empty space. The planting pattern conforms to a replacement design in which the relative densities (density in intercrop/density in sole crop) of the component species sum to one. Maize is harvested approximately two to three months after wheat, depending on local temperature regimes. A relay intercrop enables a longer total growth duration than a sole crop, and the associated greater radiation capture over the whole season tends to increase yields compared to sole crops, even when taking into account that the intercropped species are not covering the field completely (Yu et al., 2015). For instance, Zhang et al. (2008) estimated that wheat and cotton in a winter wheat-spring cotton relay intercrop each intercepted 


\section{Chapter 2}

approximately $70 \%$ as much radiation as sole crops, explaining the relative yields of each of the species also amounting to values close to $70 \%$. Thus, the whole system outperforms the sole crops. Wang et al. (2015) found that total light interception in wheat-maize intercrop in Inner Mongolia, China, was up to $30 \%$ higher than in sole wheat and $10 \%$ higher than in sole maize, resulting in land equivalent ratios (LERs) above one.

Strip intercropping has not drawn much attention in developed countries because of the challenge of mechanisation. However, given the need for increased agricultural production for food and feed on limited land, and the call for a sustainable intensification of agriculture, the principles of intercropping deserve renewed interest to derive possible options for sustainable intensification of agriculture (Lithourgidis et al., 2011a). Intercropping studies in Europe focus on cereal-legume systems, and the different crops were often sown and harvested simultaneously. For example, different combinations and seed ratios of legumes (common vetch or pea) and cereals (wheat, barley, oat, triticale, or rye) were investigated for exploring higher forage yield and protein concentration mixture in Greece (Lithourgidis et al., 2006; Dhima et al., 2007; Lithourgidis et al., 2007; Lithourgidis et al., 2011b). Nitrogen fixation and acquisition were studied in pea-barley intercrops in Denmark (Hauggaard-Nielsen and Jensen, 2001; Hauggaard-Nielsen et al., 2003; Andersen et al., 2005; Ghaley et al., 2005) and in France (Corre-Hellou et al., 2006). Some other examples refer to intercropping for grain production in organic farming, e.g. wheat-bean intercrop in the United Kingdom (Bulson et al., 1997), oat-pea intercrop in Finland (Kontturi et al., 2011), and cereals (wheat, barley, oat or triticale) intercropped with pea in Lithuania (Arlauskiene et al., 2011). As the crops in these systems were generally harvested simultaneously, mechanical separation after harvest is needed to make the system suitable for mechanization (Bulson et al., 1997). An analysis of 58 European field experiments revealed that cereal-legume intercrops had higher gross biomass and grain yield $\left(0.33\right.$ versus $\left.0.27 \mathrm{~kg} \mathrm{~m}^{-2}\right)$, as well as improved abiotic nitrogen fixation and higher grain protein concentration (11.1 versus 9.8\%) than cereal sole crops (Bedoussac et al., 2015).

There is currently no information in the literature on the productivity under European growing conditions of an intercrop of a C3 cereal with a C4 cereal. Here, we study the wheat-maize intercrop system to determine whether growing such a system is at all attractive under European conditions, and to determine the effect of planting patterns. We pay particular attention to the performance of border rows of the wheat strips as these experience no 
competition during their early growth and may be highly productive as a result, due to, e.g. strong tillering and gap filling responses (Li et al., 2001b; Zhang et al., 2007). Furthermore, we quantify yield components because these provide insight in the strength of early versus late competition. In wheat, for instance, early competition will affect tillering, while late competition will affect kernel filling. Thus, yield components can help diagnose mechanisms underlying system performance and suggest options for system improvement.

The aim of this study was 1) to quantify the yield and yield components of wheat and maize in different configurations under potential growing conditions in Western Europe, and 2) to understand how border rows and inner rows of wheat and maize in different wheat-maize intercropping configurations contributed to total productivity. Care was taken to avoid drought or nutrient stress and to control pests, diseases and weeds, therefore the growing conditions may be considered near potential (van Ittersum and Rabbinge, 1997). Three hypotheses were formulated: 1) we assume that the principles that govern the productivity of intercrops under Western European conditions are similar to those determining demonstrated high productivity under Chinese conditions; hence we expect a LER greater than one. 2) We hypothesize that the land use advantage of intercropping mostly results from enhanced resource capture and yield in border rows. We also tested systems from which one of the crop species was entirely omitted (skip-row treatment) to measure the maximum border row effect, defined as the difference in yield per plant (operationally: per meter row) in inner and border rows of the wheat strip. 3) Wheat-maize intercropping is characterized by partial temporal overlap of the growth periods of the two species. As a result of this, the species are not fully competing for resources, and we hypothesize that resource capture and yield may be increased by increasing densities of one or both of the component species beyond simple replacement, in order to achieve maximum gap filling.

\subsection{Material and Methods}

\subsubsection{Experimental set up}

The experiments were designed to contrast intercrops with sole crops, and to quantify the border row effects. There were seven treatments: sole crops of wheat (SW) and maize (SM), replacement intercrop (6:2WM), skip-row designs (6:0WM, 0:2WM), and add-row designs (8:2WM, 6:3WM) (Table 2.1 and Fig. 2.1). Sole crops were sown according to local practice: 250 plant $\mathrm{m}^{-2}$ for wheat and 10 plants $\mathrm{m}^{-2}$ for maize. Row distance was $12.5 \mathrm{~cm}$ in wheat and 75 
$\mathrm{cm}$ in maize. In the replacement design, one of every three maize rows was replaced by six rows of wheat, thus the relative density (intercrop relative to sole crop) of maize was $2 / 3$, and the relative density of wheat was $1 / 3$. Skip-row treatments were sole crops in which some rows were skipped, as if the companion crop was omitted from an intercrop, leaving only one of the species. These treatments allowed identifying the maximum border row effect. Add-row treatments were included to test the hypothesis that the relaxation of competition in an intercrop as compared to sole crops could result in some resource "leakage", i.e. resources not being fully intercepted and absorbed, e.g. radiation being lost on the soil, while increasing densities beyond replacement could remedy this leakage and achieve greater yield.

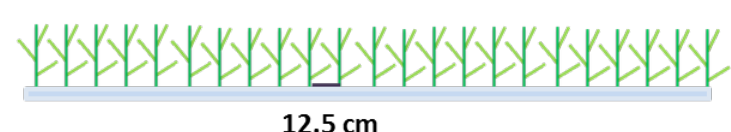

Treatment 1 Sole Wheat (SW)

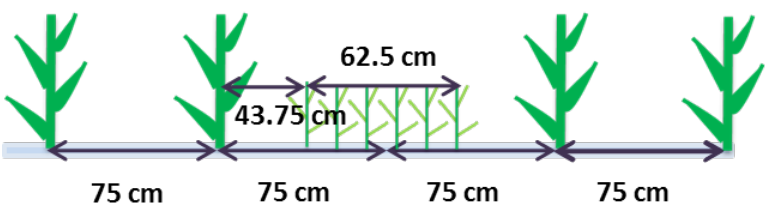

Treatment 3 Replacement Intercrop (6:2WM)

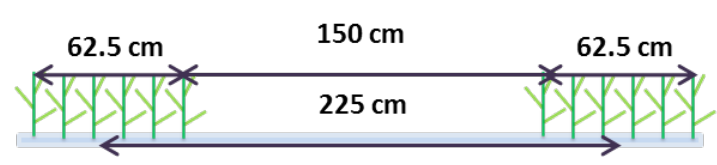

Treatment 4 Wheat Skip-row (6:0WM)

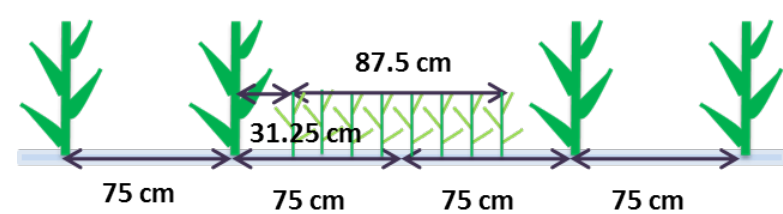

Treatment 6 Add-row Intercrop (8:2WM)

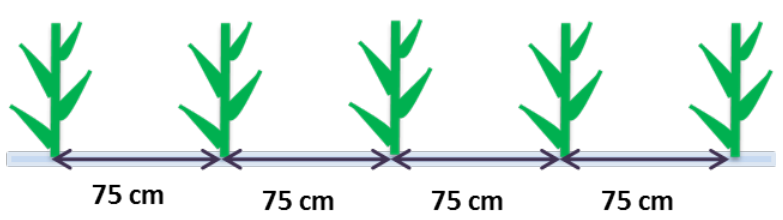

Treatment 2 Sole Maize (SM)

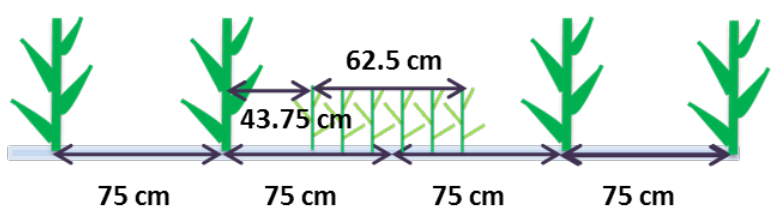

Treatment 3 Replacement Intercrop (6:2WM)

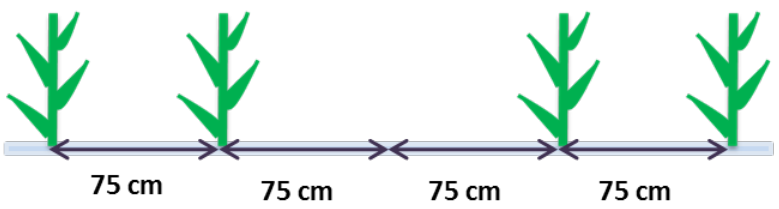

Treatment 5 Maize Skip-row (0:2WM)

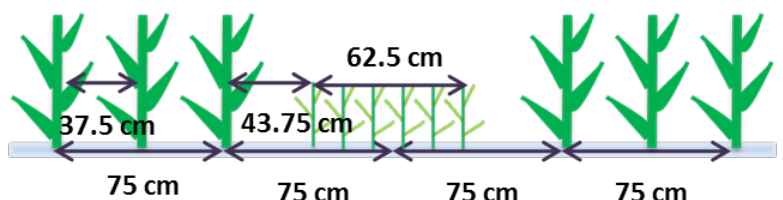

Treatment 7 Add-row Intercrop (6:3WM)

Fig. 2.1 Schematic illustration of row placement of wheat and maize in different experimental planting patterns. Treatment 1 is a sole wheat crop sown at $12.5 \mathrm{~cm}$ row distance. Treatment 2 is a sole maize crop sown at $75 \mathrm{~cm}$ row distance. Treatment 3 (shown twice for symmetry) is a replacement intercrop in which one maize row $(75 \mathrm{~cm}$ width) out of each three maize rows is replaced by six rows of wheat $(6 \times 12.5 \mathrm{~cm})$. Treatment 4 is wheat skip-row, achieved by omitting the maize from the replacement intercrop. Treatment 5 is maize skip-row, achieved by omitting the wheat from the replacement intercrop. Treatments 6 and 7 are add-row treatments in which wheat and maize rows, respectively, are added to the replacement design of treatment 3 . 


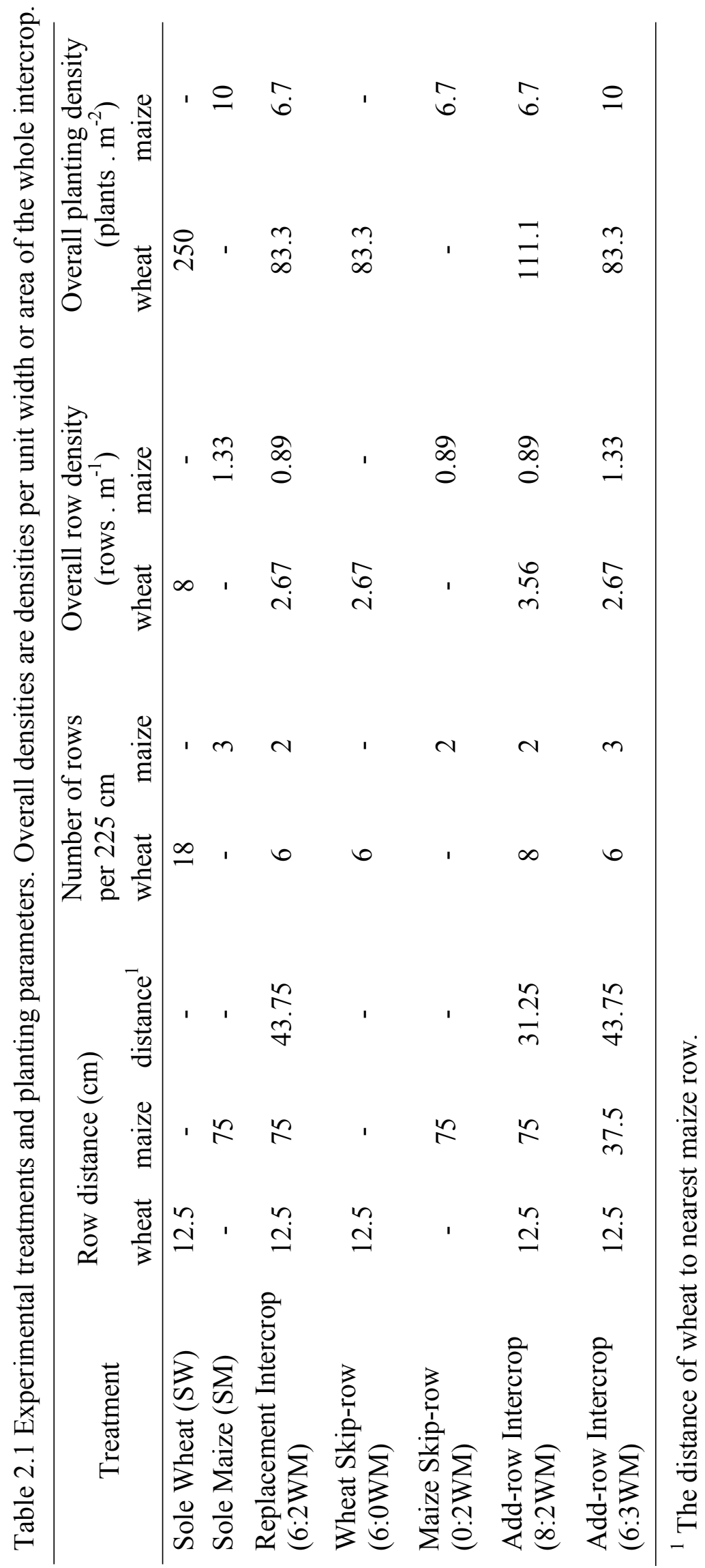


Chapter 2

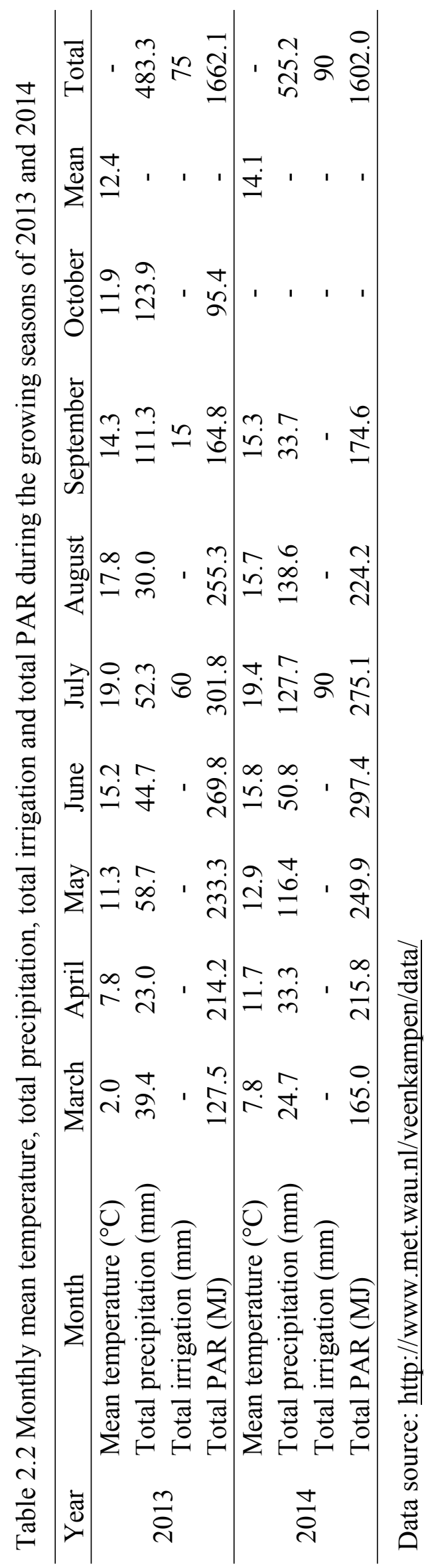



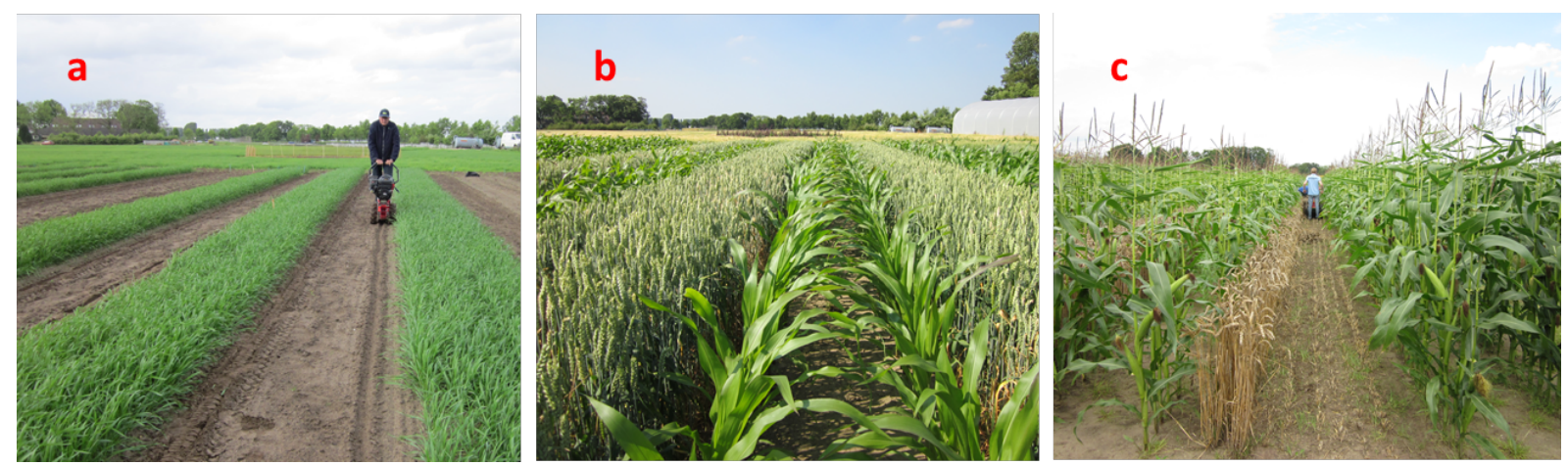

Fig. 2.2 Field management of wheat-maize intercrop (a: sowing maize in the empty space of wheat strips; $b$ : wheat and maize have similar plant height; $c$ : harvesting wheat between maize strips).

\subsubsection{Experimental site and field management}

Field experiments were conducted in 2013 and 2014 at the Wageningen University Farm in

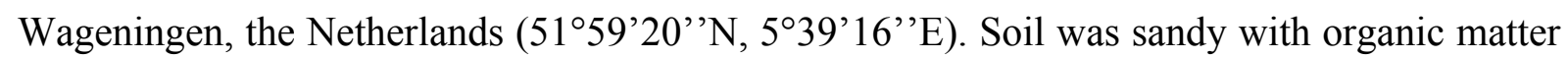
$3.1 \%$ and a $\mathrm{C} / \mathrm{N}$ ratio in the organic matter of 14 . Climate in the region is oceanic temperate (Table 2.2). In 2013, spring wheat was sown on 21 March and harvested on 20 August, while maize was sown on 14 May and harvested on 16 October. In 2014, spring wheat was sown on 13 March and harvested on 4 August, while maize was sown on 7 May and harvested on 23 September (Fig. 2.2). We used the wheat variety "Tybalt" and the maize variety "Atrium". A randomized complete block design with six (2013) and four (2014) replicates was used. Plot size was $9.75 \mathrm{~m}$ width by $22.5 \mathrm{~m}$ length in 2013, and $7.5 \mathrm{~m}$ width and $23 \mathrm{~m}$ length in 2014 . The row orientation was approximately Northwest in 2013 and North in 2014.

Fertilizer was applied homogeneously throughout the experiment (Kuhn pneumatic spreader, $18 \mathrm{~m}$ width). Before wheat sowing, $\mathrm{K}_{2} \mathrm{SO}_{4} \cdot \mathrm{MgSO}_{4}$ and $\mathrm{Ca}\left(\mathrm{H}_{2} \mathrm{PO}_{4}\right)_{2} \cdot \mathrm{H}_{2} \mathrm{O}$ were applied to supply phosphorus, potassium and calcium (Table A1, Appendix A). Total available nitrogen consisting of soil mineral nitrogen (18 $\mathrm{kg} \mathrm{N} \mathrm{ha}^{-1}$ in $2013,7 \mathrm{~kg} \mathrm{~N} \mathrm{ha}^{-1}$ in 2014) at sowing of spring wheat, an assumed decomposition of winter cover crop (white mustard, Sinapis alba L.) of $25 \mathrm{~kg} \mathrm{~N} \mathrm{ha}^{-1}$, and supplementary fertilizer to bring the total available $\mathrm{N}$ to $200 \mathrm{~kg} \mathrm{~N} \mathrm{ha}^{-1}$. Mineral nitrogen fertilizer $\mathrm{NH}_{4} \mathrm{NO}_{3} \cdot \mathrm{CaMg}\left(\mathrm{CO}_{3}\right)_{2}$ was top dressed three times during the growing season: at wheat emergence, maize sowing, and when the maize had 3 mature leaves. Weeds were controlled mechanically before wheat emergence, and chemically thereafter (Table A1, Appendix A). Supplementary water was applied by sprinkler irrigation (Perrot, 54 $\mathrm{m}$ width rain tree) during the growing season at the first indication of wilting: $15 \mathrm{~mm}$ each on July 12, 19, 22, 26 and September 6 in 2013, and 30 mm each on July 1, 4 and 22 in 2014. 


\section{Chapter 2}

\subsubsection{Measurements}

Wheat was harvested when mature (Zadoks code 9 - ripening, according to Principal growth stages) (Zadoks et al., 1974). In 2013, $1.5 \mathrm{~m}^{2}$ (two meters row length times six rows) sole wheat was harvested per plot, and samples were immediately dried on a drying floor with forced ventilation at $25{ }^{\circ} \mathrm{C}$ for 14 days (ACT-20, Ommivent Co., the Netherlands) to a standard moisture content $(\sim 15 \%)$. Approximately one fourth of each sample were counted to estimate the total ear number, and then all samples were threshed for seeds. As to wheat grown in skip-row and intercrops, two meters row length were harvested separately for each row ( 6 rows or 8 rows, depending on the treatment) per plot, and the samples were processed in the same way as sole wheat. In 2014, $3 \mathrm{~m}^{2}$ (four meters row length times six rows) sole wheat were harvested per plot and dried to a standard moisture content $(\sim 15 \%)$ on the drying floor. A sub-sample of $1 / 24^{\text {th }}$ of each sample was randomly taken to estimate dry weight after 72 hours at $70{ }^{\circ} \mathrm{C}$, and the remainder was threshed and cleaned for seeds. As to wheat grown in skip-row and intercrops, four meters row length were harvested separately for each row per plot, the sub-sample was $1 / 4^{\text {th }}$ of each sample for dry matter estimation, and the remainder was threshed and cleaned for seeds. In both years, one thousand seeds were counted and all seeds were dried at $70{ }^{\circ} \mathrm{C}$ for 72 hours to determine dry weight. Biomass, yield and ear number per meter row, kernel number per ear and harvest index were calculated.

Maize was harvested when it was mature and plant water content was around 30\%. In 2013, $1.5 \mathrm{~m}^{2}$ (one meter row length times two rows) sole maize was harvested per plot, then dry weight (after 72 hours at $70{ }^{\circ} \mathrm{C}$ ) was measured separately for green leaves, yellow leaves, stems, and cobs. As to maize grown in skip-row and intercrops, one meter row length was harvested separately for each row ( 2 rows or 3 rows, depending on the treatment) per plot, and the samples were processed in the same way as sole maize. In 2014, $6 \mathrm{~m}^{2}$ (four meters row length times two rows) sole maize was harvested per plot and fresh weight was determined in the field. A sub-sample of $1 / 4^{\text {th }}$ of each sample was randomly taken to determine dry weight of each organ as in 2013. As to maize grown in skip-row and intercrops, four meters row length was harvested separately for each row and processed as the same way as sole maize. In both years, seeds were further separated from the cob, and one thousand seeds were counted. All seeds were dried at $70{ }^{\circ} \mathrm{C}$ for 72 hours to determine dry weight. Biomass and yield per plant, kernel number per cob and harvest index were calculated. Maize lodging occurred at one week before flowering (July 28, 2013) in a heavy rainstorm, and the state had disappeared 
after two weeks.

\subsubsection{Data analysis}

Land equivalent ratio (LER) was used to calculate the land use advantage provided by intercropping (Rao and Willey, 1980):

$L E R=L E R_{\mathrm{a}}+L E R_{\mathrm{b}}=\frac{Y_{\mathrm{a}}}{M_{\mathrm{a}}}+\frac{Y_{\mathrm{b}}}{M_{\mathrm{b}}}$

where $Y_{\mathrm{a}}$ and $Y_{\mathrm{b}}$ are the yields for each crop in the intercrop, and $M_{\mathrm{a}}$ and $M_{\mathrm{b}}$ are yields for each crop in sole crops, $L E R_{\mathrm{a}}$ and $L E R_{\mathrm{b}}$ are partial LERs for each species. An LER of 1.0 indicates the same land productivity for intercropping and sole crops, whereas values greater than 1.0 indicate a land use advantage for intercropping while values smaller than 1.0 indicate a disadvantage for intercropping.

Three types of analyses were conducted. 1) Pairwise comparisons of biomass, yield per $\mathrm{m}^{2}$ (or per ha) and LER were made between all treatments, excluding the sole crops, within a year. 2) Pairwise comparison of yield and yield components per meter row (or per plant) were made among all treatments within a year. In these two analyses, ANOVA $(\mathrm{P}=0.05)$ and Tukey's HSD were used in the 'stas' package of R programming language (R Core Team, 2015); treatment and block were independent variables. 3) A t-test with unequal variance was carried out to compare sole crops and other treatments within a year for biomass and yield per $\mathrm{m}^{2}$ (or per ha).

\subsection{Results}

\subsubsection{Wheat and maize biomass, yields and LER}

Expressed per unit area of intercrop, sole crops (SW and SM) had significantly higher biomass and yield per ha than each crop in the replacement intercrop $(6: 2 \mathrm{WM})$ in both years (Table 2.3). Removing maize plants from replacement intercrop (6:0WM) significantly increased wheat biomass and yield (by 1.5 and $0.9 \mathrm{t} \mathrm{ha}^{-1}$, respectively) in 2014, but had no significant effect in 2013. Omitting wheat plants from the replacement intercrop (0:2WM) significantly increased maize biomass and yield in both years (Table 2.3). Adding two rows of wheat in replacement intercrop $(8: 2 \mathrm{WM})$ significantly increased wheat biomass and yield in 2014, while decreasing maize biomass by $2.2 \mathrm{t} \mathrm{ha}^{-1}$ in 2013 , compared to the $6: 2 \mathrm{WM}$ treatment. Adding one extra row of maize in the replacement intercrop (6:3WM) did not 
Chapter 2

significantly increase maize biomass and yield in either year, but significantly decreased wheat biomass yield in 2013 (Table 2.3).

The LER of biomass ranged from 0.96 to 1.25 , and LER of grain yield ranged from 0.97 to 1.30 in different intercropping configurations in two years (Table 2.4). All intercrops except replacement intercropping (6:2WM) in 2014 achieved an LER greater than one both for biomass and grain yield, indicating intercropping had yield advantages compared with sole crops. Add-row intercrops did not significantly increase LER relative to the replacement intercrop in either year (Table 2.4).

Table 2.3 Biomass and yield per ha for wheat and maize in different treatments and years

\begin{tabular}{|c|c|c|c|c|c|}
\hline \multirow{2}{*}{ Year } & \multirow{2}{*}{ Treatment $^{1}$} & \multicolumn{2}{|l|}{ Wheat } & \multicolumn{2}{|l|}{ Maize } \\
\hline & & Biomass $\left(\mathrm{t} \mathrm{ha}^{-1}\right)$ & Yield $\left(\mathrm{t} \mathrm{ha}^{-1}\right)$ & Biomass $\left(\mathrm{t} \mathrm{ha}^{-1}\right)$ & Yield $\left(\mathrm{t} \mathrm{ha}^{-1}\right)$ \\
\hline \multirow{7}{*}{2013} & SW & $11.9 \pm 0.92^{*}$ & $6.4 \pm 0.56^{*}$ & - & - \\
\hline & $\mathrm{SM}$ & - & - & $23.2 \pm 0.49^{*}$ & $10.1 \pm 0.21^{*}$ \\
\hline & $6: 2 \mathrm{WM}$ & $6.0 \pm 0.26 \mathrm{ab}$ & $3.1 \pm 0.14 b$ & $17.1 \pm 0.56 b$ & $8.1 \pm 0.32 b$ \\
\hline & 6:0WM & $6.0 \pm 0.24 \mathrm{~b}$ & $3.3 \pm 0.16 \mathrm{ab}$ & - & - \\
\hline & $0: 2 \mathrm{WM}$ & - & - & $19.6 \pm 0.37 \mathrm{a}$ & $9.4 \pm 0.19 \mathrm{a}$ \\
\hline & $8: 2 \mathrm{WM}$ & $6.6 \pm 0.23 \mathrm{a}$ & $3.4 \pm 0.14 \mathrm{a}$ & $14.9 \pm 0.51 \mathrm{c}$ & $7.0 \pm 0.29 b$ \\
\hline & $6: 3 \mathrm{WM}$ & $5.4 \pm 0.28 \mathrm{c}$ & $2.6 \pm 0.15 \mathrm{c}$ & $18.0 \pm 0.33 \mathrm{ab}$ & $7.7 \pm 0.23 b$ \\
\hline \multirow{7}{*}{2014} & SW & $14.6 \pm 0.87^{*}$ & $7.7 \pm 0.57^{*}$ & - & - \\
\hline & SM & - & - & $21.4 \pm 0.50^{*}$ & $11.6 \pm 0.17^{*}$ \\
\hline & $6: 2 \mathrm{WM}$ & $6.3 \pm 0.30 \mathrm{c}$ & $3.2 \pm 0.20 b$ & $11.4 \pm 1.08 b c$ & $6.4 \pm 0.51 b c$ \\
\hline & 6:0WM & $7.8 \pm 0.19 \mathrm{ab}$ & $4.1 \pm 0.04 \mathrm{a}$ & - & - \\
\hline & $0: 2 \mathrm{WM}$ & - & - & $17.3 \pm 0.35 \mathrm{a}$ & $9.3 \pm 0.21 \mathrm{a}$ \\
\hline & $8: 2 \mathrm{WM}$ & $8.4 \pm 0.28 \mathrm{a}$ & $4.3 \pm 0.23 \mathrm{a}$ & $10.1 \pm 1.25 \mathrm{c}$ & $5.4 \pm 0.61 \mathrm{c}$ \\
\hline & $6: 3 \mathrm{WM}$ & $6.8 \pm 0.15 \mathrm{bc}$ & $3.2 \pm 0.08 \mathrm{~b}$ & $14.1 \pm 0.21 \mathrm{~b}$ & $7.5 \pm 0.25 b$ \\
\hline
\end{tabular}

${ }^{1}$ ANOVA was carried out for 2013 and 2014 separately for all treatments except sole crops, and no shared letters denotes statistical significant difference $(\mathrm{P}=0.05)$ between intercrops and skip-row using Tukey's HSD. *Asterisks denote significant difference between sole crops and other treatments within a year using t-test with unequal variance.

\subsubsection{Yield components for wheat and border row effects}

Ear density (expressed per unit area of the whole system) was significantly lower in intercrops and skip-row treatments than in sole wheat (Table 2.5). The add-wheat intercrop (8:2WM) had higher ear density than the treatments with six rows of wheat $(6: 0 \mathrm{WM}, 6: 2 \mathrm{WM}$ and 6:3WM). In both years, kernel number per ear did not differ significantly across treatments, while thousand kernel weight and harvest index were lower in intercrops than in sole wheat and skip-row wheat in both years, but only significantly in 2014 (Table 2.5). 


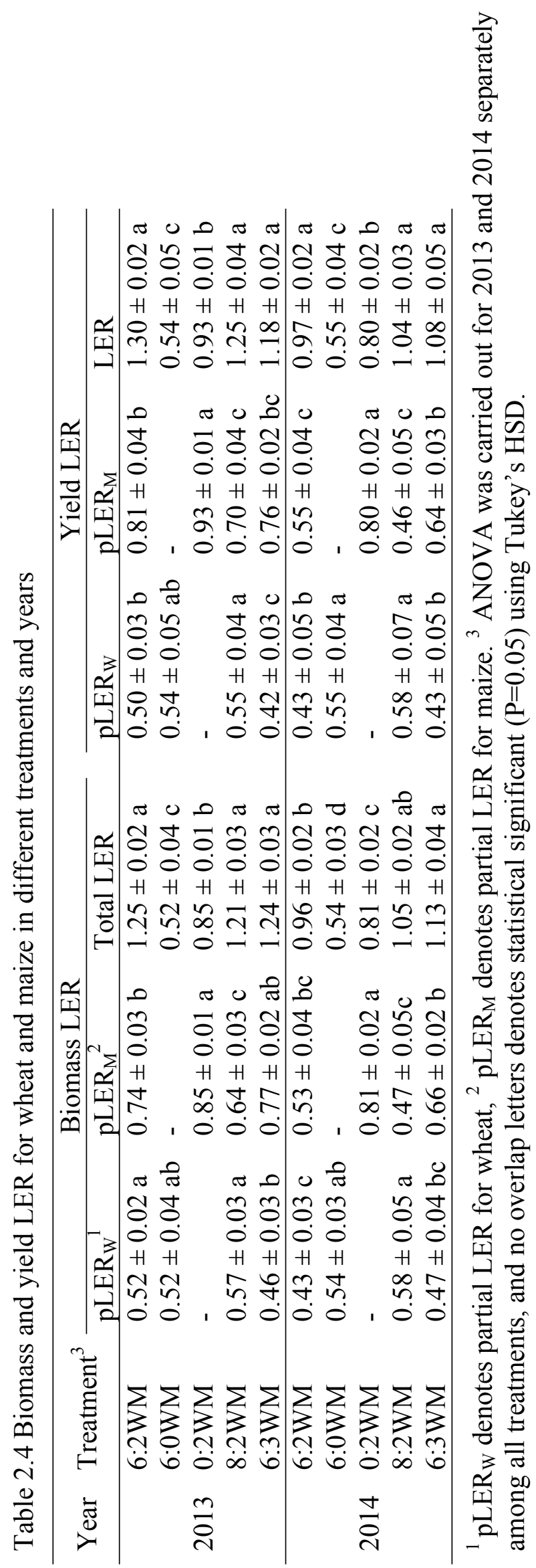




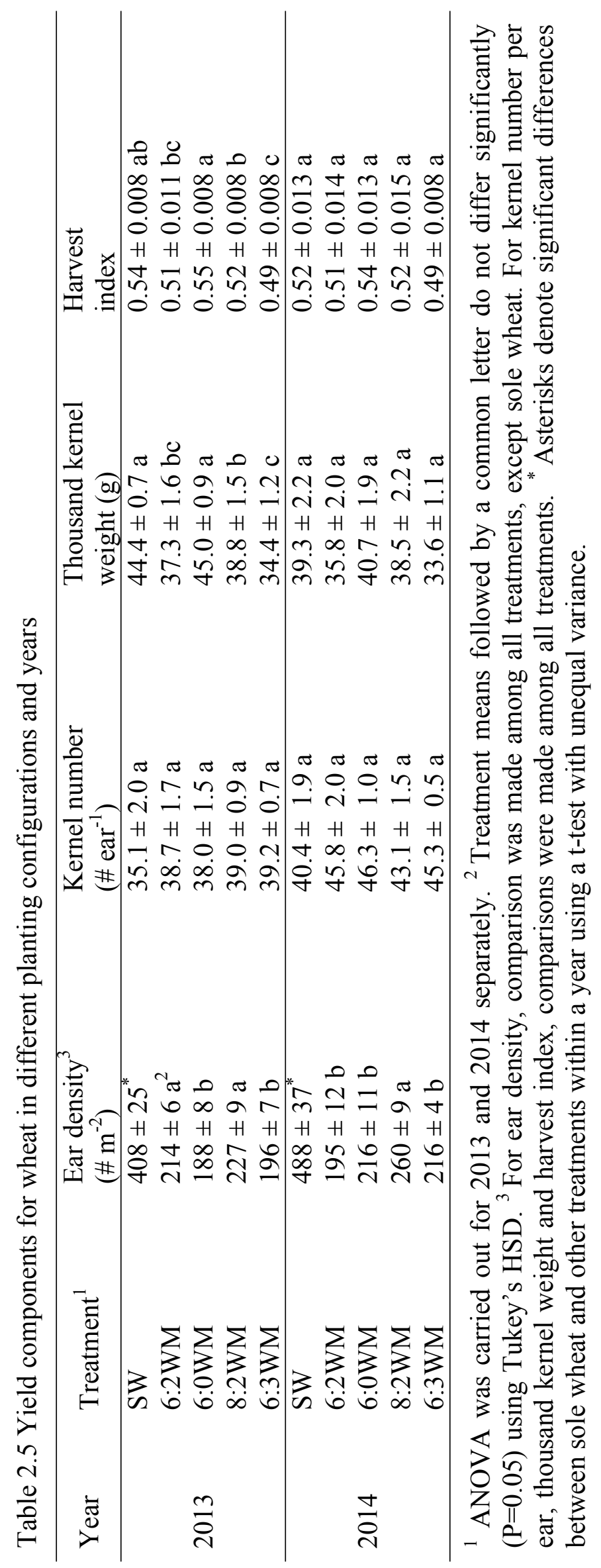


In intercrops, border row effects were positive for some wheat yield components (ear number per meter row and kernel number per ear) and negative for others (thousand kernel weight and harvest index). The number of ears per meter row and kernel number per ear were significantly greater in border rows than in inner rows (Fig. 2.3), while no differences in these variables were found between inner rows of intercrops and sole wheat (Table A2, Appendix A). As to thousand kernel weight and harvest index, the border row effects were positive for skip-row wheat (6:0WM), but negative for intercrops (Figs 2.3 and 2.4), indicating that the decreases in thousand kernel weight and harvest index in wheat border rows in intercrops were due to competition from maize. In 2013, thousand kernel weight and harvest index of wheat were significantly lower both in border rows and in inner rows of intercrops, while in 2014 this decrease was only significant in the border rows (Tables A2 and A3, Appendix A).

Wheat biomass and yield per meter row were significantly greater in border rows than in inner rows of intercrops (Fig. 2.4), while there were no differences in biomass and yield per meter row between inner rows and sole wheat rows (Table A2, Appendix A).

\subsubsection{Yield components for maize and border effects}

Maize cob number per unit of land area was significantly smaller in intercrops (6:2WM and 8:2WM) and skip-row maize than in sole maize (or 6:3WM) (Table 2.6). Maize grown in the skip-row treatment $(0: 2 \mathrm{WM})$ had the highest kernel number per cob and thousand kernel weight, while the 6:3WM treatment had the lowest kernel number per cob and thousand kernel weight. The same patterns were found in yield and biomass per plant (Table 2.6). Maize had a higher kernel number per cob, thousand kernel weight, yield and biomass per plant in the replacement intercrop (6:2WM) than in sole maize in 2013, while the reverse was found in 2014. In 2013, sole maize and the 6:3WM maize had significantly lower harvest index than other treatments. In 2014, the two add-row intercrops had significantly smaller harvest index than the replacement intercrop (Table 2.6).

One of the seven systems (6:3WM) had an inner row maize. In 2013, biomass and yield per plant, and yield components were not different between this inner row and the maize border rows (Table 2.7). In 2014, except biomass per plant $(\mathrm{P}=0.0541)$, yield per plant and yield components (kernel number per plant, thousand kernel weight and harvest index) were significantly higher in border rows than in the inner row. 

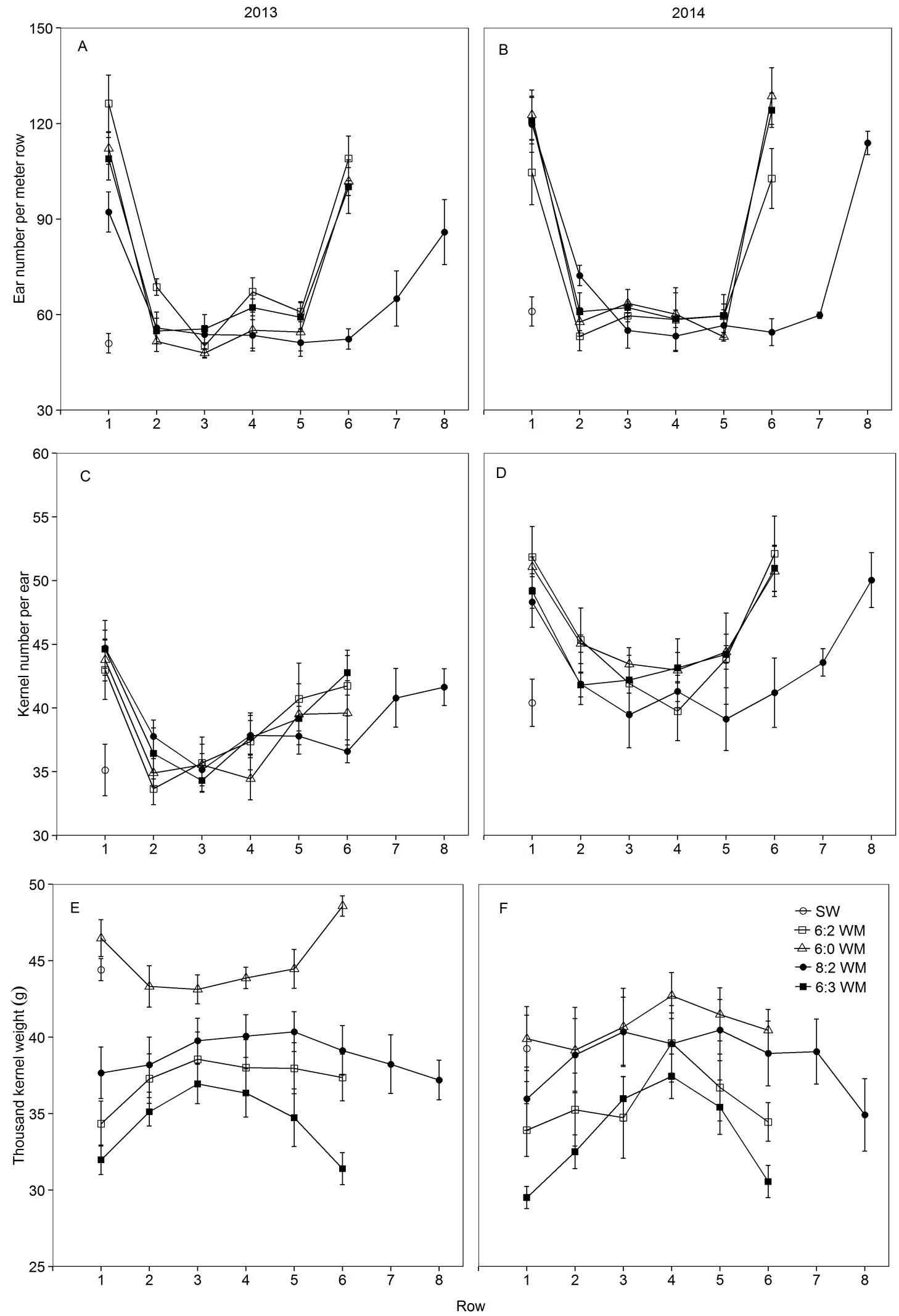

Fig. 2.3 Wheat ear number per meter row (A and B), kernel number per ear (C and D) and thousand kernel weight ( $\mathrm{E}$ and $\mathrm{F}$ ); on the horizontal axis, number 1 to 8 denotes the number of rows from west to east. Data for sole wheat is indicated in row 1. 
2013
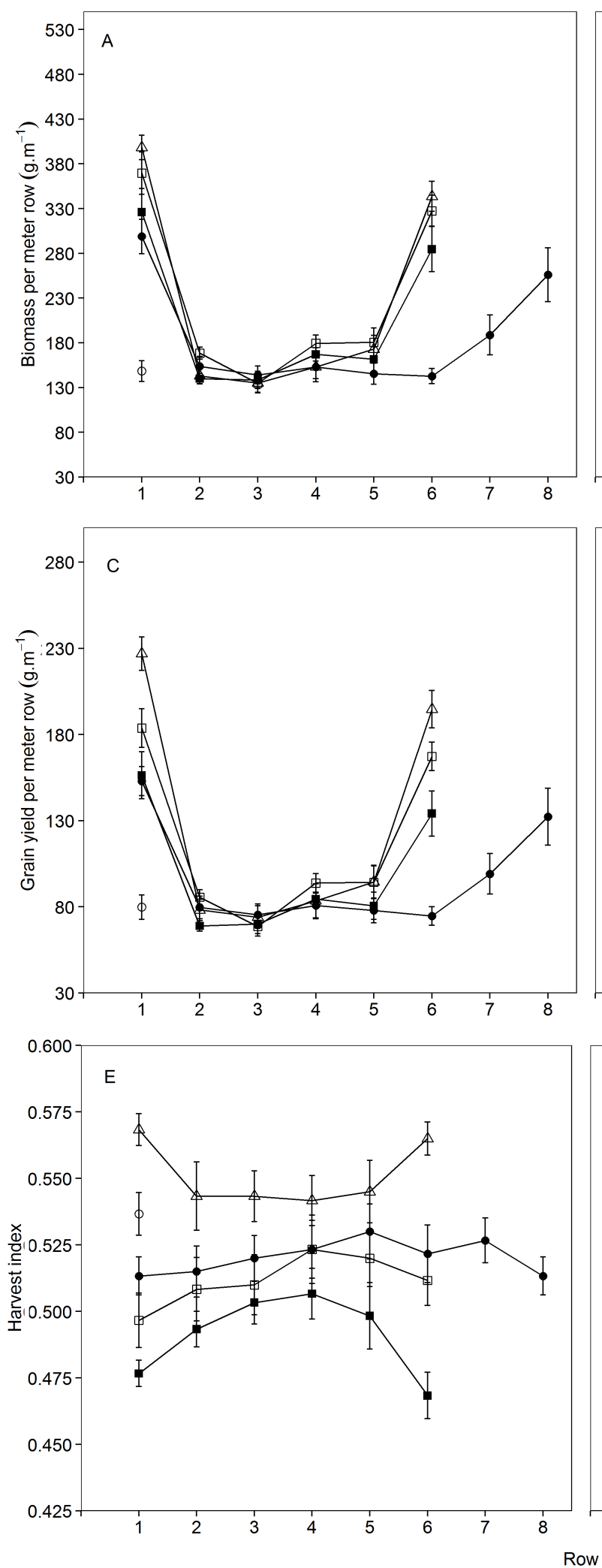

2014

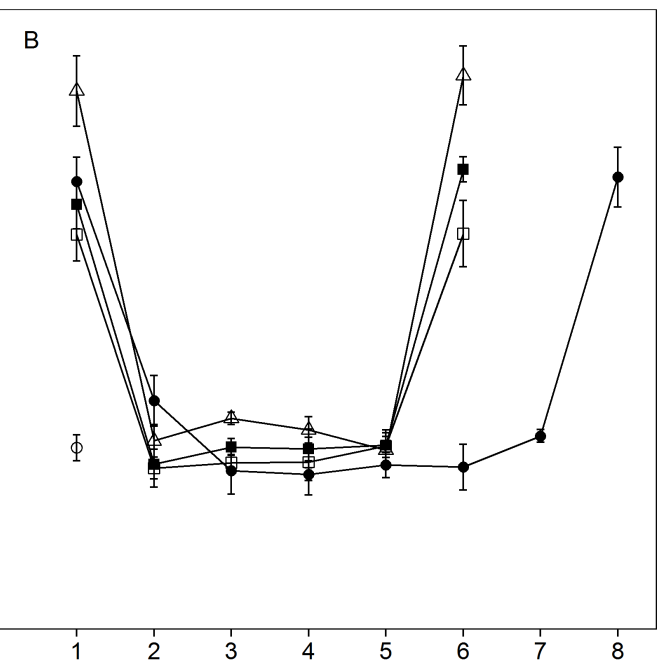

D
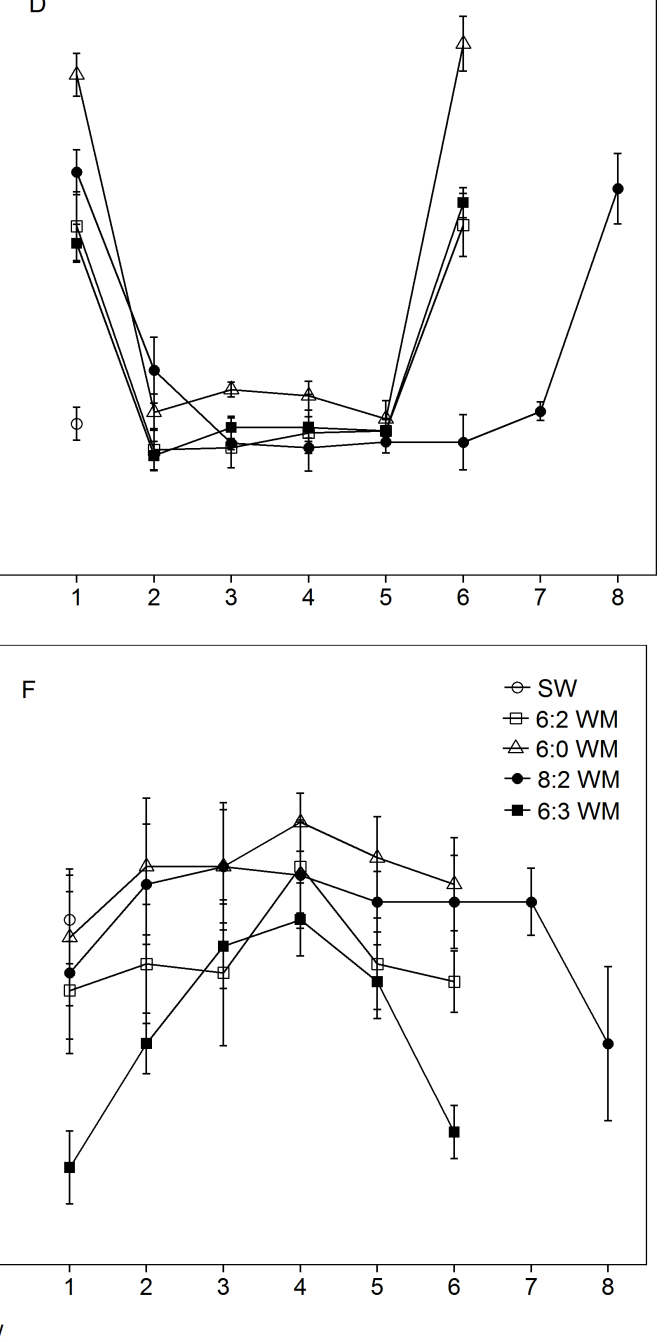

Fig. 2.4 Wheat biomass per meter row (A and B), grain yield per meter row (C and D) and harvest index ( $\mathrm{E}$ and $\mathrm{F}$ ), on the horizontal axis, number 1 to 8 denotes the number of rows from west to east. Data for sole wheat is indicated in row 1. 


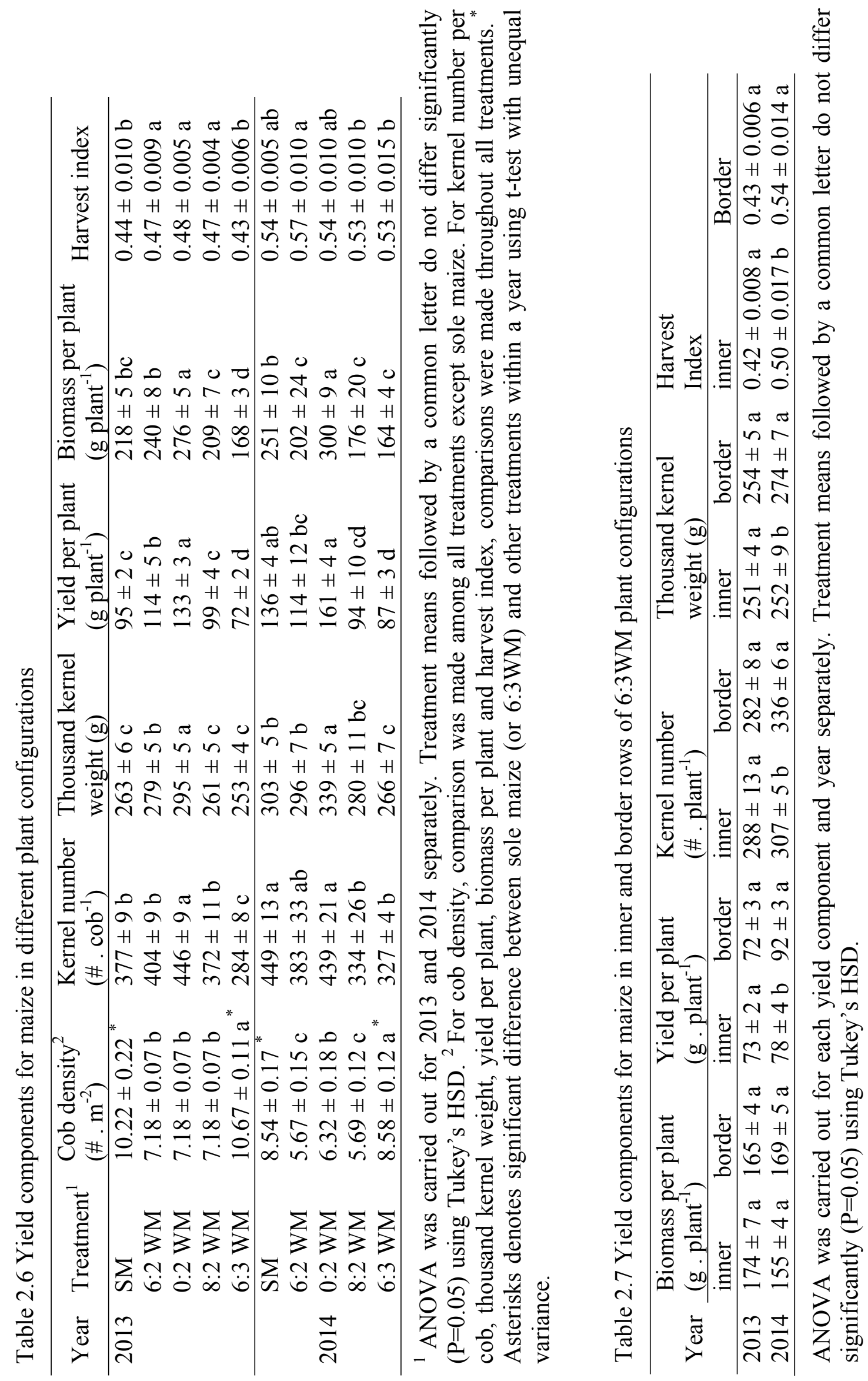




\subsection{Discussion}

This study investigated three questions: (1) does wheat-maize intercropping provide a land use advantage under Western European conditions; (2) are advantages mainly due to extra yield in border rows as compared to inner rows; and (3) is the land use equivalent ratio increased if additional rows are added to the intercrop system as compared to the replacement intercrop? The first question is answered cautiously confirmatory: intercropping provided a land use advantage in one of the two years of the study (2013), but not in the other (2014). The second question is answered confirmatory: wheat yields in border rows were up to two times as high as in inner rows in the wheat strip, demonstrating the plasticity of the wheat plants in the border rows and their ability to capture additional resources as compared to inner wheat plants, when competition is relaxed. Furthermore, the potential size of the border row was explored by omitting one of the species from the replacement intercrop (skip-row design). Skip row treatments showed moderate increases in the relative wheat yield (no significant difference in 2013, and partial LER of $0.55(6: 0 \mathrm{WM})$ vs $0.43(6: 2 \mathrm{WM})$ in $2014 ; P<0.05)$ and moderate to large increases in the relative yield of maize (partial LER of $0.93(0: 2 \mathrm{WM}) \mathrm{vs}$ $0.81(6: 2 \mathrm{WM})$ in $2013 ; P<0.05$, and $0.80(0: 2 \mathrm{WM})$ vs $0.55(6: 2 \mathrm{WM})$ in $2014 ; P<0.05)$ (Table 2.4). The wheat yield per meter border row was between 2 and 2.5 times the yield in inner rows in the 6:2WM intercrop, while the wheat yield per meter border row in the wheat skip-row treatment was up to 3 times the wheat yield in the 6:2WM intercrop (Fig. 2.4 C and D), indicating that competition from maize does constrain the border row effect in wheat in an ordinary intercrop. The third question is answered negatively: there were no significant differences in LER between a replacement intercrop and add-row systems in either of the two years.

\subsubsection{Land use advantages of relay intercropping and year effects}

Relay intercropping extends the growing season and releases the intensity of competition for resources relative to full intercropping (Fukai and Trenbath, 1993), but one of the requirements of the late-maturing crop is an ability to recover from growth arrears after the early maturing crop is harvested (Cenpukdee and Fukai, 1992). In northwest China, the mechanisms of high productivity of wheat-maize intercrop were characterized as a result from a "competition-recovery production principle" (Zhang and Li, 2003). As a late sown crop, maize was competitively weaker than wheat and had lower leaf and collar appearance rates during vegetative growth (Zhu et al., 2014), resulting in lower biomass accumulation rate than 


\section{Chapter 2}

sole maize before wheat harvest. After wheat harvest, intercropped maize had a significantly higher dry matter accumulation rate that sole maize, and finally achieved higher yield per plant than sole maize (Li et al., 2001a). The "recovery growth" of intercropped maize in our study was not as strong as in northwest China, with the biomass and yield per plant of intercropped maize at most equal to that of sole maize (Table 2.6). Two reasons could explain that lower maize yield in intercropping in the Netherlands as compared to northwest China. The first is that maize has longer growing period after wheat harvest in northwest China (wheat was harvested in July) than in the Netherlands (wheat was harvested in August). The second is that the temperature and radiation intensity are higher in northwest China than in the Netherlands in August and September (Table 2.2 and Table A4 in Appendix A), which is more favourable for maize growth. Thus, the recovery of maize after wheat harvest is facilitated by better conditions and a longer recovery time in Gansu as compared to the Netherlands. In our study, intercropped wheat had higher productivity per meter row than sole wheat which originated from plasticity of border rows, while intercropped maize had lower productivity per plant than sole maize due to negative effects of wheat shading in vegetative growth and limited recovery ability after wheat harvest. Intercropping provided a possibility of spatial (different strips) and temporal (partly overlapping growing season) complementarity (niche segregation) in the acquisition of solar radiation. The realization of this possibility depended on the effects of weather on the temporal growth patterns of the intercropped species and the resulting strength of intra- and interspecific competition.

The LER of intercrop yields was higher in 2013 (ranging from 1.18 to 1.30) than in 2014 (ranging from 0.97 to 1.08 ), and this was strongly related to interspecific interactions between wheat and maize in the intercropping system which differ under different weather conditions. The average temperature from March to May was $3.8^{\circ} \mathrm{C}$ lower in 2013 than in the same period in 2014 (Table 2.2). The cold spring limited the growth of wheat until the time of maize emergence. Thus intercropped maize experienced milder interspecific competition at seedling stage in 2013 compared to 2014, resulting in similar biomass per plant as sole maize at maturing time in 2013, but not in 2014 (Table 2.6). The warm spring of 2014 provided favourable growing conditions for wheat, and those strong wheat plants more heavily restrained the early development of neibouring maize. Furthermore, more precipitation and less sunshine hours during July and August in 2014 (Table 2.2) led to weaker compensatory growth of intercropped maize than in 2013. Thus, in 2014, final biomass and yield per plant were signigicantly smaller in intercropped maize than in sole maize, resulting in lower LER in 
2014 than in 2013.

\subsubsection{Border row effect}

In wheat-maize and wheat-cotton relay intercropping, early favourable growing conditions of wheat resulted in significant yield increase in border rows, and this border row advantage made a large contribution to the wheat yield in intercropping (Li et al., 2001b; Zhang et al., 2007). Similarly, in the $6: 2 \mathrm{WM}$ and $6: 3 \mathrm{WM}$ intercrops $50 \%$ of the wheat yield was due to the border rows ( $1 / 3$ of total rows), and $50 \%$ to inner rows ( $2 / 3$ of total rows). Percentages in the $8: 2 \mathrm{WM}$ are $40 \%$ due to border rows (1/4 of total rows) and $60 \%$ to inner rows (3/4 of total rows). The large yield in border rows can be unravelled by looking at yield components as follows:

Yield per meter row $=$ ears per meter row $\times$ kernels per ear $\times$ kernel weight

Compared to inner rows, border rows had $87 \%$ more ears (104 vs 58 ears per meter row in 2013 and 115 vs 59 ears per meter row in 2014; averaged over three intercrop types, Table A2, Appendix A). The number of kernels per ear was also greater in the border rows (43 vs 37 kernels per ear in 2013 and 50 vs 42 kernels per ear in 2014). However, the kernel weight was less in the border rows than in inner rows (35 vs 38 grams per thousand kernels in 2013 and 33 vs 37 grams per thousand kernels in 2014). Overall, these comparisons show that the basis for high yield in border rows was laid at an early crop growth stage. Before maize emergence, wheat was ready to head, the numbers of ears per meter and kernels per ear were determined (Slafer and Rawson, 1994). Thus these yield components were not significantly different to skip-row wheat (Table A2, Appendix A). Initially, wheat was the dominant crop in the competition for radiation, but the competitive dominance shifted to maize when maize surpassed wheat by height. At later growth stages, during kernel filling, the source capacity of the wheat plants in border rows did not satisfy the total demand from the kernels to the same extent as in the inner plants or in skip-row wheat, leading to a lower thousand kernel weight in border rows (Fig. 2.3). We speculate that this may be a consequence of the maize plants increasing gradually in competitive strength over time, thus changing the growing condition of the border plants of wheat from competitively privileged to competitively stressed.

\subsubsection{Density effect}

We had hypothesized that the replacement intercrop could leave resources unused, providing opportunity for extra resource capture and yield in add-row designs. This hypothesis was not 


\section{Chapter 2}

confirmed. Adding rows changed the competitive relationships in the system, tipping the system productivity towards wheat production if extra wheat rows were included or tipping it towards maize if an extra maize row was included, but it did not result in overall greater relative yield total (Table 2.4). On the contrary, due to strong maize-maize competition, maize grown in the add-row treatment $(6: 3 \mathrm{WM})$ had the lowest biomass per plant and thousand kernel weight of all treatments (Table 2.6). Thus, we conclude that plant plasticity in the replacement design under the conditions of the experiment is sufficient to fill the space and capture the available resources within the limits set by the species' biology (e.g. length of growing season, rooting depth, etc.).

\subsubsection{Scientific and practical implications}

Productivity in intercrops is influenced by interspecific interactions of mixed species; the gain of one crop goes often at the expense of the other. Initial effects can percolate through, e.g. an increase of the density of wheat causing more severe shading and growth retardation in maize at seedling stage, could eventually prevent later competitive effects of maize on wheat during grain filling (Zhu et al., 2014). These interactions are likely to be affected by differences in seasonal weather conditions. Crop growth modelling could be used to investigate how land productivity changes with various planting patterns and dates under different climatic conditions. Modelling strategies based on resource capture and growth responses by individual plants could help to clarify interactions between environment, planting patterns and plasticity in plant growth (Zhu et al., 2015). As intercropping is still widely used by farmers in developing countries, the assessment of the contribution of intercropping to food security at regional level is meaningful. A decline in the use of intercropping could pose a risk to food security if it is based on local food systems. A declining trend of intercropping was observed in the North China Plan, which is related to the increasing price of labor and a shift of rural labor into the construction and industrial sectors (Feike et al., 2012). If more income is generated off-farm, food security based on subsistence intercropping could be substituted by food purchases from other regions. The complexity of the mechanization of intercropping poses major constraints to its use in regions with high labor price and large farms, e.g. Western Europe or North America. Development of machinery for cultivating and harvesting intercrops is required to overcome this constraint. A market for such machinery may develop if the advantages of intercropping (high yield, better resource capture, building of soil organic matter, suppression of pests and diseases) are substantial and recognized (Brooker et al., 2015; 
Cong et al., 2015a).

\subsection{Conclusion}

We found a yield advantage of wheat-maize relay intercropping under Western European condition in one year, but no yield advantage in the second year. In this relay intercropping, seasonal weather variation influenced the interspecific interactions between two crops resulting in different productivities in two years. Wheat had yield advantages in terms of grain yield per meter row resulting from enhanced resource capture in border rows at early stage, but a disadvantage of small thousand kernel weight, resulting from severe competition at grain filling. The productivity of add-row designs did not significantly differ from the replacement design. In contrast, they made the intra- and interspecific competition more severe, resulting in small thousand kernel weight for intercropped wheat and smaller yield per plant for intercropped maize. The designs of replacement, skip-row and add-row treatments allowed us to investigate the consequence of different levels of intra- and interspecific competition on yield and yield components for wheat and maize, which improved the understanding of mechanism of intercropping productivity. This can further contribute to the design of better intercropping system in terms of productivity and resource use efficiency.

\section{Appendix A}

Table A1 Fertilizer and pesticides application time and amount

Table A2 Wheat yield components in border and inner rows, in different treatments and years Table A3 Wheat biomass, grain yield and HI in border and inner rows, in different treatments and years

Table A4 Monthly mean temperature, total precipitation and total sunshine duration for Wuwei (Gansu, China) condition in 2013 and 2014

\section{Acknowledgements}

We are grateful to Professor Lizhen Zhang for helpful discussions and to Wageningen Unifarm staff for valuable help during the experiments. The financial support of the China Scholarship Council (CSC) and the Key Sino-Dutch Joint Research Project of NSFC (grant number: 31210103906 ) are gratefully acknowledged. 



\title{
Chapter 3
}

\section{Intercropping wheat and maize increases total radiation interception and wheat RUE but lowers maize RUE}

\author{
Fang Gou ${ }^{1,2}$, Martin K. van Ittersum ${ }^{2}$, Elisabeth Simon $^{2}$, Peter A. Leffelaar ${ }^{2}$, \\ Peter E.L. van der Putten ${ }^{1}$, Lizhen Zhang $^{3}$, Wopke van der Werf ${ }^{1}$
}

${ }^{1}$ Centre for Crop Systems Analysis, Wageningen University, P.O. Box 430, 6700 AK Wageningen, The Netherlands

${ }^{2}$ Plant Production Systems group, Wageningen University, P.O. Box 430, 6700 AK Wageningen, The Netherlands

${ }^{3}$ China Agricultural University, College of Resources and Environmental Sciences, Agricultural Meteorology Department, Beijing 100193, China 


\title{
Chapter 3
}

\begin{abstract}
Row configuration has a large influence on the intensity of species interactions in intercrops. Row configuration affects how many crop rows interact with the same species and how many interact with the other species, shaping the expression of plasticity, resource capture, and growth. This study aims to determine how row configuration influences radiation interception and productivity in wheat-maize intercropping under western European growing conditions. Field experiments with different row configurations were carried out in 2013 and 2014 in the Netherlands. We compared seven treatments, comprising sole crops of wheat and maize (SW and SM), a replacement intercrop (6:2WM), skip-row designs (6:0WM, 0:2WM) and add-row designs (6:3WM, 8:2WM). We determined leaf area and biomass dynamics over time, and developed a simple geometry-based model to estimate light capture in these different row configurations. The model was tested with light measurements in the field. Crop radiation use efficiency (RUE) was estimated by linear regression of above-ground biomass on the calculated cumulative intercepted light (photosynthetically active radiation - PAR). This study showed that: 1) wheat-maize intercropping had significantly higher PAR interception than sole wheat in 2013 and 2014, and sole maize in 2013, but not in 2014;2) intercropping significantly increased RUE of wheat, whereas it significantly decreased RUE of maize; and 3) both light interception and light use efficiency changed with planting configuration. Thus we showed that the row configuration of the intercrop affected light interception as well as light use efficiency by modulating the strength of competitive and compensatory interactions within and between crop species.
\end{abstract}

Key words: leaf area dynamics, PAR, modelling light interception, western Europe 


\subsection{Introduction}

Intercepted solar radiation provides crops with the energy for photosynthesis, determining the potential for crop production (De Wit, 1959; Loomis and Williams, 1963). Many studies have shown relationships between dry matter production and cumulative intercepted photosynthetically active radiation (PAR) (Monteith, 1977; Gallagher and Biscoe, 1978). The slope of the relationship between total dry matter in periodic harvests and corresponding cumulative intercepted radiation up to the time of harvest has been called radiation use efficiency (RUE; g DM MJ ${ }^{-1}$ PAR) (Haverkort and Bicamumpaka, 1986). C4 species have usually higher RUE than C3 species. Within C3 species, non-legumes tend to have greater RUE than legumes (Gosse et al., 1986), while RUE may vary according to climatic conditions within a particular species. For instance, maize had a lower RUE in cooler than in warmer regions (Andrade et al., 1993).

Intercropping is the cultivation of two or more crop species simultaneously in the same field (Vandermeer, 1989). A key advantage of intercropping is the greater (relative) production per unit land area, usually expressed as a value of the land equivalent ratio (LER) greater than one. LER expresses the area of sole crops needed to produce the same yield as a unit area of intercrop. Under potential growing conditions (water and nutrients are not limiting and pests and diseases are fully controlled), yield advantages in intercropping could be achieved by increases in the interception of solar radiation and/or increases in the radiation use efficiency (Keating and Carberry, 1993).

Temporal and spatial niche complementarity may increase light interception compared to sole crops (Fukai and Trenbath, 1993). Temporal complementarity can exist if intercropped species use radiation during different periods of the season (Yu et al., 2015). Examples of temporal complementarity are planting short-season sorghum between rows (or strips) of long-season pigeonpea (Rao and Willey, 1980) and combining early-mature wheat with latesown and late-mature cotton in a relay strip intercrop (Zhang et al., 2008). Spatial complementarity can exist if intercropped species differ in plant architecture and physiology. The combination of a $\mathrm{C} 3$ and $\mathrm{C} 4$ species may result in spatial complementarity as $\mathrm{C} 4$ crops are taller than $\mathrm{C} 3$ crops and $\mathrm{C} 4$ crops have a higher light saturation level for photosynthesis than C3 crops (Trenbath and Francis, 1986). Thus, the C4 crop is exposed to a higher light intensity, fully exploiting its potential for high photosynthetic rates. The $\mathrm{C} 3$ crop is exposed to a lower light intensity and a higher ratio of diffuse to direct radiation, which tend to increase 


\section{Chapter 3}

the RUE of the C3 crop (Sinclair et al., 1992), because diffuse light contains more PAR (Sinclair and Muchow, 1999). Marshall and Willey (1983) found that RUE of groundnut (a short C3 species) increased by $46 \%$ when intercropped with millet (a tall C4 species).

The potential for complementarity is affected by row configuration because it determines how many rows of a crop species are in direct interaction with the other species. Border rows are responsible for an important part of the yield gain in some intercropping systems (Li et al., 2001b; Zhang et al., 2007; Zhu et al., 2015). Zhang et al. (2008) found that in North China, narrow strips of wheat-cotton intercropping ( 3 rows of wheat alternated with 1 row of cotton, abbreviated as $\mathrm{W} 3 \mathrm{C} 1$ ) captured more radiation than wide strips (6 rows of wheat alternated with 2 rows of cotton, abbreviated as $\mathrm{W} 6 \mathrm{C} 2$ ), resulting in a greater yields and land equivalent ratio (1.39) in the narrow strip system W3C1 than the wide strip system W6C2 (1.28) (Zhang et al., 2007). Likewise, Wang et al. (2015) found that wheat and maize in an intercropping system with narrow strips, consisting of 6 wheat rows alternated with 2 maize rows, had $29 \%$ more wheat yield per meter row than sole wheat, while the wheat yield in an intercrop system with double strip width (12 rows of wheat alternated with 4 rows of maize) had only $11 \%$ greater yield per meter row than sole wheat. These yield effects in wheat were attributed to differences in light interception, related to the configuration.

The wheat-maize relay intercrop is a combination of a short $\mathrm{C} 3$ and a tall $\mathrm{C} 4$ species that differ in growing period. This species combination offers potential for both temporal and spatial complementarity enhancing both radiation capture and use efficiency. Wheat-maize relay intercropping has been widely used in northwest China, notably in Gansu province and Ningxia autonomous region, and the land equivalent ratio is generally well above one, with values from 1.21 to 1.57 in Gansu (Li et al., 2001b) and from 1.13 to 1.24 in Inner Mongolia (Wang et al., 2015). In Chapter 2, we tested the performance of wheat-maize intercropping under Western European conditions, and found LERs varying from 0.98 to 1.30 in the Netherlands, where this system has so far only been studied in experiments but has not been used in practice. In the present study, we address the question whether yield advantages, if present in the intercrop, are caused by greater radiation interception, or by greater radiation use efficiency, or by a combination of these two.

As wheat and maize have partially temporal overlapping growing periods, we hypothesized that over the whole season the intercrop will have greater radiation interception than sole crops. In strip intercropping, due to plant plasticity, border rows have a large contribution to 
overall wheat yield in intercropping (Li et al., 2001b; Zhang et al., 2007). Plant plasticity in border rows could at least partly compensate for a reduction in the number of rows in the intercrop (Zhu et al., 2015). We hypothesized that the maximum extent of compensatory resource capture (radiation) by border rows of one species in the intercrop could be investigated by omitting the other species (skip-row designs). Therefore, we studied light interception and productivity in intercrop systems from which one of the species was omitted. Furthermore, we hypothesized that a replacement intercrop (with row distances optimized for sole crops) might not fully capture the potential for additional radiation provided by differences in growing period between species. Adding extra rows could be a more effective strategy to avoid radiation loss to the bare soil than relying on plant plasticity. Specifically, we would expect that treatments with additional rows (add-row designs) could capture more radiation and produce more dry matter than a replacement intercrop. Finally, during the wheat-maize co-growth period, the ratio of diffuse to direct light in the wheat canopy will increase due to shading by maize; therefore the radiation use efficiency of intercropped wheat (C3 crop) was hypothesized to increase.

\subsection{Material and Methods}

\subsubsection{Experimental set up and field management}

Two years of field experiments were conducted in Wageningen, the Netherlands (51 ${ }^{\circ} 59^{\prime} 20^{\prime} ' \mathrm{~N}, 5^{\circ} 39^{\prime} 16^{\prime}$ 'E) to determine the leaf area dynamics and biomass accumulation characteristics of wheat and maize in seven different row configurations (Fig. 2.1, Chapter 2). Soil at the experimental site was sandy with $3.1 \%$ organic matter and a $\mathrm{C} / \mathrm{N}$ ratio in the organic matter of 14. In 2013, spring wheat was sown on 21 March and harvested on 20 August, whereas maize was sown on 14 May and harvested on 16 October. In 2014, spring wheat was sown on 13 March and harvested on 4 August, whereas maize was sown on 7 May and harvested on 23 September. We used the wheat variety "Tybalt" and the maize variety "Atrium" in both years. A randomized complete block design with six (2013) and four (2014) replicates was used. Plots were $9.75 \mathrm{~m}$ wide by $22.5 \mathrm{~m}$ long in 2013, and $7.5 \mathrm{~m}$ wide by $23 \mathrm{~m}$ long in 2014. The row orientation was approximately Northwest in 2013 and North in 2014.

Crop management in the experiments targeted avoidance of nutrient and water stress, as well as control of yield reducing factors through adequate weed, pest and disease management. Fertilizer $\left(\mathrm{K}_{2} \mathrm{SO}_{4} \mathrm{MgSO}_{4}, \quad \mathrm{Ca}\left(\mathrm{H}_{2} \mathrm{PO}_{4}\right)_{2} \mathrm{H}_{2} \mathrm{O}\right.$ and $\left.\mathrm{NH}_{4} \mathrm{NO}_{3} \mathrm{CaMg} \quad\left(\mathrm{CO}_{3}\right)_{2}\right)$ was applied 


\section{Chapter 3}

homogeneously throughout the experiment; weeds were controlled mechanically before wheat emergence, and chemically thereafter; and supplementary water was applied during the growing season at the first indication of wilting. Further details are given in Chapter 2.

\subsubsection{Leaf area dynamics, biomass accumulation and plant height determination}

We determined the leaf area index and above-ground biomass of wheat and maize eight times (seven intermediate and one final harvest) during the growing season in 2013 and six times (five intermediate and one final harvest) in 2014. Wheat and maize were harvested separately for each row except in sole crops (Table 3.1). Depending on the treatment, we harvested in each plot six or eight rows of wheat and two or three rows (one meter per row) of maize. Considering the in-plot variability between rows in intercrops, we processed samples for each row separately, except in sole crops. Samples were stored in a fridge at $4{ }^{\circ} \mathrm{C}$, immediately after harvest. For both wheat and maize, green leaves were separated to measure their area with a leaf area meter (LI-3100 Area Meter, USA). Then green leaves, yellow leaves, stems and ears were dried at $70{ }^{\circ} \mathrm{C}$ for 72 hours to determine dry matter. The area of yellow leaves was calculated from the dry matter of yellow leaves and specific leaf area (SLA) of green leaves. The number of ears per meter row was counted at each harvest of wheat. At final harvest, wheat samples were dried on a drying floor with forced ventilation at $25{ }^{\circ} \mathrm{C}$ for 14 days (ACT-20, Ommivent Co., the Netherlands) to a standard moisture content ( 15\%). After threshing, straw and seeds were dried separately at $70{ }^{\circ} \mathrm{C}$ for 48 hours to determine biomass (details are given in Chapter 2).

Plant height was measured twice per week from crop emergence till flowering for both wheat and maize. A bar was placed parallel to the row at the top of the canopy, and the height from the soil surface to the bar was measured.

\subsubsection{Light interception measurements}

Incoming and transmitted light were measured using a SunScan canopy analysis system (Delta-T Devices Ltd, UK) over the growing season (14 times, at solar noon, 12:30 to 14:00 h) in 2014. Measurements were made in three out of four blocks. Light intensity (PAR) was determined above the canopy using a Beam Fraction Sensor (BFS, one quantum sensor) and below the canopy, at $5 \mathrm{~cm}$ above the soil surface, using a one-meter long SunScan probe with 64 quantum sensors. Recordings above and below the canopy were made at the same time. Six measurements were made in sole crops, with the SunScan probe parallel to rows; whereas 
fifteen measurements were made in intercrops and skip-row treatments. In the latter case, measurements were made at $15 \mathrm{~cm}$ intervals across a width of $225 \mathrm{~cm}$, placing the sensor parallel to the crop rows (Fig. 3.1). These measurements were used to determine the profile of light interception across strips. The overall fraction of light interception in the heterogeneous canopy was calculated as the arithmetic average of measurements at the 15 different positions.

Table 3.1 Number of rows and length of row harvested for wheat and maize in each treatment

\begin{tabular}{|c|c|c|c|c|c|c|c|c|c|}
\hline \multirow[b]{3}{*}{ Year } & \multirow[b]{3}{*}{ Treatment } & \multicolumn{4}{|c|}{ Intermediate harvests $^{*}$} & \multicolumn{4}{|c|}{ Final harvest } \\
\hline & & \multicolumn{2}{|c|}{ Wheat } & \multicolumn{2}{|l|}{ Maize } & \multicolumn{2}{|c|}{ Wheat } & \multicolumn{2}{|l|}{ Maize } \\
\hline & & $\begin{array}{l}\text { Row } \\
\text { length } \\
\text { (m) }\end{array}$ & $\begin{array}{l}\text { No. } \\
\text { of } \\
\text { rows }\end{array}$ & $\begin{array}{l}\text { Row } \\
\text { length } \\
\text { (m) }\end{array}$ & $\begin{array}{l}\text { No. } \\
\text { of } \\
\text { rows }\end{array}$ & $\begin{array}{l}\text { Row } \\
\text { length } \\
\text { (m) }\end{array}$ & $\begin{array}{l}\text { No. } \\
\text { of } \\
\text { rows }\end{array}$ & $\begin{array}{l}\text { Row } \\
\text { length } \\
\text { (m) }\end{array}$ & $\begin{array}{l}\text { No. } \\
\text { of } \\
\text { rows }\end{array}$ \\
\hline \multirow{7}{*}{2013} & SW & \multirow{7}{*}{1} & 6 & \multirow{7}{*}{1} & - & \multirow{7}{*}{2} & 6 & \multirow{7}{*}{1} & - \\
\hline & SM & & - & & 2 & & - & & 2 \\
\hline & $6: 2 \mathrm{WM}$ & & 6 & & 2 & & 6 & & 2 \\
\hline & 6:0WM & & 6 & & - & & 6 & & - \\
\hline & $0: 2 \mathrm{WM}$ & & & & 2 & & - & & 2 \\
\hline & $8: 2 \mathrm{WM}$ & & 8 & & 2 & & 8 & & 2 \\
\hline & $6: 3 \mathrm{WM}$ & & 6 & & 3 & & 6 & & 3 \\
\hline \multirow{7}{*}{2014} & SW & \multirow{7}{*}{1} & 6 & \multirow{7}{*}{1} & - & \multirow{7}{*}{4} & 6 & \multirow{7}{*}{4} & - \\
\hline & SM & & - & & 2 & & - & & 2 \\
\hline & $6: 2 \mathrm{WM}$ & & 6 & & 2 & & 6 & & 2 \\
\hline & 6:0WM & & 6 & & - & & 6 & & - \\
\hline & $0: 2 \mathrm{WM}$ & & - & & 2 & & - & & 2 \\
\hline & $8: 2 \mathrm{WM}$ & & 8 & & 2 & & 8 & & 2 \\
\hline & $6: 3 \mathrm{WM}$ & & 6 & & 3 & & 6 & & 3 \\
\hline
\end{tabular}

* In 2013, intermediate harvests were made on days 122, 136, 155, 169, 183, 197 and 217 for wheat, and on days 169, 183, 197, 211, 225, 246 and 267 for maize. In 2014, intermediate harvests were made on days 120,134, 155, 176 and 197 for wheat, and on days 169, 182, 203, 225 and 246 for maize.

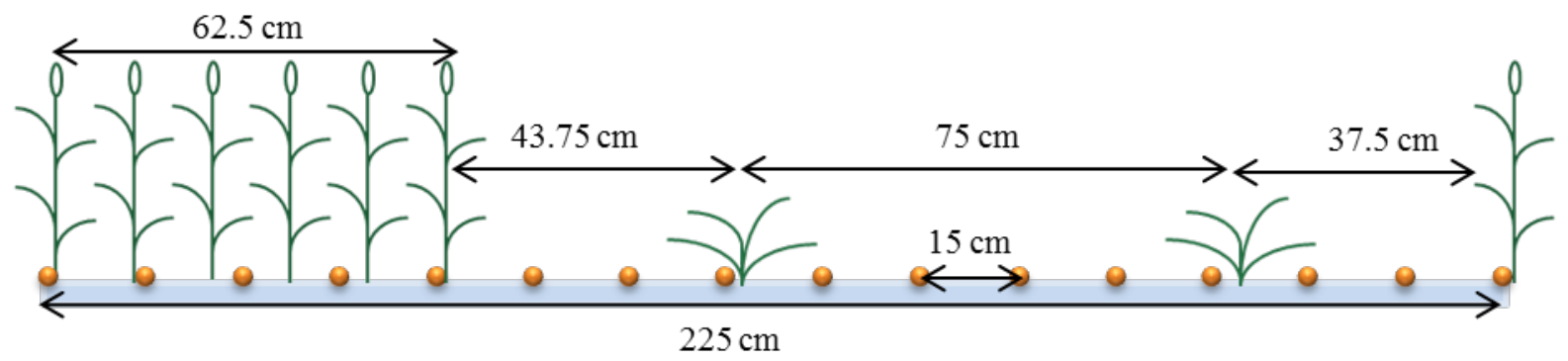

Fig. 3.1 Placement of PAR sensors under the canopy in the replacement intercrop (6:2WM). Orange points represent the positions where the SunScan probe was placed parallel to the rows. 


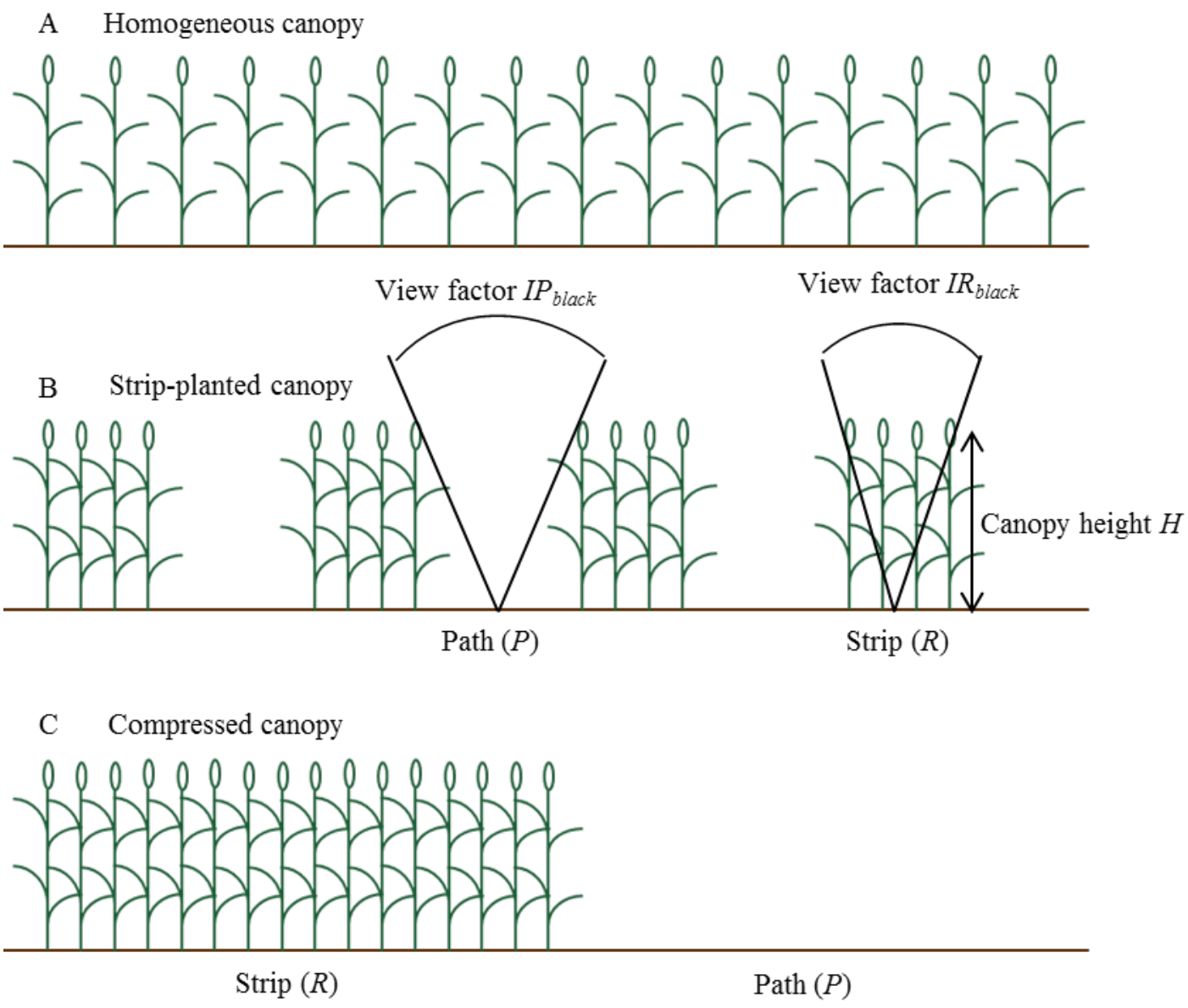

Fig. 3.2 Schematic figure of a homogeneous canopy, a strip-planted canopy and a compressed canopy.

\subsubsection{Calculation of light interception}

A model for the daily light interception per each species in a strip intercrop was developed on the basis of a model for light interception in a block structured canopy by Pronk et al. (2003). The model was previously modified and used to simulate radiation interception in a wheatcotton intercrop (Zhang et al., 2008; Mao et al., 2014). In wheat-cotton intercrop, it was not necessary to take the shading effect of cotton on wheat into account because of the short intercropping period and the small size of the cotton plants during this period. In wheat-maize intercropping, shading must be accounted for because maize is shaded by wheat in the early season and wheat is shaded by maize in the late season. Recently, shading dynamics in stripintercropping was studied by Wang et al. (2015), where they combined this strip-planted model to a horizontally homogeneous mixed canopy model (Keating and Carberry, 1993), and applied it to the wheat-maize intercrop system. Here we further elaborate the radiation interception model and modify it to account for light competition between the two species. 
The light interception of each species in the intercrop was calculated as the product of the fraction of light interception and daily incoming radiation (PAR). Daily PAR data were downloaded from an automated meteorological station at $3 \mathrm{~km}$ from the experimental site: http://www.met.wau.nl/veenkampen/data/.

\subsubsection{Fraction of light interception for a strip-planted sole crop}

We describe here in detail how the equations for the light interception in the strip intercrop are derived from elementary geometric principles and reasoning, originally developed by Goudriaan (1977) and Pronk et al. (2003), and later used with minor modifications by Zhang et al. (2008), Mao et al. (2014) and Wang et al. (2015). A strip-planted crop is a sole crop with some rows omitted to create empty paths (strip width: $R$, and path width: $P$ ) (Fig. 3.2B).

Compared to a homogenous canopy (Fig. 3.2A), a strip-planted canopy will capture less radiation at the same leaf area (counted over the whole field area) because some of the incoming radiation will fall onto the soil surface of the paths without passing through any leaf canopy (Jackson and Palmer, 1979). If we would move all the rows of a strip-planted crop to one side of the field, we would get one wide strip and one wide path (Fig. 3.2C). Such a "compressed" canopy would capture less radiation than a strip-planted canopy at the same leaf area, because the compressed canopy has no border rows, which in the strip crop there is extra radiation captured by border row plants. Thus the fraction of light interception by a strip-planted canopy $\left(f_{\text {strip_crop }}\right)$ is bracketed between two extremes: interception by a sole crop with the same $L A I$ as a maximum (homogeneous $L A I$ ), and interception by a compressed strip crop with the same overall $L A I$ as a minimum. Goudriaan (1977) and Pronk et al. (2003) proposed to calculate the radiation interception in a strip planted crop as a weighted average of these two extremes: radiation interception $f_{\text {compr }}$ by a fully compressed canopy (with weight $w$ ) and radiation interception $f_{\text {homo }}$ by a homogenous canopy (with weight $1-w$ ), Eq. 3.1 (Pronk et al., 2003):

$f_{\text {strip_crop }}=f_{\text {homo }} \times(1-w)+f_{\text {compr }} \times w$

We will derive equations for each of the terms in Eq. 3.1. In a homogenous canopy the fraction of light interception ( $\left.f_{\text {homo }}\right)$ is described as an exponential extinction function of leaf area index $(L A I)$ and the light extinction coefficient $(k)$. The light interception by a canopy of a homogeneous crop is described using Beer's Law (Monsi and Saeki, 1953). 
$f_{\text {homo }}=1-e^{-k \times L A I}$

Imagine compressing all the crop rows of the strips (width $R$ ) to one side of the field, and all the paths (width $P$ ) to the other side of the field (Fig. 3.2C). Then a part of the field $\frac{R}{R+P}$ will be covered with leaf area, and a proportion of $\frac{P}{R+P}$ will be bare. The $L A I$ in the green part of the field will be:

$L A I_{\text {compr }}=L A I \times \frac{R+P}{R}$

The fraction of light interception by this compressed canopy, considering the total land area, is $f_{\text {compr: }}$ :

$f_{\text {compr }}=\left(1-e^{-k \times L A I_{\text {compr }}}\right) \times \frac{R}{R+P}$

In a strip-planted canopy (Fig. 3.2B), the weight $w$ is a function of canopy height $(H)$, strip width $(R)$ and path width $(P)$, and its value is between 0 and 1 (Eq. 3.5).

$W=\frac{S P-S R}{1-e^{-k \times L A I} \mathrm{compr}}$

where $S P$ is the fraction of radiation transmitted to the soil surface in the path $(E q$. 3.6), and $S R$ is the fraction of radiation transmitted to soil surface under the strip (Eq. 3.7). Both $S P$ and $S R$ are functions of crop height, strip width and path width. The weight function (Eq. 3.5) is formulated in such a way that the value is 0 if the light falling on the soil in the path $(S P)$ and the strip $(S R)$ are equal, i.e. when the canopy is a homogeneous canopy. Light interception in the strip crop then equals light interception of the homogeneous canopy (Eq. 3.2). At the other extreme, the weight function is one if the strips are completely compressed. In this case, the light interception by the compressed strip is equal to $S P-S R=1-e^{-k \times L A I_{\text {compr }}}$ (see below). Equation 3.5 provides a useful weight function for all intermediate situations (Pronk et al., 2003).

$S P$ and $S R$ are calculated by separating radiation that reaches the soil surface directly from radiation and passes through leaf canopy. Radiation transmitted to the soil surface of path $(S P)$ comes from two origins, one is direct, and depends on the view factor over the path $\left(I P_{\text {black }}\right)$, and the other is transmitted from neighbouring crop rows $\left(1-I P_{\text {black }}\right) \times e^{-k \times L A I}$ : 
$S P=I P_{\text {black }}+\left(1-I P_{\text {black }}\right) \times e^{-k \times L A I}$

The view factor is the relative radiation onto the path when the canopy is assumed to have an infinite leaf area index (i.e. the canopy acts as a black block), where radiation could only transmit to the path from the top with a view angle (Fig. 3.1B and Eq. 3.7).

$I P_{\text {black }}=\frac{\sqrt{H^{2}+P^{2}}-H}{P}$

where $I P_{\text {black }}$ is the spatial integral of incoming radiation over the path assuming a spherical distribution of the angle of the incoming light beam (Goudriaan, 1977). Similarly, radiation transmitted to the soil surface under the rows $(S R)$ is coming from two origins. One is the view factor of the strip $I R_{\text {black }}$ and the other its complement $\left(1-I R_{\text {black }}\right)$. The radiation transmitted onto the soil surface under the strip is attenuated by the compressed canopy, thus it becomes $I R_{\text {black }} \times e^{-k \times L A I_{\text {compr }}}(E q$. 3.8). The other part comes from the neighbouring path and is assumed to be attenuated by the non-compressed canopy $\left(1-I R_{\text {black }}\right) \times e^{-k \times L A I}$ :

$S R=I R_{\text {black }} \times e^{-k \times L A I_{\text {compr }}}+\left(1-I R_{\text {black }}\right) \times e^{-k \times L A I}$

where $I R_{\text {black }}$ is the light interception measured in the strip, resulting from an opaque ("black") crop strip with height $H$ and width $W$, at a path width $P$ :

$I R_{\mathrm{black}}=\frac{\sqrt{H^{2}+R^{2}}-H}{R}$

wheat wheat maize

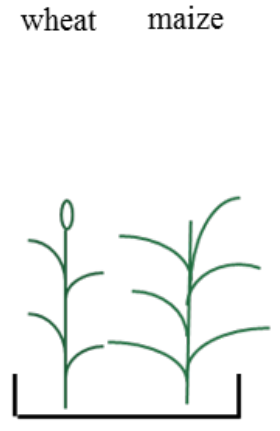

III

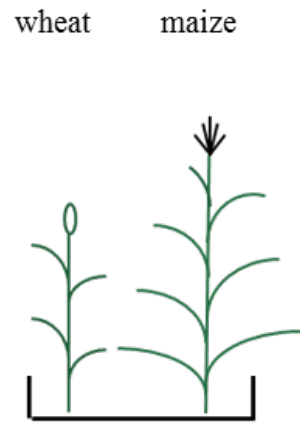

IV

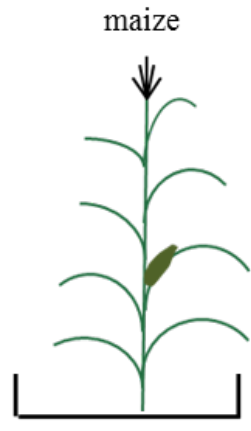

V

$$
H_{\text {wheat }}>H_{\text {maize }} \quad H_{\text {wheat }}=H_{\text {maize }} \quad H_{\text {wheat }}<H_{\text {maize }}
$$

Fig. 3.3 Schematic representation of five growth phases of the intercrop, during which different sets of equations are used to calculate light interception by wheat and maize $\left(H_{\text {wheat }}\right.$ : height of the wheat crop; $H_{\text {maize }}$ : height of the maize crop). 


\section{Chapter 3}

\subsubsection{Light interception in strip intercropping}

Five phases are distinguished to calculate light interception by intercropped wheat and maize over the growing season (Fig. 3.3). In phase I, only wheat is present, and Eq. 3.1 is used to calculate the fraction of light interception. Equation 3.1 is also used during phase $\mathrm{V}$ when only maize is present. During phases II, III and IV, both wheat and maize are present, and radiation partitioning between the species is accounted for.

In phases II and IV, one crop is taller than the other. In these cases, the canopy was divided into two layers (upper and lower layer). The upper layer is from the top of the canopy of the taller crop species to the top of the canopy of the shorter species, while the lower layer consists of alternate strips of the two species. The leaf area of the taller crop (wheat or maize) ( $\left.L A I_{\text {taller}}\right)$ was assumed to be homogeneously distributed over the vertical, and was accordingly subdivided into two parts ( $L A I_{\text {taller,upper }}$ and $\left.L A I_{\text {taller,lower }}\right)$ according to:

$$
\begin{aligned}
& L A I_{\text {taller,upper }}=\left(1-\frac{H_{\text {shorter }}}{H_{\text {taller }}}\right) \times L A I_{\text {taller }} \\
& L A I_{\text {taller,lower }}=\left(\frac{H_{\text {shorter }}}{H_{\text {taller }}}\right) \times L A I_{\text {taller }}
\end{aligned}
$$

The fraction of light interception of the taller crop $\left(f_{\text {taller }}\right)$ had two parts, in the upper layer $\left(f_{\text {taller,upper }}\right)$ and in the lower layer $\left(f_{\text {taller,lower }}\right)$ :

$f_{\text {taller }}=f_{\text {taller,upper }}+f_{\text {taller,lower }}$

Calculations for the upper layer were made using the model for a strip-planted canopy ( $E q$. 3.1), using the plant height difference of two crops and leaf area index of the upper layer of the taller crop as inputs. Light interception by the lower layer was calculated using the equations for a fully compressed canopy with leaf area indices of both species sharing the lower layer, and the fraction of light transmitted through the upper layer of the taller species as incoming light. The fraction of light interception by the lower layer of the taller crop was thus calculated as:

$f_{\text {taller,lower }}=S R_{\text {taller,upper }} \times\left(1-e^{-k_{\text {taller }} \times L A I_{\text {taller,lower,compr }}}\right) \times \frac{R_{\text {taller }}}{R_{\text {taller }}+P_{\text {taller }}}$

where $S R_{\text {taller,upper }}$ is the fraction of light transmitted through the canopy of the upper layer of the taller crop. 
The fraction of light interception of the shorter crop was calculated, similarly as $E q .3 .13$, as:

$f_{\text {shorter }}=S P_{\text {taller,upper }} \times\left(1-e^{\left.-k_{\text {shorter }} \times L A I_{\text {shorter,compr }}\right) \times \frac{R_{\text {shorter }}}{R_{\text {shorter }}+P_{\text {shorter }}}}\right.$

where $S P_{\text {taller,upper }}$ is the fraction of light transmitted between and through the strips of the taller crop onto the shorter crop.

In phase III, the two crops have the same height (Fig. 3.3). The equations for phases II and IV can then still be used, with $I P_{\text {black }}=I R_{\text {black }}=1$ for both species, and $S P=1(E q .3 .6)$.

The resulting equations for light interception by wheat and maize are those for compressed canopies:

$$
\begin{aligned}
& f_{\text {wheat }}=\left(1-e^{-k_{\text {wheat }} \times L A I_{\text {wheat,compr }}}\right) \times \frac{R_{\text {wheat }}}{R_{\text {wheat }}+P_{\text {wheat }}} \\
& f_{\text {maize }}=\left(1-e^{-k_{\text {maize }} \times L A I_{\text {maize,compr }}}\right) \times \frac{R_{\text {maize }}}{R_{\text {maize }}+P_{\text {maize }}}
\end{aligned}
$$

\subsubsection{Fraction of light interception by wheat ears}

The above calculations of the fraction of light interception by the canopy are based on leaf area (green and yellow leaves) of wheat and maize, and do not account for light interception by ears, which may be substantial in wheat. In the sole crop, wheat density is about 250 plants per $\mathrm{m}^{2}$, with approximately 500 ears per $\mathrm{m}^{2}$ after heading. Those ears capture light and contribute to photosynthesis (Araus et al., 1993; Abbad et al., 2004). To account for light interception by ears, we added an approximate area of the ears to leaf area (green and yellow) for both sole wheat and intercropped wheat, assuming that the light interception properties of leaves and ears are the same by assuming a common $k$. For example, the fraction of light interception of sole wheat $\left(f_{\text {homo }}\right)$ becomes:

$f_{\text {homo }}=1-e^{-k \times\left(L A I+\alpha_{\text {ear }} \times N_{\text {ear }}\right)}$

where, $\partial_{\text {ear }} \alpha_{\text {ear }}$ is the average half surface area of one ear $\left(\mathrm{m}^{2}\right.$ ear $\left.^{-1}\right)$. Ears of the used wheat cultivar measure approximately $8 \mathrm{~cm}$ length by $1.5 \mathrm{~cm}$ width and $1 \mathrm{~cm}$ thickness, thus, $\alpha_{e a r}$ $\partial_{\text {ear }}$ is $0.002 \mathrm{~m}^{2}$ ear $^{-1} . N_{\text {ear }}$ is the ear density $\left(\right.$ ear $\mathrm{m}^{-2}$ ), which was counted at each intermediate harvest. 
Chapter 3

Table 3.2 Summary of symbols and acronyms, their units and the equation in which they are calculated

\begin{tabular}{|c|c|c|c|}
\hline Acronym & Description & Eq. & Unit \\
\hline$f_{\text {strip-crop }}$ & Fraction of light interception of a strip-planted crop canopy & $(3.1)$ & - \\
\hline$f_{\text {homo }}$ & Fraction of light interception of a homogeneous canopy & $(3.2)$ & - \\
\hline$f_{\text {compr }}$ & Fraction of light interception of a compressed canopy & $(3.4)$ & - \\
\hline$L A I_{\text {compr }}$ & $L A I$ in the "covered" part of the field for a compressed canopy & $(3.3)$ & - \\
\hline LAI & Leaf area index over the whole intercropped area & - & - \\
\hline$w$ & $\begin{array}{l}\text { A weight function used to calculate light interception by a heterogeneous } \\
\text { canopy as a weighted sum of light interception by a homogeneous canopy } \\
\text { (weight } w \text { ) and a compressed canopy (weight } 1-w \text { ) }\end{array}$ & $(3.5)$ & - \\
\hline$S P$ & $\begin{array}{l}\text { Fraction of radiation transmitted to the soil surface in the path in a strip- } \\
\text { planted canopy }\end{array}$ & $(3.6)$ & - \\
\hline$S R$ & $\begin{array}{l}\text { Fraction of radiation transmitted to the soil surface in the strip in a strip- } \\
\text { planted canopy }\end{array}$ & $(3.7)$ & - \\
\hline$I P_{\text {black }}$ & View factor over the path & $(3.8)$ & - \\
\hline$I R_{\text {black }}$ & View factor over the strip & $(3.9)$ & - \\
\hline$L A I_{\text {taller,upper }}$ & $L A I$ of the upper layer of the taller crop in intercrop phases II and IV & $(3.10)$ & - \\
\hline$L A I_{\text {taller,lower }}$ & $L A I$ of the lower layer of the taller crop in intercrop phases II and IV & $(3.11)$ & - \\
\hline$f_{\text {taller }}$ & Fraction of light intercepted by the taller crop in intercrop phases II and IV & $(3.12)$ & - \\
\hline$f_{\text {taller,upper }}$ & $\begin{array}{l}\text { Fraction of light intercepted by the upper layer for the taller crop in intercrop } \\
\text { phases II and IV }\end{array}$ & $(3.1)$ & - \\
\hline$f_{\text {taller,lower }}$ & $\begin{array}{l}\text { Fraction of light intercepted by the lower layer for the taller crop in intercrop } \\
\text { phases II and IV }\end{array}$ & (3.13) & - \\
\hline$f_{\text {shorter }}$ & Fraction of light intercepted by the shorter crop in intercrop phases II and IV & (3.14) & - \\
\hline$S R_{\text {taller,upper }}$ & $\begin{array}{l}\text { Fraction of light transmitted through the canopy of the upper layer of the } \\
\text { taller crop }\end{array}$ & - & - \\
\hline$S P_{\text {taller,upper }}$ & Fraction of light transmitted between and through the strips of the taller crop & - & - \\
\hline$f_{\text {wheat }}$ & Fraction of light intercepted by wheat in intercrop phase III & $(3.15)$ & - \\
\hline$f_{\text {maize }}$ & Fraction of light intercepted by maize in intercrop phase III & (3.16) & - \\
\hline$k$ & Light extinction coefficient & - & - \\
\hline$k_{\text {shorter }}$ & Light extinction coefficient of the shorter crop & - & - \\
\hline$k_{\text {taller }}$ & Light extinction coefficient of the taller crop & - & - \\
\hline$k_{\text {wheat }}$ & Light extinction coefficient of wheat & - & - \\
\hline$k_{\text {maize }}$ & Light extinction coefficient of maize & - & - \\
\hline$H_{\text {taller }}$ & Crop height of taller crop in intercrop phase II and IV & - & $\mathrm{m}$ \\
\hline$H_{\text {shorter }}$ & Crop height of shorter crop in intercrop phase II and IV & - & $\mathrm{m}$ \\
\hline$R_{\text {wheat }}$ & Strip width of wheat in intercrop & - & $\mathrm{m}$ \\
\hline$P_{\text {wheat }}$ & Path width of wheat in intercrop & - & $\mathrm{m}$ \\
\hline$R_{\text {maize }}$ & Strip width of maize in intercrop & - & $\mathrm{m}$ \\
\hline$P_{\text {maize }}$ & Path width of maize in intercrop & - & $\mathrm{m}$ \\
\hline$R_{\text {shorter }}$ & Strip width of shorter crop in intercrop & - & $\mathrm{m}$ \\
\hline$P_{\text {shorter }}$ & Path width of shorter crop in intercrop & - & $\mathrm{m}$ \\
\hline$R_{\text {taller }}$ & Strip width of taller crop in intercrop & - & $\mathrm{m}$ \\
\hline$P_{\text {taller }}$ & Path width of taller crop in intercrop & - & $\mathrm{m}$ \\
\hline$L A I_{\text {shorter,compr }}$ & Compressed $L A I$ of the shorter crop & - & - \\
\hline$L A I_{\text {wheat,compr }}$ & Compressed $L A I$ of wheat & - & - \\
\hline$L A I_{\text {maize,compr }}$ & Compressed $L A I$ of maize & - & - \\
\hline
\end{tabular}




\subsubsection{Data analysis}

Root mean square error (RMSE) was used to estimate the accuracy of simulations as compared to observations.

$\operatorname{RMSE}=\sqrt{1 / N \times \sum_{i}^{N}\left(O_{i}-S_{i}\right)^{2}}$

where $O_{i}$ is the observed value, $S_{i}$ is the simulated value, and $N$ is the number of observations.

To calculate light interception, daily leaf area index and plant height were linearly interpolated from observations using the "approx" function in R (R Core Team, 2015). Radiation use efficiency (RUE) was estimated by linear regression of above-ground biomass on the calculated cumulative light interception. Pairwise comparisons of accumulated PAR and RUE were made among all treatments within a year. ANOVA $(\mathrm{P}=0.05)$ and Tukey's HSD were conducted, using the 'stas' package of the R programming language ( $\mathrm{R}$ Core Team, 2015).

\subsection{Results}

\subsubsection{Leaf area dynamics for wheat and maize in different planting configurations}

Leaf area dynamics over time differed for wheat and maize. The maximum leaf area index was attained in June (day 160 to 180) for wheat and during July and August (day 200 to 260) for maize. Wheat provided ground cover during the early growing season (Fig. 3.4, A and B), while maize provided ground cover in the later part of the growing season (Fig. 3.4, C and D). Wheat-maize intercrops spread ground cover with leaf area more evenly over the length of the growing season than the sole wheat or maize crops (Fig. 3.4, E and F). Relay intercropping therefore provided better canopy dynamics to capture radiation than sole crops.

Sole wheat had a higher leaf area index (considering the whole intercrop area) than intercropped wheat. The add- wheat intercrop (8:2WM) had higher wheat leaf area index than the other intercrops $(6: 2 \mathrm{WM}$ and $6: 3 \mathrm{WM})$ and skip-row wheat $(6: 0 \mathrm{WM})$. There was no significant difference in wheat leaf area index among the $6: 2 \mathrm{WM}, 6: 3 \mathrm{WM}$ and $6: 0 \mathrm{WM}$ configurations (Fig. 3.4, A and B). Sole maize had a higher leaf area index than intercropped maize. Add-row maize intercrop (6:3WM) had a significantly higher maize leaf area index than skip-row maize (0:2WM) and other intercrops (6:2WM and 8:2WM) (Fig. 3.4, C and D). 

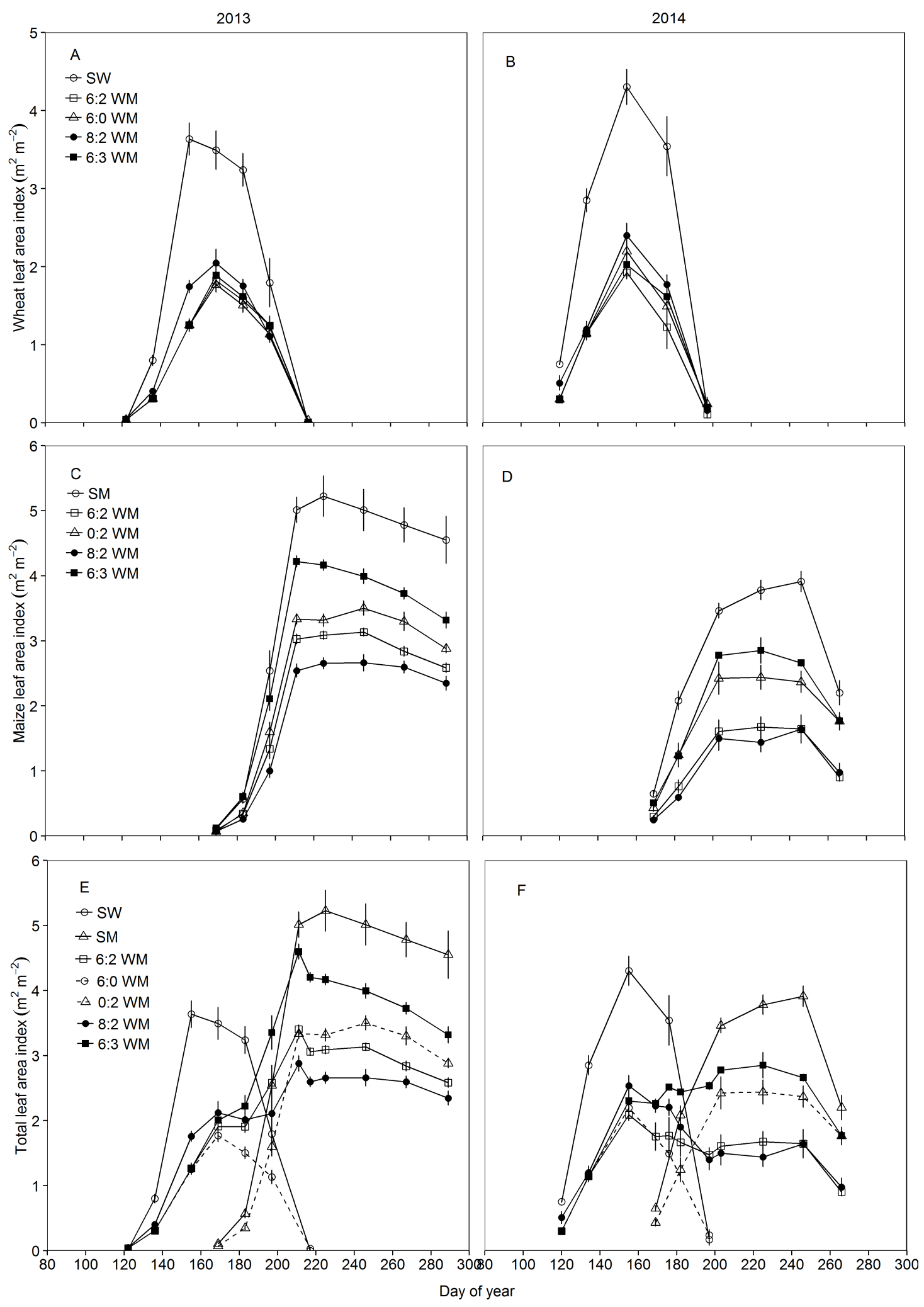

Fig. 3.4 Leaf area index dynamics of wheat (A: 2013; B: 2014) and maize (C: 2013; D: 2014) in different configurations. Panels $\mathrm{E}$ and $\mathrm{F}$ show the total leaf area. Full lines in panels $\mathrm{E}$ and F represent sole crops and intercrops, while dashed lines represent skip-row treatments. All leaf area indices are expressed per unit area of the whole system. 

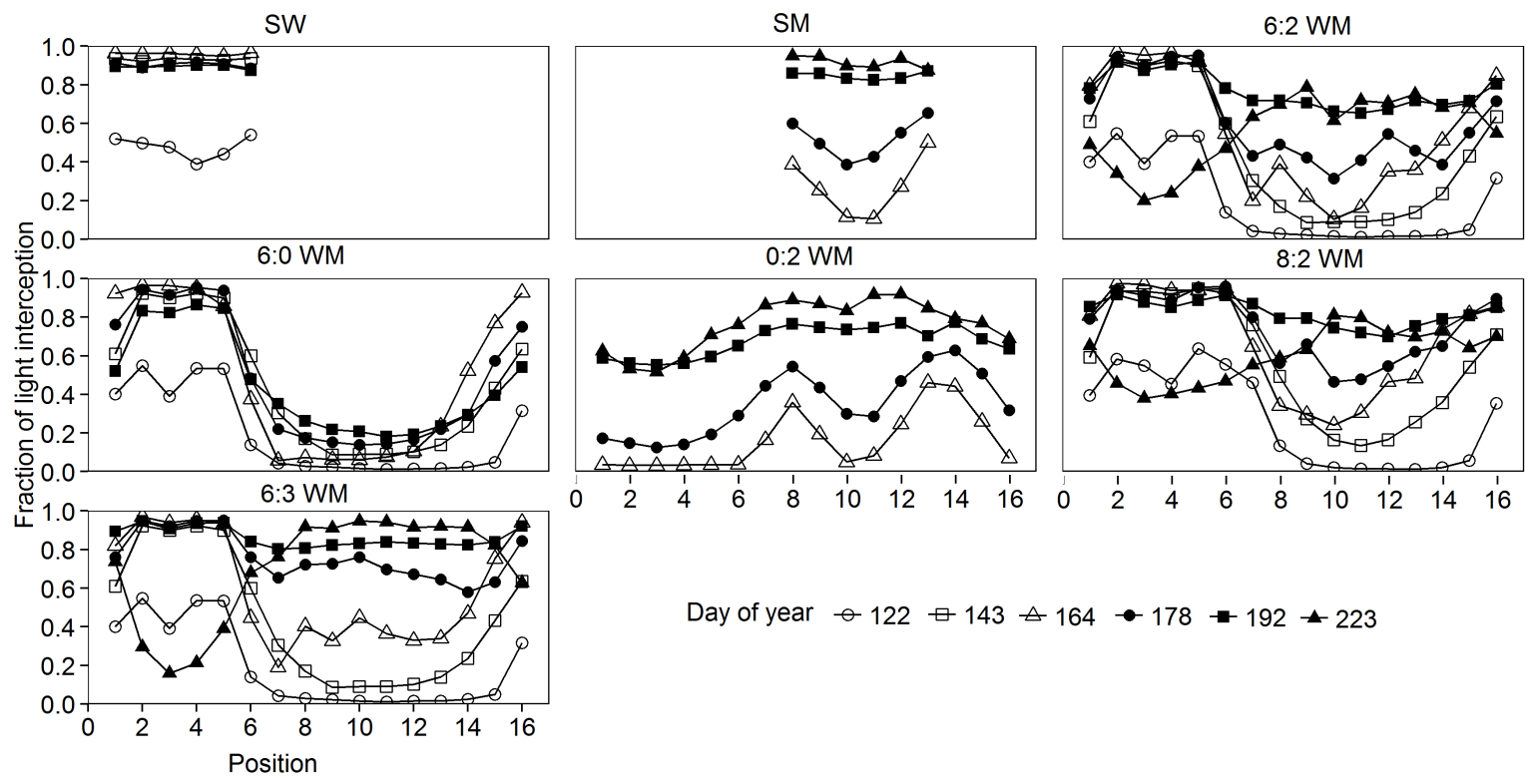

Day of year $\bullet 122 \nleftarrow 143 \triangle 164-178-192 \_223$

Fig. 3.5 Fraction of light interception across intercrop rows in different planting configurations during the growing season. The x-axis represents the position of measurements in the $6: 2 \mathrm{WM}$ configuration. Sensors were placed at $15 \mathrm{~cm}$ intervals across a $225 \mathrm{~cm}$-wide intercrop strip (Fig. 3.1). Positions 1 to 6 are in the wheat strip, while positions 7 to 15 are in the maize strip. The SunScan probe was placed parallel to the rows.

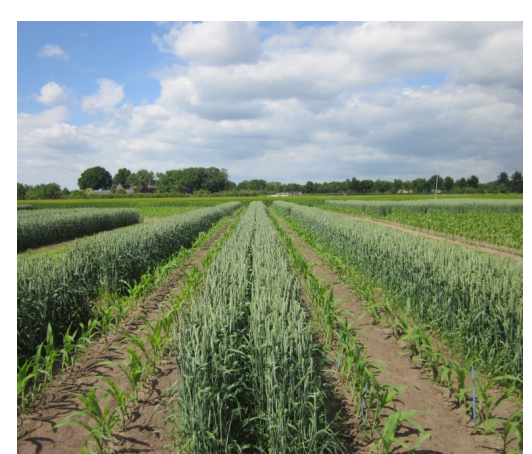

Day 164

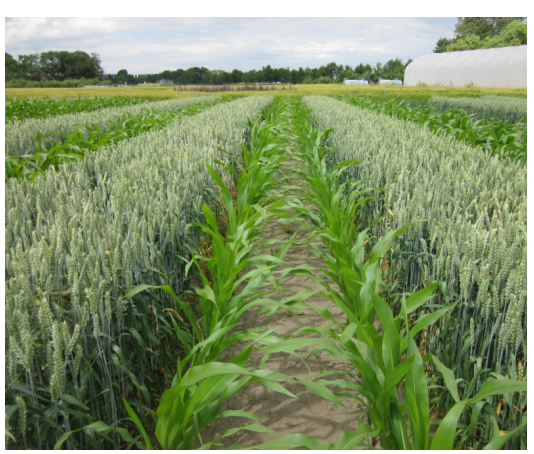

Day 181

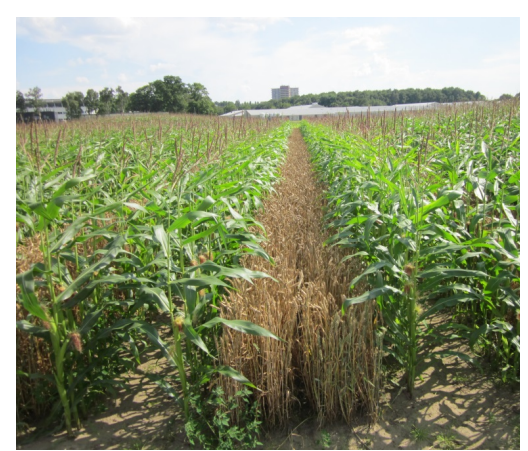

Day 205

Fig. 3.6 Photos of wheat-maize intercrop canopy on day 164 (June 13), day 181 (June 30) and day 205 (July 24) in 2014.

\subsubsection{Dynamics of the fraction of light interception during the season in different planting configurations}

Sole wheat and maize intercepted more than $90 \%$ of the incoming radiation when the canopy cover was high (Fig. 3.5), but the sole crops had a shorter period of radiation interception than intercrops, as shown by the leaf area dynamics (Fig. 3.4) and the temporal profiles of light interception (Fig. 3.5). In the replacement intercrop, only the wheat strips captured light during the early season, but gradually the fraction of light interception increased in maize 
strips. The wheat strips in the replacement intercrop (6:2WM) had a similar fraction of light interception as sole wheat (above 90\%), but maize strips had a lower fraction of light interception than sole maize. Skip-row wheat (6:0WM) did not capture much radiation in the path, while skip-row maize $(0: 2 \mathrm{WM})$ had a greater ability to do so (e.g. around $60 \%$ interception in the path at days 192 and 223) (Fig. 3.5). Compared with the replacement intercrop, the add-wheat intercrop (8:2WM) had a greater fraction of light interception in the wheat strips, while the add-maize intercrop $(6: 3 \mathrm{WM})$ had a greater fraction of light interception in the maize strips.

\subsubsection{Daily fraction of light interception for wheat and maize in different planting patterns}

The daily fraction of light interception was calculated using the model presented in Section 3.2.4 with appropriate parameters to describe each system. The same values of the light extinction coefficient of wheat $\left(k_{\text {wheat }}=0.63\right)$ and maize $\left(k_{\text {maize }}=0.69\right)$ were used in all treatments. The $k$ values were derived from $L A I$ and light measurements in sole wheat and sole maize by fitting Beer's law $k=-\ln \left(1-f_{\text {homo }}\right) / L A I$.

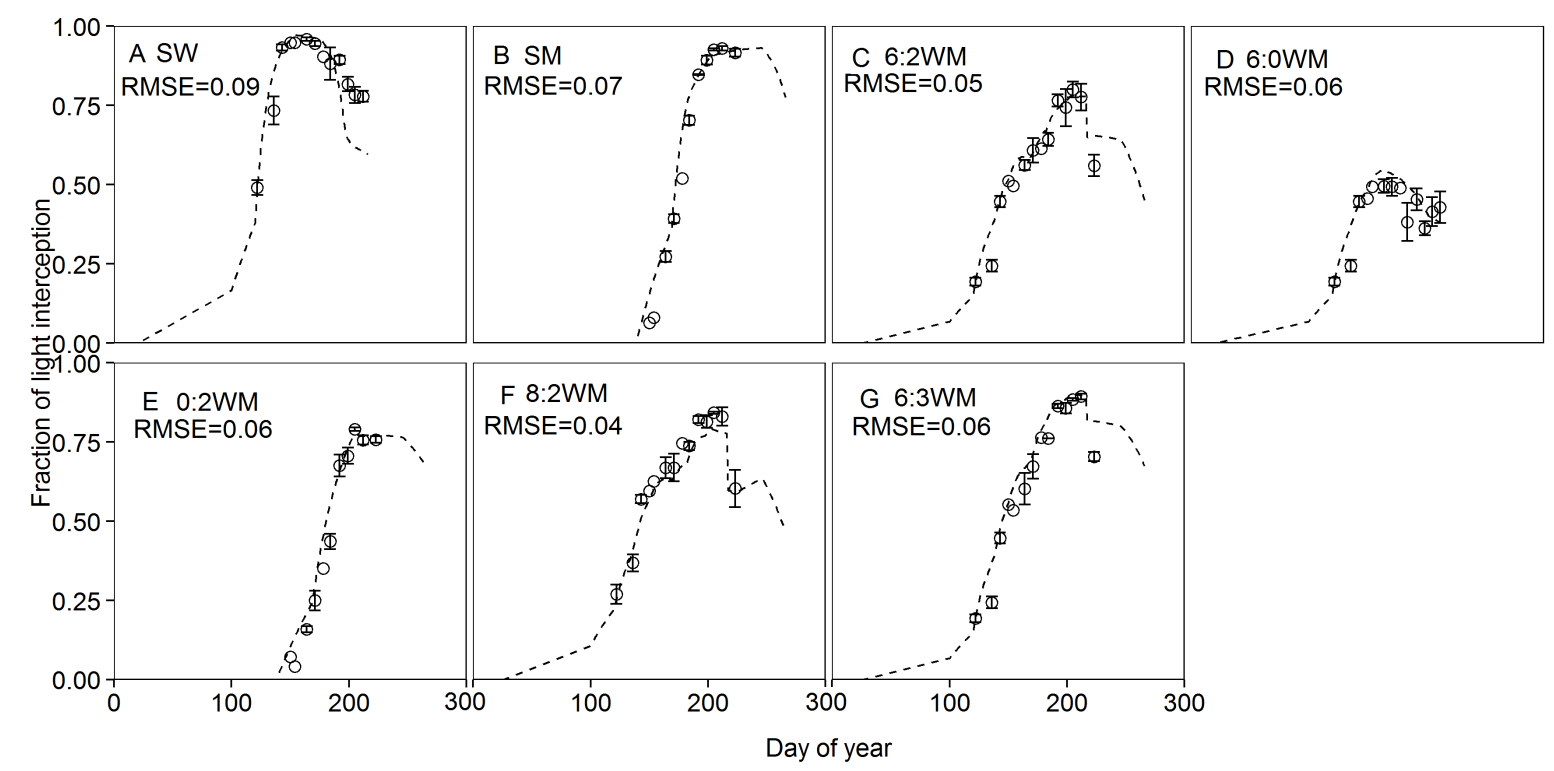

Fig. 3.7 Observed and simulated fraction of light interception in different treatments in 2014 as a function of time (dashed lines represent calculated values, circles represent observations).

The areas of green leaves, yellow leaves and ears (wheat) were used to simulate the total fraction of light interception by the canopy. Calculated and observed light interception were compared to test the light interception model (light interception on yellow leaves was not used 
for calculating light use efficiency; see below). For intercrops (6:2WM, 8:2WM and 6:3WM), the value of daily fraction of light interception was the sum of the simulated values for wheat and maize. The root mean square error (RMSE) varied from 0.04 (8:2WM) to 0.09 (SW) (Fig. 3.7), indicating acceptable to good correspondence between calculated and measured fraction of light interception.

\subsubsection{Light interception, biomass accumulation and light use efficiency by wheat and maize in different planting patterns}

The areas of green leaves and green ears (wheat) were used to calculate the light interception by the canopy as a basis for calculating light use efficiency. Light interception by yellow leaves was discounted because yellow leaves are not expected to be photosynthetically active, e.g. De Koeijer and van der Werf (1995) and because they are at the bottom of the canopy and therefore not competing with the green leaves for light. For wheat, cumulative PAR interception started from emergence (day 106 in 2013 and day 88 in 2014) until all leaves and ears had turned yellow (day 217 in 2013 and day 196 in 2014). For maize, cumulative PAR interception started from emergence (day 154 in 2013 and day 139 in 2014) until final harvest (day 289 in 2013 and day 266 in 2014).

Sole wheat had higher overall (i.e. whole system) cumulative PAR interception than wheat in intercrops and skip-row wheat. Wheat grown in replacement intercrop $(6: 2 \mathrm{WM})$ and wheat grown in add-maize intercrop (6:3WM) had a similar PAR interception course (Fig. 3.8, A and B). Total PAR interception was $244 \mathrm{MJ} \mathrm{m}^{-2}$ (2013) and $259 \mathrm{MJ} \mathrm{m}^{-2}$ (2014) for wheat in 6:2WM, and $240 \mathrm{MJ} \mathrm{m}^{-2}$ (2013) and $269 \mathrm{MJ} \mathrm{m}^{-2}$ (2014) for wheat in 6:3WM (Table 3.3). Before maize emergence (at day 154 in 2013, and day 139 in 2014), skip-row wheat (6:0WM) had a similar course of light interception as wheat in the replacement intercrop. After maize emergence, skip-row wheat had higher light interception than wheat in 6:2WM and 6:3WM treatments, due to light competition with maize. Eventually, skip-row wheat had a similar PAR accumulation as wheat in the add-row intercrop (8:2WM) (Fig. 3.8, A and B, Table 3.3).

Sole maize had a higher cumulative PAR interception than intercropped maize and skip-row maize. Maize grown in the replacement intercrop (6:2WM) had significantly higher light interception than maize in the add-wheat intercrop (8:2WM) in 2013 (548 $\mathrm{MJ} \mathrm{m}^{-2}$ vs $498 \mathrm{MJ}$ $\mathrm{m}^{-2}$ ), whereas this difference was consistent but not significant in 2014 (425 MJ m${ }^{-2}$ vs 390 $\mathrm{MJ} \mathrm{m}^{-2}$ ). 
Chapter 3
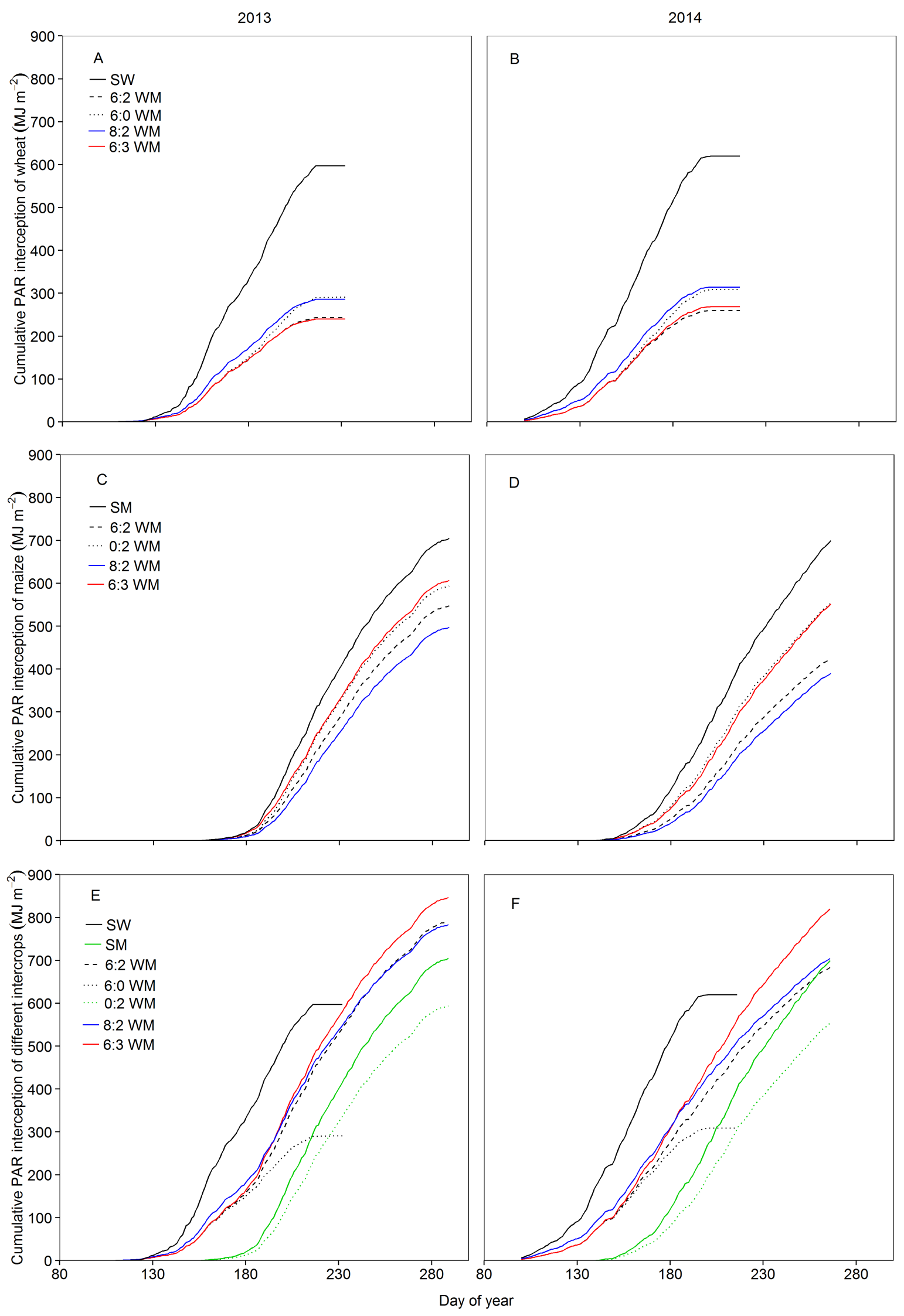

Fig. 3.8 Cumulative PAR interception of wheat and maize in different treatments and years (A and $\mathrm{B}$ for wheat, $\mathrm{C}$ and $\mathrm{D}$ for maize, $\mathrm{E}$ and $\mathrm{F}$ for wheat-maize). 

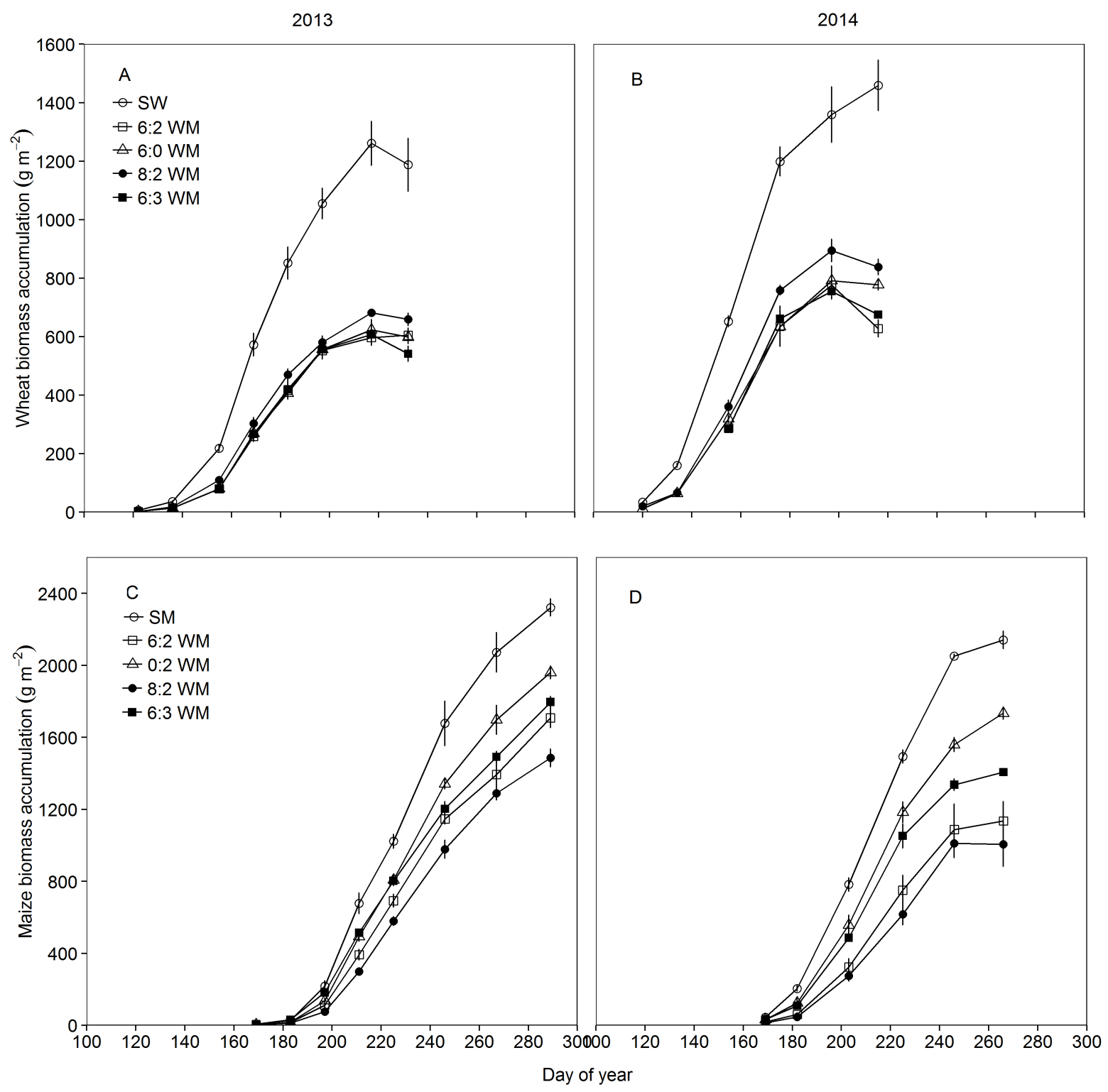

Fig. 3.9 Wheat and maize biomass accumulation dynamics in different treatments and years (A and B for wheat, C and D for maize in 2013 (left figures) and 2014 (right figures)).

Skip-row maize had a similar course of light interception as maize in the add-maize intercrop (6:3WM), with cumulative PAR interception of $594 \mathrm{MJ} \mathrm{m}^{-2} \mathrm{vs} 607 \mathrm{MJ} \mathrm{m}^{-2}$ in 2013, and 554 $\mathrm{MJ} \mathrm{m}^{-2}$ vs $551 \mathrm{MJ} \mathrm{m}^{-2}$ in 2014 (Fig. 3.8, C and D, Table 3.3). Add-maize intercrop (6:3WM) had the highest total cumulative PAR among all treatments, $847 \mathrm{MJ} \mathrm{m}^{-2}$ in 2013 and $820 \mathrm{MJ}$ $\mathrm{m}^{-2}$ in 2014 , followed by the $6: 2 \mathrm{WM}$ and $8: 2 \mathrm{WM}$ intercrops and sole maize. The replacement intercrop $(6: 2 \mathrm{WM})$ and the add-row wheat intercrop $(8: 2 \mathrm{WM})$ had significantly higher light interception than sole maize in 2013, but similar light interception as sole maize in 2014 (Fig. 3.8, E and F, Table 3.3). Skip-row maize (0:2WM) had significantly lower cumulative PAR interception than all intercrops and sole maize, i.e. $594 \mathrm{MJ} \mathrm{m}^{-2}$ in 2013 and $554 \mathrm{MJ} \mathrm{m}^{-2}$ in 2014. Skip-row wheat (6:0WM) had the lowest light interception of all treatments, i.e. $291 \mathrm{MJ}$ 
Chapter 3

$\mathrm{m}^{-2}$ in 2013 and $309 \mathrm{MJ} \mathrm{m}^{-2}$ in 2014 (Table 3.3).

The time course of above-ground biomass accumulation was similar to that of PAR accumulation for wheat and maize. Per unit land area, sole crops had the highest biomass of wheat or maize. The rank order of biomass in treatments was similar to that of cumulative PAR, with the exception of maize grown in skip-row (0:2WM) and add-maize intercrop (6:3WM) treatments: maize had similar cumulative PAR in these two treatments (Fig. 3.8, C and D), but maize grown in skip-row treatment had significantly more biomass than in the add-maize intercrop (Fig. 3.9, C and D).

Radiation use efficiency (RUE) was estimated by linear regression of above-ground biomass on cumulative PAR interception on green leaves and ears (Fig. 3.10). Intercropping consistently increased RUE of wheat and decreased RUE of maize, with significant differences between sole crops and intercrops in most but not all pairwise comparisons (Table 3.3). This effect of intercropping of wheat and maize on RUE was consistent over the two years of the study. The RUE of skip-row wheat (6:0WM) was intermediate between intercrops and sole wheat, and all intercropped wheat had similar RUE. Apart from the replacement intercrop in 2013, maize had significantly smaller RUE than sole maize and skiprow maize in intercrops (Table 3.3).

Table 3.3 Cumulative light interception and radiation use efficiency of wheat and maize in different configuration treatments and in 2013 and 2014

\begin{tabular}{|c|c|c|c|c|c|c|}
\hline \multirow[t]{2}{*}{ Year } & \multirow[t]{2}{*}{ Treatment } & \multicolumn{3}{|c|}{$\begin{array}{l}\text { Total intercepted PAR } \\
\qquad\left(\mathrm{MJ} \mathrm{m}^{-2}\right)\end{array}$} & \multicolumn{2}{|c|}{$\begin{array}{l}\text { Radiation use efficiency } \\
\qquad\left(\mathrm{g} \mathrm{MJ}^{-1}\right)\end{array}$} \\
\hline & & Wheat & Maize & Total & Wheat & Maize \\
\hline \multirow{7}{*}{2013} & SW & $597 \mathrm{a}$ & - & $597 d$ & $2.12 \mathrm{c}$ & - \\
\hline & $\mathrm{SM}$ & - & $705 \mathrm{a}$ & $705 \mathrm{c}$ & - & $3.21 \mathrm{a}$ \\
\hline & $6: 2 \mathrm{WM}$ & $244 \mathrm{c}$ & $548 \mathrm{c}$ & 792 b & $2.50 \mathrm{a}$ & $2.97 \mathrm{ab}$ \\
\hline & 6:0 WM & $291 \mathrm{~b}$ & - & $291 \mathrm{e}$ & $2.21 b c$ & - \\
\hline & $0: 2 \mathrm{WM}$ & - & $594 \mathrm{~b}$ & $594 \mathrm{~d}$ & - & $3.19 \mathrm{a}$ \\
\hline & $8: 2 \mathrm{WM}$ & $286 \mathrm{~b}$ & $498 \mathrm{~d}$ & $784 \mathrm{~b}$ & $2.36 \mathrm{ab}$ & $2.91 \mathrm{~b}$ \\
\hline & $6: 3 \mathrm{WM}$ & $240 \mathrm{c}$ & $607 \mathrm{~b}$ & $847 \mathrm{a}$ & $2.47 \mathrm{a}$ & $2.85 \mathrm{~b}$ \\
\hline \multirow{7}{*}{2014} & SW & $620 \mathrm{a}$ & - & $620 \mathrm{c}$ & $2.31 \mathrm{~b}$ & \\
\hline & $\mathrm{SM}$ & - & $700 \mathrm{a}$ & $700 \mathrm{~b}$ & & $3.15 \mathrm{a}$ \\
\hline & $6: 2 \mathrm{WM}$ & $259 \mathrm{c}$ & $425 \mathrm{c}$ & $684 \mathrm{~b}$ & $2.59 \mathrm{ab}$ & $2.75 \mathrm{~b}$ \\
\hline & 6:0 WM & $309 \mathrm{~b}$ & - & $309 e$ & $2.57 \mathrm{ab}$ & - \\
\hline & $0: 2 \mathrm{WM}$ & - & $554 \mathrm{~b}$ & $554 \mathrm{~d}$ & - & $3.19 \mathrm{a}$ \\
\hline & $8: 2 \mathrm{WM}$ & $314 \mathrm{~b}$ & $390 \mathrm{c}$ & $704 \mathrm{~b}$ & $2.76 \mathrm{a}$ & $2.70 \mathrm{~b}$ \\
\hline & $6: 3 \mathrm{WM}$ & $269 \mathrm{c}$ & $551 \mathrm{~b}$ & $820 \mathrm{a}$ & $2.71 \mathrm{a}$ & $2.72 \mathrm{~b}$ \\
\hline
\end{tabular}

ANOVA was carried out separately for 2013 and 2014. No shared letters denote a statistically significant difference $(\mathrm{P}=0.05)$ using Tukey's HSD. 

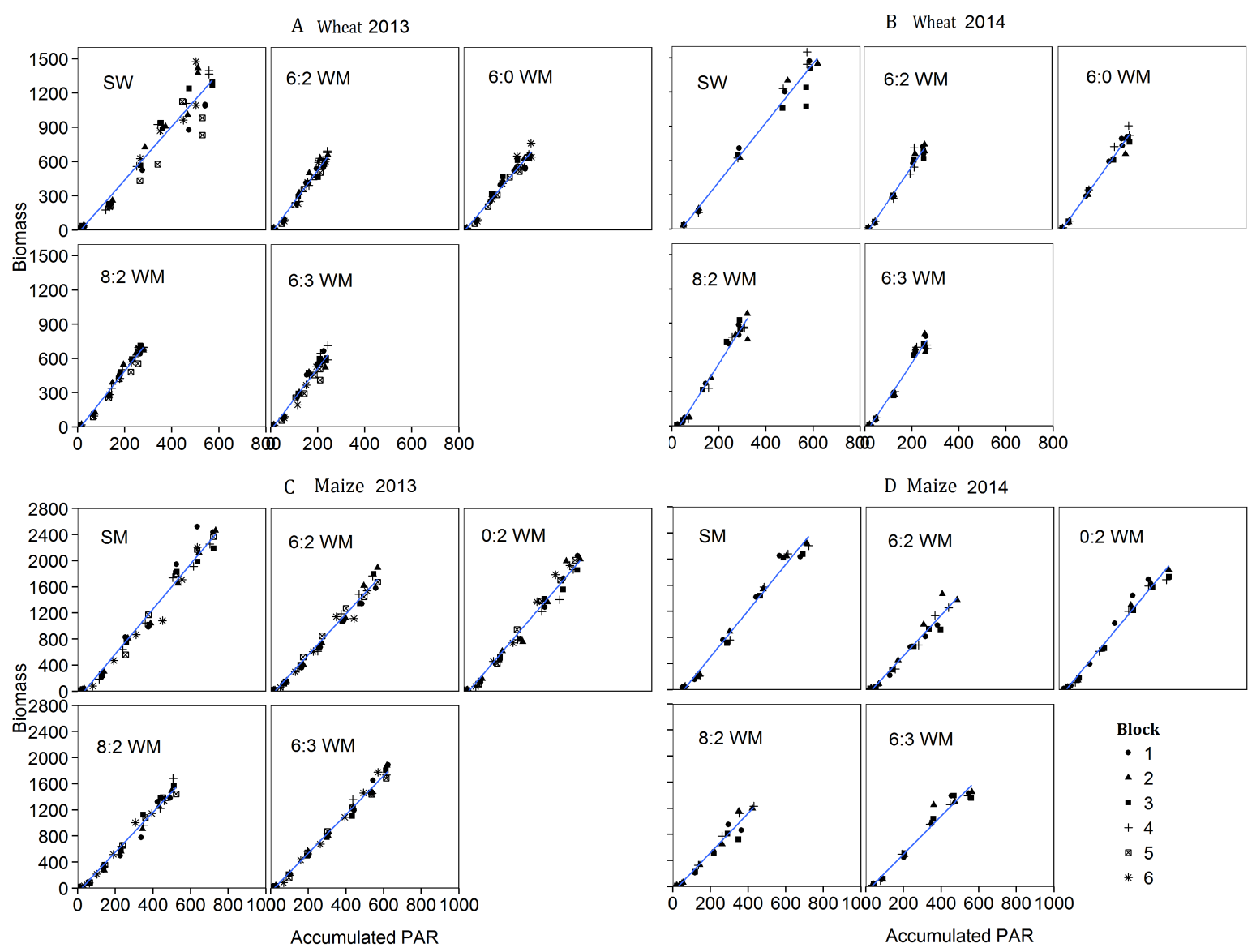

Fig. 3.10 Relationship (linear regression) between above-ground biomass of wheat and maize and cumulative PAR interception on green leaves and ears (wheat only) in different configuration treatments and years (A and B for wheat, C and D for maize in 2013 (left figures) and 2014 (right figures)).

\subsection{Discussion}

Four hypotheses were formulated based on our previous knowledge: 1) wheat-maize intercropping will enhance light interception compared to sole wheat and sole maize by extending the growing season; 2) plasticity of border row plants in strip intercropping will fill gaps and therefore mitigate the effect of omitting crop rows of a species in the intercrop; 3 ) add-row intercrops will capture more radiation than replacement intercrops due to limitations in gap filling responses in the replacement intercrop; and 4) wheat will realize a higher RUE in intercrops than in sole wheat due to shading by maize resulting in a lower light intensity and a higher proportion of diffuse radiation. The first hypothesis received partial support from the data. Intercepted PAR was significantly higher in the replacement intercrop (6:2WM) than in sole wheat in both years and significantly higher than in sole maize in 2013, but it had 


\section{Chapter 3}

similar PAR interception as sole maize in 2014. As to the second hypothesis, we found that with one third of the planting density, skip-row wheat (6:0WM) captured $50 \%$ as much PAR as sole wheat (291 $\mathrm{MJ} \mathrm{m}^{-2}$ vs $597 \mathrm{MJ} \mathrm{m}^{-2}$ in 2013 and $309 \mathrm{MJ} \mathrm{m}^{-2}$ vs $620 \mathrm{MJ} \mathrm{m}^{-2}$ in 2014), while skip-row maize captured around $80 \%$ as much PAR as sole maize with two thirds of the planting density (594 $\mathrm{MJ} \mathrm{m}^{-2}$ vs $705 \mathrm{MJ} \mathrm{m}^{-2}$ in 2013, $554 \mathrm{MJ} \mathrm{m}^{-2}$ vs $700 \mathrm{MJ} \mathrm{m}^{-2}$ in 2014) (Table 3.3). Thus, the second hypothesis was strongly confirmed, though gap filling responses were not strong enough to reach the sole crop yields in the skip-row treatments. As to the third hypothesis, we confirmed that increasing the density in the intercrop enhanced radiation interception, especially in the add-maize intercrop (6:3WM) which had significantly higher PAR interception than the replacement intercrop in both years. Indeed, gap filling responses were insufficient to compensate fully for the reduction in plant density that each species experienced in the intercrop; hence each species incurred a reduction in radiation interception and yield, but less than proportional to the reduction in density. Finally, we found that intercropped wheat has a higher radiation use efficiency than sole wheat, whereas intercropped maize has a lower radiation use efficiency than sole maize.

Overall, we conclude that intercrop productivity was explained by radiation interception and by changes in radiation use efficiency resulting from plant interactions. The light interception model applied in this study is based on the geometry of the crop and requires only few parameters (or inputs) that are easy to obtain in experiments. The model resulted in a good correspondence with measurements (Fig. 3.7). The model is likely to be valid for assessing competitive light capture in other strip intercropping systems. The model lacks detail to capture variation within species, e.g. the difference of light interception between plants in border rows and inner rows. Functional-structural plant models may be more suitable for making calculations at such a detailed level (Zhu et al., 2015).

\subsubsection{Radiation interception in intercrops}

Intercropping can enhance radiation capture by combining species which cover the soil and use radiation during different parts of the growing season. In the wheat-maize system, wheat has a high ground cover from May to July, while maize provides good soil cover from July to September (Fig. 3.4). The difference between wheat and maize in the time course of LAI has the potential to extend the length of the overall growing season and therewith the productivity of the system, but comes at the penalty of reduced density for either species. Results of the study indicate that the advantage of temporal complementarity is greater than the 
disadvantage of gaps in the canopy due to a reduced density of each species.

\subsubsection{Radiation interception by wheat in intercrops}

In the replacement intercrop $(6: 2 \mathrm{WM})$, wheat captured slightly more than $40 \%$ of the PAR by sole wheat (41\% in 2013 and 42\% in 2014). Per meter row, wheat captured 23\% (in 2013) and 25\% (in 2014) more radiation in the intercrop than in sole wheat. These values were higher than those reported by Wang et al. (2015) who found $17 \%$ increase in radiation capture per wheat row in a replacement intercrop under Chinese conditions. This difference may be due to differences in the intercropping patterns between the studies. In northwest China, the distance between wheat strips was $80 \mathrm{~cm}$ (two rows of maize at $40 \mathrm{~cm}$ row distance), while in our study, the distance between wheat strips was $150 \mathrm{~cm}$ (two rows of maize with 75 row distance). The wider path between wheat strips provided greater advantages in radiation capture for the border row of wheat in our study as compared to Wang et al. (2015).

Though the amount of light captured by border row plants as compared to interior plants could not be calculated with the current model, plasticity of border row plants (in tillering) was reported to be the main reason for increased light capture for intercropped wheat by Zhu et al. (2015). Wheat in the 6:0WM and 6:2WM treatments showed initially the same radiation interception (Fig. 3.8, A and B). After emergence of maize, they diverged, with greater radiation interception by wheat in the treatment without maize. At wheat harvest, wheat grown in 6:2WM had intercepted 16\% less radiation $\left(47 \mathrm{MJ} \mathrm{m}^{-2}\right.$ and $50 \mathrm{MJ} \mathrm{m}^{-2}$ PAR in 2013 and 2014) than wheat in 6:0WM. Wheat was initially the dominant species in the competition for light in the wheat-maize intercrop, but the competitive advantage shifted gradually to maize, with progressively less light coming to wheat from the path in the wheat-maize intercrop compared to the skip-row wheat. The results indicate that the early competition by maize did not strongly influence the growth and development of wheat (similar tiller number per meter row, similar kernel number per ear in 6:2WM and 6:0WM) (Chapter 2). However, when maize surpassed wheat by height, wheat became increasingly shaded, and this shading negatively influenced wheat grain filling. Eventually, wheat had lower thousand kernel weight in intercrops border rows as compared to wheat in inner rows or sole crops (Chapter 2).

\subsubsection{Radiation interception by maize in intercrops}

In the replacement intercrop, maize captured $78 \%$ as much PAR per unit area as sole maize in 


\section{Chapter 3}

2013 and $61 \%$ as much in 2014. Per meter row, intercropped maize captured 17\% more radiation than sole maize in 2013, but it captured 9\% less radiation than sole maize in 2014 . Wang et al. (2015) found that intercropped maize in Inner Mongolia captured 28\% more PAR than sole maize per meter row. Thus, intercropped maize had less advantage in radiation capture in our study than in northwest China. Several differences between the experimental growing conditions in northwest China and the Netherlands could be responsible for this difference in the effect of intercropping on radiation by maize between the current study and Wang et al. (2015). First of all, the co-growth period (from maize emergence to wheat harvest) is longer in the Netherlands (approximately 11 weeks) than in northwest China (approximately 9 weeks). The co-growth period is related to sowing and harvesting days which are chosen to take maximum advantage of the growing season, taking into account phenology of the chosen varieties and temperature regimes in the different agro-ecological environments. The long co-growth period in the Netherlands enhanced the interspecific competition for light between the two species and shortened the "recovery period" of maize after wheat harvest. Another factor potentially affecting the light acquisition effects of intercropping in the two areas is a difference in relative density. The intercrop in Inner Mongolia had relative densities of 0.47 for wheat and 0.53 for maize, whereas in the replacement intercrop in our experiments the relative density of wheat was 0.33 and the relative density of maize was 0.67 . Due to more maize and less wheat in the system in northwest China, the radiation capture advantage in northwest China would be expected to be greater for maize (relatively greater free space after wheat harvest) and smaller for wheat (relatively less free space before maize emergence). Indeed, the results are in agreement with this expectation.

When maize was grown as a skip-row (0:2WM), it captured 8\% (in 2013) and 30\% (in 2014) more PAR than in the replacement intercrop with wheat. The extra intercepted radiation originated both from a higher leaf area index (Fig. 3.4, C and D) and the absence of shading by wheat. Higher maize leaf area index in skip-row as compared to replacement intercrop indicates that early competition affected the initial maize growth in intercrops, confirming results of Zhu et al. (2014).

Intercropped maize had a lower light interception than sole maize when expressed per plant. According to model calculations by Zhu et al. (2015), a major part of the reduction (64\%) was due to plant plasticity (e.g. intercropped maize had fewer leaves than sole maize), while the 
rest of the reduction was due to row configuration (e.g. maize was partly shaded by neighbouring wheat in the early growing season). In our study, maize leaf area index in addrow maize intercrop (6:3WM) was higher than in skip-row (0:2WM, Fig. 3.4, C and D), but maize captured similar amounts of radiation in these two treatments (Fig. 3.8, C and D, Table 3.3), indicating that the narrow row distance in the maize strip increased mutual shading and cancelled out the potential increase in radiation capture resulting from greater leaf area. Thus, row configuration and row distance had a strong effect on light interception. Furthermore, maize had significantly lower biomass accumulation in 6:3WM than in 0:2WM (Fig. 3.9, C and D), which suggests that radiation use efficiency was negatively affected by competitive interactions in the 6:3WM intercrop.

\subsubsection{Radiation use efficiency}

Previous studies found that the combined RUE (the ratio of accumulated biomass of intercrop to total radiation intercepted) was higher in intercrops than in sole crops. For instance, maizepigeonpea intercrop had higher RUE than maize and pigeonpea grown in mono-culture (Sivakumar and Virmani, 1984). Mahallati et al. (2015) found that due to reduced nitrogen competition in maize-bean intercrop, maize RUE increased by $7 \%$ to $11 \%$ compared to sole maize. In our study, wheat (C3) had a higher RUE in intercropping than sole wheat, and the RUE of wheat grown in skip-row (6:0WM) was not significantly different from that in sole crop and intercrops (Table 3.3). The increase of wheat RUE in intercrop treatments, but not in skip-row wheat, may be related to shading by maize. Through shading, wheat in intercrop plots may have captured less radiation but produced a similar amount of biomass as in skiprow wheat, indicating a more efficient use of the captured radiation. Such an increase in RUE was reported for groundnut in an intercrop with millet (Harris et al., 1987). The conclusion that shading by maize is involved in the increase of RUE in intercropped wheat is supported by the lack of an increase of RUE in the wheat skip row treatment. Likewise, Zhang et al. (2008) found no change in RUE if wheat was intercropped with cotton, a species with comparatively late sowing and slow early development, which does not cause significant shading of wheat before wheat harvest.

In our study, intercropped maize had a significantly lower RUE than sole maize and skip-row maize, confirming results of Wang et al. (2015) in Inner Mongolia. As maize grown in replacement intercropping had a similar canopy structure (row pattern) as in skip-row, the lower RUE of intercropped maize may be related to early competition with wheat. Shade 


\section{Chapter 3}

affected maize plant physiology and structure of leaves, such as a decreased leaf and collar appearance rate, and larger blade and sheath lengths at low leaves ranks (Zhu et al., 2014). These shaded leaves are thinner and their photosynthetic rate per unit area leaf is lower under high light intensity than normal leaves (Hawkins, 1982). Furthermore, competition for soil nutrients cannot be ruled out, especially as wheat roots can expand laterally and extract nutrients from the adjacent maize strip, even before the sowing of maize ( $\mathrm{Li}$ et al., 2006). Zhang et al. (2008) found no effect of intercropping on cotton RUE, which may be related to the high amounts of fertilizer given in their experiments as compared to the tailored nutrient amounts applied in our experiments, which could inadvertently have resulted in some nutrient stress for the second sown crop.

\subsection{Conclusion}

We found replacement wheat-maize intercrop enhanced radiation interception by extending the growth duration compared to the sole crops in 2013, but not in 2014. Intercropped wheat captured similar amounts of radiation in the two years, while intercropped maize had less radiation capture in 2014 than in 2013. Adding one row of maize in the replacement intercrop significantly increased radiation interception but did not increase biomass. Intercropped wheat had significantly higher RUE than sole wheat, while intercropped maize had a significantly lower RUE than sole maize. Skip-row wheat had an intermediate RUE compared to sole wheat and intercropped wheat; and skip-row maize had a similar RUE as sole maize. Thus, row configuration substantially influenced radiation capture and also affected radiation use efficiency. Interspecific interactions had strong effects on RUE in both wheat and maize.

\section{Acknowledgements}

We are grateful to Prof. Dr Jan Goudriaan for helpful discussions and advice, and to Dr Junqi Zhu, Dr Yang Yu, Mr. Marcello Labra Fernandez, Dr Hiroe Zenihiro, Mr. Niel Verhoog and Wageningen UR Unifarm staff for valuable help during the experiments. The financial support of the China Scholarship Council (CSC) and the Key Sino-Dutch Joint Research Project of NSFC (grant number: 31210103906) are gratefully acknowledged. 


\title{
Chapter 4
}

\section{Simulating potential growth in a relay-strip intercropping system:}

\section{model description, calibration and testing}

\author{
Fang Gou ${ }^{1,2}$, Martin K. van Ittersum ${ }^{2}$, Wopke van der Werf ${ }^{1}$ \\ ${ }^{1}$ Centre for Crop Systems Analysis, Wageningen University, P.O. Box 430, 6700 AK \\ Wageningen, The Netherlands \\ ${ }^{2}$ Plant Production Systems group, Wageningen University, P.O. Box 430, 6700 AK \\ Wageningen, The Netherlands
}




\title{
Chapter 4
}

\begin{abstract}
Intercropping tends to have a higher productivity than traditional sole crops, mainly due to complementary resource use in time and space among different species. Intercropping may become more important in a world that needs to produce $60-70 \%$ more food by 2050 with limited land and other agricultural resources. To assess the role of intercropping in agricultural systems and its contribution to future food security, an intercrop model is needed for growth and yield predictions of intercrops under different growing conditions. Strip intercropping is a prevalent intercropping system, but the existing intercrop models are generally built for full mixtures and are less suitable for strip intercrops. Here we describe a simple intercrop model which is developed based on a sole crop model using the radiation use efficiency (RUE) concept and a strip intercrop light partitioning module. The model allows simulating the growth and yield of each intercropped species in relay-strip intercropping under potential growing conditions (only competition for light; other resources are assumed to be non-limiting), and the intercrop could vary in species combination, planting configuration, sowing densities and sowing dates. The daily inputs of the model are temperature and radiation, and crop-specific parameters are required to accurately simulate crop leaf area index (LAI), biomass and final yield. Data collected during two years (2013 and 2014) field experiments were used to calibrate and test the model. The experiments consisted of two sole crop treatments (sole wheat, SW and sole maize, SM) and three intercrop treatments (replacement intercrop, 6:2WM and add-row intercrops, 8:2WM and 6:3WM). The experiments were conducted in Wageningen, the Netherlands. Data of sole crops (SW and SM) and replacement intercrop (6:2WM) treatment were used to calibrate the model, and data of add-row intercrops (8:2WM and $6: 3 \mathrm{WM})$ were used to test the model. Bayesian analysis was applied to calibrate RUE of wheat and maize in sole crops and intercrop. This calibration procedure resulted in posterior distributions of RUE for sole crops and intercrop, on the basis of which distributions of biomass and land equivalent ratio (LER) were simulated. Biomass accumulation and yield of each species were simulated adequately but LAI was slightly overestimated compared to observations. The intercrop model allows simulating border row effects in terms of biomass per meter row. It combines a simple structure with easy calibration and enables growth and yield simulations for a wide range of relay-strip intercrops. The model thus can be of value in exploratory land use studies to assess the role of intercropping.
\end{abstract}

Key words: intercropping model, relay-strip intercrop, maize, wheat, Bayesian method 


\subsection{Introduction}

Intercropping is defined as the cultivation of two or more crop species simultaneously in the same field (Vandermeer, 1989). Relay intercropping is the cultivation of different crop species with partial overlap in growing period, and strip intercropping is the cultivation of different crop species in alternating narrow strips. In strip intercropping, the crop strips usually are wide enough to permit independent cultivation but narrow enough for the crop species to interact with each other at the plant level (Vandermeer, 1989). A relay-strip intercrop is a relay intercrop which is arranged in strips. Examples are the wheat-maize intercrop and wheat-soybean intercrop in northwest China ( $\mathrm{Li}$ et al., 2001b; Knörzer et al., 2009), where wheat is sown in March and harvested in July, while maize and soybean are sown in April and harvested in September. A relay intercrop allows for a longer total growth duration compared to each sole crop, and the associated greater radiation capture over the whole season tends to increase yields compared to the sole crops (Fukai and Trenbath, 1993; Zhang et al., 2008; Yu et al., 2015). When relay intercrops are arranged as strips, the plants growing in border rows have more space and resources, especially during the time before or after the co-growth period. Those border row plants are likely to be more productive than those in inner rows or in a sole crop. For instance, in wheat-cotton intercrop, the co-growth of wheat and cotton is about seven weeks, resulting in significantly higher (61\%) wheat grain yield in border rows than in inner rows (Zhang et al., 2007).

Relay-strip intercrops have been widely practiced by farmers in China (Li et al., 2001b; Zhang et al., 2007), but a declining trend of intercropping is observed in the North China Plan due to the increasing labour price and a shift of rural labour into the construction and industrial sectors (Feike et al., 2012). This decline in the usage of intercrops could pose a risk to local food security as sole crops are generally less productive. Land use studies can be helpful to reveal the role of intercrops in sustainable food systems in regions where intercrops have played or are playing an important role in food security. Crop models can integrate abiotic and biotic factors to assess the land productivity under different conditions and with different crop systems. Sole crop models are used to analyse yield potentials and yield gaps, for instance for rice, wheat and maize (Boling et al., 2010; Liang et al., 2011; Laborte et al., 2012; van Ittersum et al., 2013). They may also be used to study the resource allocation at farm or regional levels (Lu et al., 2004; van Oort et al., 2015). 


\section{Chapter 4}

Several intercrop models exist which simulate light competition between two intercropped species, but most of the models assume a homogeneous canopy (Kropff et al., 1984; Lantinga et al., 1999). For example, the crop-weed competition model INTERCOM (Kropff and van Laar, 1993) assumed horizontally homogeneous canopy for crop and weed and is used in celery-leek intercrop (Baumann et al., 2002). A homogeneous mixing was also used to simulate pea-barley intercrop (Brisson et al., 2004; Corre-Hellou et al., 2009) and cereal-legume mixture (Tsubo et al., 2005). These models, however, are not well-suited to simulate the light competition in relay-strip intercrops, where the border row effect plays an important role (Zhu et al., 2015; Zhu et al., 2016) and the strength of competition for light depends on the planting configuration (row spacing, sowing density and dates).

Crop radiation use efficiency (RUE) is defined as the ratio between dry matter production and cumulative intercepted photosynthetically active radiation (PAR) (Monteith, 1977; Gallagher and Biscoe, 1978; Haverkort and Bicamumpaka, 1986). The RUE concept laid the foundation for crop models to simplify crop biomass accumulation from parameter-rich photosynthesis process-based models, e.g., SUCROS (Bouman et al., 1996; van Ittersum et al., 2003) to more parameter-sparse models based on light interception and utilization , e.g., LINTUL (Spitters and Schapendonk, 1990; Bouman et al., 1996) and APSIM (Keating et al., 2003). The RUE of a crop in an intercrop may differ, however, from its value in a sole crop. For example, when intercropped with millet, groundnut has a higher RUE than when it is grown as sole crop (Marshall and Willey, 1983; Harris et al., 1987). Intercropping of wheat and maize increases wheat RUE but lowers maize RUE (Chapter 3). These different RUEs are not captured in crop growth models. Often, intercrop models are parameterised based on characteristics of sole crops and then used for intercrops, e.g., celery-leek intercrop (Baumann et al., 2002) and pea-barley intercrop (Corre-Hellou et al., 2009). While similarity of RUE in sole crops and intercrops is a useful null hypothesis and starting point for intercrop modelling, it may not be realistic for asymmetric competitive relationships in intercrops that affect radiation use efficiencies. All in all, the existing intercrop models could neither be well suited to simulate light competition in relay-strip intercropping arrangement, nor be properly calibrated for intercropping growing conditions.

The objectives of this paper are: 1) to develop an intercrop model based on the radiation use efficiency approach for a strip intercrop; 2) to calibrate this crop model based on literature data and experimental data for sole crops and replacement intercrops with wheat and maize, 
taking into account possible differences in radiation use efficiency between crops grown as sole crops or as intercrops; 3 ) to test the model by comparing simulated leaf area index, and biomass accumulation in augmentative intercrops with field data; 4) to show in a simulation study how accounting for strip structure affects calculated light interception and biomass growth of each species; and 5) to illustrate by sensitivity analysis how the key parameters influence the leaf area index and biomass growth of each intercropped species.

\subsection{Materials and Methods}

\subsubsection{Model description}

The model consists of two crops which are planted as relay-strip intercrop, with strip width (Strip 1) and path width (Path 1) for the early sown crop, and strip width (Strip 2) and path width (Path 2) for the late sown crop (Fig. 4.1). The two crops are assumed to only compete for light. For each crop, phenological growth and biomass growth are simulated and related to a temperature sum $\left(T_{\text {sum }}\right)$. Fig. 4.2 shows the general structure of the model; feedbacks of light interception, biomass accumulation and leaf area dynamics are simulated for each crop. The strength of light competition of two crops is determined by their height, leaf area indices and planting configuration (strip and path width of each species).

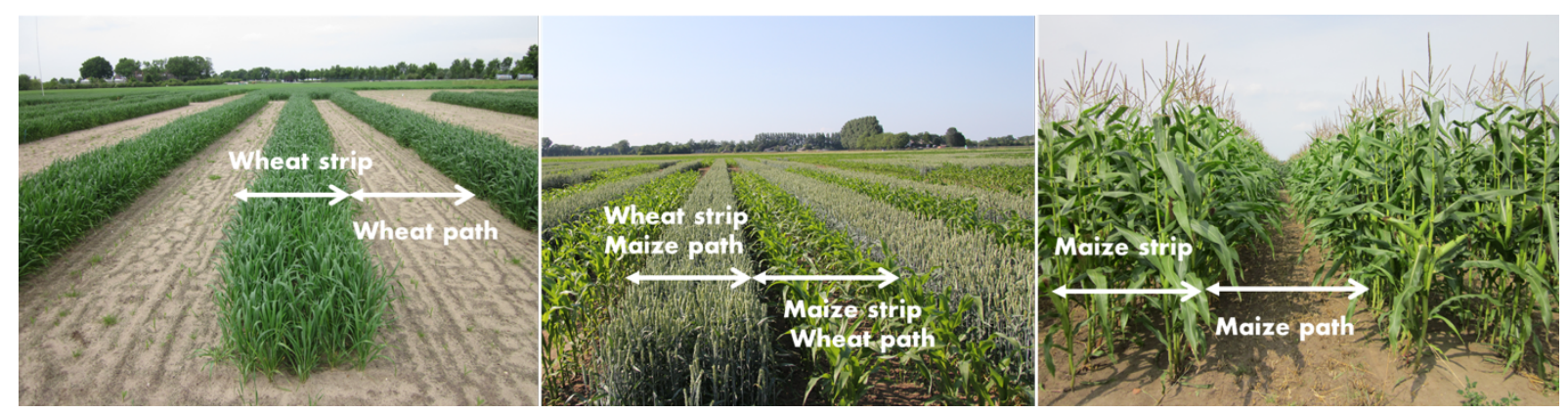

Fig. 4.1 Illustration of wheat-maize relay strip intercropping (a: before maize sowing wheat grown alone with wheat strips and empty paths alternating; b: co-growth period of the two crops; c: after wheat harvest, maize growing alone for two months). The arrows show the width of strip and path for each crop species, the strip of one species is the path of the other. 


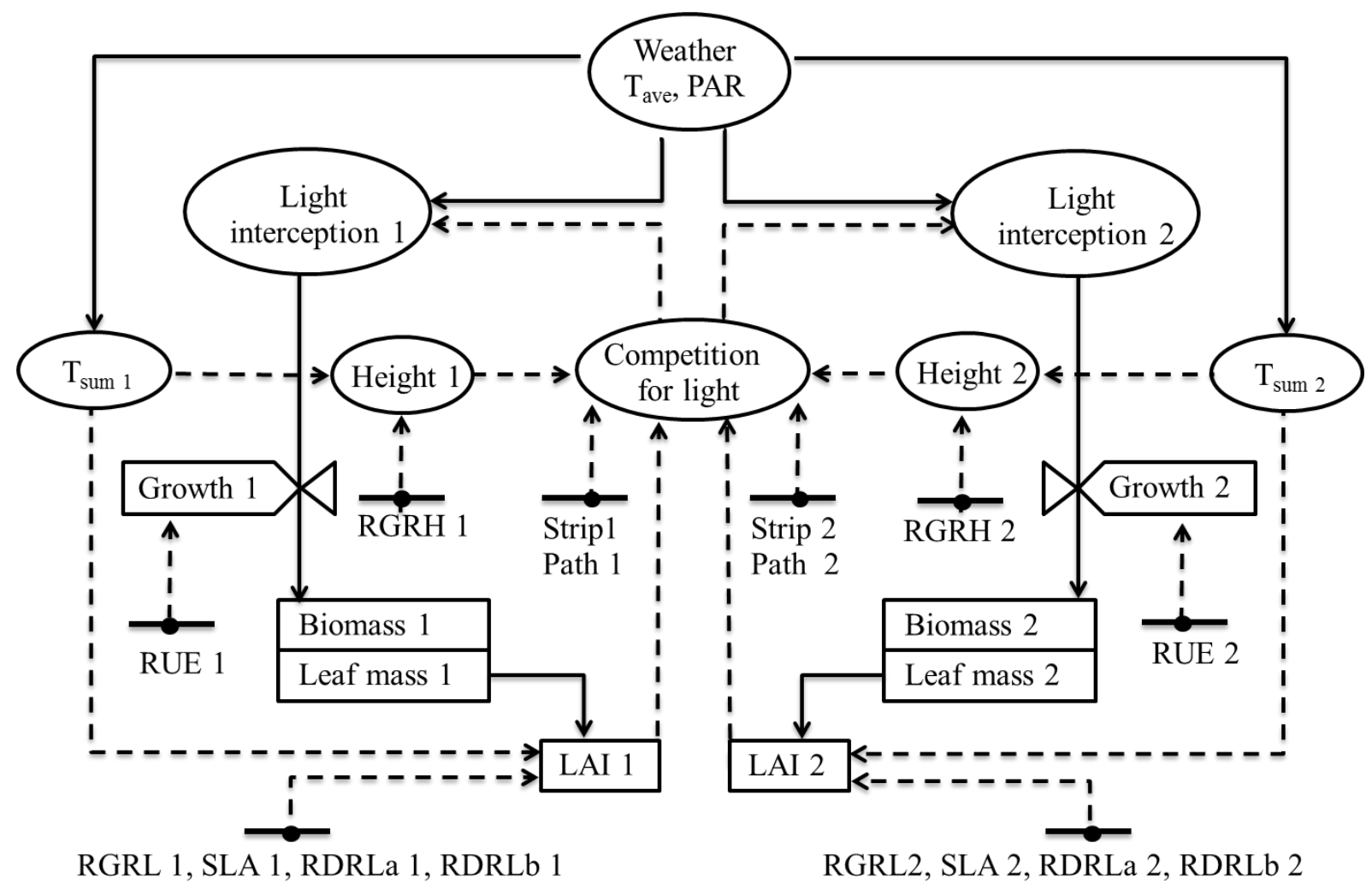

Fig. 4.2 General structure of relay-strip intercrop growth model under potential growing conditions (only competing for light). The figure is modified based on Baumann et al. (2002). Compared to the original diagram, the influence on light competition in a relay-strip intercrop (plant height and planting configurations) were added, while the water balance module was removed. RGRH is relative growth rate of plant height, RUE is radiation use efficiency, LAI is leaf area index, RGRL is the relative growth rate of LAI, SLA is specific leaf area, RDRLa is relative death rate of LAI before grain filling, and RDRLb is relative death rate of LAI during grain filling.

\subsubsection{Phenological development}

Crop phenological development is determined by temperature sum (or thermal time, $T_{\text {sum }},{ }^{\circ} \mathrm{C} \cdot \mathrm{d}$ ) from sowing date to crop maturity. The $T_{\text {sum }}$ is calculated on the basis of daily mean temperature ( $\left.T_{\text {ave }}\right)$ and crop base temperature $\left(T_{\mathrm{b}}\right)$; and $T_{\text {sum }}$ is also an indicator for simulation of leaf area dynamics (leaf growth and senescence) and biomass partitioning.

$T_{\text {sum }}=\sum \max \left(0,\left(T_{\text {ave }}-T_{b}\right)\right)$

where the "max" function means zero degrees will be added to $T_{\text {sum }}$ when the daily average temperature is lower than $T_{\mathrm{b}}$. 


\subsubsection{Leaf area expansion}

Simulation of light interception and crop growth requires simulation of leaf area index (Monteith, 1977; Jamieson et al., 1998). Under potential growing conditions, when crops are supplied sufficiently with water and nutrients and their growth is not reduced by pests and diseases (van Ittersum and Rabbinge, 1997), the main factors affecting the rate of LAI increase are temperature (Horie et al., 1979), radiation and dry matter accumulation (Dale, 1988). In this model, two phases of LAI expansion (LAIa and LAIb) are recognized for each intercropped species: temperature-dependent and radiation-limited expansion. The critical point of transition occurs when LAI $\approx 1.5$ (under sole crop condition) for wheat when self-shading or self-competition begins to be important (van Delden et al., 2001). For temperature-dependent growth, an exponential growth of LAI is assumed, and the relative growth rate of the leaves (RGRL) is a function of daily active temperature (Eq. 4.2).

$\Delta L A I \mathrm{a}=L A I_{\mathrm{t}-1} \times R G R L \times \max \left(0,\left(T_{\mathrm{ave}}-T_{\mathrm{b}}\right)\right)$

where $L A I_{\mathrm{t}-1}$ is the leaf area index at the previous day, $\triangle L A I a$ represents daily LAI increase during temperature-dependent growth, $R G R L$ is the relative growth rate of LAI $\left(\left({ }^{\circ} \mathrm{C} \cdot \mathrm{d}\right)^{-1}\right)$.

During radiation-limited growth, leaf area expansion is proportional to leaf weight increase, where the daily leaf area expansion equals the daily leaf weight increase multiplied by a specific leaf area (SLA, Eq. 4.3), i.e., the amount of leaf area per unit of dry matter $\left(\mathrm{m}^{-2} \cdot \mathrm{g}^{-1}\right)$. During this period, leaf senescence is considered.

$\Delta L A I b=\Delta B_{\text {leaf }} \times S L A-\Delta L A I d$

where $\Delta L A I b$ represents daily LAI change during radiation-limited growth, $\Delta B_{\text {leaf }}$ is daily leaf biomass partitioned from the daily total biomass increment $\left(\mathrm{g} \cdot \mathrm{m}^{-2}\right), \Delta L A I d$ represents daily senescence of LAI. Two exponential leaf senescence processes are applied to account for the decrease of LAI, i.e. two relative death rates (RDRLa and RDRLb) are distinguished for different growth stages and they are calibrated according to observations (Eq. 4.4).

$\Delta L A I d=L A I_{\mathrm{t}-1} \times R D R L \times \max \left(0,\left(T_{\mathrm{ave}}-T_{\mathrm{b}}\right)\right)$

where RDRL ( $R D R L a$ or $R D R L b$ depending on growth stage) is the relative death rate of LAI $\left(\left({ }^{\circ} \mathrm{C} \cdot \mathrm{d}\right)^{-1}\right)$. 


\section{Chapter 4}

\subsubsection{Plant height dynamics}

Plant height is one of the main drivers for light partitioning between two species in strip intercrops, thus accurate simulation of plant height dynamics is essential for precise estimation of light interception. In this study, a logistic growth was applied to simulate plant height, and the relative growth rate was influenced by daily active temperature (Eq. 4.5).

$\Delta$ Height $=$ Height $_{\mathrm{t}-1} \times R G R H \times\left(1-\frac{\text { Height }_{\mathrm{t}-1}}{H_{\max }}\right) \times \max \left(0,\left(T_{\mathrm{ave}}-T_{\mathrm{b}}\right)\right.$

where $R G R H$ is the initial relative growth rate $\left(\left({ }^{\circ} \mathrm{C} \cdot \mathrm{d}\right)^{-1}\right)$ and $H_{\max }$ is the maximum plant height $(\mathrm{cm})$.

\subsubsection{Light competition and interception}

A light interception model modified from a strip planted crop model (Pronk et al., 2003) was applied to calculate the daily fraction of light interception of each species in strip intercrops, named a strip-canopy model. Five different phases were distinguished according to plant height difference of wheat and maize, and the fraction of light interception was calculated separately for each phase. Using this strip-canopy model, the effects of row configurations on light competition could be captured. The model was described and validated in Chapter 3.

We also implemented a homogeneous canopy model into the intercrop model to allow for comparison with the strip-canopy model in terms of light interception and biomass growth simulation. In this model, the light interception between species is divided according to their light extinction coefficient $(k)$ and LAI using the following equations (Keating and Carberry, 1993):

$f=1-e^{-(k 1 \times L A I 1+k 2 \times L A I 2)}$

$f 1=\frac{k 1 \times L A I 1}{k 1 \times L A I 1+k 2 \times L A I 2} \times f$

$f 2=\frac{k 2 \times L A I 2}{k 1 \times L A I 1+k 2 \times L A I 2} \times f$

where $f$ is the total fraction of light interception in intercrop in a layer, $k 1$ and $k 2$ are light extinction coefficients for crop 1 and crop 2, LAI1 and $L A I 2$ are leaf area index for crop 1 and crop 2 at this layer, and $f 1$ (and $f 2$ ) is the fraction of light interception for crop 1 (and crop 2) at this layer. For each species, the total fraction of light interception is the sum of fraction of light interception at all layers. This model can account for differences in the vertical profile of 
LAI between species, however, it assumes that the intercropped species have their leaf areas distributed homogeneously horizontally, named a horizontally homogeneous canopy (HHC) model. In the HHC model, two layers of canopy are assumed in intercropping period according to plant height, and Beer's law is applied to the upper layer canopy, and Eq. 4.6 to 4.8 are applied to the lower layer canopy.

\subsubsection{Biomass accumulation and partitioning}

Daily above-ground biomass was calculated by multiplying intercepted radiation (PAR) with radiation use efficiency (RUE) (Spitters and Schapendonk, 1990; Bouman et al., 1996).

$\Delta$ Biomass $=f_{\mathrm{t}} \times R U E \times P A R_{\mathrm{t}}$

where $f_{\mathrm{t}}$ is the daily fraction of light interception, and $P A R_{t}$ is the total photosynthetic active radiation on day $(\mathrm{MJ}), \Delta$ Biomass is the daily increase of biomass $\left(\mathrm{g} \mathrm{m}^{-2}\right)$. The accumulated above-ground biomass was further allocated to leaves, stems and storage organ as a function of temperature sum $\left(T_{\text {sum }}\right)$. The final grain yield is calculated as the biomass located to storage organ multiplying a coefficient $P_{\text {grain, }}$, i.e. the proportion of grain in the ear or cob.

\subsubsection{Model inputs and outputs}

A sole crop model was also built based on all above mechanisms but the light interception was replaced by Beer's law (Monsi and Saeki, 1953). For the intercrop model, there are two categories of inputs. The first is planting information, including sowing dates of two crops, strip width (Strip 1 or 2) and path width (Path 1 or 2) and density of each species. Under optimal sowing density, the initial value of LAI in sole crop (LAIS 1 or 2) was 0.01 for both wheat and maize. In intercrop, the initial value of LAI (LAII 1 or 2) was proportional to the relative density, i.e. the sowing density $\left(\right.$ plant $\cdot \mathrm{m}^{-2}$ ) of each species relative to the sowing density in sole crops. This planting configuration information will be given after the description of field experimentation (Table 4.1). The second category of inputs is weather data, including daily mean temperature $\left(T_{\text {ave }}\right)$ and photosynthetically active radiation (PAR). The outputs of the model are for each crop: daily fraction of light interception, daily PAR interception, LAI dynamics, biomass accumulation and final yield. 


\section{Chapter 4}

\subsubsection{Model calibration}

\subsubsection{Field experiments}

Data collected during two years of field experiments were used to calibrate and test the intercrop model. The experiments were conducted in the growing seasons of 2013 and 2014 at the Wageningen University Farm in Wageningen, the Netherlands (51 ${ }^{\circ} 59^{\prime} 20^{\prime \prime} \mathrm{N}, 5^{\circ} 39^{\prime} 16^{\prime}$ 'E). The experiments were designed to contrast intercrops with sole crops, comprising two sole crops and three intercrops: sole wheat (SW) and sole maize (SM), replacement intercrop (6:2WM), and add-row designs (8:2WM, 6:3WM) (Fig. 2.1 and Table 2.1, Chapter 2). Crop management in the experiments aimed at meeting crop demand for water and nutrients, and control of yield reducing factors through adequate weed, pest and disease management. Fertilizer application $\left(\mathrm{K}_{2} \mathrm{SO}_{4} \mathrm{MgSO}_{4}, \mathrm{Ca}\left(\mathrm{H}_{2} \mathrm{PO}_{4}\right)_{2} \mathrm{H}_{2} \mathrm{O}\right.$ and $\left.\mathrm{NH}_{4} \mathrm{NO}_{3} \mathrm{CaMg}\left(\mathrm{CO}_{3}\right)_{2}\right)$ was the same in all treatments. Weeds were controlled mechanically before wheat emergence and chemically thereafter. Supplementary water was applied during the growing season at the first signs of wilting. Details of experimental design and field management were illustrated in Chapter 2. Data from three treatments (SW, SM, 6:2WM) were used to calibrate parameters, and data from the other two treatments $(8: 2 \mathrm{WM}, 6: 3 \mathrm{WM})$ were used to test the performance of the model.

Table 4.1 Model inputs related to planting configurations in intercrops

\begin{tabular}{llllllllll}
\hline Treatment & $\begin{array}{l}\text { Strip 1 } \\
(\mathrm{cm})\end{array}$ & $\begin{array}{l}\text { Path 1 } \\
(\mathrm{cm})\end{array}$ & $\begin{array}{l}\text { Strip 2 } \\
(\mathrm{cm})\end{array}$ & $\begin{array}{l}\text { Path 2 } \\
(\mathrm{cm})\end{array}$ & LAIS 1 & LAIIS 2 & LAII 1 & LAII 2 & $\begin{array}{l}\text { Relative } \\
\text { density total }\end{array}$ \\
\hline SW & - & - & - & - & 0.01 & - & - & - & 1 \\
SM & - & - & - & - & - & 0.01 & - & - & 1 \\
6:2WM & 75 & 150 & 150 & 75 & - & - & 0.0033 & 0.0067 & 1 \\
$8: 2 \mathrm{WM}$ & 100 & 125 & 125 & 100 & - & - & 0.0044 & 0.0067 & 1.11 \\
6:3WM & 75 & 150 & 150 & 75 & - & - & 0.0033 & 0.01 & 1.33 \\
\hline
\end{tabular}

LAIS is the initial value of LAI in sole crops; LAII is the initial value of LAI in intercrops.

\subsubsection{Parameters identification and calibration}

The model has only few parameters. All parameters are identified and calibrated to allow the model to run and represent an intercrop system. For each parameter, the data and method used for calibration are shown in Table 4.2.

Parameters that could be found from literature and derived from measurements were first determined ( $T_{\mathrm{b}}, k, T_{\text {sum }}$ of growth stages, SLA, $P_{\text {grain }}$ and parameters of plant height dynamics). 


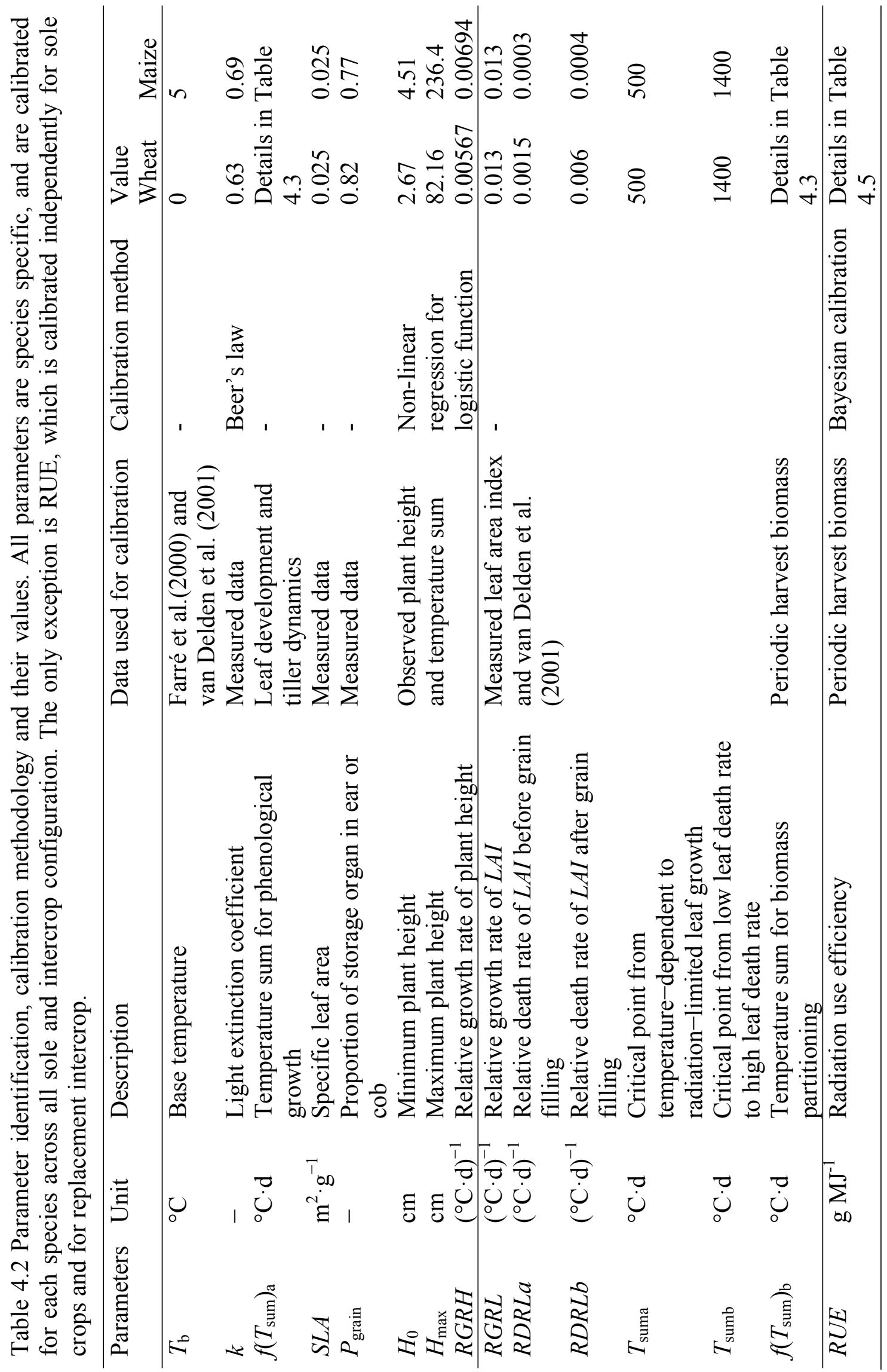




\section{Chapter 4}

Then the parameters related to leaf area growth and senescence, together with the parameters of biomass partitioning were calibrated at the same time, because they are correlated. At this step, previously estimated values of RUE for sole and intercrop wheat and maize (Table 3.3, Chapter 3) were used. Finally, RUEs were calibrated using a Bayesian approach as a 'closure' parameter for each year individually. An advantage of the Bayesian approach is that it provides the uncertainties of parameters according to the data. Except for RUE, all parameter values were kept the same for sole and intercrop across the two years.

Accumulation of $T_{\text {sum }}$ starts at the day of sowing $\left(T_{\text {sun }}=0{ }^{\circ} \mathrm{C} \cdot \mathrm{d}\right)$; crop base temperature was $0{ }^{\circ} \mathrm{C}$ for wheat and $5{ }^{\circ} \mathrm{C}$ for maize. The light extinction coefficient $(k)$ was derived from $L A I$ and light measurements in sole wheat and sole maize by fitting Beer's law; values of 0.63 and 0.69 were used for wheat and maize, respectively (Chapter 3). Parameters related to plant height dynamics were calibrated from observed data using non-linear regression, from which the minimum plant height $\left(H_{0}\right)$ was calculated. $H_{0}$ represents the plant height at emergence, and the maximum plant height $\left(H_{\max }\right)$ represents the plant height at the beginning of anthesis. The values are shown in Table 4.2.

Table 4.3 Summary of biomass partitioning fractions to leaves, stems and storage organs as a function of $T_{\text {sum }}$

\begin{tabular}{lcccc}
\hline \multicolumn{1}{c}{ Growth stage } & $T_{\text {sum }}\left({ }^{\circ} \mathrm{C}\right.$ day) & Leaf & Stem & Storage \\
\hline wheat & & & & \\
\hline Emergence (10) & 120 & 0.8 & 0.2 & 0 \\
Main shoot (25) & 500 & 0.6 & 0.4 & 0 \\
Stem elongation (31) & 850 & 0.35 & 0.65 & 0 \\
Ear emergence(55) & 950 & 0.1 & 0.5 & 0.4 \\
Beginning of anthesis (61) & 1000 & 0 & 0.2 & 0.8 \\
Milking (73) & 1200 & 0 & 0 & 1 \\
Ripening (92) & 1750 & 0 & 0 & 1 \\
\hline Maize & & & & \\
\hline Emergence (10) & 120 & 0.75 & 0.25 & 0 \\
5 leaves unfolded (15) & 500 & 0.6 & 0.4 & 0 \\
7 leaves unfolded (17) & 600 & 0.3 & 0.7 & 0 \\
Flag leaf unfolded (39) & 950 & 0.05 & 0.45 & 0.5 \\
Beginning of anthesis (61) & 1000 & 0 & 0.2 & 0.8 \\
Milking (73) & 1200 & 0 & 0 & 1 \\
Ripening (92) & 1650 & 0 & 0 & 1 \\
\hline
\end{tabular}

*Numbers in brackets represent growth stages according to Tottman (1987).

A range of thermal times for each growth stage was read from the observed data on tip appearance, collar emergence and tiller dynamics (Figs. B1 and B2, Appendix B). The starting point of partitioning parameters was obtained from the LINTUL-maize model (Farré 
et al., 2000; van Ittersum et al., 2003), and the exact values of $T_{\text {sum }}$ and fraction of biomass partitioning to leaf, stem and storage organ (Table 4.3) were updated using data of organ fractions from periodic harvests of sole crops (Chapter 3). Since these proportions were relatively stable across systems (Fig. B3, Appendix B), we used the same set of partitioning parameters for crops grown in sole crop and intercrop.

\subsubsection{Bayesian calibration for RUEs}

RUEs were calibrated using Bayesian method as a 'closure' parameter for each year, and the calibration reference was the observed above-ground biomass during periodic harvests, i.e. eight times harvests in 2013 and six times in 2014 (Chapter 3). Bayesian methods allow estimating model parameters from prior information and observed data, and the outcome of Bayesian calibration is a probability distribution of parameter values, named the posterior distribution (Wallach et al., 2013). Based on prior knowledge, a normal distribution was used as the prior distribution of wheat with a mean of $2.5 \mathrm{~g} \mathrm{MJ}^{-1}$ and a standard deviation of $1 \mathrm{~g}$ $\mathrm{MJ}^{-1}$. As a prior distribution for maize RUEs were used a normal distribution with a mean of 3 $\mathrm{g} \mathrm{MJ}^{-1}$ and a standard deviation of $1 \mathrm{~g} \mathrm{MJ}^{-1}$. The posterior distribution results from 30000 MCMC iterations after a burn-in of 20,000 (i.e. discarding the first 20,000 iterations) and thinning by a factor of 2 (Bolker, 2008). Outputs were analysed with the R package "coda" (Plummer et al., 2006).

Deviance information criterion (DIC) was used to compare Bayesian models, where lower values of DIC indicates a better model fit (Bolker, 2008). Here we compared two models. The first of these assumed a unique RUE for sole crop and intercrop, while the model assumed different RUEs for sole crops and intercrop. Their DIC values were computed from MCMC outputs as:

$D I C=-2 \times\left(\right.$ BayesianLL $\left.-P_{\mathrm{dic}}\right)$

$P_{\text {dic }}=2 \times($ BayesianLL - MeanLL $)$

where BayesianLL represents the log-likelihood of observed data under the distribution of simulated time course of biomass at the posterior mean of RUE; MeanLL represents the mean $\log$-likelihood from MCMC iterations after burn-in and thinning; $P_{\text {dic }}$ denotes the effective number of parameters which acts as a penalty for parameter-rich models (Gelman et al., 2014). 


\section{Chapter 4}

\subsubsection{Statistical and sensitivity analysis}

The model was developed in the R programming language (R Core Team, 2015). Parameters related to plant height $\left(H_{0}, H_{\max }\right.$, and $\left.R G R H\right)$ were estimated by a Nonlinear Least Squares function "nls", and RUE was calibrated using Bayesian methods (Wallach et al., 2013). The package "coda" was used to analyse outputs from Markov chain Monte Carlo (MCMC) simulations and to conduct diagnostic tests of convergence (Plummer et al., 2006). Root mean square error (RMSE) was used to estimate the accuracy of simulation as compared to observations, and coefficient of prediction (CE), also called "coefficient of efficiency" was used to examine how much better a model performed compared with using the mean of time series as a simple-minded forecaster (Nash and Sutcliffe, 1970; Turchin, 2003).

$$
\begin{aligned}
& R M S E=\sqrt{\frac{1}{N} \times \sum_{i}^{N}\left(O_{i}-S_{i}\right)^{2}} \\
& C E=1-\frac{\sum_{i}^{N}\left(S_{i}-O_{i}\right)^{2}}{\sum_{i}^{N}\left(\bar{O}-O_{i}\right)^{2}}
\end{aligned}
$$

where $O_{i}$ is observed value, $S_{i}$ is simulated value, $\bar{O}$ is the mean of observed values and $N$ is the number of observations.

Sensitivity analysis shows how model outputs change with model inputs. Here, we investigated how crop LAI and biomass changed with some key parameters ( $k, S L A, R U E)$ within a biologically plausible range $( \pm 10 \%)$, for wheat and maize in a replacement intercrop.

\subsection{Result}

We first present the calibration results for the radiation use efficiency (RUE) using the Bayesian method (Section 4.3.1), and then we test the model performance in terms of LAI and biomass production (Section 4.3.2). Subsequently, we compare the performance of the stripcanopy model with a horizontally homogenous canopy (HHC) model (Section 4.3.3), and we investigate whether the strip intercrop model accounts for plant plasticity in intercrops (Section 4.3.4). Finally, we report the sensitivity of the model outcomes for changes in several parameters (Section 4.3.5). 


\subsubsection{Radiation use efficiency (RUE) in different models}

The posterior distributions of RUE show that intercropped wheat had a higher RUE than sole wheat, whereas intercropped maize had a lower RUE than sole maize in both years (Fig. 4.3), which is consistent to the findings from a linear regression of observed above-ground biomass on the calculated cumulative intercepted light (Chapter 3). Additionally, substantially lower DIC values from the model with different RUEs than a model with the same RUE (Table 4.4), indicate that the model with different RUEs fits the data better than the model with the same RUE for the sole and intercrop.
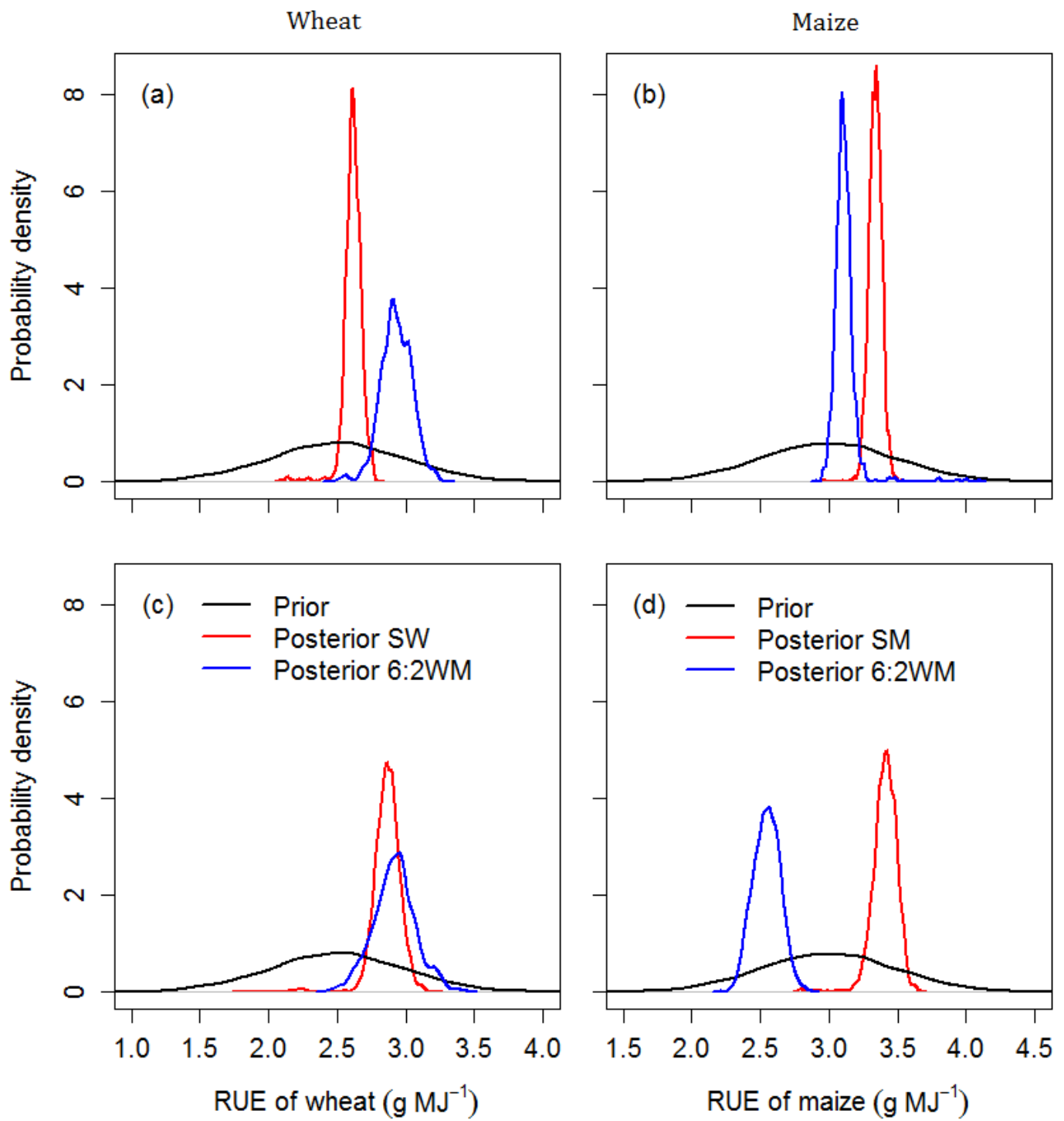

Fig. 4.3 Prior and posterior distributions of wheat and maize RUEs in sole crops and replacement intercrop. The left panels are for wheat and the right panels are for maize, $a$ and $b$ are for 2013, and c and d are for 2014. 
Table 4.4 Comparison of models with single or different RUEs for wheat and maize in different planting configurations

\begin{tabular}{ccccccc}
\hline Year & Model & Parameters & MeanLL & BayesianLL & $\mathrm{P}_{\text {dic }}$ & DIC \\
\hline \multirow{2}{*}{2013} & Single RUE $^{1}$ & 2 & -182 & -180 & 4 & 367 \\
& Different RUEs $^{2}$ & 4 & -174 & -172 & 5 & 354 \\
\hline \multirow{2}{*}{2014} & Single RUE & 2 & -156 & -155 & 3 & 316 \\
& Different RUEs & 4 & -142 & -140 & 5 & 290 \\
\hline
\end{tabular}

${ }^{1}$ Single RUE represents the model with the same parameter (RUE) for sole wheat and intercropped wheat, and the same parameter for sole maize and intercropped maize; ${ }^{2}$ different RUEs represents the model with different parameters (RUE) for wheat and maize in sole crop and intercrop. MeanLL is the mean log-likelihood from MCMC iterations after burn-in and thinning; BayesianLL represents the log-likelihood of observed data under the distribution of simulated time course of biomass at the posterior mean of RUE; $\mathrm{P}_{\text {dic }}$ is the effective number of parameters which acts as a penalty for parameter-rich models; DIC is deviance information criterion.
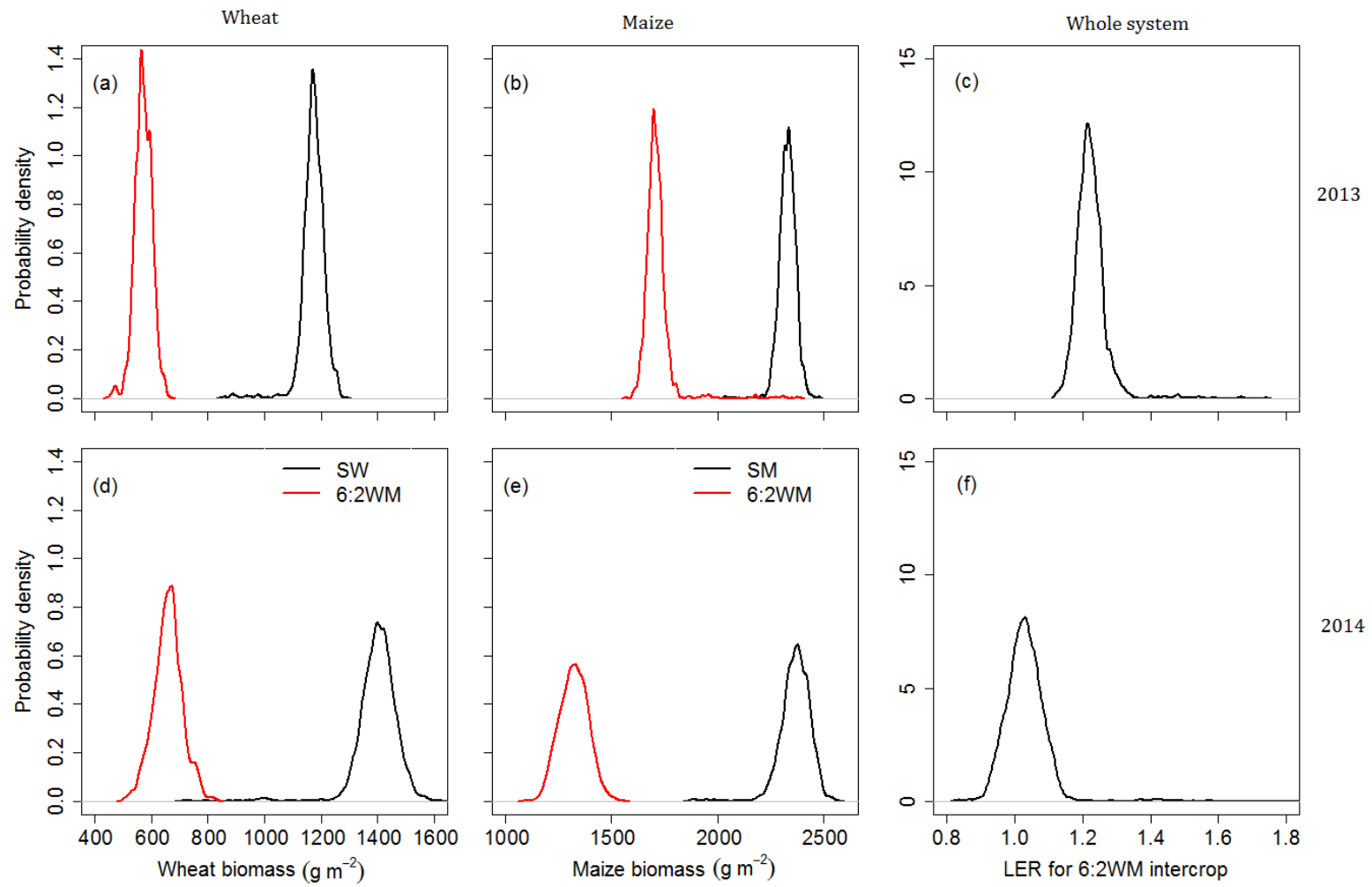

Fig. 4.4 Probability density of biomass and LER for wheat and maize in sole crop and intercrops. $\mathrm{a}$ and $\mathrm{d}$ are for wheat biomass, $\mathrm{b}$ and e are for maize biomass, $\mathrm{c}$ and $\mathrm{f}$ are LER for replacement intercrop (6:2WM). a, b and c are for 2013, d, e and f are for 2014.

The distributions of biomass in sole crops and intercrop (6:2WM) were obtained from the simulation with the posterior distributions of RUEs for 2013 and 2014, respectively, and the distributions of LERs were then calculated from the distribution of biomass (Fig. 4.4). Table 4.5 shows the mean and $95 \%$ credible interval (CI) of the posterior distribution of RUE, as 
well as the simulated distributions of biomass and LER. The mean LER of the replacement intercrop was 1.23 in 2013 and 1.03 in 2014.

Table 4.5 Mean and 95\% credible interval of RUE, biomass and LER

\begin{tabular}{llllllll}
\hline Year & Treatment & \multicolumn{2}{l}{ RUE $\left(\mathrm{g} \cdot \mathrm{MJ}^{-1}\right)^{3}$} & \multicolumn{2}{l}{ Biomass $\left(\mathrm{g} \cdot \mathrm{m}^{-2}\right)$} & LER \\
& & Mean & $\mathrm{CI}^{1}$ & Mean & CI & Mean & CI \\
\hline 2013 & SW & 2.62 & $(2.49,2.73)$ & 1172 & $(1095,1243)$ & - & - \\
& SM & 3.34 & $(3.24,3.44)$ & 2329 & $(2255,2404)$ & - & - \\
& Intercropped wheat $^{2}$ & 2.93 & $(2.70,3.15)$ & 573 & $(510,630)$ & 1.23 & $(1.16,1.31)$ \\
& Intercropped maize $^{2}$ & 3.12 & $(3.00,3.26)$ & 1714 & $(1635,1809)$ & & \\
\hline 2014 & SW & 2.86 & $(2.66,3.04)$ & 1398 & $(1271,1514)$ & - & - \\
& SM & 3.41 & $(3.22,3.56)$ & 2365 & $(2219,2482)$ & - & - \\
& Intercropped wheat & 2.91 & $(2.60,2.74)$ & 660 & $(556,764)$ & 1.03 & $(0.93,1.13)$ \\
& Intercropped maize & 2.55 & $(2.36,2.74)$ & 1323 & $(1194,1455)$ & & \\
\hline
\end{tabular}

${ }^{1} \mathrm{CI}$ means $95 \%$ credible interval, ${ }^{2}$ intercrop represents replacement intercrop $6: 2 \mathrm{WM},{ }^{3}$ these values are from model with different RUEs for sole crop and intercrop. When calibrate with a single RUE for sole crop and intercrop, wheat RUE is $2.67 \mathrm{~g} \mathrm{MJ}^{-1}$ in 2013 and $2.87 \mathrm{~g} \mathrm{MJ}^{-1}$ in 2014, maize RUE is $3.24 \mathrm{~g} \mathrm{MJ}^{-1}$ in 2013 and $3.04 \mathrm{~g} \mathrm{MJ}^{-1}$ in 2014.

\subsubsection{Model testing for LAI and biomass prediction}

The intercrop model with the above parameters were applied to predict LAI and biomass trajectory of wheat and maize in add-row intercrops (8:2WM and 6:3WM) in 2013 and 2014, using the posterior mean RUEs calibrated from the replacement intercrop and sole crops in the simulations. The model inputs for planting configurations are shown in Table 4.1. The simulated LAI and biomass trajectory of wheat and maize in 8:2WM and 6:3WM are compared to the periodic harvest data (Figs. 4.5 and 4.6). The solid lines are simulation results using RUEs calibrated from model with different RUEs with RMSE_a and CE_a, and the dashed lines are simulation results using RUEs calibrated from model with a single RUE with RMSE_b and CE_b.

In the left panels of Fig. 4.5, both solid lines and dashed lines are slightly above the observed LAI for wheat with similar RMSE and CE across crop systems and years. The root mean square error (RMSE) ranges from 0.15 to 0.6 and the coefficient of prediction (CE) ranges from 0.44 to 0.95 . For maize, the solid lines are slightly lower than observed LAI in 2013, but higher than observed LAI in 2014 (right panels in Fig. 4.5), but the dashed lines are above the observed LAI in both years with very high RMSE and very low CE in 2014. 
Wheat
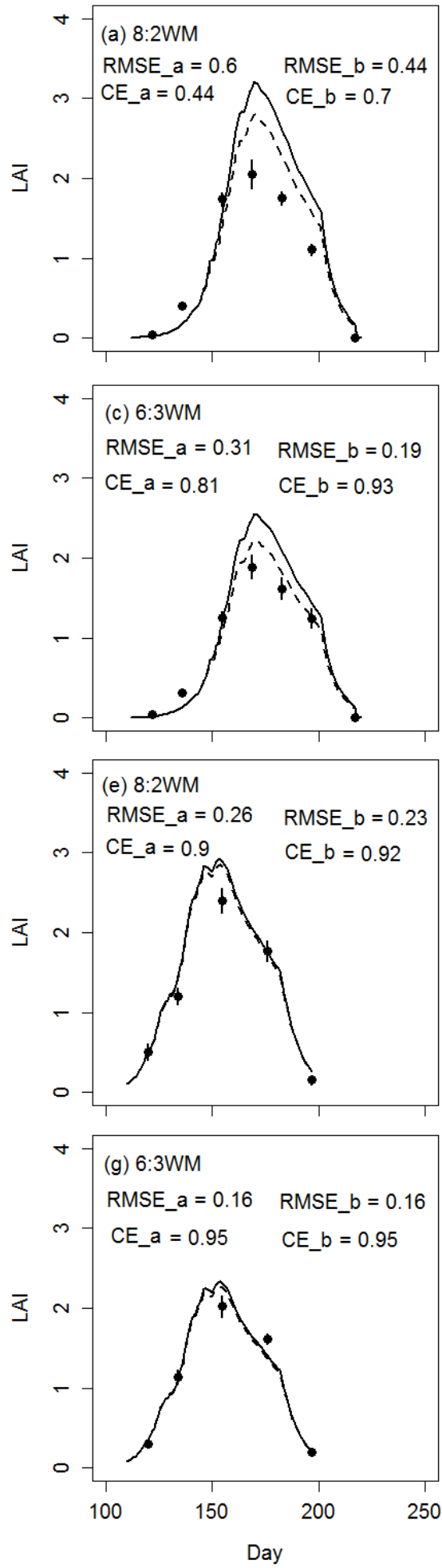

Maize

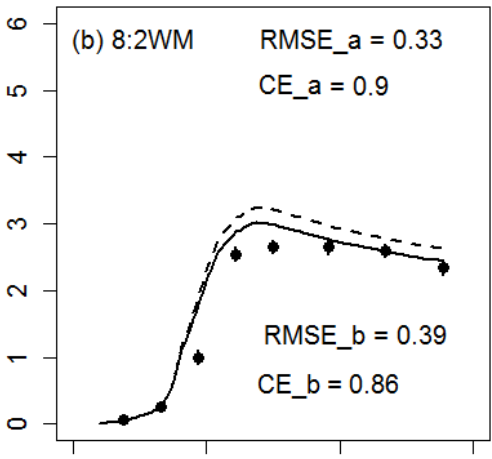

2013

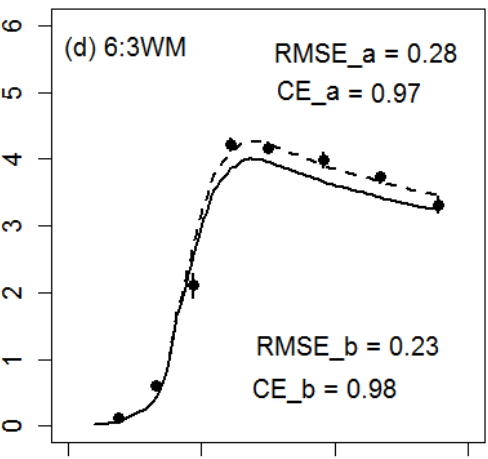

2013

2014
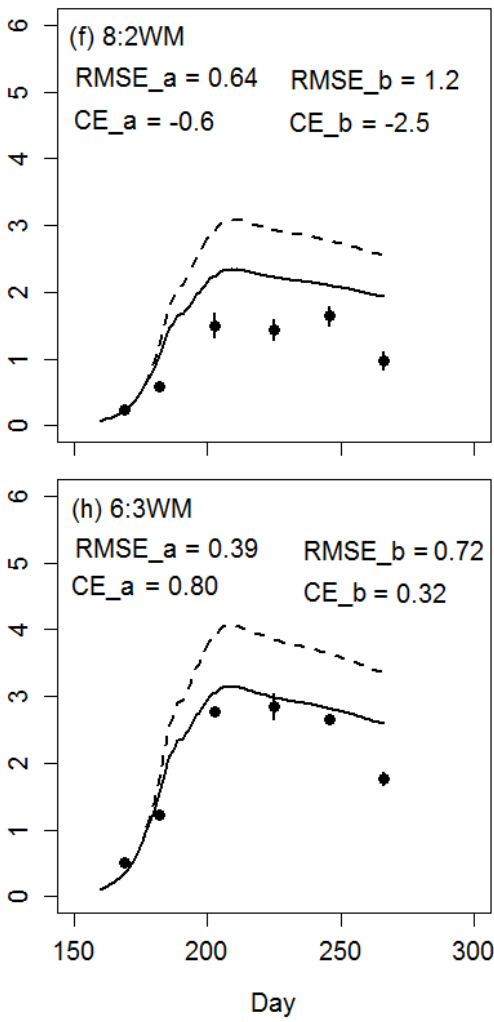

Fig. 4.5 Model testing for LAI in add-row intercrops (8:2WM and 6:3WM); the left panels are for wheat; the right panels are for maize. The solid lines are simulation results using RUEs calibrated from model with different RUEs with RMSE_a and CE_a, and the dashed lines are simulation results using RUEs calibrated from model with a single RUE with RMSE_b and CE_b. The dots are observations. a-d are for 2013, and e-h are for 2014. 

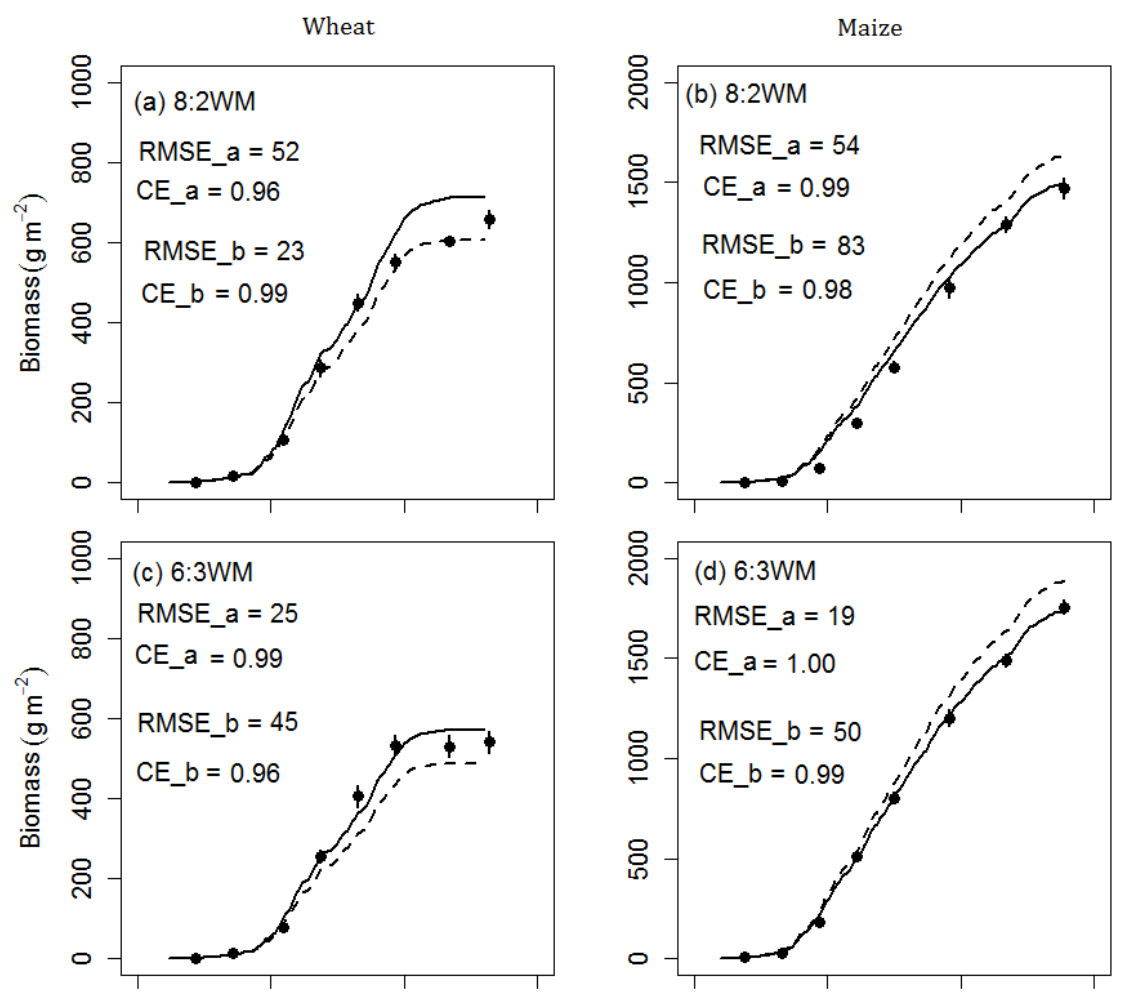

2013
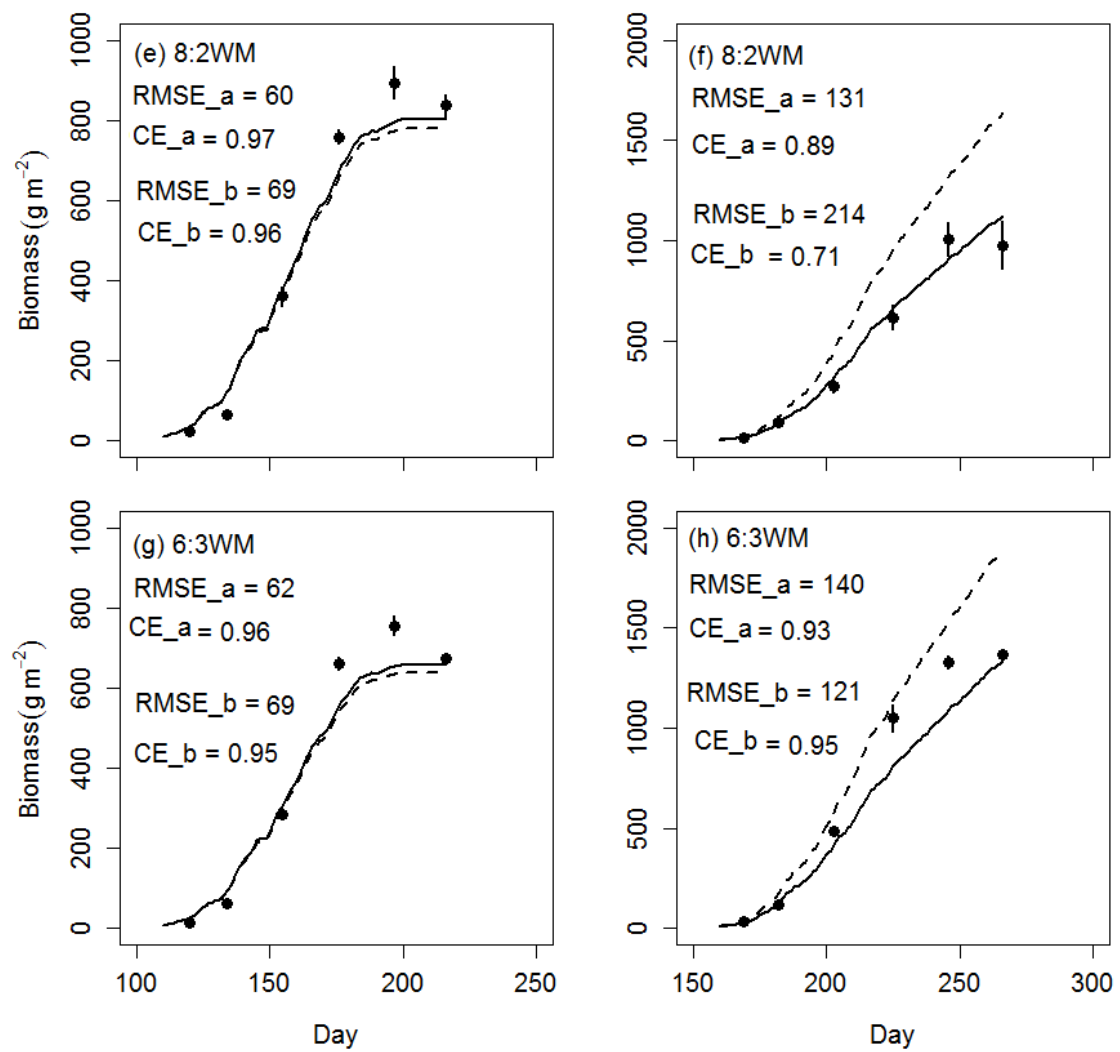

Fig. 4.6 Model testing for biomass in add-row intercrops (8:2WM and 6:3WM); the left panels are for wheat, and the right panels are for maize. The solid lines are simulation results using RUEs calibrated from model with different RUEs with RMSE_a and CE_a, and the dashed lines are simulation results using RUEs calibrated from model with a single RUE with RMSE_b and CE_b. The dots are observations. $\mathrm{a}-\mathrm{d}$ are for 2013, and $\mathrm{e}-\mathrm{h}$ are for 2014. 


\section{Chapter 4}

The simulated biomass for wheat and maize has a good agreement with the observed values when different RUEs are used in sole crops and in intercrops, with a coefficient of prediction (CE_a) greater than 0.89 (solid lines in Fig. 4.6). RMSE is increased and CE is reduced when the same RUE is used in sole crops and in intercrops except in 8:2WM wheat in 2013 (Fig.4.6, panel a) and 6:3WM maize in 2014 (Fig. 4.6, panel h).

A simple parameter $\left(P_{\text {grain }}\right)$ was used for each crop species to convert the dry matter of the storage organ (ear for wheat, and cob for maize) to grain yield. Thus grain yield and harvest index (HI) is one of the outputs from the model. Table 4.6 shows the simulated biomass, yield, HI and yield LER are similar to the observed values (data in brackets). The HI of wheat is similar in sole crop and intercrops, while the HI of maize in intercrops is higher than in the sole crop. Higher LERs for grain yields were obtained in 2013 than in 2014.

Table 4.6 Simulated and observed biomass, yield, HI and LER for different planting configurations (values in the brackets are observations from field experiments in Wageningen from 2013 to 2014 (Chapter 2)).

\begin{tabular}{|c|c|c|c|c|c|c|c|c|}
\hline \multirow{2}{*}{ Year } & \multirow{2}{*}{ Treatment } & \multicolumn{3}{|c|}{ Wheat $\left(\mathrm{g} \cdot \mathrm{m}^{-2}\right)$} & \multicolumn{3}{|c|}{ Maize $\left(\mathrm{g} \cdot \mathrm{m}^{-2}\right)$} & \multirow{2}{*}{$\begin{array}{l}\text { Yield } \\
\text { LER }\end{array}$} \\
\hline & & Biomass & Yield & HI & Biomass & Yield & $\mathrm{HI}$ & \\
\hline \multirow{5}{*}{2013} & SW & $\begin{array}{c}1172 \\
(1188)\end{array}$ & $\begin{array}{c}627 \\
(639)\end{array}$ & $\begin{array}{c}0.53 \\
(0.54)\end{array}$ & - & - & - & - \\
\hline & SM & - & - & - & $\begin{array}{c}2304 \\
(2321)\end{array}$ & $\begin{array}{c}1151 \\
(1010)\end{array}$ & $\begin{array}{c}0.50 \\
(0.44)\end{array}$ & - \\
\hline & $6: 2 \mathrm{WM}$ & $\begin{array}{c}573 \\
(605)\end{array}$ & $\begin{array}{c}301 \\
(308)\end{array}$ & $\begin{array}{c}0.53 \\
(0.51)\end{array}$ & $\begin{array}{c}1685 \\
(1708)\end{array}$ & $\begin{array}{c}911 \\
(811)\end{array}$ & $\begin{array}{c}0.54 \\
(0.47)\end{array}$ & $\begin{array}{c}1.27 \\
(1.30)\end{array}$ \\
\hline & $8: 2 \mathrm{WM}$ & $\begin{array}{c}711 \\
(659)\end{array}$ & $\begin{array}{c}372 \\
(343)\end{array}$ & $\begin{array}{c}0.53 \\
(0.52)\end{array}$ & $\begin{array}{c}1531 \\
(1486)\end{array}$ & $\begin{array}{c}841 \\
(702)\end{array}$ & $\begin{array}{c}0.55 \\
(0.47)\end{array}$ & $\begin{array}{c}1.32 \\
(1.25)\end{array}$ \\
\hline & $6: 3 \mathrm{WM}$ & $\begin{array}{c}571 \\
(541)\end{array}$ & $\begin{array}{c}300 \\
(264)\end{array}$ & $\begin{array}{c}0.52 \\
(0.49)\end{array}$ & $\begin{array}{c}1778 \\
(1796)\end{array}$ & $\begin{array}{c}946 \\
(767)\end{array}$ & $\begin{array}{c}0.53 \\
(0.43)\end{array}$ & $\begin{array}{c}1.30 \\
(1.18)\end{array}$ \\
\hline \multirow{5}{*}{2014} & SW & $\begin{array}{c}1398 \\
(1459)\end{array}$ & $\begin{array}{c}762 \\
(768)\end{array}$ & $\begin{array}{c}0.55 \\
(0.52)\end{array}$ & - & - & - & - \\
\hline & SM & - & - & - & $\begin{array}{c}2340 \\
(2142)\end{array}$ & $\begin{array}{c}1188 \\
(1162)\end{array}$ & $\begin{array}{c}0.51 \\
(0.54)\end{array}$ & - \\
\hline & $6: 2 \mathrm{WM}$ & $\begin{array}{c}660 \\
(628)\end{array}$ & $\begin{array}{c}365 \\
(320)\end{array}$ & $\begin{array}{c}0.55 \\
(0.51)\end{array}$ & $\begin{array}{c}1294 \\
(1135)\end{array}$ & $\begin{array}{c}702 \\
(639)\end{array}$ & $\begin{array}{c}0.54 \\
(0.57)\end{array}$ & $\begin{array}{c}1.08 \\
(0.97)\end{array}$ \\
\hline & $8: 2 \mathrm{WM}$ & $\begin{array}{c}804 \\
(838)\end{array}$ & $\begin{array}{c}442 \\
(433)\end{array}$ & $\begin{array}{c}0.55 \\
(0.52)\end{array}$ & $\begin{array}{c}1182 \\
(1006)\end{array}$ & $\begin{array}{c}649 \\
(537)\end{array}$ & $\begin{array}{c}0.55 \\
(0.53)\end{array}$ & $\begin{array}{c}1.12 \\
(1.04)\end{array}$ \\
\hline & $6: 3 \mathrm{WM}$ & $\begin{array}{c}659 \\
(675)\end{array}$ & $\begin{array}{c}365 \\
(325)\end{array}$ & $\begin{array}{c}0.55 \\
(0.49)\end{array}$ & $\begin{array}{c}1403 \\
(1407)\end{array}$ & $\begin{array}{c}748 \\
(747)\end{array}$ & $\begin{array}{c}0.53 \\
(0.53)\end{array}$ & $\begin{array}{l}1.10 \\
(1.08)\end{array}$ \\
\hline
\end{tabular}

\subsubsection{The comparison of homo-canopy and strip-canopy models}

The HHC model and strip-canopy model were both applied to simulate the fraction of light interception and biomass in the replacement intercrop $(6: 2 \mathrm{WM})$ under growing conditions of 
2013. With the HHC model, intercropped wheat captured above $80 \%$ of incoming radiation, while the strip-model captured slightly more than $40 \%$ of the total radiation (Fig. $4.7 \mathrm{a}$ ). The HHC model thus greatly overestimated the fraction of light interception for the first sown crop (wheat), while it underestimated the fraction of light interception by the second sown crop (maize). The same was true for biomass accumulation (Fig. 4.7).
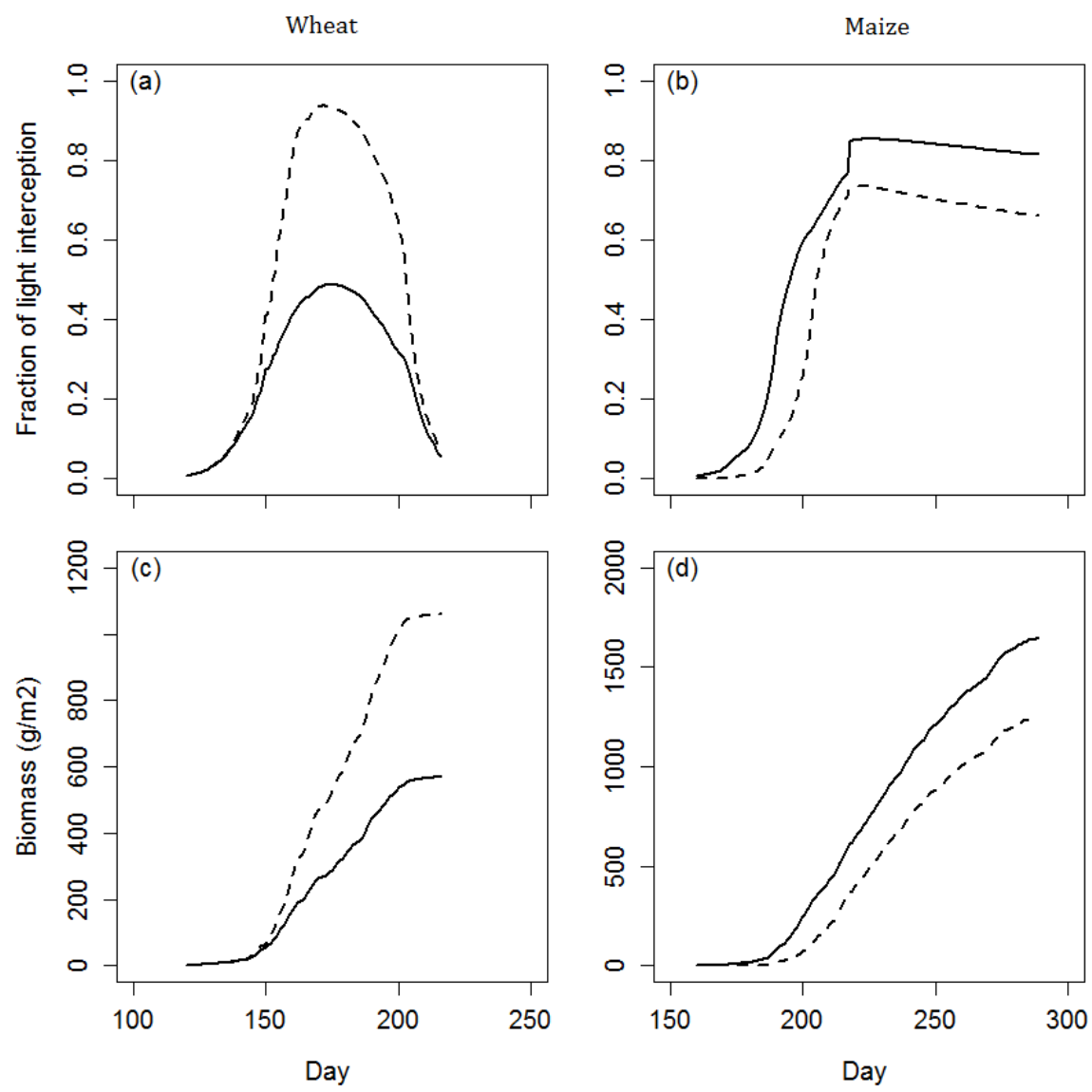

Fig. 4.7 Comparison of light interception and biomass accumulation of wheat and maize as calculated by a horizontally homogeneous canopy (HHC, dotted lines) model and by a stripcanopy model (drawn lines) at year 2013 for replacement intercrop (6:2WM). The left panels are for wheat, and the right panels are for maize.

\subsubsection{Accounting for plant plasticity}

Biomass per meter row was calculated based on the biomass per $\mathrm{m}^{2}$ and row density (the row density is shown in Table 2.1, Chapter 2) of each species in sole crops and intercrops (i.e. not accounting for differences between rows). For example, the biomass per meter row is $1 / 8$ of biomass per $\mathrm{m}^{2}$ in sole wheat, because the row distance of sole wheat is $12.5 \mathrm{~cm}$, and there is 8 rows in one meter width. Similar calculations were applied to other treatments. The 


\section{Chapter 4}

simulated biomass per meter row in different treatments are shown in Fig. 4.8, the simulated and observed final biomass and yield per meter row are shown in Table 4.7.

Compared to sole wheat, all intercropped wheat had higher biomass per meter row. Wheat had slightly lower biomass per meter row in 8:2WM than in 6:2WM and 6:3WM (Fig. 4.8a), because the former had 1/4 border row plants and the latter had a larger proportion of border row plants (1/3). Compared to sole maize, intercropped maize had smaller biomass per meter row (or per plant) at the beginning of growing season (Fig. 4.8b). In the end, however, maize grown in 6:2WM has surpassed maize in sole crop in terms of biomass per plant in 2013 but not in 2014, while maize grown in 8:2WM and 6:3WM treatments did not surpass maize in sole maize in either of the two years. Maize grown in 8:2WM had smaller biomass per plant than maize in $6: 2 \mathrm{WM}$, and maize grown in $6: 3 \mathrm{WM}$ has the smallest biomass per plant among all treatments. These results show that the model can account for the key consequences of plant plasticity by accounting for radiation capture.

Table 4.7 Simulated and observed biomass and yield per meter row in different planting configurations (values in the brackets are observations from field experiments in Wageningen from 2013 to 2014).

\begin{tabular}{|c|c|c|c|c|c|}
\hline \multirow{2}{*}{ Year } & \multirow{2}{*}{ Treatment } & \multicolumn{2}{|c|}{ Wheat (g per meter row) } & \multicolumn{2}{|c|}{ Maize (g per meter row) } \\
\hline & & Biomass & Yield & Biomass & Yield \\
\hline \multirow{5}{*}{2013} & SW & $\begin{array}{c}147 \\
(148)\end{array}$ & $\begin{array}{c}78 \\
(80)\end{array}$ & - & - \\
\hline & SM & - & - & $\begin{array}{c}1700 \\
(1707)\end{array}$ & $\begin{array}{c}838 \\
(751)\end{array}$ \\
\hline & $6: 2 \mathrm{WM}$ & $\begin{array}{c}215 \\
(227)\end{array}$ & $\begin{array}{c}113 \\
(116)\end{array}$ & $\begin{array}{c}1856 \\
(1900)\end{array}$ & $\begin{array}{c}992 \\
(893)\end{array}$ \\
\hline & $8: 2 \mathrm{WM}$ & $\begin{array}{c}200 \\
(185)\end{array}$ & $\begin{array}{l}105 \\
(96)\end{array}$ & $\begin{array}{c}1685 \\
(1656)\end{array}$ & $\begin{array}{c}916 \\
(778)\end{array}$ \\
\hline & $6: 3 \mathrm{WM}$ & $\begin{array}{c}214 \\
(203)\end{array}$ & $\begin{array}{l}112 \\
(99)\end{array}$ & $\begin{array}{c}1309 \\
(1321)\end{array}$ & $\begin{array}{c}688 \\
(568)\end{array}$ \\
\hline \multirow{5}{*}{2014} & SW & $\begin{array}{c}175 \\
(182)\end{array}$ & $\begin{array}{c}95 \\
(95)\end{array}$ & - & - \\
\hline & SM & - & - & $\begin{array}{c}1759 \\
(1555)\end{array}$ & $\begin{array}{c}893 \\
(840)\end{array}$ \\
\hline & $6: 2 \mathrm{WM}$ & $\begin{array}{c}247 \\
(235)\end{array}$ & $\begin{array}{c}137 \\
(120)\end{array}$ & $\begin{array}{c}1455 \\
(1254)\end{array}$ & $\begin{array}{c}790 \\
(715)\end{array}$ \\
\hline & $8: 2 \mathrm{WM}$ & $\begin{array}{c}226 \\
(236)\end{array}$ & $\begin{array}{c}124 \\
(123)\end{array}$ & $\begin{array}{c}1329 \\
(1099)\end{array}$ & $\begin{array}{c}731 \\
(582)\end{array}$ \\
\hline & $6: 3 \mathrm{WM}$ & $\begin{array}{c}247 \\
(253)\end{array}$ & $\begin{array}{c}137 \\
(124)\end{array}$ & $\begin{array}{c}1055 \\
(1027)\end{array}$ & $\begin{array}{c}563 \\
(544)\end{array}$ \\
\hline
\end{tabular}



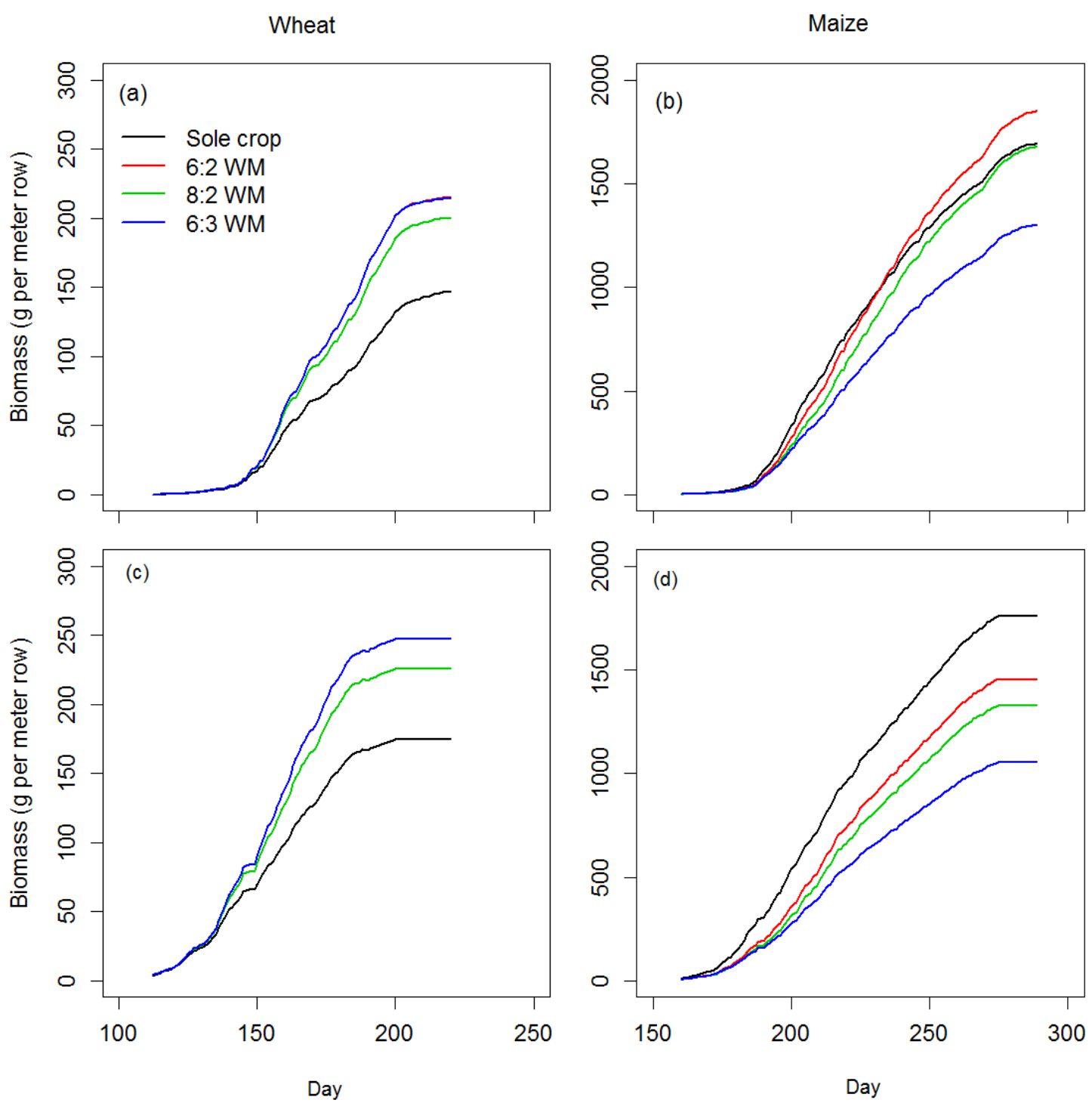

Fig. 4.8 Simulated biomass per meter row for wheat and maize in sole crops and different intercrops at year 2013 and 2014. Note that the line for $6: 2 \mathrm{WM}$ and $6: 3 \mathrm{WM}$ are overlapping in panels a and c. Biomass per meter row was calculated based on the biomass per $\mathrm{m}^{2}$ and row density (Table 2.1, Chapter 2) of each species in sole crops and intercrops.

\subsubsection{Sensitivity analysis}

Generally, both LAI and biomass of wheat and maize changed if their key parameters changed, while the change of parameters of one crop had comparatively little effect on LAI or biomass of the other crop. For instance, changing the $k 1$, SLA1 and RUE1 had a strong effect on the LAI and biomass of wheat, while their change had only little effect on LAI or biomass of maize, and vice versa. In Fig. 4.9 a and b, the green lines overlap the blue lines, which indicates that the LAI is equally sensitive to the changes in SLA and RUE. This was true for both wheat and maize. Compared to SLA and RUE, the change of $k$ values had a smaller 


\section{Chapter 4}

effect on LAI. For both wheat and maize, the change of SLA had the smallest effect on biomass among all the tested parameters, and the change of RUE had the largest effect on biomass. Furthermore, Fig. 4.4 and Table 4.5 showed the uncertainty of biomass simulation due to the uncertainty of RUEs.

Wheat
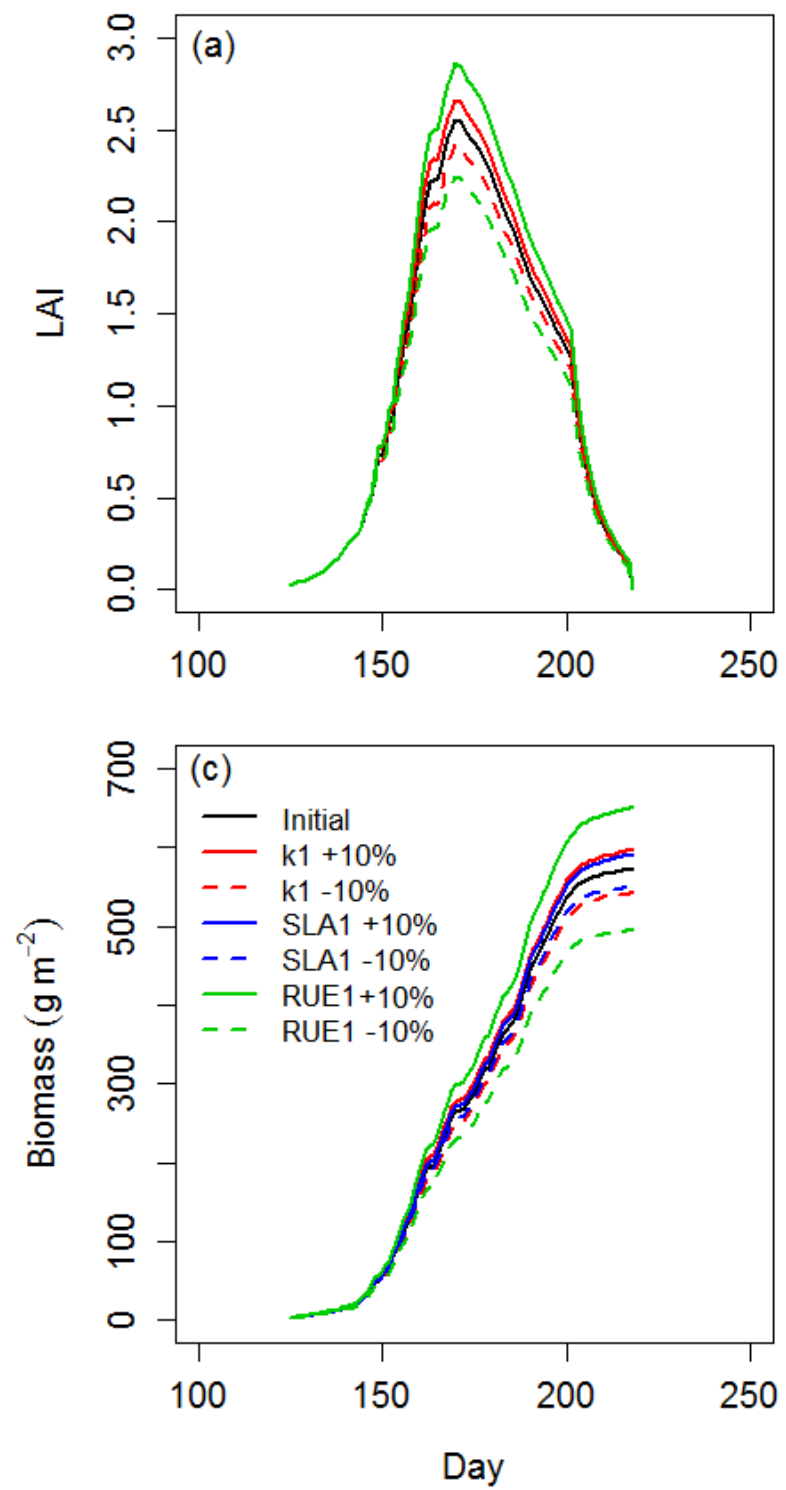

Maize
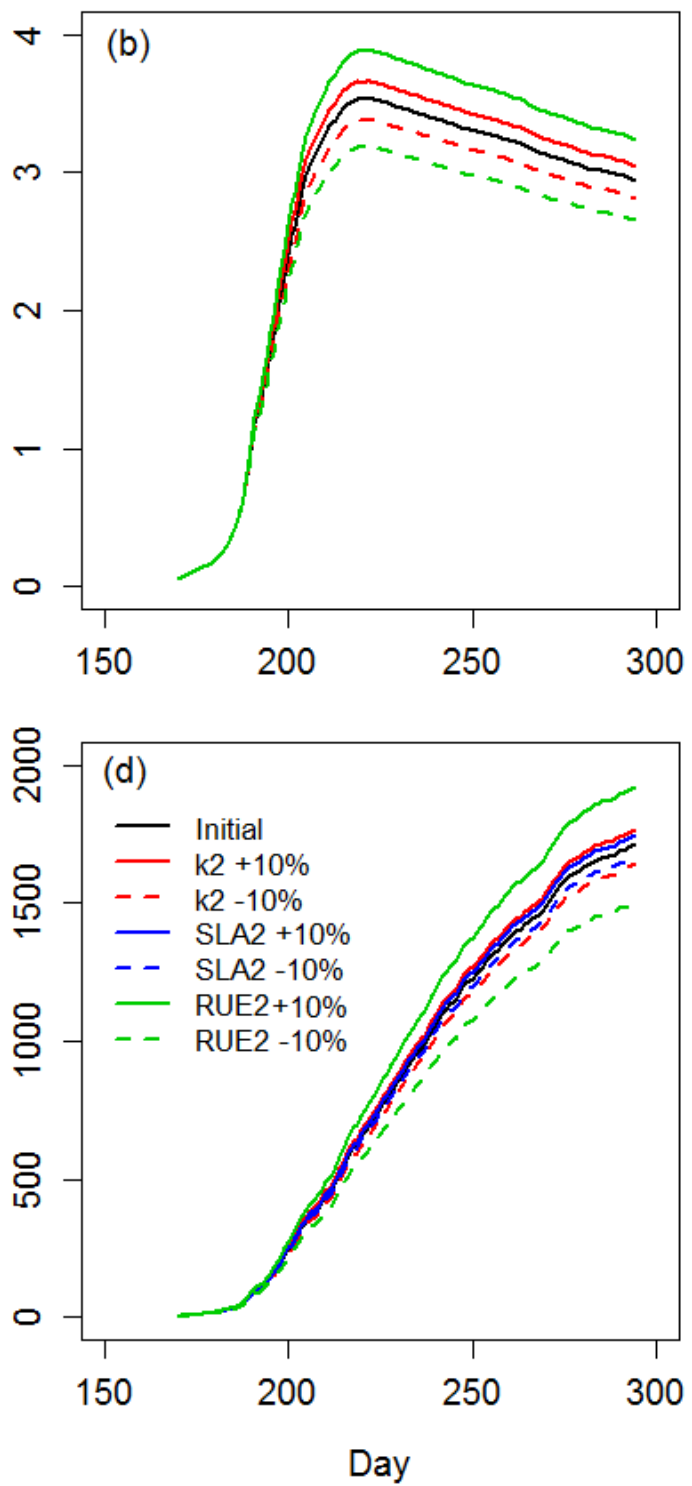

Fig. 4.9 Simulated LAI and biomass of wheat and maize for different parameters values for wheat and maize in replacement intercrop (6:2WM) in the year 2013. The left panels are for wheat, and the right panels for maize. Panels a and b are for LAI, $\mathrm{c}$ and $\mathrm{d}$ are for biomass per unit land. Different colours and line types represent the LAI or biomass changes when the parameters $(\mathrm{k}$, SLA and RUE) increase $(+)$ or decrease $(-) 10 \%$ for each crop separately from the base values in Tables 4.2 and 4.5. 


\subsection{Discussion}

In this paper, we present, calibrate and test a crop growth model for relay-strip intercrops. The novelties of this study are: 1) this is the first fully integrated intercrop model in the literature that accounts for a strip-structured canopy, which allows investigating how planting configurations (strip width, sowing density and sowing time) influence plant growth and productivity; 2) the combination of ordinary process parameterization using regression analysis of process level experimental data and a Bayesian approach to achieve "closure" of the model parameterization by calibrating RUE to field level data on productivity; 3) this is the first parameterization and testing of an intercrop model with maize and wheat under different planting configurations; 4) this is the first demonstration in the literature of the effect of strip structure on the light interception and biomass accumulation in intercrops, calculated with a crop model and compared with a horizontally homogenous canopy (HHC) model. The presented strip intercrop model has a simple structure and calibration is straightforward. It allows the simulation of growth and yield of relay-strip intercrops with different species combinations and planting configurations.

\subsubsection{Simulate light competition between two species in relay-strip intercrop}

Compared to sole crop models, the intercrop model differs in the simulation of light capture. In a relay-strip intercrop, the first crop is arranged in strips with plant strips and paths alternating. After the second crop has been added, the two species start to compete for light and their competitive ability shifts according to their plant height. A light competition model with strip-canopy was in Chapter 3 and it showed good agreement with field observations under different intercrop configurations. The HHC model overestimates the light interception by the strip crops when the companion crop is not present. The light transmitted to the bare soil between the trips is not intercepted by the canopy in reality but it is calculated as such the HHC model. Moreover, during the co-growth, the light interception and growth of the taller species is overestimated by a HHC model whereas that of the lower "over-grown" species is underestimated. (Fig. 4.7). Therefore, the HHC model is not suitable for relay-strip intercrops. However, the homogeneous-canopy model has been used successfully to estimate light interception in cases where it is realistic to assume the canopy is horizontally homogeneously distributed, e.g., in mixed pastures (Johnson et al., 1989) or in crop-weed competitions (Kropff and van Laar, 1993). 


\section{Chapter 4}

\subsubsection{Simulating plant plasticity in intercrop}

In this intercrop model, the crop strips are treated as rectangulars in cross section, and within each rectangle, the LAI is homogenized. This is not true in reality, especially not for a tillering crop. For example, the number of tillers per plant and LAI in border rows are found to be about twice that in inner rows in a wheat-maize intercrop (Fig. B4, Appendix B); the same is true for biomass and yield (Chapter 2). Though neither the row types (inner or border rows) are distinguished in the model, nor the number of tillers are simulated as in the functional structure model (Zhu et al., 2015), the consequences of plant plasticity in border rows were nevertheless captured by the simplified strip-canopy model, and the border row effects are distributed across the plants within the imaginary rectangular strip. This is reflected in biomass per meter row (Fig. 4.8).

Due to border row effects, wheat grown in intercrops had a larger biomass per meter row than when grown in a sole crop for the entire growing season. On the other hand, maize grown in intercrops had a smaller biomass per meter row (or per plant) than when grown in a sole crop at the beginning of the growing season, because maize is a weaker competitor than wheat during that stage (Zhang and Li, 2003; Zhu et al., 2014). In the 8:2WM treatment, maize had a smaller biomass per plant than maize in the $6: 2 \mathrm{WM}$, due to more wheat plants and a narrower space between wheat and maize (inter-specific competition). Maize grown in 6:3WM had a smaller biomass per plant than maize in $6: 2 \mathrm{WM}$ due to self-competition between maize plants (intra-specific competition). Thus, the strip crop model, by accounting for the radiation partitioning in a mixture, captured the key consequence of plant plasticity for crop production (i.e. border row effects, inter- and intra-specific competition) as found in field experiments (Zhang et al., 2007).

\subsubsection{Model calibration and testing}

Bayesian calibration combines the prior knowledge of parameters (prior distribution of parameter) and observations. The output (parameter posterior distribution) characterizes the uncertainty of the parameters, which allows parameterization and uncertainty analysis conducted at the same time. When the observed data is not sufficient, the prior distribution plays an important role in the parameterization, while in contrast, the prior distribution plays a less important role in parameterization when the observations are sufficient. Furthermore, the uncertainties of model outputs could be obtained by simulating with the parameter posterior 
distributions. In this study, the uncertainty of crop biomass and intercrop land productivity (LER) were generated by running the model with the posterior distribution of RUEs. Here, we are more certain on the RUE obtained for 2013 than for 2014 which is reflected by the band width of posterior distributions, as well as the biomass and LER (Fig. 4.3 and 4.4).

Except for RUE, the crop-specific parameters used in the model are the same for sole crops and intercrop, and they do not change between years. On the one hand, this simplifies the model calibration, but on the other hand, all other differences between sole crop and intercrop are accounted for by the single parameter RUE. In this study, different RUEs in sole crop and intercrop are shown to give a better agreement with the observed data than a species-specific RUE, that is the same RUE in sole crop and intercrop (according to the DIC values in Table 4.4 and RMSE values in Figs. 4.5 and 4.6). The RUEs calibrated by data from 6:2WM were used to test the model in $8: 2 \mathrm{WM}$ and $6: 3 \mathrm{WM}$ treatments under the assumption that RUE did not change in those intercrop treatments. The intercrop model was tested by predicting growth in add-row intercrops and showed good agreement with observed biomass from periodic harvests. The RUEs were also separately calibrated for different years, because different LAI dynamics, biomass accumulations and yield were observed between the two years (Chapters 2 and 3). Those year differences were caused by variations in climate and field management.

Under potential growing condition, both wheat RUE and maize RUE could be expected to increase in wheat-maize relay intercrop compared to sole crops, because wheat and maize shades each other during different growing period. Shading provides both lower light intensity and a higher ratio of diffuse light to direct light. Previous studies showed that crop RUE increased with the fraction of diffuse radiation (Norman and Arkebauer, 1991; Sinclair et al., 1992; Hammer and Wright, 1994). In addition, in C3 crops, photosynthetic rate increases less than proportionally as the light intensity increases (Ögren and Evans, 1993), indicating a higher radiation use efficiency at low as compared to high light intensity in C3 crops. These two factors can explain the RUE increase in intercropped wheat. C4 species such as maize show an approximately linear increase in photosynthetic rate as the light intensity increase (Ögren and Evans, 1993). Thus maize tends to use light at the same efficiency under high and low intensity. Other factors could have provided a positive response of maize RUE to the higher proportion of diffuse radiation. Nevertheless, RUE of intercropped maize would be expected to increase as a result of higher diffuse light fraction radiation compared to sole maize, but his was not observed in this study. During the experiments, we aimed to create 


\section{Chapter 4}

potential growing conditions for the two species. However, this is very difficult to attain in reality; for example, maize stress (purple leaves) was observed at the seedling stage in 2014 in intercrops. This was probably caused by phosphorus deficiency in relation to compacted soil and very rainy weather. Furthermore, less green leaves were also observed in intercropped maize than sole maize during flowering and grain filling stages, indicating the depletion of nutrients that were taken up by the earlier emerging wheat crop.

The simulated biomass trajectory (Fig. 4.6) and final yield had a better agreement with observed values in 2013 than in 2014 for wheat and maize, this may because potential growing conditions were assumed, and the plants grown in 2013 were closer to potential growth than in 2014. The uncertainty of RUEs and biomass in 2014 is also greater than in 2013 (Figs. 4.3 and 4.4). The simulated LAI was higher than the observed values for wheat, but the simulated biomass was not higher than the observed biomass. Possibly, the inconsistency in LAI and biomass is due to not considering the area of the ear in the model. Wheat ears capture light and contribute to photosynthesis during flowering and grain filling stages (Araus et al., 1993; Abbad et al., 2004), while the number of ears not were simulated in this model, thus a higher leaf area compensated for the green area of ear in light capture.

\subsection{Conclusion}

A simple intercrop model was developed based on radiation use efficiency and a strip-canopy light competition module, and calibrated and tested with field data from wheat-maize intercrops. The simulations show good agreement with observed LAI and biomass under intercrop conditions. The model allows simulating the plant plasticity in terms of biomass per meter row. With easy calibration of plant specific parameters, this intercrop model is applicable to a wider range of intercrops, e.g. different crop combinations and planting configurations, and it can be used to explore alternative land use options with sole and intercrops.

\section{Appendix B}

Fig. B1 Wheat and maize tip and collar emergence time (thermal time) in sole crops and 6:2WM intercrop.

Fig. B2 Wheat tiller dynamics and maize leaf senescence with thermal time. 
Fig. B3 Biomass partitioning fractions to leaves, stems and organs for wheat and maize in different systems across two years.

Fig. B4 Tiller number per plant and leaf area per meter row in inner rows and border rows in replacement intercrop (6:2WM) in 2013 and 2014.

\section{Acknowledgements}

We are grateful to Dr David Makowski for helpful advice on Bayesian statistics, and to Mr. Peter van der Putten, Dr Junqi Zhu, Dr Yang Yu, Mr. Marcello Labra Fernandez, Dr Hiroe Zenihiro, Mr. Niel Verhoog and Wageningen UR Unifarm staff for valuable help during the experiments. The financial support of the China Scholarship Council (CSC, grant number: 201206350067) and the Key Sino-Dutch Joint Research Project of NSFC (grant number: 31210103906) are gratefully acknowledged. 



\section{Chapter 5}

\section{Wheat-maize intercropping lowers leaf nitrogen but increases leaf}

\section{photosynthesis in maize: a puzzle of plant plasticity and}

\section{competitive resource acquisition}

Fang Gou ${ }^{1,2}$, Martin K. van Ittersum ${ }^{2}$, Antoine Couëdel $^{3}$, Yue Zhang ${ }^{4}$, Yajun Wang ${ }^{5}$, Peter E.L. van der Putten ${ }^{1}$, Lizhen Zhang $^{4}$, Wopke van der Werf ${ }^{1}$

${ }^{1}$ Centre for Crop Systems Analysis, Wageningen University, P.O. Box 430, 6700 AK Wageningen, The Netherlands

${ }^{2}$ Plant Production Systems group, Wageningen University, P.O. Box 430, 6700 AK Wageningen, The Netherlands

${ }^{3}$ Université de Toulouse - INP - Ecole d'ingénieur de Purpan, UMR 1248 AGIR - 75 voie du TOEC BP 57611, 31076 Toulouse cedex, France

${ }^{4}$ China Agricultural University, College of Resources and Environmental Sciences, Agricultural Meteorology Department, Beijing 100193, China

${ }^{5}$ Northwest Institute of Eco-Environment and Resources, Chinese Academy of Sciences, Lanzhou 730000, China

This chapter has been submitted to Annals of Botany 


\section{Chapter 5}

\section{Abstract}

Maize is the late sown crop in wheat-maize relay intercropping, and its vegetative growth is affected by competition with wheat. Maize in the intercrop has a lower crop radiation use efficiency (RUE) over the whole growing season than maize grown as a sole crop. In this research, we study leaf traits of intercropped maize to test whether nitrogen content and photosynthetic rate can explain the lower RUE of maize in intercropping. A field experiment was conducted in 2014 in Wageningen, the Netherlands. Maize was planted as sole crop, as an intercrop with wheat, and as a skip-row system (i.e. an intercrop configuration from which the companion wheat crop was omitted). Three different intercrop configurations were compared: a replacement intercrop, and two augmentative intercrops in which either wheat or maize rows were added to the replacement configuration. Maize leaf traits of the ear leaf (usually leaf number 9), i.c. specific leaf area (SLA), leaf nitrogen concentration, chlorophyll content (SPAD), and photosynthetic rate (A) were determined over three weeks during maize flowering. SLA was significantly higher (thinner leaves) in intercrops than in skip-row maize. Leaf nitrogen concentration was not different among sole maize, skip-row and replacement intercrop, but significantly higher in the three treatments than in augmentative intercrops. Leaf chlorophyll content was highest in sole and skip-row maize, intermediate in maize in the replacement intercrop, and lowest in maize grown in the augmentative intercrops. Photosynthetic rate was significantly higher in the replacement intercrop than in sole maize, skip-row maize and intercrop with an additional maize row. The hypothesis that intercropped maize would have lower leaf photosynthetic rate was thus rejected. We infer that competition during the maize seedling stage did - as expected - result in less favourable leaf traits (e.g. a smaller $\mathrm{N}$ content and lower chlorophyll concentration) in intercropped maize, especially in augmentative configurations, but these alterations did not affect photosynthetic rate negatively. Other factors, such as differences between treatments in concentration of water and nutrients in the soil, in response to intercropping, or differences among treatments in rooting traits, may have contributed to a higher photosynthetic rate. The measurements on chlorophyll content and gas exchange parameters indicate that partitioning of nitrogen between light capture (chlorophyll) and CO2 capture (Rubisco) was changed by intercropping. Overall, these findings exemplify the complexity of competitive relationships and plastic plant responses in intercrops, and the need for further study of resource distribution and resource acquisition in intercrop systems.

Key words: specific leaf area, specific leaf nitrogen, chlorophyll content, stomatal conductance 


\section{$5.1 \quad$ Introduction}

Intercropping is the cultivation of two or more crop species simultaneously in the same field (Vandermeer, 1989). Due to complementary resource use in time and space among different species, intercropped species often achieve higher productivity than the same species in sole crops, i.e. the land equivalent ratio (LER) is greater than one (Lithourgidis et al., 2007; Malézieux et al., 2009; Li et al., 2013; Yu et al., 2015). When intercropped species have similar growing periods, the potential advantages of intercropping result from different strategies in resource acquisition or a decrease of the crop failure probability. Those mechanisms apply especially under low input conditions and their yield advantages decrease with the increase of inputs. For example, in sorghum-groundnut and millet-groundnut intercrops, the LER decreased with increased irrigation (Natarajan and Willey, 1986). Similarly, in pea-barley intercropping, the LER was lower at high $\mathrm{N}$ fertilizer input than at low $\mathrm{N}$ fertilizer input (Jensen, 1996). When intercropped species have different growing periods, i.e. relay intercropping, the intercrop advantage is in part due to complementary resource use in time. Such intercrops have a high LER at high input levels (Yu et al., 2015).

Wheat-maize relay intercropping is an example of a high input relay intercrop system, and is widely used by farmers in northwest China (Knörzer et al., 2009), notably in Gansu province. In wheat-maize relay intercropping, spring wheat is sown as 6 rows-wide strips in March, while two rows of maize are sown in empty swaths between the wheat strips in April, then wheat is harvested in July and maize is harvested in September (Li et al., 2001b). The land equivalent ratio of this wheat-maize reply intercropping system is up to 1.6 (Mu et al., 2013).

Maize is the late sown crop in wheat-maize relay intercropping. Maize seedlings grow initially under strong competition for resources from the earlier sown wheat plants. Nevertheless, it has been found that intercropped maize can achieve higher yield per plant than sole-cropped maize in northwest China (Li et al., 2001a). Thus, on average over the whole growing period, maize plants in the intercrop experience less competition for resources than maize plants in a sole maize crop. The heavy competition from wheat during early maize growth is compensated after wheat harvest when maize is growing at a lower density than sole maize, resulting in a relaxation of interspecific competition. In this period, the maize plants show recovery growth. This pattern of strong competition during early growth, changing into relaxed competition and recovery during later growth was described as an 


\section{Chapter 5}

example of the "competition-recovery production principle" by Zhang and Li (2003). During vegetative growth, maize growth and development is suppressed by wheat. For instance, intercropped maize has a lower leaf appearance rates (Zhu et al., 2014) and a lower biomass accumulation rate per plant than sole maize. After wheat harvest, intercropped maize has a significantly higher dry matter accumulation rate per plant than sole maize, and it finally achieves a higher yield per plant than sole maize (Li et al., 2001a). The strength of the recovery growth depends on the growing conditions. In Chapter 2, we found that under Dutch conditions intercropped maize had a lower biomass per plant than sole maize at maturity, resulting from a strong competition with wheat for light, water and nutrients during maize seedling stage, and a weak "recovery" growth after wheat harvest. Furthermore, intercropped maize was found to have a lower radiation use efficiency (RUE) than sole maize over the whole growing period (Chapter 3). Wang et al. (2015) also found a consistently lower RUE in intercrop than in sole crop when measuring over shorter periods, e.g. from mid-May to midJune, and from mid-June to mid-July. In this study we aim to find out whether differences in leaf traits between sole maize and intercropped maize can provide an explanation for the difference in RUE.

Muchow and Davis (1988) and Sinclair and Horie (1989) found a linear relationship between radiation use efficiency (RUE) and specific leaf nitrogen (SLN) in maize. This positive relationship is strong at low SLN but it saturates at higher SLN, resulting in a hyperbolic relationship (Massignam et al., 2009). Similarly, the relationship between leaf photosynthetic rate and leaf SLN was also found to be linear or hyperbolic (Osman and Milthorpe, 1971; Rawson and Hackett, 1974; Yoshida and Coronel, 1976; Muchow and Sinclair, 1994). Thus a lower RUE may be caused by a lower SLN and a lower leaf photosynthetic rate. Here, we hypothesize that intercropped maize has a lower SLN and a lower photosynthetic rate than sole maize, due to competition for nutrients with wheat. In addition, Björkman (1981) reported that the leaves developing under shaded conditions were thinner and had a larger surface area per unit dry weight in order to optimize light interception. Thus we also hypothesize that intercropped maize has a higher SLA ("thinner" leaves) than sole maize due to shade avoidance during the early growth of maize, when the plants are shaded by earlier sown wheat. 


\subsection{Materials and methods}

\subsubsection{Experimental design}

Measurements were made in a field experiment in Wageningen, the Netherlands $\left(51^{\circ} 59^{\prime} 20^{\prime \prime} \mathrm{N}, 5^{\circ} 39^{\prime} 16^{\prime \prime} \mathrm{E}\right)$ in 2014 . We determined the leaf traits and photosynthetic rate of maize in sole crop and in intercrops. Soil at the experimental site was sandy with $3.1 \%$ organic matter and a $\mathrm{C} / \mathrm{N}$ ratio in the organic matter of 14 . Spring wheat (variety "Tybalt") was sown on 13 March and harvested on 4 August, while maize (variety "Atrium") was sown on 7 May and harvested on 23 September. A randomized complete block design with four replicates was used. Plots were $7.5 \mathrm{~m}$ wide by $23 \mathrm{~m}$ long. The row orientation was approximately north-south.

The experiment had seven crop configurations as treatments: two sole crops, three intercrops and two skip-row treatments: sole wheat (SW) and sole maize (SM), replacement intercrop (6:2WM), skip-row wheat and maize (6:0WM, 0:2WM), and add-row designs (8:2WM, 6:3WM) (Table 2.1 and Fig. 2.1, Chapter 2). Details of the experimental design and field management are given in Chapter 2. Crop management in the experiments aimed at meeting crop demand for water and nutrients, and control of yield reducing factors through adequate weed, pest and disease management. Fertilizer was applied homogeneously throughout the experiment. Before wheat sowing, $\mathrm{K}_{2} \mathrm{SO}_{4} \cdot \mathrm{MgSO}_{4}$ and $\mathrm{Ca}\left(\mathrm{H}_{2} \mathrm{PO}_{4}\right)_{2} \cdot \mathrm{H}_{2} \mathrm{O}$ were applied to supply phosphorus, potassium and calcium. Total available nitrogen was $200 \mathrm{~kg} \mathrm{~N}$ per ha, including $7 \mathrm{~kg} \mathrm{~N}$ of soil mineral nitrogen at sowing of wheat, an estimated $25 \mathrm{~kg} \mathrm{~N}$ from winter cover crop decomposition (white mustard, Sinapis alba L.), and $168 \mathrm{~kg} \mathrm{~N}$ from nitrogen fertilizer $\left(\mathrm{NH}_{4} \mathrm{NO}_{3} \cdot \mathrm{CaMg}\left(\mathrm{CO}_{3}\right)_{2}\right)$. Weeds were controlled mechanically before wheat emergence and chemically thereafter. Supplementary water was applied during the growing season at the first signs of wilting.

\subsubsection{Photosynthesis measurements}

At flowering stage we measured photosynthesis of the ear leaf (usually the $9^{\text {th }}$ leaf) from 09:00 - 17:00 h using a Li-6400XT portable photosynthesis system (Licor Inc., Lincoln, NE, USA). The measurements were conducted during three weeks in four blocks. In weeks 29 and 30 (week of the year), four plants per row were measured with an adaptation time of 5 minutes; and in week 31, two plants per row were measured with an adaptation time of 15 


\section{Chapter 5}

minutes (Table 5.1). In the treatments SM, 0:2WM, 6:2WM and 8:2WM, two rows of maize plants were measured in each plot; in the 6:3WM treatment, plants in each of three maize rows were measured in each plot. Measurements were conducted at a constant light level of $1000 \mu \mathrm{mol} \cdot \mathrm{m}^{-2} \cdot \mathrm{s}^{-1}$ and a constant $\mathrm{CO}_{2}$ level of $400 \mu \mathrm{mol} \mathrm{mol}{ }^{-1}$. Leaf temperature during measurements was about $27^{\circ} \mathrm{C}$. Besides photosynthetic rate, stomatal conductance was also investigated which reflects water availability during the photosynthetic process.

Table 5.1 time schedule for leaf measurements during silking stage

\begin{tabular}{cccccc}
\hline Week & DOY & DAE & Block & Number of leaf per row & Adaption time (min) \\
\hline 29 & 197 & 58 & 1,2 & 4 & 5 \\
29 & 198 & 59 & 3,4 & 4 & 5 \\
30 & 204 & 65 & 1,2 & 4 & 5 \\
30 & 205 & 66 & 3,4 & 4 & 5 \\
31 & 211 & 72 & 1,2 & 2 & 15 \\
31 & 212 & 73 & 3 & 2 & 15 \\
31 & 213 & 74 & 4 & 2 & 15 \\
\hline
\end{tabular}

DOY: day of year, DAE: day after maize emergence.

\subsubsection{Leaf traits measurements}

After the photosynthesis measurements, the leaves were cut and brought to lab for further analyses. A section of approximately $20 \mathrm{~cm}$ length was cut from each maize leaf, and the midrib was removed. The greenness of the leaf, as a proxy of chlorophyll content was measured using a SPAD 502 Plus Chlorophyll Meter (SPAD-502, Minolta Camera, Tokyo, Japan). Twelve different points on each blade were measured for chlorophyll content (SPAD). The leaf area was measured using a leaf area meter (LI-3100 Area Meter, USA). Afterwards, the leaves were dried in a $70{ }^{\circ} \mathrm{C}$ oven for 24 hours to determine dry matter content. Finally, the nitrogen concentration of each oven-dried leaf was determined using the Kjeldahl method (Novozamsky et al., 1983). The oven-dried leaves were ground, and $0.1 \mathrm{~g}$ fine sample was digested in a mixture of concentrated $\mathrm{H}_{2} \mathrm{SO}_{4}$ and $\mathrm{H}_{2} \mathrm{O}_{2}$, then the digests were analyzed by a Kjeldahl device (KDY 9820, Tongrunyuang, China).

\subsubsection{Data analysis}

Four types of analyses were conducted. 1) The leaf traits and photosynthetic rate were analyzed separately for each week, and pairwise comparisons were made between all treatments within a week. Treatment and block were factors in this analysis. 2) Leaf traits and photosynthetic rate were analyzed combining data for all the three weeks, with treatment, 
week and block as factors in the analysis. Pairwise comparisons were made between treatments. In these two analyses, ANOVA $(\mathrm{P}=0.05)$ and Tukey's HSD were used in the 'stas' package of $\mathrm{R}$ programming language (R Core Team, 2015). 3) Linear regression was used to analyse the relationship between SPAD values and nitrogen concentration (NC), between SPAD values and SLN, and between photosynthetic rate and SLN, respectively. 4) A hyperbolic model (Eq. 5.1) was applied to analyse the relationship of photosynthetic rate $A$ and stomatal conductance for $\mathrm{CO}_{2}\left(g_{\mathrm{s}}\right)$.

$A=A_{\max } \times \frac{g_{s}}{g_{s}+g_{s 50}}$

where $A$ is photosynthetic rate ( $\mu$ mol $\mathrm{CO}_{2} \mathrm{~m}^{-2} \mathrm{~s}^{-1}$ ), $A_{\max }$ is the estimated maximum photosynthetic rate $\left(\mu \mathrm{mol} \mathrm{CO} \mathrm{CO}^{-2} \mathrm{~s}^{-1}\right), g_{s}$ is the stomatal conductance for $\mathrm{CO}_{2}$ diffusion (mol $\left.\mathrm{m}^{-2} \mathrm{~s}^{-1}\right)$, and $g_{s 50}$ is the stomatal conductance for $\mathrm{CO}_{2}$ at $1 / 2 A_{\max }\left(\mathrm{mol} \mathrm{m} \mathrm{m}^{-2} \mathrm{~s}^{-1}\right)$. The functions were fitted to different pooled data of the five treatments, and to different subsets of the data to determine whether there were differences in photosynthetic responses between treatments or groups of treatments. Specifically, the data were fitted using five lines, i.e. one line for each treatment; using two lines, i.e. one line for sole maize and skip-row maize, another line for intercrop; and one line, i.e. one line for the data of all treatments combined. Akaike's Information Criterion (AIC) was used to judge the grouping of the treatment data that was best supported, with small AIC values representing better overall fits (Bolker, 2008).

\section{$5.3 \quad$ Results}

\subsubsection{Maize leaf traits and photosynthetic rate}

Generally, there is a trend that sole maize and skip-row maize have better leaf traits (i.e. leaf traits supporting high photosynthetic rates) than intercropped maize, e.g. lower SLA (i.e. “thicker" leaves), and higher SLN and chlorophyll content (SPAD), but intercropped maize did not show lower photosynthetic rate than sole maize (Table 5.2). Except for SPAD, the significance of treatment differences for all other parameters showed changes across the three weeks.

SLA showed consistent trends in treatment effects during the three weeks of measurement (Table 5.2). Overall, maize grown in add-row intercrop (6:3WM) had the largest SLA ("thinnest" leaves) and significantly higher SLA than maize in the sole crop and skip-row, as 


\section{Chapter 5}

well as the replacement intercrop, but not significantly different from the 8:2WM intercrop. Differences between treatments were similar for leaf nitrogen concentration (NC) and specific leaf nitrogen (SLN). Both parameters were significantly lower in the augmentative intercrops than in the sole crop, skip-row and replacement intercrop, indicating that the stronger competition in augmentative designs had resulted in lower $\mathrm{N}$ concentration. SPAD values were in all three weeks lower in all of the three intercrops than in sole maize or skip-row maize (Table 5.2), and the overall analyses showed that maize in the augmentative intercrops had lower SPAD than maize in the replacement intercrops (Table 5.2 and Fig. 5.1). Overall, the patterns in these leaf traits support the hypothesis that competition with wheat lowers nitrogen concentration and specific leaf nitrogen and increases specific leaf area. Other things being equal, these differences would point to lowered photosynthesis rates in intercropped maize as compared to sole or skip-row maize.

Stomatal conductance for $\mathrm{CO}_{2}\left(g_{s}\right)$ was not significantly different between treatments in any week; however, when analyzed across the three weeks, $g_{s}$ was significantly greater in maize in the replacement intercrop than in sole maize and skip-row maize (Table 5.2 and Fig. 5.1). The same was found for stomatal conductance for water $\left(C_{i}\right)$. The photosynthetic rate $(A)$ was significantly higher in replacement intercrop $(6: 2 \mathrm{WM})$ than in sole maize during the first two weeks, but not in the third week. Overall, maize in the replacement intercrop had the highest rate of photosynthesis among all treatments, followed by maize in the augmentative intercrops, and with sole maize and skip-row maize having the lowest rates of photosynthesis.

\subsubsection{Relationships between leaf traits and photosynthetic rate}

The slopes of the linear regressions between nitrogen SPAD values and concentration (NC) were not significantly different from zero for sole maize, skip-row maize and maize in replacement intercrop. The standard errors were large in all treatments (Table 5.3). However, the slopes of linear regression between SPAD values and specific leaf nitrogen (SLN) were significantly different from zero in all treatments, and with small standard errors (Fig. 5.2 and Table 5.3). The wide range of NC and SLN in intercrops shows a strong competition for nitrogen and large variations among individual plants. 


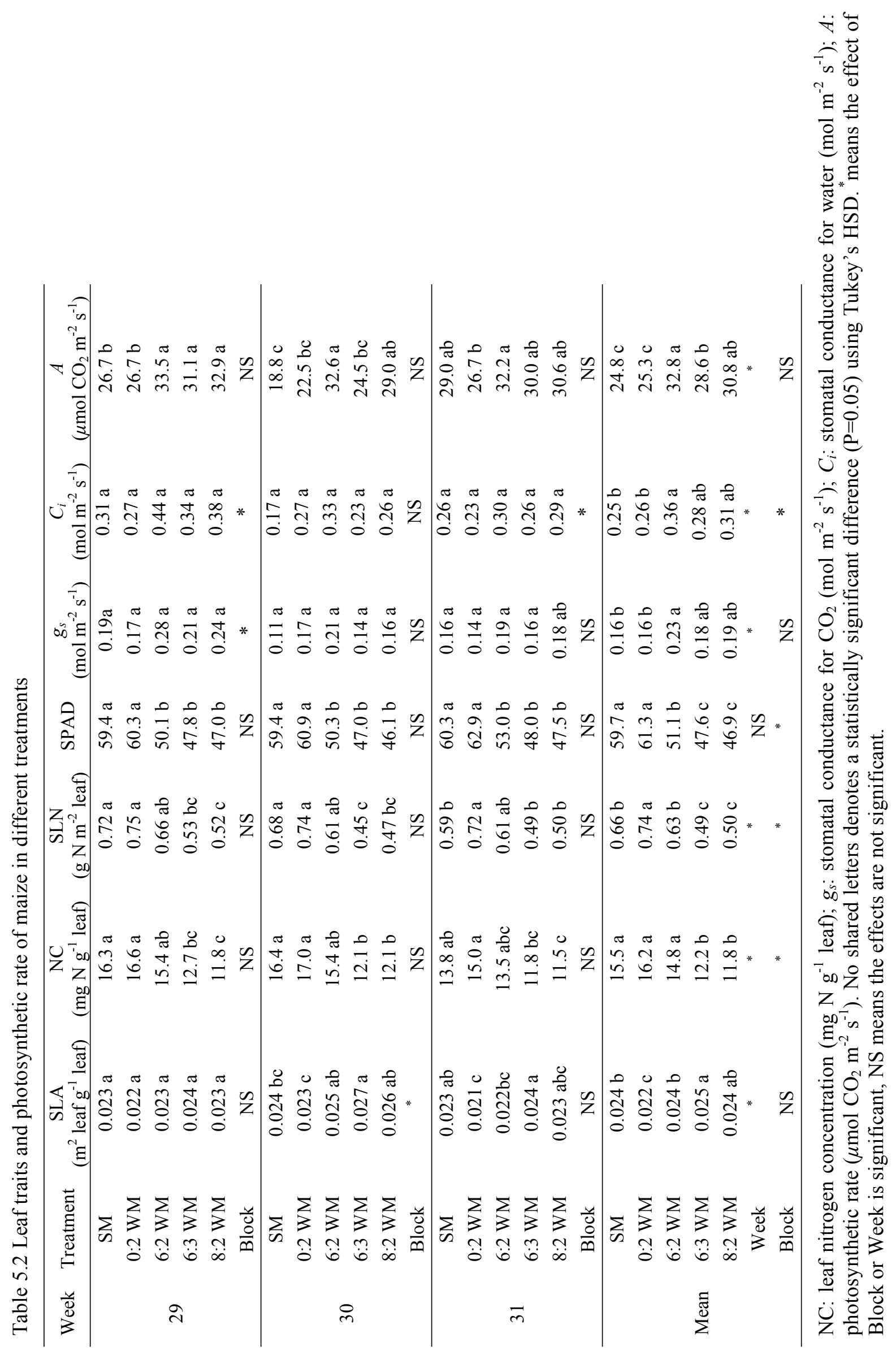


(a) Specific leaf area

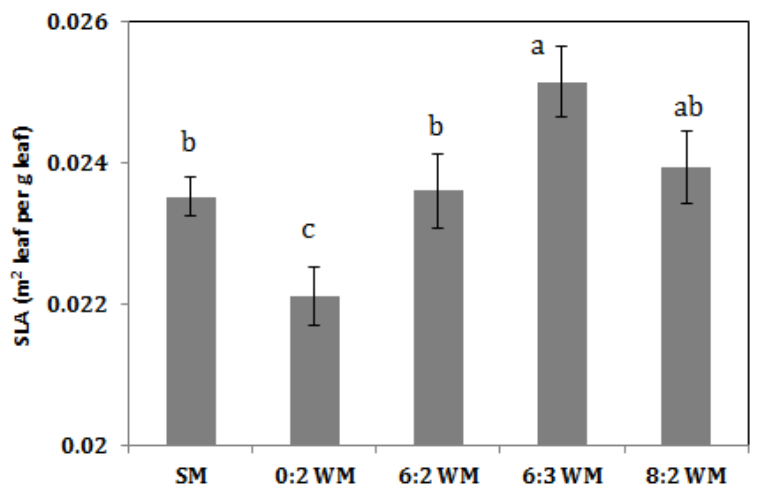

(c) Specific leaf nitrogen

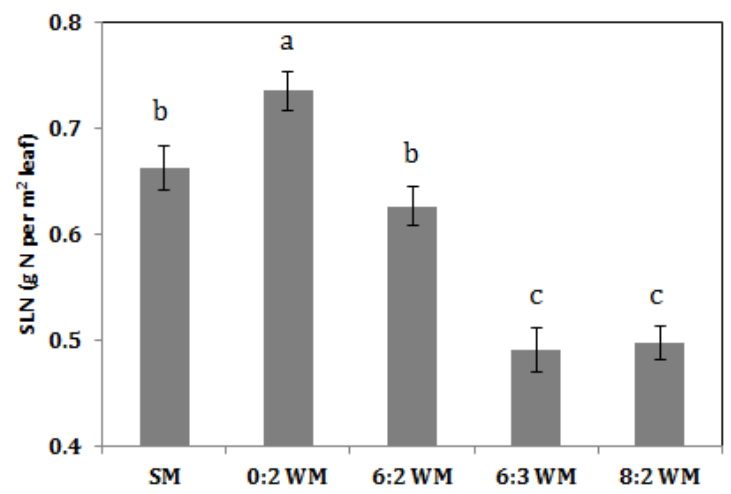

(e) Stomatal conductance for $\mathrm{CO}_{2}$

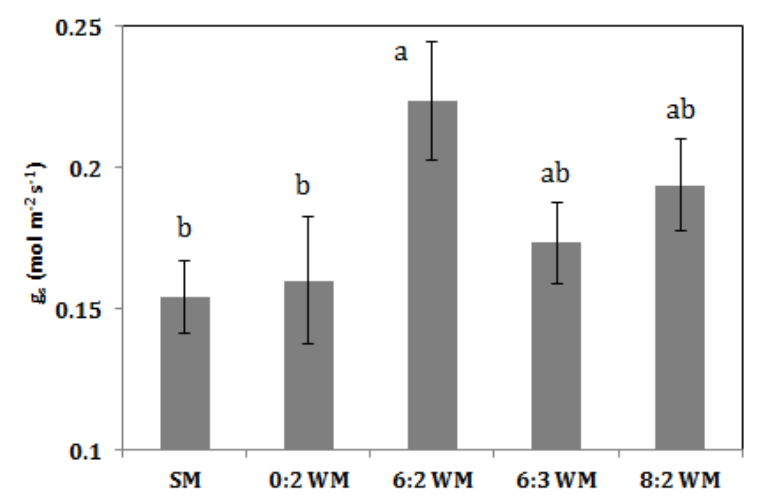

(b) Nitrogen concentration

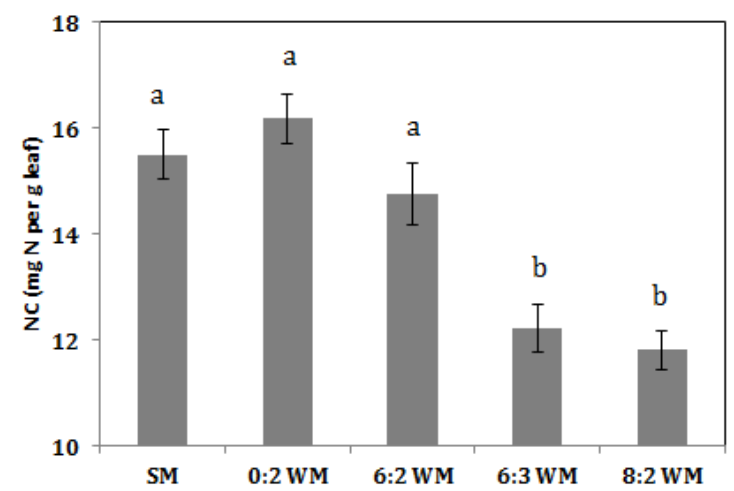

(d) SPAD

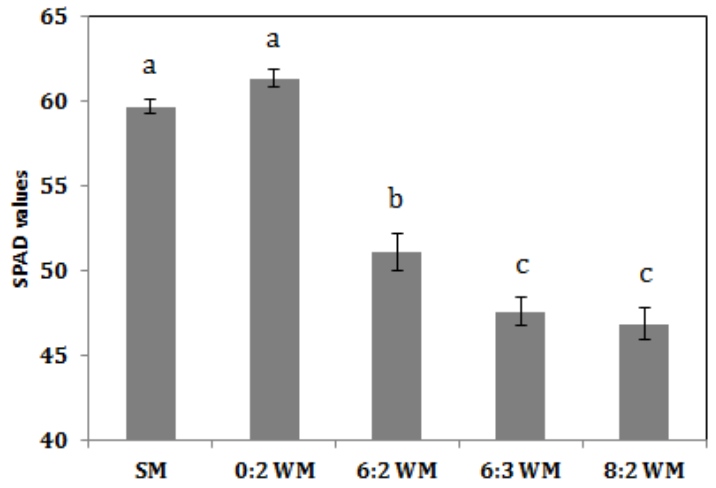

(f) Photosynthetic rate

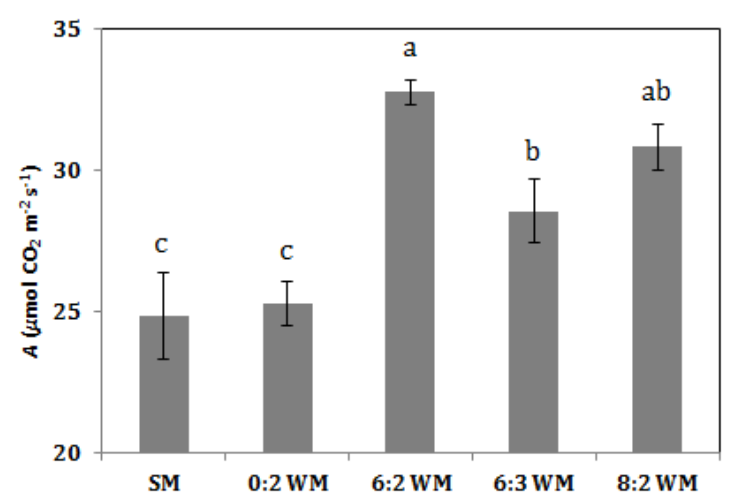

Fig. 5.1 Maize ear leaf traits and photosynthetic rates in five treatments, the values are averaged over three weeks. Panels a-f are data for SLA, NC, SLN, SPAD, stomatal contactance for $\mathrm{CO}_{2}\left(g_{s}\right)$, and photosynthetic rate, respectively. Letters denote significance of treatment difference according to Tukery's HSD. Stomatal constance for water $\left(C_{i}\right)$ shows the same pattern over treatments as $g_{s}$, and is not shown in the figure. 

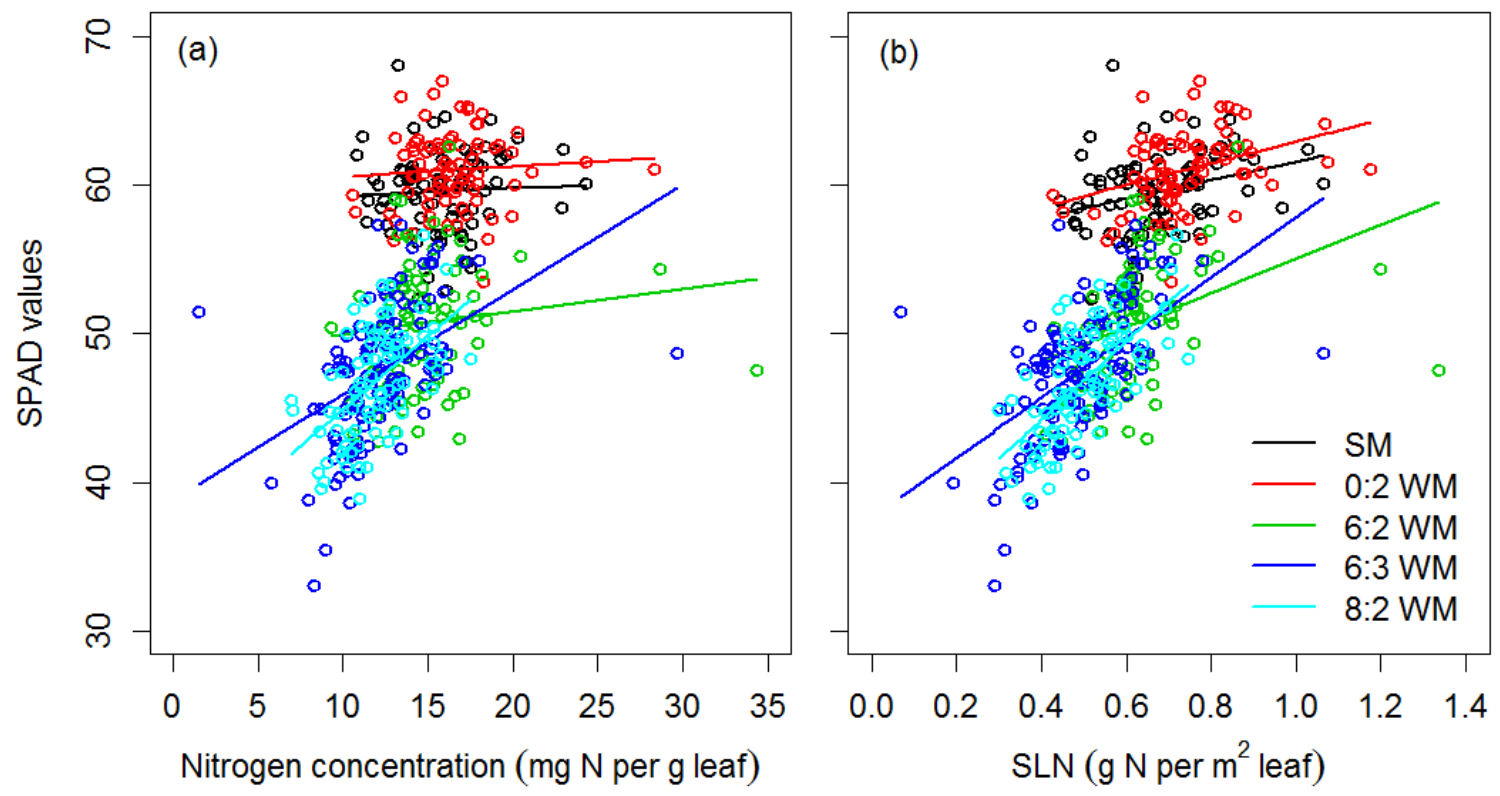

Fig. 5.2 Linear regression of nitrogen concentration and SPAD values (panel a); linear regression of SLN and SPAD values (panel b).
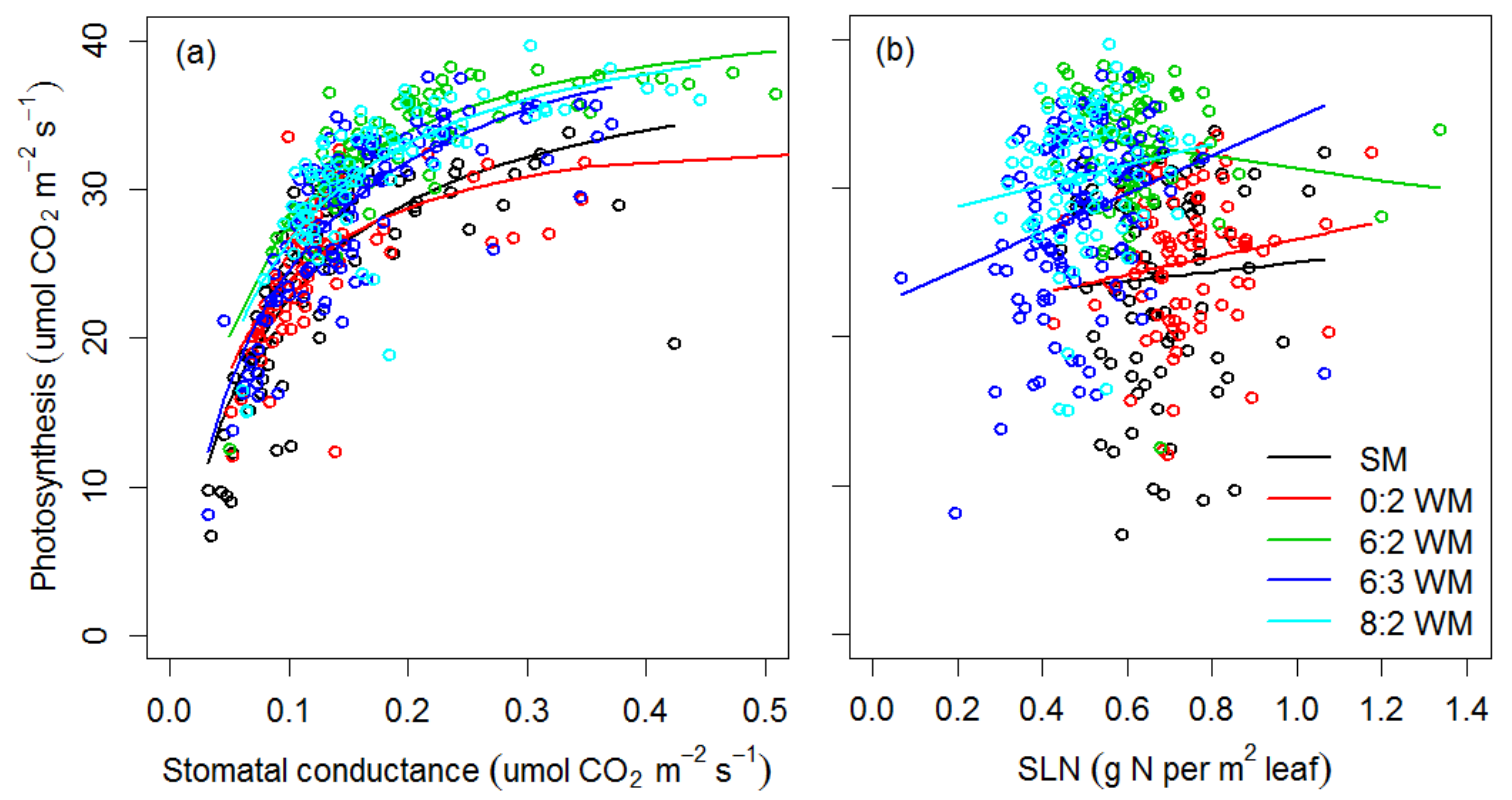

Fig. 5.3 Non-linear regression (hyperbola function) of photosynthetic rate and stomatal conductance for $\mathrm{CO}_{2}$ (panel a); linear regression of photosynthetic rate and SLN (panel b).

The estimated maximum photosynthetic rate $\left(A_{\max }\right)$ from the hyperbolic function $(E q .5 .1)$ are approximately $43 \mu \mathrm{mol} \mathrm{CO} \mathrm{m}^{-2} \mathrm{~s}^{-1}$ in intercrops, but only $39 \mu \mathrm{mol} \mathrm{CO} \mathrm{Cm}^{-2} \mathrm{~s}^{-1}$ in sole maize and $35 \mu \mathrm{mol} \mathrm{CO} \mathrm{Cm}^{-2} \mathrm{~s}^{-1}$ in skip-row maize (Table 5.3). The values of stomatal conductance for $\mathrm{CO}_{2}$ at $1 / 2 A_{\max }$ range from 0.051 to $0.081 \mu \mathrm{mol} \mathrm{CO}_{2} \mathrm{~m}^{-2} \mathrm{~s}^{-1}$ in different treatments (Fig. 5.3a and Table 5.3). The curves are different from each other, AIC is smallest (2227) when 


\section{Chapter 5}

fitting the hyperbolic function separately for each individual treatment (five curves) and highest (2347) when fitting the curve with data of all treatments pooled (one line), AIC is 2261 when fitting two curves (one curve for sole maize and skip-row maize, and another curve for intercrops). Fig. 5.3a shows that at the same stomatal conductance, intercropped maize has a higher photosynthesis than sole maize and skip-row maize.

The slope of linear regression of photosynthetic rate $(A)$ and SLN is only significant in the 6:3WM treatment (Fig. 5.3b and Table 5.3). The five lines are different from each other, AIC value is 2695 for fitting five lines, 2733 for fitting two lines and 2842 for fitting one line. Fig. $5.3 \mathrm{~b}$ shows intercropped maize has a higher rate of photosynthesis than sole maize and skiprow maize at the same SLN.

Table 5.3 Parameters of linear or hyperbolic regressions

\begin{tabular}{cccccc}
\hline Treatment & SPAD NC & SPAD $\sim$ SLN & \multicolumn{2}{c}{$A \sim g_{s}$} & $A \sim$ SLN \\
& $\mathrm{S} 1$ & $\mathrm{~S} 2$ & $\begin{array}{c}A_{\max } \\
\left(\mu \mathrm{mol} \mathrm{CO} \mathrm{m}^{-2} \mathrm{~s}^{-1}\right) .\end{array}$ & $\begin{array}{c}g_{s 50} \\
\left(\mathrm{~mol} \mathrm{~m}^{-2} \mathrm{~s}^{-1}\right) .\end{array}$ & $\mathrm{S} 3$ \\
\hline SM & $0.056 \pm 0.12$ & $6.23 \pm 2.36^{*}$ & $39.31 \pm 2.01^{*}$ & $0.080 \pm 0.011^{*}$ & $3.15 \pm 6.11$ \\
$0: 2 \mathrm{WM}$ & $0.068 \pm 0.11$ & $7.34 \pm 2.23^{*}$ & $35.35 \pm 1.67^{*}$ & $0.051 \pm 0.008^{*}$ & $5.99 \pm 4.22$ \\
$6: 2 \mathrm{WM}$ & $0.015 \pm 0.15$ & $11.49 \pm 3.42^{*}$ & $42.73 \pm 1.00^{*}$ & $0.058 \pm 0.006^{*}$ & $-4.08 \pm 3.51$ \\
6:3 WM & $0.71 \pm 0.13^{*}$ & $20.19 \pm 2.77^{*}$ & $43.61 \pm 1.48^{*}$ & $0.081 \pm 0.008^{*}$ & $12.83 \pm 4.21^{*}$ \\
8:2 WM & $0.98 \pm 0.17^{*}$ & $26.33 \pm 3.29^{*}$ & $42.70 \pm 1.50^{*}$ & $0.064 \pm 0.008^{*}$ & $7.06 \pm 5.62$ \\
\hline
\end{tabular}

$\mathrm{S} 1, \mathrm{~S} 2$ and $\mathrm{S} 3$ are the slopes of linear regression of SPAD values and nitrogen concentration (NC), SPAD values and SLN, and photosynthetic rate $(A)$ and SLN, respectively; $A_{\max }$ is the maximum photosynthetic rate estimated by the hyperbolic function $(E q .1)$, and $g_{s 50}$ is the stomatal conductance for $\mathrm{CO}_{2}$ at $1 / 2 A_{\max }$. Asterisks represent the estimated values are significantly different from $0(\mathrm{P}=0.05)$.

\subsection{Discussion}

In this Chapter we tested three hypotheses: 1) maize has a lower nitrogen content and chlorophyll content when grown in intercrops than in sole and skip-row maize; 2) maize has a higher SLA when grown in intercrops than in sole and skip-row maize due to shade avoidance; 3) maize has a lower photosynthetic rate when grown in intercrops than sole and skip-row maize due to a lower nitrogen content and a higher SLA. The first hypothesis was confirmed by the data. Compared to sole maize, the intercropped maize had a significantly smaller chlorophyll content (SPAD), while the nitrogen concentration (NC) and specific leaf nitrogen (SLN) were significantly smaller in maize in add-row intercrops, though not significantly in the replacement intercrop as compared to sole maize and skip-row maize. The findings support the notion that competition with wheat in intercrops lowers leaf nitrogen and 
chlorophyll content. The second hypothesis received weak confirmation. Maize SLA tended to be high in systems with strong competition (e.g. 6:3WM intercrop) and low in systems with weak competition (i.c. skip-row maize). The third hypothesis was, however, rejected. Intercropped maize did not have a lower photosynthetic rate $(A)$ than sole maize or skip-row maize, but a higher photosynthetic rate than sole maize, especially in the replacement intercrop. Furthermore, maize in the replacement intercrop had a higher photosynthetic rate and stomatal conductance for $\mathrm{CO}_{2}$ and water than sole and skip-row maize, while maize in the add-row intercrops had intermediate photosynthetic rate. Overall, these findings indicate that competition with wheat resulted in leaf traits (nitrogen concentration and chlorophyll) that in general tend to lower the capacity for photosynthesis, however, the photosynthetic rate measured in the field was not lower in the intercrops, but, on the contrary, higher. This indicates that other additional factors than these leaf traits affected photosynthesis.

\subsubsection{Hypotheses for high photosynthetic rate in intercropped maize}

Photosynthetic rate is known to increase with SLN (Sinclair and Horie, 1989; Muchow and Sinclair, 1994), however, in this research this is not the case. Intercropped maize had a lower SLN but a higher photosynthetic rate than sole maize and skip-row maize. Three hypotheses can be formulated to explain this result.

A first hypothesis is that intercropped maize had less water stress than sole maize or skip-row maize. This could be a consequence of the two intercropped species having peak water demand during different periods, or a changed roots distribution in the intercrop as compared to sole crop. In the wheat-maize relay intercrop, wheat is almost mature during maize flowering stage and the wheat plants have at that time a low water demand. There could therefore be more water available for maize in the intercrop than in sole maize. Furthermore, such niche differentiation could be amplified by below-ground root plasticity. Li et al. (2006) reported that the roots distributed differently in wheat-maize intercropping as compared to sole crops. Intercropped wheat spread its roots more widely than sole wheat, while intercropped maize proliferated its roots more deeply than sole maize, and both intercropped wheat and maize had a greater root length density (root length per unit soil volume) than the sole crops. Also, Cong et al. (2015b) reported that intercrops produced a greater belowground root biomass than sole crops. Deeper and longer roots in the intercrop could support better access to ground water than is achieved in sole crops, thus the intercropped maize may have a lower water stress than that in sole crops. The explanation of lower water stress in 


\section{Chapter 5}

intercropped maize is supported by the observed greater stomatal conductance for water $C_{i}$ in intercrops (particularly the replacement intercrops) as compared to sole crops (Table 5.2). Furthermore, the stomatal conductance for water in skip-row maize was also lower than that in replacement intercrop, indicating that plant plasticity in roots may play a key role in the advantage of water acquisition in the intercrop during this period.

A second hypothesis explaining high photosynthesis rate in intercropped maize is that the ear leaf (most often the $9^{\text {th }}$ leaf) of intercropped maize had a higher probability to be exposed to direct sunlight than the ear leaf of sole maize, due to a difference in canopy structure. As shown in Fig. 5.4, the ear leaf is at the middle height of the plant in sole maize, and there are six to seven leaves above it. Light is strongly extinguished at this level. However, in the intercrop, the position of ear leaf is above the height of the wheat crop and the total amount of leaf area (in terms of LAI) above the ear leaf in the intercrop is substantially less (Fig. 5.4b) than in the sole crop (Fig. 5.4a). Therefore, the ear leaves in the intercrop are more strongly exposed to sunlight. Thus, the ear leaf of intercropped maize may adapt to a higher level of sunlight, while the ear leaf of sole maize may adapt to a lower level of sunlight. Furthermore, due to this light adaptation, nitrogen may have been allocated differently within the leaf among chlorophyll, Rubisco, electron transport and other enzymes for photosynthesis processes (Field, 1983; Stitt and Schulze, 1994). Shaded leaves contain increased chlorophyll, relative to electron transport proteins and relative to Rubisco protein (Leong and Anderson, 1986; Terashima and Evans, 1988). Because the function of chlorophyll is to absorb light, the demand for chlorophyll is lower under high than under low light, and the remainder of nitrogen can be allocated to other functions to optimize photosynthesis. This interpretation is consistent with the values of SPAD and SLN, i.e. there is no significant difference in SLN between replacement intercrop and sole maize, but the SPAD values are significantly different. This indicates that in the sole crop, a larger proportion of nitrogen is distributed into chlorophyll than in the replacement intercrop. Furthermore, in the sole crop, as the ear leaves have adapted to a lower light level, the amount of Rubisco and other enzymes may also be adapted to a lower light condition. During photosynthesis measurements, when the leaf was exposed to $1000 \mu \mathrm{mol} \mathrm{m} \mathrm{m}^{-2} \mathrm{~s}^{-1}$ light condition, though the leaf in sole maize could absorb more light (due to high chlorophyll content) and capture more electrons than in intercrop, the amount of Rubisco and other enzymes in the sole crop may not be sufficient to assimilate $\mathrm{CO}_{2}$ as fast as in the intercropped maize, i.e. Rubisco and other enzymes are the limiting factors of photosynthesis in sole maize. 

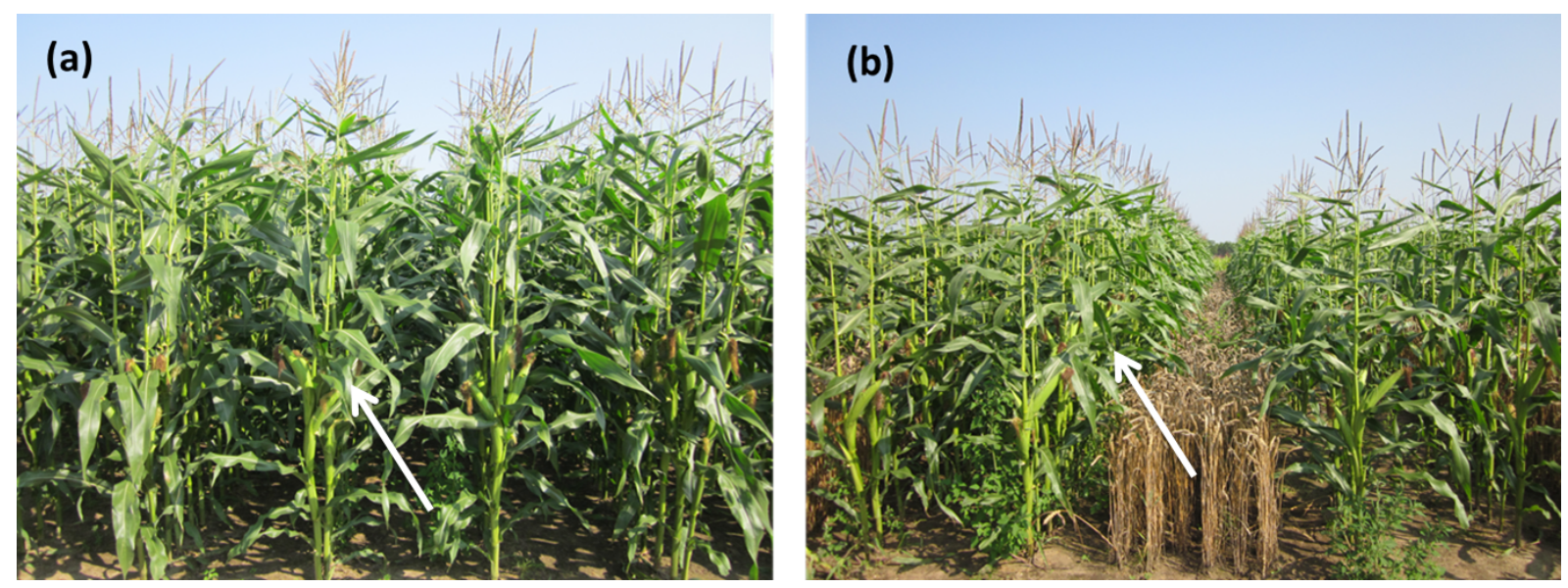

Fig. 5.4 Canopy structure of sole maize (panel a) and replacement intercrop (panel b) during maize flowering stage, the arrows point the positions of the ear leaf.

A third hypothesis is that the importance of the ear leaf as a source of assimilates differs between sole maize and intercropped maize. We focussed on the ear leaf because we assumed that the ear leaf, due to its proximity to the ear, would be the most important source of assimilates for ear growth during flowering and grain filling. This may not be true in sole maize, as the upper leaves (leaves above the ear leaf) have good access to sunlight, those upper leaves may have high photosynthetic rate and provide enough assimilates to support plant growth, and the lower leaves could perhaps become "lazy". In contrast, the intercropped maize has fewer and smaller leaves above the ear leaf (Zhu et al., 2014), and the nitrogen concentration in those leaves is probably lower than those in sole maize. Therefore, assimilates from these upper leaves may not be sufficient for ear growth, and the lower leaves have to work harder to compensate for this. Thus a higher photosynthetic rate can be found with a lower leaf nitrogen in intercrop as compared to sole crop.

These three hypotheses could explain why intercropped maize had a higher photosynthetic rate with a lower leaf nitrogen as compared to sole maize. In short, the potential explanations are: (1) differences in water availability due to temporal complementarity in water use between two species and plant plasticity in root growth responding to different patterns of below-ground competition; (2) differences in allocation of limiting resources (e.g. nitrogen) to different chemical pools at leaf level, as a plastic response to differences in above-ground resource availability (light) between different crop systems; and (3) differences in the importance of the ear leaf with respect to the supply of assimilates to the growing ear. The three hypotheses do not exclude each other. They could all be true at the same time. Our measurements do not exclude any of these explanations. Further work is needed. 


\section{Chapter 5}

\subsubsection{The relationship between leaf $A$ and RUE}

The complexity of predicting crop biomass accumulation from leaf photosynthetic rates have long been recognized (Sinclair and Horie, 1989), and the assessment of RUE by leaf assimilation rate is very difficult, due to differences in temporal and spatial scale between crop growth over a season and RUE on the one hand (seasonal time scale; spatial scale of whole crop), and leaf photosynthetic rate on the other hand (time scale of minutes; spatial scale of single leaf). The RUE is usually estimated over the entire growing period which is determined by the assimilation and respiration of the whole canopy, and influenced by photosynthetic rates across a population of individual leaves. In sole crops, there are positive relationships between leaf photosynthetic rate and SLN, similarly for RUE and SLN (Muchow and Sinclair, 1994). Therefore, a higher photosynthetic rate is expected with a higher RUE. But the relationship between leaf nitrogen and photosynthesis depends on leaf position and leaf age.

In the intercrop, leaf photosynthesis may have a larger variation in time and across different leaves in the canopy than in the sole crop, due to plastic responses, interspecific interactions and the shifts of dominance between two intercropped species in above- and belowground competition. In the seedling stage of maize, due to shading from wheat, maize was in an unfavourable condition and also less competitive for water and nitrogen compared to the neighbouring wheat. As a result, intercropped maize may have a lower photosynthetic rate compared to sole maize. After maize surpassed wheat in height and achieved a better light environment, it had a relatively high photosynthetic rate at a low nitrogen concentration. However, it is uncertain whether this high photosynthetic rate can be maintained till maturity if leaf nitrogen is limiting. A decrease of RUE in intercropped maize may result from nitrogen deficiency during the later part of the growing season. In the intercrop, border row wheat has more tillers and produces more yield than sole wheat per plant. Thus, this wheat takes up more nutrients per plant than sole wheat, and there may be less left for intercropped maize. The spatial nutrient capture strategy of the wheat is not precisely known, but root distribution indicates that nutrients are acquired outside the strips that are sown with wheat, possibly creating nutrient depleted conditions in the maize strip, with lower resource availability compared to sole maize. This depletion of nutrients is likely to be more severe in add-row intercrop than in replacement intercrop, due to a higher plant density. The deficiency of nitrogen may not considerably affect photosynthesis during flowering stage, but it could still 
happen at a later stage after the grains withdraw nitrogen from the leaves (Pommel et al., 2006; Masclaux-Daubresse et al., 2008). If this explanation is true, the low RUE of maize could be remedied by adequate supply of nitrogen (and probably other nutrients) to intercropped maize, so it may maintain the same RUE as sole maize or even will have a higher RUE than sole maize, as found in the experiments in Wuwei, northwest China (Chapter 6). A higher RUE is supported by various mechanisms, e.g. during the vegetative stage, slight shading by wheat may increase maize RUE due to a higher proportion of diffuse light (Sinclair et al., 1992); and during the later growth stages, a better canopy structure in the intercrop as compared to the sole crop can optimize the leaf photosynthesis at plant level (Liu et al., 2006). In hindsight, although we aimed to create potential growing conditions with no nutrient limitation in our experiment, we have to conclude that it is likely we did not succeed during all growth stages and for all treatments.

\subsection{Conclusion}

Leaf traits (SLA, NC, SLN, chlorophyll content) and photosynthetic rate of the maize ear leaf were determined in sole crop and intercrops during flowering stage. Sole maize and skip-row maize had overall superior leaf traits, i.e. smaller SLA ("thicker" leaves), higher SLN and chlorophyll content than intercropped maize, especially in comparison to the add-row treatments. However, the photosynthetic rate in intercropped maize was higher than in sole maize, especially in the replacement intercrop. This inconsistent finding can be explained by differences in water availability, plastic rooting traits, differences in light distribution in the canopy, nitrogen distribution across biochemical compartments within the leaf and the different importance of the ear leaf between sole maize and intercropped maize. A lower maize RUE over the whole growing season in the intercrop as found in Chapters 3 and 4 may relate to nitrogen deficiency during grain filling stage. Those hypotheses can be tested by further studies, e.g. through the determination of nitrogen allocation within leaf and among leaf positions and other organs, and by measuring the leaf photosynthetic rates at different positions and ages, and by investigating water stress in sole crops and in intercrops. The current study mainly focuses on the inter- and intraspecific interactions and productivity at plant level. Physiological studies at organ level, as well as spatially explicit studies on belowground resource distribution and resource acquisition are needed to elucidate the underlying mechanisms. 
Chapter 5

\section{Acknowledgements}

We are grateful to Dr Xinyou Yin and Dr Herman Berghuijs for helpful discussions and comments for the manuscript, and to Ms. Guoyu Wang, Dr Junqi Zhu, Dr Yang Yu and Wageningen UR Unifarm staff for valuable help during the experiments. The financial support of the National Key Research and Development Program of China (2016YFD0300202), the China Scholarship Council (CSC), the Key Sino-Dutch Joint Research Project of NSFC (grant number: 31210103906) and the International Cooperation and Exchange of the National Science Foundation of China (31461143025) are gratefully acknowledged. 


\title{
Chapter 6
}

\section{On yield gains and yield gaps in intercropping: opportunities for increasing grain production in northwest China}

\author{
Fang Gou ${ }^{1,2}$, Wen Yin ${ }^{3}$, Yu Hong ${ }^{4}$, Wopke van der Werf $^{1}$, Qiang Chai ${ }^{3}$,
} Nico Heerink ${ }^{4}$, Martin K. van Ittersum ${ }^{2}$

${ }^{1}$ Centre for Crop Systems Analysis, Wageningen University, P.O. Box 430, 6700 AK Wageningen, The Netherlands

${ }^{2}$ Plant Production Systems group, Wageningen University, P.O. Box 430, 6700 AK Wageningen, The Netherlands

${ }^{3}$ College of Agronomy, Gansu agricultural university Lanzhou 730070, China

${ }^{4}$ Wageningen University, Development Economics Group, P.O. Box 8130, 6700 EW Wageningen, The Netherlands 


\title{
Chapter 6
}

\begin{abstract}
Wheat-maize intercropping has been widely used by farmers in northwest China and agronomists report it has a higher productivity than sole crops based on field experiments. However, the yields from farmers' fields have not been investigated yet. Yield gap analysis provides a framework to examine land productivity, i.e. the actual yields realized in farmers' fields versus the potential yields under optimum management. In this research, we aim to define yield potentials and yield gaps in strip intercropping systems, and apply this to an irrigated wheat-maize relay intercrop in Zhangye city, Gansu province in northwest China. Data from three years' field experiments (2010-2012) were used to calibrate and test crop models, for sole crops and intercrop. Potential yields were estimated for five years (2010-2014) by model simulations, and actual yields were determined by surveys of 310 farm households in 2013. The main results are: 1) in sole crops, the potential yield of spring wheat is $7.3 \mathrm{t}$ $\mathrm{ha}^{-1}$ and the potential yield of maize is $14.2 \mathrm{tha}^{-1} ; 2$ ) in wheat-maize intercrop with a land area ratio of 0.5 for each crop, the potential yield of wheat is $4.8 \mathrm{t} \mathrm{ha}^{-1}$ and that of maize is $12.0 \mathrm{tha}^{-1} ; 3$ ) comparing the yield in intercrop and the expected yield (i.e. the yield in sole crop multiplied by the land area ratio in intercrop for each species), the intercropped wheat gained 32\% under potential growing conditions and $67 \%$ under actual growing conditions; while the intercropped maize gained $69 \%$ under potential growing conditions and $64 \%$ under actual growing conditions; 4) farmers achieved $67 \%$ of potential yield for sole wheat, and $85 \%$ for intercropped wheat; however, farmers achieved only $51 \%$ of potential yield for sole maize and $49 \%$ for intercropped maize. The farm survey showed that wheatmaize relay intercropping is still widely used by farmers in Gaotai county, and farmers gained extra yield from wheat-maize intercrop compared to sole crops, but the gap between potential and actual yields is large especially for maize in this region. Water is likely to be the main limiting factor for maize production despite the irrigation. We conclude by exploring how grain production in Gaotai county would be affected by substituting intercropping by sole crops. We find that the grain production will decrease between $18 \%$ to $44 \%$ if all the farmers would replace wheat-maize relay intercrop by either wheat or maize sole crop compared to the current land use. Intercropping thus contributes to food production at the watershed level, and this contribution can be further increased by closing yield gaps.
\end{abstract}

Key words: potential yield, spring wheat, spring maize, intercrop model 


\subsection{Introduction}

The world faces the challenge of a population growing beyond 9 billion by 2050. It has been estimated that grain production must increase by ca. $60-70 \%$ to meet food requirements (Tilman et al., 2002; Alexandratos and Bruinsma, 2012). At the same time, modern agriculture is also responsible for enormous environmental impacts, including soil degradation, desertification and water pollution (Matson et al., 1997; Gregory et al., 2002). Thus, the development of more sustainable practice and intensification is urgent, and one potential strategy is intercropping (Lithourgidis et al., 2011a).

Intercropping is the cultivation of two or more crop species simultaneously in the same field for the whole or a part of their growing period (Willey, 1990). A meta-analysis showed that intercropping uses the land $22 \%$ more efficiently than corresponding sole crops (Yu et al., 2015). The main mechanism of high productivity of intercrops is complementary resource use in time and space among different species (Lithourgidis et al., 2007; Li et al., 2013; Bedoussac et al., 2015), and it has played an important role in both high and low input agriculture in Asia, Africa and Latin America (Vandermeer, 1989; Malézieux et al., 2009; Li et al., 2013). For example, it is reported that wheat-maize, wheat-soybean and wheat-cotton intercropping are widely used by farmers in China (Li et al., 2001b; Zhang et al., 2007; Li et al., 2013). However, in recent years, due to the increasing labour price and labour shift from rural areas to cities, a declining trend of intercropping has been reported (Feike et al., 2012). This could pose a risk to local food security as sole crops generally use land less efficiently than intercrops. Explorative land use studies perform quantitative analysis of different land use strategies to assess the sustainability of production, and to explore optimal land use strategies subject to different goals (van Ittersum et al., 1998). Such studies can reveal the role of intercrops in sustainable food systems in regions where intercrops have played or are playing an important role in food security.

Yield gap analysis aims to examine the productivity levels, i.e. the actual yields realized in farmers' fields, and to investigate the space for improvement by investing more inputs and better technologies (Simane et al., 1994; Bell et al., 1995; Laborte et al., 2012). Yield gaps have been investigated for rice, wheat and maize grain productions from regional to global scales (Neumann et al., 2010; Hochman et al., 2012; Mueller et al., 2012; van Ittersum et al., 2013), and a wide range of yield gaps are observed around the world, ranging from roughly 


\section{Chapter 6}

$20 \%$ to even $80 \%$ of yield potential (Lobell et al., 2009). Yield gaps have not been defined and quantified for intercropping systems.

The performance of intercropping is often evaluated by the land equivalent ratio (LER), which is calculated as the sum of the relative yields of component species in an intercrop as compared to their respective sole crops. The LER is interpreted as the area of sole crops that would be required to obtain the same yields of the component crops as a unit area of intercrop (Mead and Willey, 1980; Vandermeer, 1989). As LER is based on ratios comparing the intercrop yields to the sole crops yields, it is difficult to judge the production level by investigating LER, and this evaluation is only fair and possible when both sole crops and intercrop are grown under the same condition, for instance in well-managed field experiments. LER is often used by researchers to compare the productivity of sole crop and intercrop, but it is not an easy term to be understood by farmers and policy makers. A new approach is required to assess the performance of intercropping in farmers' fields, which is similar to yield gap analysis in sole crops. This approach should also be combined with concepts for assessing the potential increase in productivity by using intercropping.

Wheat and maize are two of world's three largest cereal crops (Fischer et al., 2012). In addition, winter wheat and spring maize double cropping system is the main crop system in northern China, especially in North China Plain (Liang et al., 2011; Dai et al., 2013; Ha et al., 2015). However, in northwest China, the thermal time is not sufficient to grow wheat and maize after each other in one growing season, while solar radiation is abundant (annually $6000 \mathrm{MJ} \mathrm{m}^{-2}$ ) and irrigation water is locally available from rivers that original from Qinghai province. Spring wheat and spring maize relay intercropping has been practiced by farmers in Gansu province since the 1960s (Li et al., 2001b). According to previous studies, the wheatmaize relay intercropping system has substantial yield advantages compared to sole crops, with an average LER of 1.37 in field experiments in this region (Li et al., 2001b; Song et al., 2006; Yang et al., 2011; Mu et al., 2013). However, the potential yields and farmers yields of wheat and maize in intercrops have not been studied. Water shortage is the main constraint of agricultural production in this region and could be an important reason for differences between potential and actual farmers' yields. In Zhangye city, the yearly precipitation is about $160 \mathrm{~mm}$, and agricultural production depends on the snowmelt from Qilian Mountains. However only $50 \%$ of the farmland is well irrigated, and much arable land has been abandoned due to water shortage (Zhang et al., 2014). In addition, there are other land use 
options that may be more economically attractive to farmers than intercropping grain crops, such as seed crops, including watermelon, cabbage and maize. These seed crops are competing with land for grain productions. Thus, the share of land for grain production is currently less than $40 \%$ in all counties in Zhangye city (Shi et al., 2014). Furthermore, wheatmaize intercrop has recently disappeared in farmers' fields in Wuwei city due to changes in local water management policy, while this region used to be an important grain producer in China. Thus the effect of changes in land use and cropping systems on grain production needs to be investigated.

In this research, we aim to develop new methods to assess farmers' yields in intercropping, to investigate potential yields and yield gaps of wheat and maize in sole crops and in intercrop in northwest China, and to investigate how grain production would change if intercropping was abandoned by the farmers.

\subsection{Methods and Materials}

\subsubsection{Concepts}

\subsubsection{Potential yield in sole crop and in intercrop}

In a sole crop, potential yield ( $Y_{\mathrm{p}}$ in Table 6.1) is defined as the yield of an adapted crop cultivar when grown with water and nutrients non-limiting and biotic stress effectively controlled (Evans, 1993; van Ittersum and Rabbinge, 1997). Similarly, in intercrop, the potential yields $\left(I Y_{\mathrm{p}}\right.$ in Table 6.1) are the yields of all the component species that may be attained in a given crop combination and planting pattern, under non-limiting resource inputs, and management. The potential yield of the intercrop is a set of yield combinations for all component crop species in this intercrop, and it depends on the sowing densities of the crops and their planting configuration. An increase in yield of one species will often be accompanied by a decrease in the yield of the other (due to competition for light, even under otherwise non-limiting provision with water and nutrients). These potential yields can be obtained by crop model simulations or estimated from well managed field experiments or best farmers' practice (Lobell et al., 2009; van Ittersum et al., 2013). The actual yield is defined as the yield actually achieved in a farmers' fields ( $Y_{\mathrm{a}}$ for sole crops, and $I Y_{\mathrm{a}}$ for intercrops); it is usually obtained by farm surveys or on-farm measurements. 


\section{Chapter 6}

In this study, we consider an intercrop with two species, crop 1 and 2, which are grown with land area ratio $R^{1}$ and $R^{2}$. The land area ratio is determined by the sowing density and configuration. If the intercrop is arranged by strips, the land area ratio of each species is calculated by the strip width of each species:

$R^{1}=\frac{S^{1}}{S^{1}+S^{2}}$

$R^{2}=\frac{S^{2}}{S^{1}+S^{2}}$

where $S^{1}$ is the strip width of crop species 1 in intercrop, and $S^{2}$ is the strip width of crop species 2 in intercrop. The sum of land area ratio of two species is one: $R^{1}+R^{2}=1$.

If the intercrop is a full mixture, it is calculated by the relative sowing density $(R D)$ as follows:

$R D^{1}=\frac{I D^{1}}{D^{1}}$

$R D^{2}=\frac{I D^{2}}{D^{2}}$

where $R D^{1}$ is the relative density of crop species 1 in intercrop, and $I D^{1}$ is the sowing density of crop species 1 in intercrop and $D^{1}$ is the sowing density of crop species 1 in sole crop, and similarly for $R D^{2}$.

If $R D^{1}+R D^{2}=1$, then, $R^{1}=R D^{1}$ and $R^{2}=R D^{2}$. If $R D^{1}+R D^{2} \neq 1$, then $R^{1}=\frac{R D^{1}}{R D^{1}+R D^{2}}$ and $R^{2}=\frac{R D^{2}}{R D^{1}+R D^{2}}$, where $R D^{1}+R D^{2}$ is relative density total (RDT).

\subsubsection{Expected yield in intercrop}

Under the null hypothesis of no advantage or disadvantage of intercrop, crop plants grow the same in intercrops as in sole crops. The yield of each species in intercrop is proportional to the land area ratio of each species, namely expected yield. When the term is used for potential growing conditions, it is called expected potential yield ( $E Y_{\mathrm{p}}$ in Table 6.1), and when is used for actual growing conditions, it is expected actual yield ( $E Y_{\mathrm{a}}$ in Table 6.1), and they are calculated as: 
$E Y_{\mathrm{p}}^{i}=Y_{\mathrm{p}}^{i} \times R^{i}$

$E Y_{\mathrm{a}}^{i}=Y_{\mathrm{a}}^{i} \times R^{i}$

where $E Y_{\mathrm{p}}{ }^{i}$ is the expected potential yield for crop species $i$, and $Y_{\mathrm{p}}{ }^{i}$ is the potential yield for species $i$ in sole crop, and $R^{i}$ is the land area ratio for species $i$ in intercrop; $E Y_{\mathrm{a}}{ }^{i}$ is the expected actual yield for crop species $i$, and $Y_{\mathrm{a}}^{i}$ is the actual yield for species $i$ in sole crop.

\subsubsection{Yield gain in intercrop}

Due to complementarity in using resources among species and the differences in inter- and intra-specific competition, crop growth and development may differ under intercropping conditions compared to sole crop conditions, and thus the yields in an intercrop per unit sowing area may differ from the expected yields of the respective crops. The purpose of intercropping is to achieve additional yield by exploring species complementarities. We therefore define the difference between the yield in intercrop and the expected yield as yield gain. When the yield gain is evaluated under potential conditions, we define the yield gain as potential yield gain ( $\Delta Y_{\mathrm{p}}$ in Table 6.1), when farmers' yields are evaluated, we define it as actual yield gain $\left(\Delta Y_{\mathrm{a}}\right.$ in Table 6.1). $\Delta Y_{\mathrm{p}}$ and $\Delta Y_{\mathrm{a}}$ are calculated as:

$\Delta Y_{\mathrm{p}}^{i}=I Y_{\mathrm{p}}^{i}-E Y_{\mathrm{p}}^{i}$

$\Delta Y_{\mathrm{a}}^{i}=I Y_{\mathrm{a}}^{i}-E Y_{\mathrm{a}}^{i}$

where $\Delta Y_{\mathrm{p}}{ }^{i}$ is the potential yield gain for crop species $i, I Y_{\mathrm{p}}{ }^{i}$ is the potential yield for species $i$ in intercrop, and $E Y_{\mathrm{p}}{ }^{i}$ is the expected potential yield for species $i ; \Delta Y_{\mathrm{a}}^{i}$ is the actual yield gain for crop species $i, I Y_{\mathrm{a}}{ }^{i}$ is the actual yield for species $i$ in intercrop, and $E Y_{\mathrm{a}}{ }^{i}$ is the expected actual yield for species $i$. The potential yield gain answers the question how much more yield can be potentially (i.e. under potential growing condition) achieved by changing sole crops to intercrops, while the actual yield gain answers the question how much more yield is actually achieved by growing intercrops instead of sole crops.

The yield gain is positive when the intercrop yield (per unit of whole intercrop area) is higher than the expected yield, and negative when lower than expected yield. The negative yield gain is also called yield loss. A positive yield gain shows this intercropped component benefits from intercropping via complementary resource usage. A negative yield gain, or yield loss 


\section{Chapter 6}

shows this intercropped component experienced more severe competition in the intercrop than in sole crops. In an intercrop, a good species combination may result in a positive yield gain for both species, while a poor species combination may result in negative yield gain for both species.

\subsubsection{Yield gap}

Yield gap is defined as the difference between potential yield and actual yield in sole crops (van Ittersum and Rabbinge, 1997; Lobell et al., 2009; van Ittersum et al., 2013). Similarly in intercrops, the yield gap is the difference between potential yield and actual yield for each component species, and they are calculated as:

$Y_{\mathrm{g}}^{i}=Y_{\mathrm{p}}^{i}-Y_{\mathrm{a}}^{i}$

$I Y_{\mathrm{g}}^{i}=I Y_{\mathrm{p}}^{i}-I Y_{\mathrm{a}}^{i}$

where $Y_{\mathrm{g}}{ }^{i}$ is the yield gap for crop $i$ in sole crop, $Y_{\mathrm{p}}{ }^{i}$ is potential yield for crop $i$ in sole crop, and $Y_{\mathrm{a}}{ }^{i}$ is the actual yield for crop $i ; I Y_{\mathrm{g}}{ }^{i}$ is the yield gap for crop $i$ in intercrop, $I Y_{\mathrm{p}}{ }^{i}$ is the potential yield for crop $i$ in intercrop and $I Y_{\mathrm{a}}{ }^{i}$ is the actual yield for crop $i$ in intercrop. The yield gap in a sole crop answers the question how much more yield can be achieved by improving management in the sole crop, while the yield gap in intercrop answers the question how much more yield can be achieved by improving management in the intercrop for a given planting configuration. The notations of the definitions are shown in Table 6.1 and illustrated in Fig. 6.1.

Table 6.1 Concepts and notation for potential yield, actual yield, expected yield, yield gain and yield gap in sole crop and intercrop

\begin{tabular}{lllll}
\hline \multirow{2}{*}{ Concept } & \multicolumn{2}{c}{ Sole crop } & \multicolumn{2}{c}{ Intercrop } \\
\cline { 2 - 5 } & Crop 1 & Crop 2 & Crop 1 & Crop 2 \\
\hline Land area ratio & 1 & 1 & $R^{1}$ & $R^{2}$ \\
Potential yield & $Y_{\mathrm{p}}{ }^{1}$ & $Y_{\mathrm{p}}{ }^{2}$ & $I Y_{\mathrm{p}}{ }^{1}$ & $I Y_{\mathrm{p}}{ }^{2}$ \\
Expected potential yield & & & $E Y_{\mathrm{p}}{ }^{1}$ & $E Y_{\mathrm{p}}{ }^{2}$ \\
Potential yield gain & & & $\Delta Y_{\mathrm{p}}{ }^{1}$ & $\Delta Y_{\mathrm{p}}{ }^{2}$ \\
\hline Actual yield & $Y_{\mathrm{a}}{ }^{1}$ & $Y_{\mathrm{a}}{ }^{2}$ & $I Y_{\mathrm{a}}{ }^{1}$ & $I Y_{\mathrm{a}}{ }^{2}$ \\
Expected actual yield & & & $E Y_{\mathrm{a}}{ }^{1}$ & $E Y_{\mathrm{a}}{ }^{2}$ \\
Actual yield gain & & & $\Delta Y_{\mathrm{a}}{ }^{2}$ & $\Delta Y_{\mathrm{a}}{ }^{2}$ \\
\hline Yield gap & $Y_{\mathrm{g}}{ }^{1}$ & $Y_{\mathrm{g}}{ }^{2}$ & $I Y_{\mathrm{g}}{ }^{1}$ & $I Y_{\mathrm{g}}{ }^{2}$ \\
\hline
\end{tabular}

Explanation for descriptors: $R$ is for "ratio", $Y$ is for "yield", $E$ is for "expected", $\mathrm{p}$ is for "potential", a is for "actual", $I$ is for "intercrop", $g$ is for "gap", and $\Delta$ is for "yield gain". 

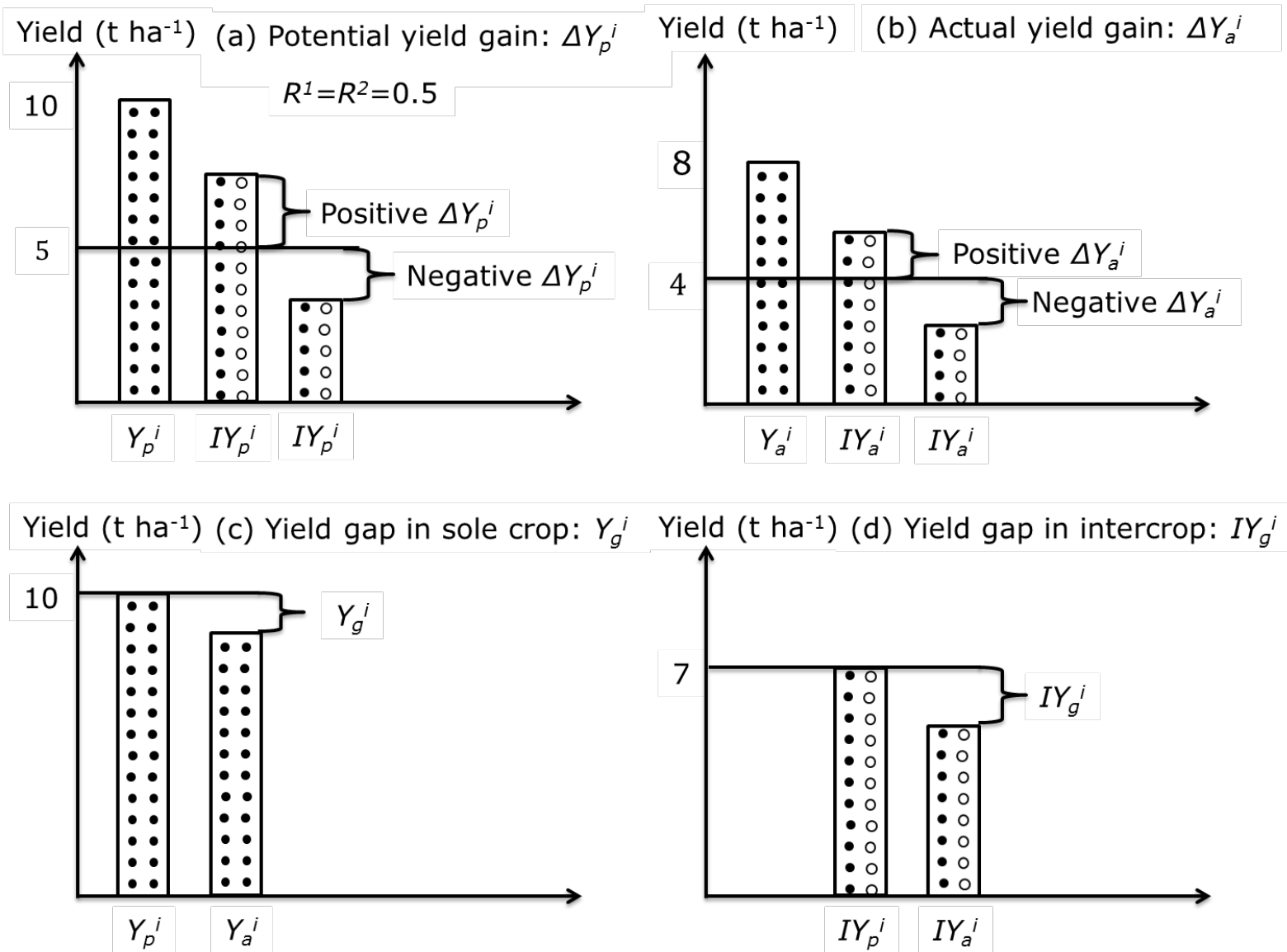

Fig. 6.1 Illustration of potential yield, actual yield, expected yield, yield gain and yield gap in a sole crop and the corresponding species $i$ in the intercrop. The index $i$ can take the value 1 or 2. The bar with closed dots denotes the yield of sole crop $i$, and the bar with empty and closed dots denotes the yield of crop $i$ in intercrop.

\subsubsection{Field Experiments}

\subsubsection{Experimental site}

Data collected from three-years' field experiments were used to calibrate and test a sole crop and an intercrop model. The experiments were conducted in the growing seasons of 2010 2012 at the Gansu Agricultural University Research Station, in Wuwei, China $\left(37^{\circ} 96^{\prime} \mathrm{N}\right.$, $\left.102^{\circ} 64^{\prime} \mathrm{E}\right)$. The climate is arid with annual mean temperature $7.2^{\circ} \mathrm{C}$, a frost-free period of 156 days, precipitation about $160 \mathrm{~mm}$, solar radiation of $6000 \mathrm{MJ} \mathrm{m}^{-2}$ and ca. $3000 \mathrm{~h}$ sunshine per year (data are averaged for the period from 1960 to 2009) (Hu et al., 2016). The soil was classified as an Aridisol with a bulk density of $1.40 \mathrm{~g} \mathrm{~cm}^{-3}$. Total nitrogen, phosphorus and organic matter in the top soil $(0-60 \mathrm{~cm})$ are $0.78 \mathrm{~g} \mathrm{~kg}^{-1}, 1.14 \mathrm{~g} \mathrm{~kg}^{-1}$ and $14.3 \mathrm{~g} \mathrm{~kg}^{-1}$, respectively (Yang et al., 2011; Mu et al., 2013; Hu et al., 2016). 


\section{Chapter 6}

\subsubsection{Experimental set up and field management}

The experiments were designed to contrast the intercrop with sole crops: sole wheat (SW) and sole maize (SM) and wheat-maize intercrop (6:2WM). Sole wheat was sown in rows at a row distance of $0.12 \mathrm{~m}$. The overall density was 675 plants $\mathrm{m}^{-2}$. Sole maize was sown in rows at a row distance of $0.4 \mathrm{~m}$, with an overall density of 8.25 plants $\mathrm{m}^{-2}$. In intercrop, six rows wheat were sown as strips at a row distance of $0.12 \mathrm{~m}$, and two rows of maize were sown between wheat strips at a row distance of $0.4 \mathrm{~m}$; the distance of adjacent wheat and maize plants was $0.3 \mathrm{~m}$ (Fig. 6.2). The wheat strip is assumed to take $80 \mathrm{~cm}$ width in one intercrop strip (160 $\mathrm{cm})$, and the same for the maize strip. Thus the land area ratio for wheat and maize is $0.5\left(R^{1}\right.$ $\left.=R^{2}=0.5\right)$. The overall density for intercropped wheat was 375 plants $\mathrm{m}^{-2}$, and for maize was 5.25 plants $\mathrm{m}^{-2}$. This intercrop is an argumentative design in terms of sowing density, the relative density of wheat is 0.56 (i.e. sowing density of wheat in intercrop divided by the sowing density of wheat in sole crop: $375 / 675$ ), and the relative density of maize is 0.64 (i.e. sowing density of maize in intercrop divided by the sowing density of maize in sole crop: 5.25/8.25), and the relative density total is 1.2 (i.e. the sum of relative density of wheat and maize). Wheat was sown in late March and harvested mid-July, while maize was sown in late April and harvested in late September or early October. The wheat variety "Yongliang 4" and maize variety "Wuke 2" were used, the plot size was $48 \mathrm{~m}^{2}$ ( $4.8 \mathrm{~m}$ width and $10 \mathrm{~m}$ length) for both sole crops and intercrop treatments. Plastic film was used after maize sowing for the maize strips to increase soil temperature and moisture and to suppress weeds.

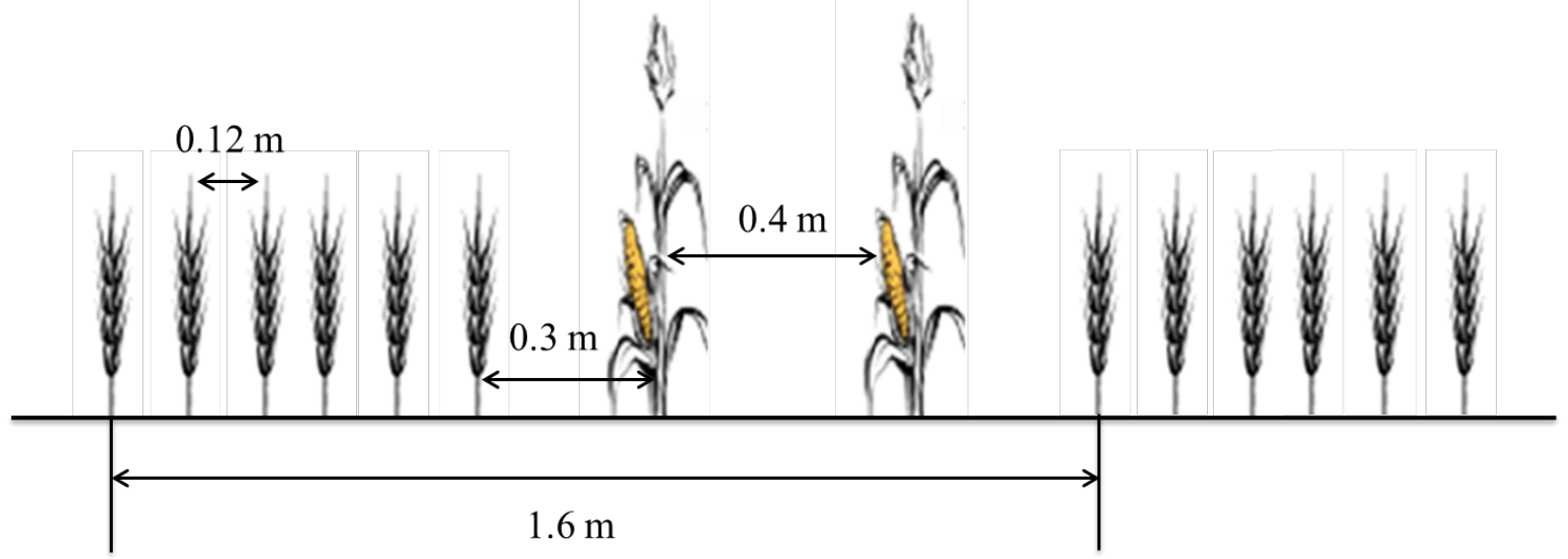

Fig. 6.2 Illustration of wheat-maize intercrop configuration. 
Crop management in the experiments targeted avoidance of nutrient and water stress, as well as the control of yield reducing factors through adequate weed, pest and disease management. Irrigation was supplied to sole wheat three times during growing the season, and the total irrigation amount was $360 \mathrm{~mm}$ (including $120 \mathrm{~mm}$ winter irrigation in mid-November before frozen). Irrigation was supplied to sole maize five times during growing season, with a total irrigated amount of $525 \mathrm{~mm}$ (including $120 \mathrm{~mm}$ winter irrigation). Irrigation was supplied six times to intercrop, and the total irrigation amount was $600 \mathrm{~mm}$ (including $120 \mathrm{~mm}$ winter irrigation) (Table C1, Appendix C). Nitrogen and phosphorus fertilizer were applied manually to sole crops and intercrop, the nitrogen rates were $225 \mathrm{~kg} \mathrm{~N}^{-1}$ for sole wheat, $450 \mathrm{~kg} \mathrm{~N}^{-}$ ${ }^{1}$ for sole maize and $338 \mathrm{~kg} \mathrm{~N} \mathrm{ha}^{-1}$ for intercrop, respectively. The phosphorus rate was $150 \mathrm{~kg}$ $\mathrm{P}_{2} \mathrm{O}_{5}$ ha $^{-1}$ for all cropping systems (Table C2, Appendix C).

\subsubsection{Leaf area dynamics, biomass accumulation and plant height determination}

The leaf area index and above-ground biomass were measured five times during the growing season for sole and intercropped wheat, and eight times for sole and intercropped maize in each of the three years. Wheat was sampled at tillering, shooting, flowering, grain filling and dough maturity. At each periodic harvest, 25 wheat plants were randomly taken from five locations in each plot; at the final harvest, six rows of wheat and 2 meters of each row were harvested to determine the final yield. The leaf length and width of each green leaf were measured by a ruler, and the leaf area was estimated by the product of leaf length and width with a shape coefficient 0.83 (Miralles and Slafer, 1991; Zhang et al., 2008). Maize was sampled at the growing stages of seeding, three mature leaves, five mature leaves, seven mature leaves, silking, grain filling, dough-maturity and full-maturity. Before maize shooting, 10 maize plants were randomly taken from five locations in each plot, and after maize shooting 5 maize plants were randomly taken from five locations in each plot, at final harvest, two rows of maize and 2 meters for each row were harvested to determine the final yield. The maize leaf area was measured similarly as for wheat, using a shape coefficient of 0.75 . Finally, the leaves, stems and ears were dried at $80{ }^{\circ} \mathrm{C}$ for 72 hours to determine dry matter. Plant height was measured at the same day of periodic harvests for wheat and maize. 


\section{Chapter 6}

\subsubsection{Model calibration and testing}

The calibration procedure followed the calibration protocol in Chapter 4 for sole crops and intercrop. The phenological development was calibrated using the observations of development stages, i.e. the average of three years observations (Tables C3, C4 and C5, Appendix C). The radiation use efficiencies (RUEs) were calibrated as a 'closure' parameter for each year individually (Chapter 4). The nonlinear least-squares (NLS) method was applied to find the best values for RUEs, using the "nls" function in R (Wallach et al., 2013; R Core Team, 2015). The calibrated RUEs are shown in Table C6 (Appendix C), and then the mean values of the three years were applied to test the performance of models by comparing the simulated values to the observed values (Figs C1 and C2, Appendix C). Except for RUE, all other parameter values were kept the same for sole and intercrop.

\subsubsection{Farm survey}

A farm survey was conducted in 2014 covering 360 farm households in 5 villages located in Gaotai county, Zhangye city, Gansu, northwest China. This county is located in northwest of Wuwei city with distance of $400 \mathrm{~km}$, Wuwei is the place where the field experiments were conducted. The two cities both belong to Hexi Corridor and have similar climate. This survey was part of a Heihe river survey, conducted by the survey teams from Northwest Agriculture and Forestry University, Yangling and the University of the Chinese Academy of Sciences, Beijing. The five villages, Luocheng, Huaqiangzi, Hexi, Dingpin and Heiquan, were selected because wheat-maize intercropping is commonly used by farmers. Interviews with the farmers were conducted face-to-face and questions designed for capturing farm household agricultural production, consumption and expenditure. In this region, wheat and maize are the major crops, and the minor crops are beans, cotton, rapeseed, lettuce and watermelon. On average, the farm size is 0.72 ha with 9 field plots. In these 360 farm households, 310 out of the 360 farm households cultivated sole wheat, sole maize, and/or wheat-maize intercrop (Table 6.2). Yields of wheat and maize in sole crop and intercrop were the focus, and farmers' reported yields were converted to dry matter to compare with simulated yields. Moisture contents of $13.5 \%$ for wheat and $15.5 \%$ for maize were used (http://www.yieldgap.org/web/guest/ methods-actual-yield). The intercrop planting configuration in farmers' fields was similar to the field experimental design (Fig. 6.2), wheat strip width is $80 \mathrm{~cm}$, and the same for maize. Thus the land area ratios $R^{1}$ and $R^{2}$ were 0.5 in the wheat-maize intercropping system under actual growing conditions. 
Table 6.2 Number of farms which cultivated sole wheat, sole maize, and/or wheat-maize intercrop

\begin{tabular}{ll}
\hline Cropping systems & Farm households \\
\hline Sole wheat only & 36 \\
Sole maize only & 18 \\
Sole wheat and sole maize & 18 \\
\hline Intercrop only & 192 \\
Sole wheat and intercrop & 10 \\
Sole maize and intercrop & 33 \\
Sole wheat, sole maize and intercrop & 3 \\
\hline Total & 310 \\
\hline
\end{tabular}

\subsubsection{Data analysis}

The normality, skewness and kurtosis of farmers' yields distributions were determined. The normality of data was tested by the Shapiro-Wilks test in R (R Core Team, 2015), and the skewness and kurtosis were calculated as (Crawley, 2012):

skewness $=\frac{m_{3}}{S_{3}}$

kurtosis $=\frac{m_{4}}{s_{4}}$

where $m_{3}$ is the third moment about the mean, and $S_{3}$ the cube of the standard deviation of the data; $m_{4}$ is the fourth moment about the mean, and $S_{4}$ the square of the variation.

The skewness measures the extent to which a distribution has long tail on one side or the other, a normal distribution is symmetrical and has a skewness of 0 . Negative values of skewness mean skew to the left and positive values mean skew to the right. The kurtosis is a measure of non-normality that has to do with the peakiness, or flat-toppedness of a distribution. The flat-topped distribution is platykurtic, while a pointy distribution is leptokurtic. A normal distribution has a kurtosis of 3, while a flat topped (platykurtic) distribution has a kurtosis value smaller than 3 , and a pointy (leptokurtic) distribution has a kurtosis value larger than 3 .

\subsubsection{Explorative land use studies}

With the farm survey data, we compared the grain production under four land use strategies to the current land use. The current land use is the proportion of land used for sole wheat, sole 


\section{Chapter 6}

maize and intercrop based on the farm survey, and the four scenarios are: S1: all land is cultivated with sole wheat; S2: all land is cultivated with sole maize; S3: $50 \%$ of the land is cultivated with sole wheat and 50\% with sole maize; S4: $100 \%$ of the land is cultivated with wheat-maize intercrop. First we assumed that each interviewed farm is 0.8 ha of land (the averaged farm size is 0.73 from farm survey), and it is used for wheat and maize, either for sole crop or intercrop. If the farm only has sole wheat, the cultivated area is 0.8 ha for sole wheat, and zero for others; if the farm has both sole wheat and sole maize, then the cultivation area is 0.4 ha for each, and similarly for other options. This is a simplified land use, as in reality farmers also cultivate some other crops, including beans, rapeseed, cotton, lettuce and watermelon. Secondly, the total wheat yield and maize yield are calculated with the cultivated areas and average actual yields in sole crops and in intercrop. Finally, four different land use scenarios are investigated for yields, calories and gross income. The caloric value of wheat is 339 calories per 100 gram, and the caloric value of maize is 365 calories per 100 gram. The price of wheat is 2.8 Yuan per $\mathrm{kg}$, and the price of maize is 2.6 Yuan per $\mathrm{kg}$ from survey in 2014. Calories are calculated as the sum of wheat calories and maize calories in each land use scenario, and similarly for gross income.

\subsection{Results:}

\subsubsection{Potential yields in sole crops and in intercrop}

The potential yield of wheat in the five years varied from 6.7 to $8.3 \mathrm{t} \mathrm{ha}^{-1}$ in sole crop, and from 4.3 to $5.9 \mathrm{t} \mathrm{ha}^{-1}$ in intercrop; the potential yield of maize varied from 12.8 to $15.6 \mathrm{t} \mathrm{ha}^{-1}$ in sole crop, and from 10.7 to $13.3 \mathrm{t} \mathrm{ha}^{-1}$ in intercrop. Intercropped wheat had a lower harvest index (HI) than sole wheat, while intercropped maize had a higher HI than sole maize (Table $6.3)$.

\subsubsection{Farmers' actual yield}

Generally, farmers' yields varied a lot (Fig. 6.3). The mean actual yield in farmers' fields was $4.9 \mathrm{t} \mathrm{ha}^{-1}$ for sole wheat, $7.2 \mathrm{t} \mathrm{ha}^{-1}$ for sole maize, $4.1 \mathrm{t} \mathrm{ha}^{-1}$ for intercropped wheat, and $5.9 \mathrm{t}$ $\mathrm{ha}^{-1}$ for intercropped maize (Table 6.4). The minimum yield was found in intercropped maize, $0.6 \mathrm{t} \mathrm{ha}^{-1}$, while the maximum yields were found in sole maize, $11.4 \mathrm{t} \mathrm{ha}^{-1}$ (Table 6.4). 
Table 6.3 Potential yields of wheat and maize in sole crop and intercrop by model simulations from year 2010 to 2014 (values in the brackets are observations from field experiments in Wuwei from 2010 to 2012).

\begin{tabular}{|c|c|c|c|c|c|c|c|}
\hline \multirow{2}{*}{ Year } & \multirow{2}{*}{ Treatment } & \multicolumn{3}{|c|}{ Wheat } & \multicolumn{3}{|c|}{ Maize } \\
\hline & & Biomass $\left(\mathrm{t} \mathrm{ha}^{-1}\right)$ & Yield $\left(\mathrm{t} \mathrm{ha}^{-1}\right)$ & HI & Biomass $\left(\mathrm{t} \mathrm{ha}^{-1}\right)$ & Yield $\left(\mathrm{t} \mathrm{ha}^{-1}\right)$ & $\mathrm{HI}$ \\
\hline \multirow{3}{*}{2010} & SW & $\begin{array}{c}15.7 \\
(16.5)\end{array}$ & $\begin{array}{c}6.9 \\
(6.6)\end{array}$ & $\begin{array}{l}0.44 \\
(0.40)\end{array}$ & - & - & - \\
\hline & SM & - & - & - & $\begin{array}{l}27.7 \\
(26.8)\end{array}$ & $\begin{array}{l}12.8 \\
(11.5)\end{array}$ & $\begin{array}{c}0.46 \\
(0.43)\end{array}$ \\
\hline & $6: 2 \mathrm{WM}$ & $\begin{array}{c}11.2 \\
(14.2)\end{array}$ & $\begin{array}{l}4.3 \\
(5.2) \\
\end{array}$ & $\begin{array}{l}0.38 \\
(0.36)\end{array}$ & $\begin{array}{c}21.3 \\
(21.0) \\
\end{array}$ & $\begin{array}{l}10.7 \\
(9.1) \\
\end{array}$ & $\begin{array}{r}0.50 \\
(0.43) \\
\end{array}$ \\
\hline \multirow{3}{*}{2011} & SW & $\begin{array}{c}16.3 \\
(15.7)\end{array}$ & $\begin{array}{c}7.3 \\
(6.4)\end{array}$ & $\begin{array}{l}0.45 \\
(0.41)\end{array}$ & - & - & - \\
\hline & SM & - & - & - & $\begin{array}{c}29.7 \\
(28.6)\end{array}$ & $\begin{array}{c}13.7 \\
(12.7)\end{array}$ & $\begin{array}{c}0.46 \\
(0.44)\end{array}$ \\
\hline & $6: 2 \mathrm{WM}$ & $\begin{array}{c}12.0 \\
(13.3) \\
\end{array}$ & $\begin{array}{c}4.8 \\
(4.9) \\
\end{array}$ & $\begin{array}{c}0.40 \\
(0.37) \\
\end{array}$ & $\begin{array}{c}23.1 \\
(23.6) \\
\end{array}$ & $\begin{array}{l}11.6 \\
(9.8) \\
\end{array}$ & $\begin{array}{r}0.50 \\
(0.42) \\
\end{array}$ \\
\hline \multirow{3}{*}{2012} & SW & $\begin{array}{c}16.3 \\
(16.6)\end{array}$ & $\begin{array}{c}7.3 \\
(6.2)\end{array}$ & $\begin{array}{c}0.45 \\
(0.37)\end{array}$ & - & - & - \\
\hline & SM & - & - & - & $\begin{array}{l}33.0 \\
(28.8)\end{array}$ & $\begin{array}{c}15.6 \\
(11.7)\end{array}$ & $\begin{array}{c}0.47 \\
(0.40)\end{array}$ \\
\hline & $6: 2 \mathrm{WM}$ & $\begin{array}{c}12.0 \\
(13.2)\end{array}$ & $\begin{array}{c}4.8 \\
(4.5) \\
\end{array}$ & $\begin{array}{c}0.40 \\
(0.34) \\
\end{array}$ & $\begin{array}{c}25.9 \\
(23.1) \\
\end{array}$ & $\begin{array}{l}13.3 \\
(9.9) \\
\end{array}$ & $\begin{array}{c}0.51 \\
(0.43) \\
\end{array}$ \\
\hline \multirow{3}{*}{2013} & SW & 15.5 & 6.7 & 0.43 & - & - & - \\
\hline & SM & - & - & - & 29.4 & 13.7 & 0.47 \\
\hline & $6: 2 \mathrm{WM}$ & 11.8 & 4.5 & 0.39 & 22.6 & 11.4 & 0.51 \\
\hline \multirow{3}{*}{2014} & SW & 19.1 & 8.3 & 0.43 & - & - & - \\
\hline & SM & - & - & - & 33.1 & 15.2 & 0.46 \\
\hline & $6: 2 \mathrm{WM}$ & 15.1 & 5.9 & 0.39 & 26.0 & 13.0 & 0.50 \\
\hline \multirow{3}{*}{ Mean } & SW & 16.6 & 7.3 & 0.44 & - & - & - \\
\hline & SM & - & - & - & 30.6 & 14.2 & 0.46 \\
\hline & $6: 2 \mathrm{WM}$ & 12.4 & 4.8 & 0.39 & 23.8 & 12.0 & 0.50 \\
\hline
\end{tabular}

Table 6.4 The minimum, median, mean and maximum yields $\left(\mathrm{t} \mathrm{ha}^{-1}\right)$ in farmers' fields for wheat and maize in sole crop and in intercrop

\begin{tabular}{lllllll}
\hline Treatment & Min & $5 \%$ quantile & Median & Mean & 95\% quantile & Max \\
\hline Sole wheat & 1.9 & 3.2 & 5.2 & 4.9 & 6.5 & 7.8 \\
Sole maize & 3.8 & 5.1 & 6.3 & 7.2 & 10.3 & 11.4 \\
Intercropped wheat & 0.8 & 3.2 & 3.9 & 4.1 & 5.2 & 6.5 \\
Intercropped maize & 0.6 & 4.4 & 6.3 & 5.9 & 7.6 & 10.1 \\
\hline
\end{tabular}

Table 6.5 Yield gain under potential and actual condition for wheat-maize intercrop (percentage yield gain is calculated as the \% yield gain relative to the expected yield).

\begin{tabular}{ccccccc|cccccc}
\hline \multicolumn{7}{l|}{ Under potential growing condition } & \multicolumn{5}{c}{ Under actual growing condition } \\
\hline Crop & $Y_{\mathrm{p}}{ }^{i}$ & $R^{i}$ & $E Y_{\mathrm{p}}{ }^{i}$ & $I Y_{\mathrm{p}}{ }^{i}$ & $\Delta Y_{\mathrm{p}}{ }^{i}$ & $\begin{array}{c}\text { Percentage } \\
\text { yield gain }\end{array}$ & $Y_{\mathrm{a}}{ }^{i}$ & $R^{i}$ & $E Y_{\mathrm{a}}{ }^{i}$ & $I Y_{\mathrm{a}}{ }^{i}$ & $\Delta Y_{\mathrm{a}}{ }^{i}$ & $\begin{array}{c}\text { Percentage } \\
\text { yield gain }\end{array}$ \\
\hline Wheat & 7.3 & 0.5 & 3.7 & 4.8 & 1.1 & $32 \%$ & 4.9 & 0.5 & 2.5 & 4.1 & 1.6 & $67 \%$ \\
Maize & 14.2 & 0.5 & 7.1 & 12.0 & 4.9 & $69 \%$ & 7.2 & 0.5 & 3.6 & 5.9 & 2.3 & $64 \%$ \\
\hline
\end{tabular}




\section{Chapter 6}

\subsubsection{Yield gain of intercrop}

All farmers used the same configuration (six rows of wheat altering with two rows of maize) in this region. Thus the expected yields were half of the sole crops for wheat and maize under potential and actual conditions. Comparing intercrop to sole crop, the yield gain under potential growing conditions (using simulations) was low for wheat $\left(1.1 \mathrm{t} \mathrm{ha}^{-1}\right)$ but high for maize $\left(4.9 \mathrm{t} \mathrm{ha}^{-1}\right)$. In farmers' fields, intercropped wheat gained $1.6 \mathrm{t} \mathrm{ha}^{-1}$ and intercropped maize gained $2.3 \mathrm{t} \mathrm{ha}^{-1}$ (Table 6.5).
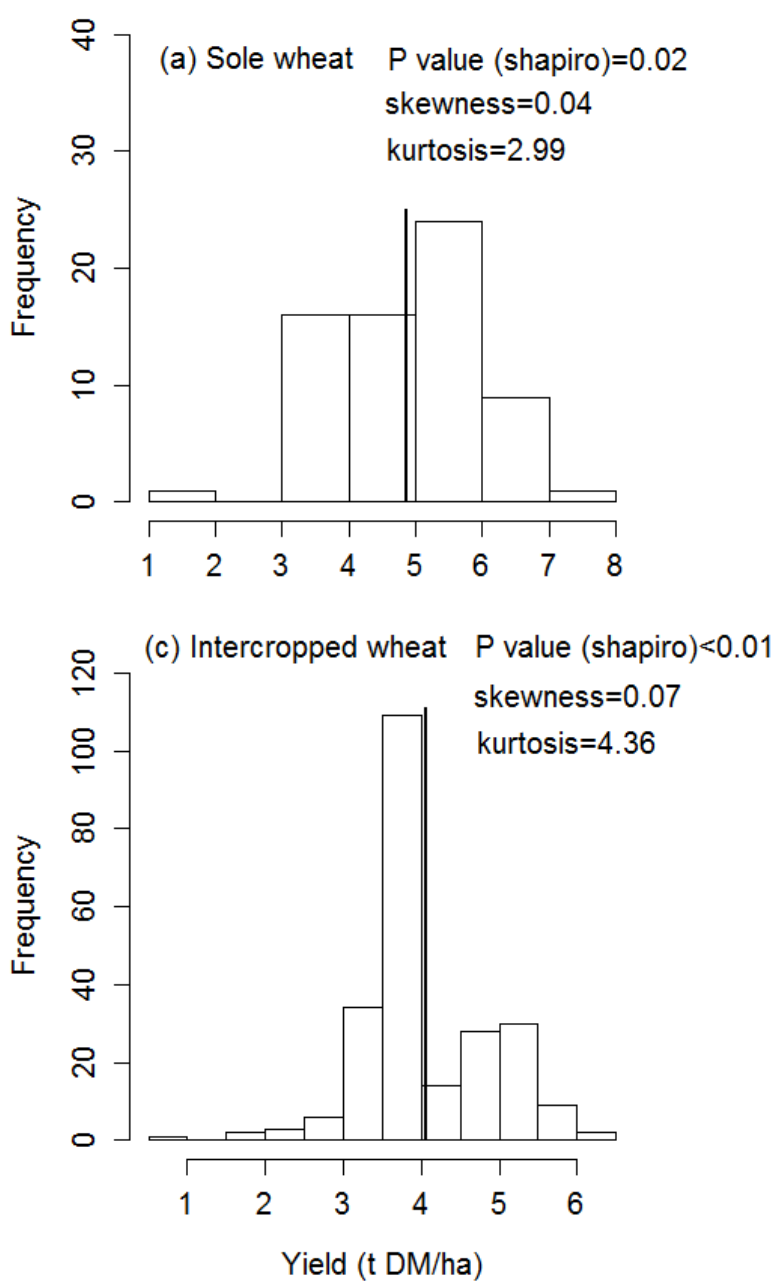

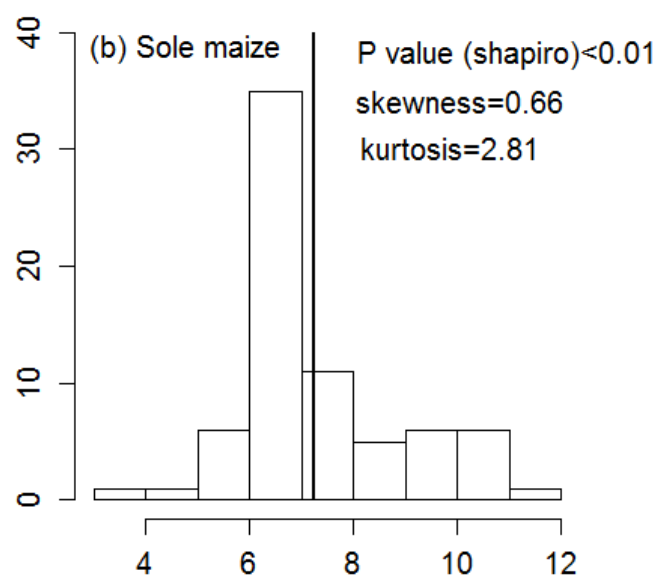

(d) Intercropped maize $P$ value (shapiro) $<0.01$

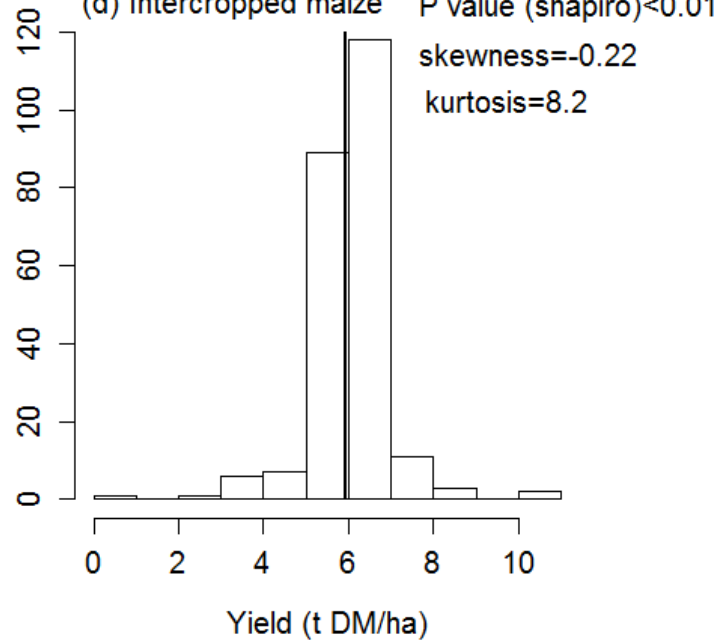

Fig. 6.3 Histogram of farmers' yields in wheat and maize sole crops and intercrop. For the yields of sole wheat, the hypothesis that they are distributed normally could not be rejected $(\mathrm{p}>0.01)$. The other yields had $\mathrm{p}$-values smaller than 0.01 from the Shapiro-Wilks test, implying that the normal distribution hypothesis should be rejected. The yields of sole maize and intercropped wheat had positive skewness, while the yields of intercropped maize had a negative skewness value. The yields of sole maize had a kurtosis smaller than 3 (platykurtic), while the yields of intercropped wheat and intercropped maize had kurtosis values larger than 3 (leptokurtic). 


\subsubsection{Yield gap}

By comparing the simulated potential yields with the average farm yields, the yield gaps of wheat and maize in sole crop and intercrop were determined. The yield gaps of wheat were 2.4 and $0.7 \mathrm{tha}^{-1}$ in sole wheat and in intercrop, indicating that the farm average wheat yield was $67 \%$ of potential yield in sole wheat and $85 \%$ of potential yield in intercrop. The yield gaps of maize were 7.0 and $6.1 \mathrm{t} \mathrm{ha}^{-1}$ in sole maize and intercrop, and farm average maize yield was $51 \%$ of potential yield in sole maize and $49 \%$ of potential yield in intercrop (Table 6.6).

Table 6.6 Yield gaps of wheat and maize in sole crops and in intercrop (percentage yield gap is calculated as the \% yield gap relative to the potential yield)

\begin{tabular}{lllll|llll}
\hline \multicolumn{3}{l}{ Yield gaps in sole crops } & \multicolumn{4}{|c}{ Yield gaps in intercrop } \\
\hline Crop & $Y_{\mathrm{p}}{ }^{i}$ & $Y_{\mathrm{a}}{ }^{i}$ & $Y_{\mathrm{g}}{ }^{i}$ & Percentage yield gap & $I Y_{\mathrm{p}}{ }^{i}$ & $I Y_{\mathrm{a}}{ }^{i}$ & $I Y_{\mathrm{g}}{ }^{i}$ & Percentage yield gap \\
Wheat & 7.3 & 4.9 & 2.4 & $33 \%$ & 4.8 & 4.1 & 0.7 & $15 \%$ \\
Maize & 14.2 & 7.2 & 7.0 & $49 \%$ & 12.0 & 5.9 & 6.1 & $51 \%$ \\
\hline
\end{tabular}

\subsubsection{The effect of land use change on grain production}

When an average farm size of 0.8 ha is assumed, the total area for the 310 farms is 248 ha, in which $16 \%$ is currently cultivated for sole wheat, $14 \%$ for sole maize and $70 \%$ for wheatmaize intercrop (Table 6.7). Under the first land use scenario (only sole wheat is cultivated), $34 \%$ more wheat will be produced, but $100 \%$ maize will be lost. Under the second land use scenario (only sole maize is cultivated), $41 \%$ more maize will be produced, but $100 \%$ wheat will be lost. Under the third land use scenario, when $50 \%$ land is cultivated sole wheat, and 50\% land is cultivated sole maize. The 310 farms will produce $33 \%$ less wheat and $29 \%$ less maize compared to the current land use (Table 6.8). Finally, under the fourth land use scenario (100\% land is cultivated wheat-maize intercrop), the 310 farms will produce $13 \%$ more wheat and $15 \%$ more maize.

In the five land use strategies, including current land use and four hypothetical scenarios, the maximum total grain production is $2480 \mathrm{t}$ in scenario 4 , i.e. $100 \%$ of the land is used for wheat-maize intercrop, this scenario can produce $14 \%$ more grain yield than the current cultivation (Table 6.8). While the land use strategies of scenario 1, i.e. $100 \%$ of the land is used for sole wheat will produce the least grain yield, which is $46 \%$ less than the grain yield produced as current land use. The trend keeps the same when total calories and gross income is considered (Table 6.8). 


\section{Chapter 6}

Table 6.7 Cultivation areas for sole wheat, sole maize, and wheat-maize intercrop (numbers in brackets denote the percentage of land used for sole wheat, sole maize and wheat-maize intercrop).

\begin{tabular}{lcccc}
\hline \multirow{2}{*}{ Crop systems } & \multirow{2}{*}{ Farm households } & \multicolumn{3}{c}{ Cultivation area (ha) } \\
& & Sole wheat & Sole maize & Intercrop \\
\hline Sole wheat only & 36 & 0.8 & 0 & 0 \\
Sole maize only & 18 & 0 & 0.8 & 0 \\
Sole wheat and sole maize & 18 & 0.4 & 0.4 & 0 \\
\hline Intercrop only & 192 & 0 & 0 & 0.8 \\
Sole wheat and intercrop & 10 & 0.4 & 0 & 0.4 \\
Sole maize and intercrop & 33 & 0 & 0.4 & 0.4 \\
Sole wheat, sole maize and & 3 & 0.26 & 0.26 & 0.28 \\
intercrop & & $40.8(16 \%)$ & $35.6(14 \%)$ & $171.6(70 \%)$ \\
\hline Total cultivated areas & & &
\end{tabular}

\subsection{Discussion}

In this chapter, we developed a conceptual framework to evaluate the productivity of intercrops with two crop species, comparing mixed cropping with sole cropping, and comparing potential growing conditions with actual conditions. On the basis of experiments, simulations with a crop model and farm survey, we quantified yield gains of the intercrop in potential and actual growing conditions, and we determined yield gaps of farm yields for the two crops in sole crop and intercrop. The potential yields were 7.3 and $4.8 \mathrm{t} \mathrm{ha}^{-1}$, respectively, for wheat in sole crops and in intercrop, 14.2 and $12.0 \mathrm{t} \mathrm{ha}^{-1}$, respectively, for maize in sole crop and in intercrop. Wheat and maize had positive yield gains in intercrop under both potential and actual growth conditions. The average farm yields were $67 \%$ of potential yield in sole wheat and $85 \%$ in intercropped wheat, and $51 \%$ of maize potential yield in sole crop and $49 \%$ in intercrop. The land use strategy S1, in which $100 \%$ land is used for sole wheat, will produce the least total yield and calories, and the land use strategy S4, in which $100 \%$ land is used for wheat-maize intercrop, will produce the highest total yield and calories.

\subsubsection{Potential yields for wheat and maize in northwest China}

The definition and the determination of potential yield for yield gap analysis of crops has been well discussed (Lobell et al., 2009; van Ittersum et al., 2013), and one of the recommendations is to estimate the potential yield by crop model simulations. This has been applied in many yield gap studies (Boling et al., 2010; Liang et al., 2011; Laborte et al., 2012). 


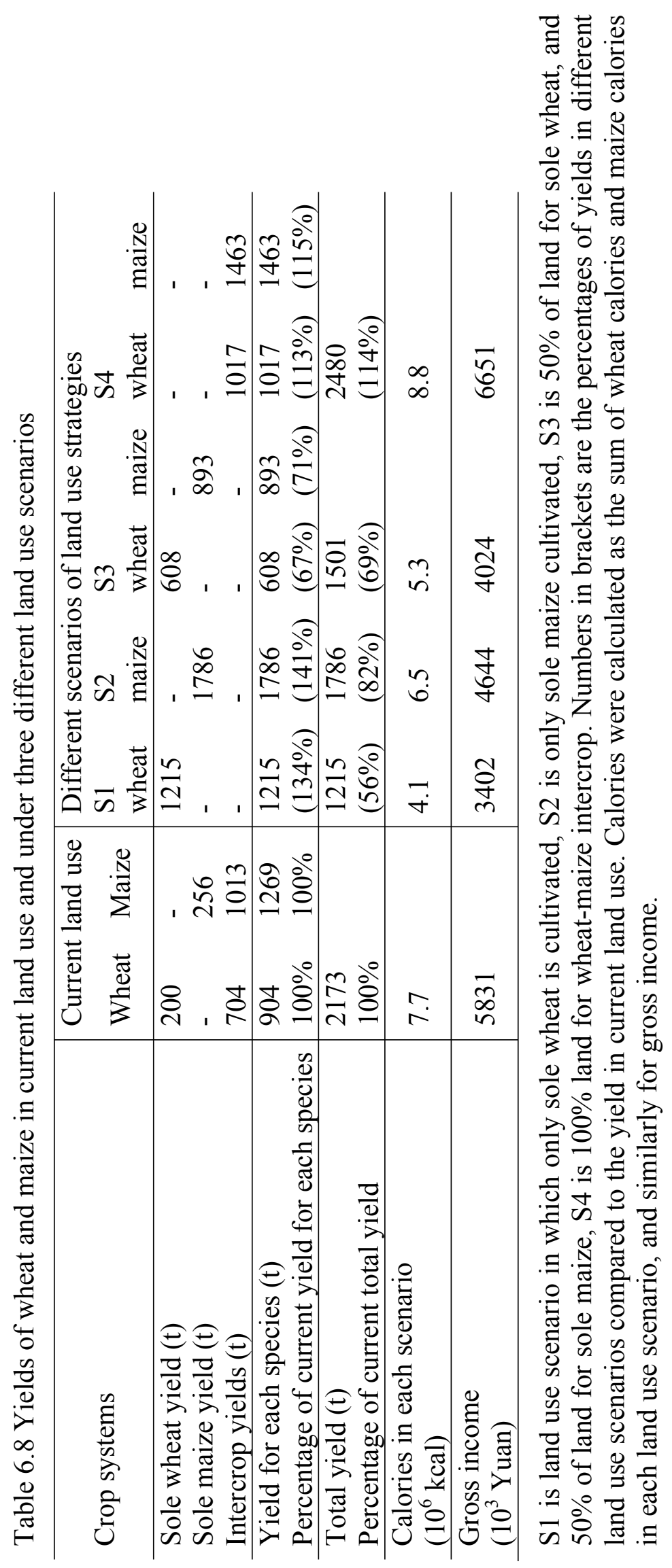




\section{Chapter 6}

In this study, we calibrated the sole crop model and the intercrop model with three years' field experimental data at Wuwei experimental station (2010-2012), RUEs were calibrated for sole crop and intercrop separately. The average RUE (across the years) was used to simulate potential yields in Zhangye, where the farm survey was conducted (2010-2014). The overall potential yield was then estimated by the average simulated yields over the five years. The averaged potential yield of spring wheat in sole crop was $7.3 \mathrm{t} \mathrm{ha}^{-1}$, which was $33 \%$ higher than the average yield from field experiments in this region (5.5 $\mathrm{t} \mathrm{ha}^{-1}$ ) (Liu et al., 2011), but similar to the reported highest yield from field experiments $\left(7.2 \mathrm{t} \mathrm{ha}^{-1}\right)$ (Yang et al., 2011). The averaged potential yield of spring maize in sole crop was $14.2 \mathrm{t} \mathrm{ha}^{-1}$, which was $5.3 \mathrm{tha}^{-1}$ lower than the potential yield simulated by the Hybrid-Maize model in this region (Meng et al., 2013), but it is similar to the highest reported yield from experiments $\left(15.2 \mathrm{t} \mathrm{ha}^{-1}\right)$ (Song et al., 2006). The potential yield of the intercrop was first defined and determined for wheatmaize intercropping, and it was $4.8 \mathrm{t} \mathrm{ha}^{-1}$ for wheat and $12 \mathrm{t} \mathrm{ha}^{-1}$ for maize. These yields were similar to the highest yield in the literature, $5.1 \mathrm{tha}^{-1}$ for intercropped wheat and $10.2 \mathrm{t} \mathrm{ha}^{-1}$ for intercropped maize (Fan et al., 2013; Mu et al., 2013). The average LER under potential conditions was 1.51 (Table C7, Appendix C), and was in the range of LER values reported from this region, i.e. from 1.1 to 1.6 (Li et al., 2001b; Song et al., 2006; Yang et al., 2011; Mu et al., 2013).

\subsubsection{Where does yield gain come from in the wheat-maize intercrop?}

The yield gains for wheat and maize were positive under potential and actual growing conditions, indicating that both wheat and maize benefited from intercropping. Under potential growing conditions, the two crops are assumed to only compete for light, while water and nutrients are assumed to be sufficiently supplied. In this condition, there are two ways to improve productivity, one is to capture more solar radiation, and the other is to improve the radiation use efficiency (RUE). Strip-relay intercropping is often proposed to capture more light due to a better canopy structure and a longer growing season than in sole crops (Zhang et al., 2008; Wang et al., 2015; Zhu et al., 2015). However, the RUE varies substantially across different studies. For example, Zhang et al. (2008) found that RUEs of wheat and cotton were the same in sole crop as in intercrop in wheat-cotton relay intercrop, Wang et al. (2015) found that the RUE of maize decreased in intercrop while the RUE of wheat did not change in Inner Mongolia, China. In Chapter 3, we found that intercropping increased the RUE of wheat but decreased RUE of maize in the Netherlands. In this study, 
through crop model calibration, we found that both wheat and maize had higher RUEs in the intercrop than in sole crops (Table C6, Appendix C).

The increase of RUE in wheat may be explained by shading by maize during the wheat grain filling stage (late-June to mid-July). During this period, the light intensity was high and wheat (C3 crop) may have used light more efficiently in intercrop than in sole crop, due to a higher proportion of diffuse light (Sinclair et al., 1992). Maize, on the other hand, was suppressed by wheat in the seedling stage, but when it surpassed wheat in height, it had better light distribution in the canopy and a higher photosynthetic rate (Chapter 5). Thus, maize had the chance to recover and to produce a larger biomass per plant in intercrop than in sole crop (Zhang and Li, 2003). However, this recovery process was weak under the growing conditions in Inner Mongolia (Gao et al., 2014; Wang et al., 2015) and in the Netherlands (Chapter 2), because of the relatively low temperature and low light intensity after wheat harvest. Due to the differences in growing conditions for maize following wheat harvest, higher LERs (ranging from 1.1 to 1.6) were found in Wuwei (Li et al., 2001b; Song et al., 2006; Yang et al., 2011; Mu et al., 2013), and lower LERs were found in Inner Mongolia (ranging from 1.0 to 1.2) (Gao et al., 2014; Wang et al., 2015) and in the Netherlands (ranging from 0.97 to 1.30 ) (Chapter 2).

The yield gain of wheat was $1.6 \mathrm{t} \mathrm{ha}^{-1}$ in farmers' fields which was $0.5 \mathrm{t} \mathrm{ha}^{-1}$ higher than potential yield gain, while the actual yield gain of maize was $2.3 \mathrm{t} \mathrm{ha}^{-1}$ which was $2.6 \mathrm{tha}^{-1}$ lower than the potential yield gain (Table 6.5). This suggests that in wheat-maize intercropping, the yield advantage from wheat is easier to realize than from maize. This can be explained by the growth characteristics of the two crops and the fact that water may have been not completely non-limiting in actual conditions. Wheat is the first sown crop, it covers half of the field and has advantages to use water and nutrients before maize is added; this advantage occurs in most farmers' fields. Thus the yield gain of intercropped wheat is easy to achieve. However, the growth of intercropped maize was suppressed at the early stage, and the recovery growth of maize is crucial to achieve a high yield in the intercrop, but this recovery growth process needs sufficient water and nutrient supply. This may differ substantially among different farm fields due to management and input levels, resulting in an enormous yield range for intercropped maize among farmers, i.e. from $0.6 \mathrm{tha}^{-1}$ to $10.1 \mathrm{tha}^{-1}$ (Table 6.4). 


\section{Chapter 6}

\subsubsection{Why do yield gaps exist?}

In this study we found that farmers achieved $67 \%$ of potential yield in sole wheat but only $51 \%$ in sole maize (Table 6.6). This is similar to the yield gap closure in other regions in China. For example, the actual yields were 65\% ( $\mathrm{Li}$ et al., 2014) and 68\% ( $\mathrm{Lu}$ and Fan, 2013) of potential for winter wheat in North China plain and $51 \%$ of potential for spring maize in northeast China (Liu et al., 2012). In intercrop, the farmers achieved $85 \%$ of potential yield for wheat and $49 \%$ for maize. The small yield gap for intercropped wheat is related to the high yield gain of intercropped wheat.

The main factors leading to yields gaps investigated in previous studies include too high sowing density, suboptimal variety choice and sowing dates, poor irrigation practice and unbalanced fertilization (Liang et al., 2006; Lobell et al., 2009). In the five surveyed villages, farmers have easy access to markets for good quality seeds (e.g. hybrid maize), all types of fertilizers, pesticides and herbicides. However, farmers reported that for the sake of their health, they hardly used pesticides and herbicides for wheat and maize though they are aware of the presence of weeds and pests. In addition, there are limitations in using herbicides in wheatintercropping due to the biological similarities between wheat and weeds. Thus, the yield loss caused by pests and weeds may be one of the reasons for the existing yield gap. Apart from this, water shortage is presumably the main factor leading to yield gaps in the studied region. Zhangye city is well-known for oasis agriculture and is located in the up- and middle-stream of Heihe River. Agriculture is fully dependent on irrigation and uses 94\% of Heihe's water (Li et al., 2015). In this region, water is managed and allocated by the local government, namely Water Management Bureau (WMB). Due to water shortage, only part of the land is classified to have water use rights (Zhang et al., 2014). Thus for crops grown on land outside the irrigation area or not having water use rights, the plant growth depends on precipitation (about $160 \mathrm{~mm}$ per year) and the yields are very water-limited.

\subsubsection{Land use strategies in this region}

In this study, we investigated the changes in grain production under four land use scenarios compared to the current land use. We found that if all farmers discarded wheat-maize intercrop, the grain production will decrease between $18 \%$ to $44 \%$ depending on the land share for sole wheat and sole maize. However, if all famers used wheat-maize intercrop the total grain production could increase $14 \%$ compared to the current situation (under actual 
growing conditions). Similar results are found when we consider the production of calories and the gross income. However, except for the change from intercrop to sole crops, other changes are also important in this region, i.e. from grain production to cash crops. The rich agricultural resources in Hexi corridor attracted many agricultural related companies, including seed companies and food-processing companies. Zhang et al. (2014) reported that in another county of Zhangye city (Minle county), the land use changed from grain production to potato production due to the cooperation of the local government and a agro-processing company. This has substantially changed the water allocation in this region. Similar changes are also observed in Wuwei city, where seed maize has a large share of land and water. Those factors lead to a decrease in area of grain production and intercropping. Li et al. (2001b) reported that in year 1995 the wheat-maize intercropping area was 75,000 ha in Ningxia province and 200,000 ha in Gansu province. Assuming the actual yields that we found in our survey for Gaotai county, farmers would produce $1.1 \times 10^{6} \mathrm{t}$ wheat and $1.6 \times 10^{6} \mathrm{t}$ maize with those intercropping area. However, if all farmers change intercropping to sole wheat and sole maize cropping (e.g. $50 \%$ of land is assumed to cultivate sole wheat and $50 \%$ for maize) and again assuming actual yields from our survey, the wheat production will be $0.7 \times 10^{6} \mathrm{t}$ wheat and the maize production will be $1.0 \times 10^{6} \mathrm{t}$. This indicates that the land use changing from wheat-maize intercropping to sole crops would decrease grain production by $40 \%$ (wheat) and $39 \%$ (maize) in this region.

\subsection{Conclusion}

In this study, we quantified the potential yield, yield gain and yield gaps of wheat and maize in sole crops and intercrop in northwest China. To our knowledge, this is the first attempt to define and quantify yield gaps in intercropping. Yield gains were found for wheat and maize in intercrop under potential and actual conditions, and the average farmers' yields were $67 \%$ and $85 \%$ of potential yield for sole wheat and intercropped wheat, while $51 \%$ and $49 \%$ were achieved of maize potential yield in sole crop and in intercrop. The leading factor of yield gap in this region is the limited water resource. Though wheat-maize intercrop was found in 238 farms out of 360 surveyed farms in Gaotai county, a declining trend is expected due to many social economic factors, e.g. the local water management policy does not allow farmers to grow wheat-maize intercrop for the sake of water saving, and farmers' decisions switch to high economic return cash crops. Those land use changes will substantially decrease the grain production in this region based on the scenario analysis. 
Chapter 6

\section{Appendix C}

Table C1 Irrigation schedule ( $\mathrm{mm}$ ) for different cropping systems

Table C2 Fertilizer application schedule for different crop systems

Table C3 Model inputs related to planting configurations in intercrops

Table C4 Description of parameters and their values

Table C5 Summary of biomass partitioning fractions to leaves, stems and storage organs as a function of $T_{\text {sum }}$

Table C6 Mean RUE from calibration

Fig. C1 Simulated values versus observed values for LAI.

Fig. C2 Simulated values versus observed values for biomass

Table C7 LER of wheat-maize intercrop by model simulations from year 2010 to 2014

\section{Acknowledgements}

The financial support of the China Scholarship Council (CSC, grant number: 201206350067) and the Key Sino-Dutch Joint Research Project of NSFC (grant number: 31210103906) are gratefully acknowledged. 
Chapter 7

General discussion 


\section{Chapter 7}

Wheat and maize are two major grain crops in the world (Fischer et al., 2012) and intercropping these two cereal species showed substantial yield advantages (i.e. a land equivalent ratio, LER larger than one) in China (Li et al., 2001b). Additional studies of wheatmaize intercropping are needed to test whether this system can give yield advantages in other growing conditions. If so, a wider usage of wheat-maize intercropping could greatly increase grain production and substantially contribute to future food security. In this thesis, I tested wheat-maize intercropping performance under Dutch growing conditions, and investigated plant development and growth characteristics, radiation interception and radiation use efficiency under different planting configurations. With this knowledge I developed an intercrop model for potential growing conditions. This model can be used to investigate the optimal planting arrangement and yield potential in relay-strip intercropping systems. Finally I investigated the grain production of wheat-maize intercropping in farmers' fields in northwest China and assessed the importance of intercropping to local food production. In this chapter, I will first summarize the main findings of this thesis (Section 7.1), secondly the wheat-maize intercrop performance will be compared in different growing conditions (Section 7.2), thirdly the mechanisms of the yield advantage of wheat-maize intercropping will be investigated (Sections 7.3 to 7.6), and finally I will discuss the current state and future prospects of wheat-maize intercropping research and its contribution to future food security (Sections 7.7 and 7.8).

\subsection{Main questions answered by this thesis}

\subsubsection{Does wheat-maize intercropping give a yield advantage under Dutch growing conditions?}

Yields in intercrops depend on planting configurations of intercropped species in interaction with local growing conditions. Therefore, the advantages of intercropping in one location may not be true in other locations. In Chapter 2, data are presented of two years field experiments on yield and yield components of spring wheat and spring maize intercrops under Dutch growing conditions. Three intercrop configurations were tested: one replacement intercrop $(6: 2 \mathrm{WM})$ in which the relative density total is one and two augmentative intercrops $(8: 2 \mathrm{WM}$ and $6: 3 \mathrm{WM}$ ) in which the relative density total is greater than one. The three intercrops showed yield advantages in 2013. The land equivalent ratio (LER) varied from 1.18 to 1.30. However, no yield advantages were found in 2014 and the LER varied from 0.97 to 1.08. 


\subsubsection{Does wheat-maize intercropping enhance radiation interception and radiation use efficiency compared to sole crops?}

Solar radiation provides crops with energy for photosynthesis and determines the potential for crop production (De Wit, 1959; Loomis and Williams, 1963). Intercrops with temporal and spatial niche complementarity may increase radiation interception compared to sole crops, and thus increase productivity (Fukai and Trenbath, 1993). The relay intercrop of wheat and maize provides both temporal and spatial niche complementarity. The two crops use radiation during different periods of the season: spring wheat is sown in March and harvested in August, while maize is sown in May and harvested in October. The two species use radiation in different space: wheat is a short C3 crop and maize is a tall $\mathrm{C} 4$ crop, the tall and short combination allow for better complementary light capture (Ghanbari et al., 2010). Furthermore, intercropped wheat is expected to have a higher radiation use efficiency (RUE) than sole wheat due to shading during the final stage of the growing period. Because wheat is a C3 crop, it has a lower light saturation level for photosynthesis than C4 crops (Trenbath and Francis, 1986), and tends to use light more efficiently at low light intensity than at high light intensity (Ögren and Evans, 1993). In Chapter 3, I calculated the radiation interception throughout the growing season for sole crops and intercrops and estimated the RUEs for wheat and maize. The results showed that the wheat-maize intercropping system had significantly higher radiation interception than sole wheat in 2013 and 2014, and higher interception than sole maize in 2013, but not 2014. For both years, intercropped wheat had a higher RUE than sole wheat, whereas intercropped maize had a lower RUE than sole maize.

\subsubsection{Does intercropped maize have the same leaf traits and photosynthetic rate as sole maize?}

In wheat-maize relay intercrop, maize is the late sown crop and its initial vegetative growth is negatively affected by shading from wheat (Zhu et al., 2014). In addition, intercropped maize was found to have a lower RUE than sole maize in Chapters 3 and 4 confirming the results of Wang et al. (2015). In Chapter 5, the leaf traits and photosynthetic rate of the maize ear leaf were determined to explore why intercropped maize had a lower RUE than sole maize. The measurements were taken in three weeks during maize flowering. The results showed that sole maize (rather than intercropped maize) tended to have leaf traits that are usually associated with high photosynthetic rate, i.e. smaller specific leaf area (SLA) or thicker leaves, and higher specific leaf nitrogen (SLN) and higher chlorophyll content than intercropped 


\section{Chapter 7}

maize. Nevertheless, intercropped maize had a higher photosynthetic rate per unit leaf area than sole maize.

\subsubsection{Does wheat-maize intercropping provide yield advantages in farmers' fields?}

The yield advantages of wheat-maize intercropping have been reported by agronomists based on field experiments, but the yields from farmers' fields have not been investigated yet. Chapter 6 quantified the yields of wheat and maize in sole crops and in intercrop in farmers' fields from a farm survey in Gansu, Zhangye city. The average farm yields were $4.9 \mathrm{t} \mathrm{ha}^{-1}$ in sole wheat and $4.1 \mathrm{t} \mathrm{ha}^{-1}$ in intercropped wheat, $7.2 \mathrm{t} \mathrm{ha}^{-1}$ in sole maize and $5.9 \mathrm{t} \mathrm{ha}^{-1}$ in intercropped maize, indicating yield advantages in the intercrop compared to sole crops (i.e. the relative yield total $>1$ ). This can be understood as: if a farmer has one hectare of land, he will harvest $1.7 \mathrm{t}$ more wheat and $2.3 \mathrm{t}$ more maize from one hectare of intercrop than from 0.5 hectare of sole wheat plus 0.5 hectare of sole maize. Thus wheat-maize intercropping provides substantial yield advantages in farmers' fields.

\subsection{Wheat-maize intercrop performance in different locations}

To date, wheat-maize intercropping has been reported to be tested in four locations (Table 7.1), and the average LER across all locations was 1.29. The highest average LER was found in Henan province, China, where winter wheat and spring maize were used. At other sites, spring wheat and spring maize were used. The average LER in Gansu was greater than in Inner Mongolia and in Wageningen. In Chapter 2, a LER of 1.14 was found when averaged for two years and three intercrop configurations in Wageningen, which was similar to the LER in Inner Mongolia and smaller than the LER observed in the other two locations (Table 7.1). Wheat-maize intercrop is a relay system, i.e. the two crops have complementary resource use in time. A wheat-maize intercrop with a greater temporal niche differentiation (TND) is expected to have a greater LER due to relaxation of competition between the species (Vandermeer, 1989; Li et al., 2013; Yu et al., 2015). Thus the variation of LER among locations may be caused by differences in temporal niche differentiation. In intercrop, TND measures the relative length of the co-growth period compared to the total intercropping growing period, and it is calculated as:

$T N D=\frac{P_{\text {system }}-P_{\text {overlap }}}{P_{\text {system }}}=1-\frac{P_{\text {overlap }}}{P_{\text {system }}}$ 
where $P_{\text {overlap }}$ is the period of overlap of the growth period of the intercropped species, and $P_{\text {system }}$ is the duration of the whole intercrop (Yu et al., 2015). TND is zero if the two intercropped species are sown and harvested at the same time, TND is one if the second crop is sown after the harvest of the first crop, i.e. double cropping. In a meta-analysis, Yu et al. (2015) found that LER was 1.18 when TND was zero, and LER increased to 1.39 when TND is approaching one (double cropping). Therefore, if the temperature sum in a region is sufficient, double cropping would be a better alternative than relay intercropping. This is reasonable as relay intercropping often leaves part of the land bare during part of the growing season. In this Chapter, the TND was calculated based on the sowing time of wheat and maize in different locations from my thesis and the literature (Table 7.1). The highest TND of 0.85 was found in Henan with an LER of 1.57, while the smallest TND was found in Gansu (0.5) with an LER of 1.35. I used a linear mixed effect model to analyse the effect of TND on LER, with study (or publication) as a random factor. Fig. 7.1 shows that with TND of 0.85 (Full-set) and without TND of 0.85 (Sub-set), the relationship between LER and TND differs. Here I conclude there is no significant relationship between TND and LER in this analysis, which is different from the findings in Yu et al. (2015).

Table 7.1 Reported LER of wheat-maize intercropping from literature

\begin{tabular}{|c|c|c|c|c|}
\hline Site & Crop system & $\begin{array}{l}\text { Mean } \\
\text { TND }\end{array}$ & LER & Data source \\
\hline Gansu, China & $\begin{array}{l}\text { Spring wheat- } \\
\text { Spring maize }\end{array}$ & 0.50 & $\begin{array}{c}1.35 \\
(1.1 \sim 1.6)^{1}\end{array}$ & $\begin{array}{l}\text { (Li et al., 2001b; Song } \\
\text { et al., 2006; Yang et al., } \\
\text { 2011; Mu et al., 2013) }\end{array}$ \\
\hline $\begin{array}{l}\text { Inner Mongolia, } \\
\text { China }\end{array}$ & $\begin{array}{l}\text { Spring wheat- } \\
\text { Spring maize }\end{array}$ & 0.54 & $\begin{array}{c}1.11 \\
(1.0 \sim 1.23)\end{array}$ & $\begin{array}{l}\text { (Gao et al., 2014; } \\
\text { Wang et al., 2015) }\end{array}$ \\
\hline Henan, China & $\begin{array}{l}\text { Winter wheat- } \\
\text { Spring maize }\end{array}$ & 0.85 & 1.57 & (Gao et al., 2009) \\
\hline $\begin{array}{l}\text { Wageningen, } \\
\text { the Netherlands }\end{array}$ & $\begin{array}{l}\text { Spring wheat- } \\
\text { Spring maize }\end{array}$ & 0.58 & 1.23 & (Zhu et al., 2016) \\
\hline $\begin{array}{l}\text { Wageningen, } \\
\text { the Netherlands }\end{array}$ & $\begin{array}{l}\text { Spring wheat- } \\
\text { Spring maize }\end{array}$ & 0.54 & $\begin{array}{c}1.14 \\
(0.97 \sim 1.30) \\
\end{array}$ & Chapter 2 \\
\hline
\end{tabular}

${ }^{1}$ Numbers in brackets give the range of LER reported for a specific location.

\subsection{Wheat and maize performed differently in sole crops and in intercrop}

In Chapter 6, the yield gain was defined to assess whether intercropped species have a yield advantage in the intercrop as compared to sole crop. It is defined as the difference of yield in intercrop and the expected yield in the intercrop. The expected yield is the yield of each 


\section{Chapter 7}

species in the intercrop when crop plants grow the same as in sole crops, and it is calculated as the yield in sole crop multiplied by the land area ratio of each species in the intercrop (Chapter 6). In Chapter 6, yield gain was found in farmers' fields for both wheat and maize in Zhangye city. In this Chapter, I compare yield gain in different locations based on reported yields in literature. In order to compare different studies, relative yield gain is used, calculated as the ratio of yield gain to the expected yield (Fig. 7.2).

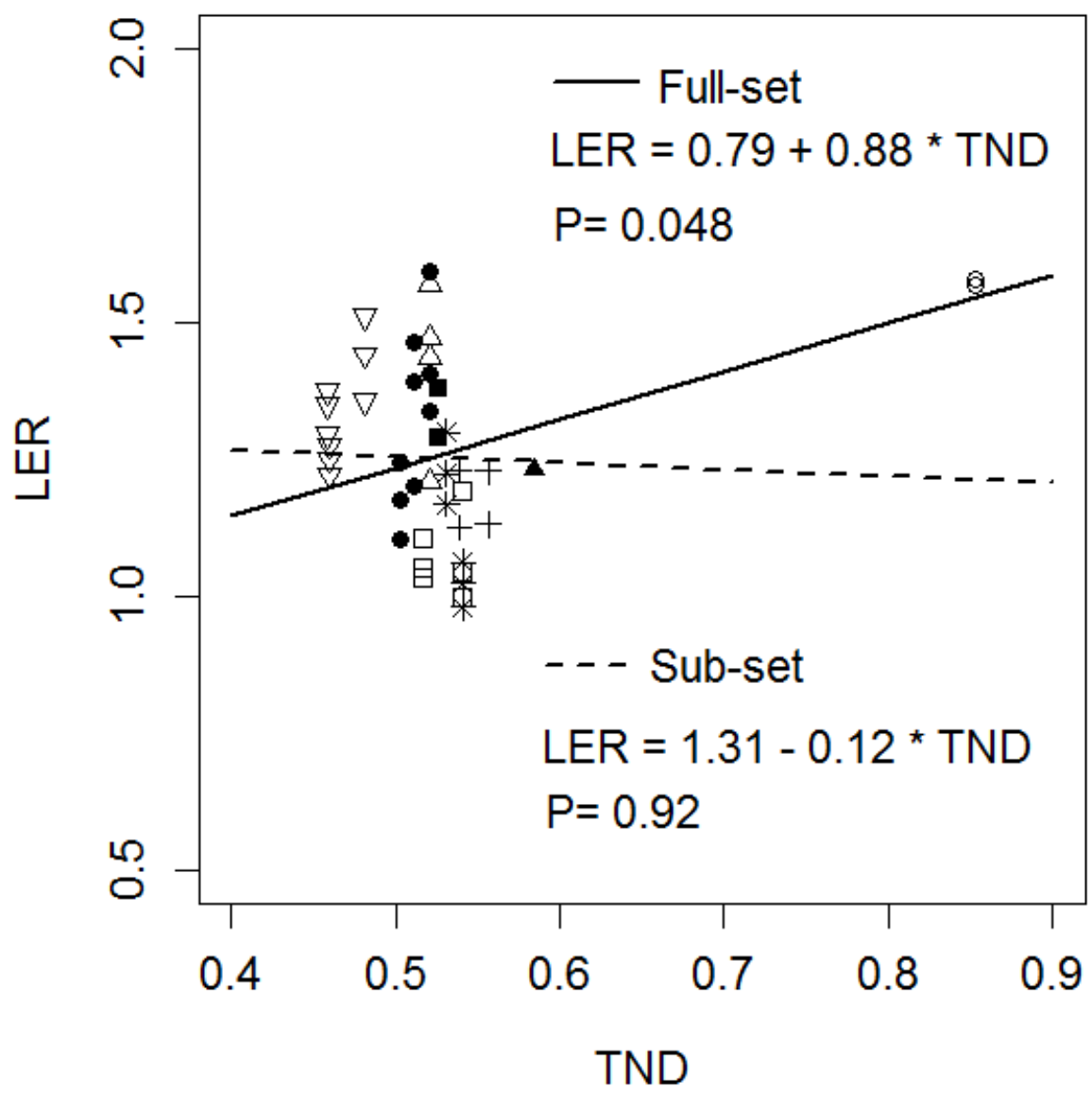

Fig. 7.1 Relationship between LER and TND estimated with a mixed effects model, publication is the random factor. Full-set: data from nine publications are used; Subset: data from eight publications are used (the data points with TND of 0.85 are deleted). The same symbol means data from the same publications.

Fig. 7.2 shows that intercropped wheat had a positive yield gain in all locations, indicating yield advantages in intercrop compared to sole crop. In the nine studies (Table 7.1), the relative yield gain of wheat was $27.3 \%$ on average (ranging from $8.1 \%$ to $77.3 \%$ ) (Fig. 7.2 ) and the gain of grain yield originated mostly from border row effects, i.e. higher yield per plant in border rows (Li et al., 2001b). In Chapter 2, I quantified the border row effect in intercrop and investigated the maximum extent of the border row effect with a skip-row 
treatment $(6: 0 \mathrm{WM})$. Wheat plants in strip border rows were found to have more tillers per plant and greater kernel number per ear than plants in sole wheat, while the thousand kernel weight and harvest index (HI) in the skip-row treatment intercrop were significantly larger than in the intercrop. Those results indicate enhanced resource capture in border row wheat at the early growth stage but more severe competition at grain filling in the intercrop than in sole crop or skip-row.

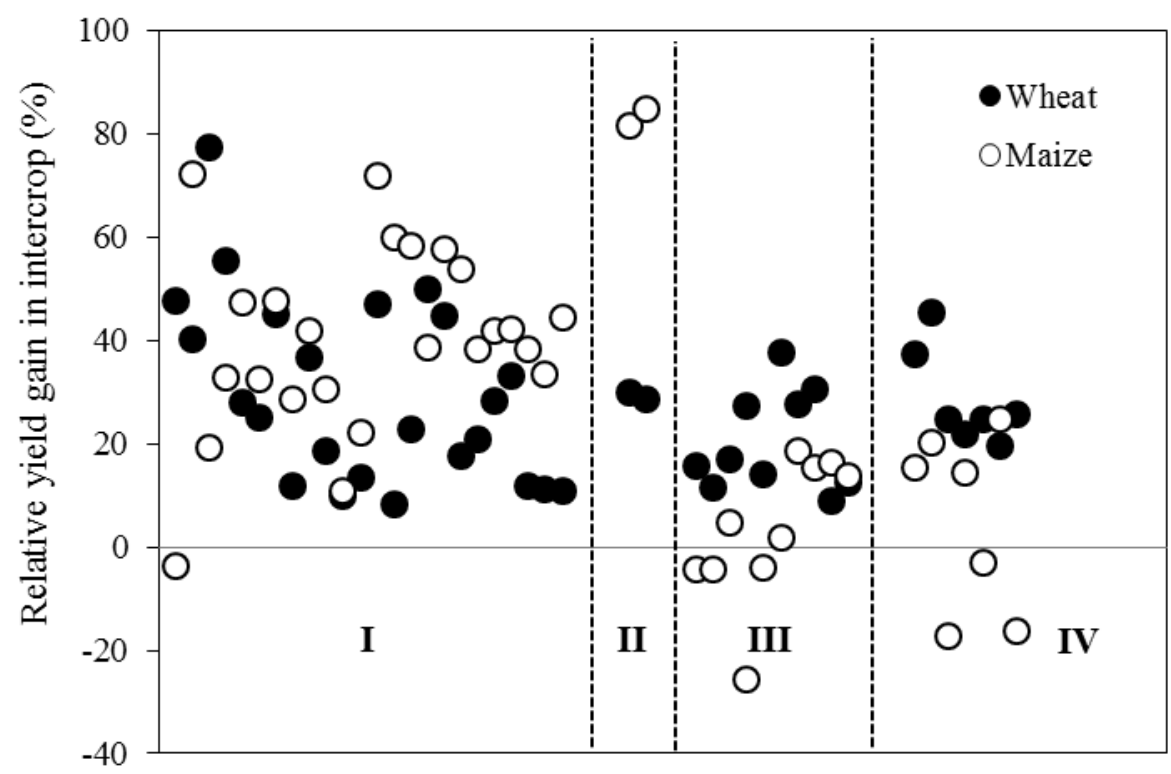

Observations

Fig. 7.2 Relative yield gain in intercrop. A value greater than zero means that the crop has yield gain in intercrop compared to the sole crop, and a value smaller than zero means the crop has a yield loss in the intercrop compared to the sole crop. The four panels present values in four locations: Gansu (I), Henan (II), Inner Mongolia (III) and Wageningen (IV). The data source is the same as Table 7.1.

Intercropped maize showed both yield gain and yield loss in the intercrop compared to the sole crop. The average relative yield gain of maize was $27.8 \%$ across all locations but it varied a lot among locations. There was only one out of 24 observations with a yield loss in Gansu, but about half of the observations showed yield loss in Inner Mongolia and in Wageningen (Fig. 7.2). Maize is the late sown crop in wheat-maize relay intercrop, it experiences a strong competition during seedling stage, resulting in a lower leaf appearance rate (Zhu et al., 2014) and a lower biomass accumulation rate (per plant) than sole maize. However, when maize surpassed wheat by height, the competitive dominance shifts from wheat to maize. And after wheat harvest, intercropped maize has a significantly higher dry matter accumulation rate per plant than sole maize, and this phenomenon is called "recovery 
growth" (Zhang and Li, 2003). The difference of relative maize yield gain in different locations indicate different levels of recovery growth after wheat harvest, and this may relate to local temperature and radiation during the late growing season.
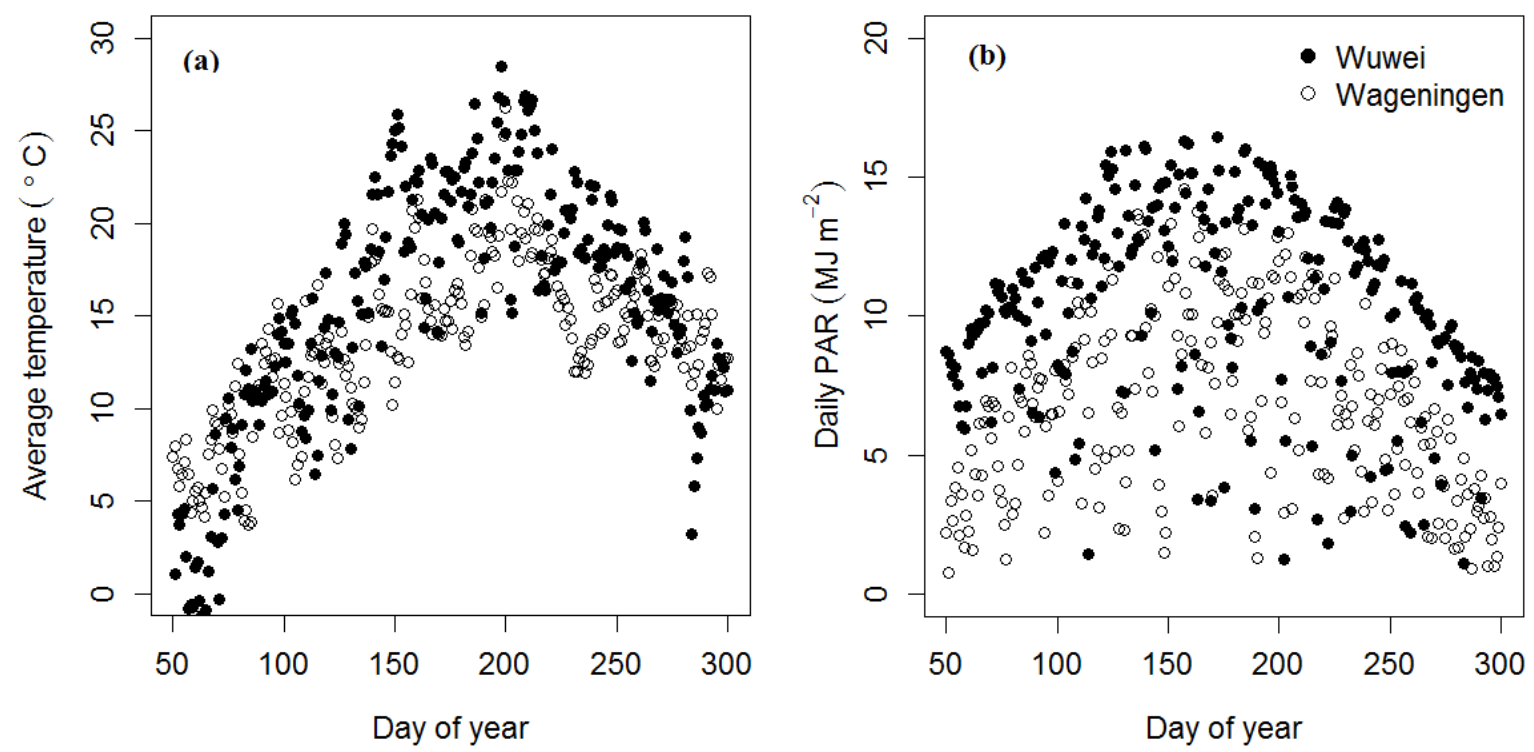

Fig. 7.3 Average temperature and daily PAR in two locations during growing season at year 2014. Wuwei is located in Gansu province, northwest China, where many wheat-maize field experiments were conducted.

Generally, the average temperature and daily photosynthetic active radiation (PAR) in Wuwei Gansu are higher than in Wageningen (Fig. 7.3). Because of a higher temperature, wheat in Wuwei was harvested earlier (mid-July) than wheat in Wageningen (mid-August), resulting in a longer recovery growth period for maize in Wuwei than in Wageningen. And because of a higher light intensity and temperature in Wuwei, intercropped maize had the chance to recover and catch up with sole maize (on a per plant basis). In Wuwei, intercropped maize achieved a greater yield per plant than sole maize at maturity. However, it is a great challenge for intercropped maize to outperform sole maize when maize is grown under relatively low temperature and low light intensity conditions, such as in the Netherlands. Another point is that in the warm regions (i.c. northwest China) corn maize is used while in the cool regions (i.c. the Netherlands) maize is grown as silage maize. The different maize cultivars may shape different interspecific interactions between wheat and maize. 


\subsection{Radiation interception and use efficiency (RUE) in wheat-maize intercrop}

\subsubsection{Relay intercropping tends to increase radiation interception compared to sole crops}

It is rational to expect a higher radiation interception in wheat-maize intercrop than in sole crops, because the relay-strip intercrop provides a longer growing season, better ground cover over the whole growing season, and more diverse canopy structure, including the difference of plant height and strip configuration (Keating and Carberry, 1993). Thus it is often found that relay intercropping intercepts more radiation in a year than any of the component species in sole crops. For example, sorghum-pigeonpea intercepted $1350 \mathrm{MJ} \mathrm{m}^{-2} \mathrm{PAR}$ in intercrop, which was $67 \%$ higher than the radiation interception in sole sorghum and $9 \%$ higher than in in sole pigeonpea (Natarajan and Willey, 1980). Similar results were found in maizepigeonpea intercrop (Sivakumar and Virmani, 1980), wheat-cotton intercrop (Zhang et al., 2008) and wheat-maize intercrop (Wang et al., 2015). However, when intercropped species have a similar growth period, the radiation interception over the growing season in the intercrop is often smaller than that of the sole crop with the highest radiation interception. For example millet-groundnut intercrop intercepted about $11 \%$ less radiation than sole groundnut (Marshall and Willey, 1983), and groundnut-sorghum intercrop intercepted 17\% less radiation than sole sorghum (Harris et al., 1987). This indicates that temporal niche differentiation has positive effects on radiation interception in intercrops. In Chapter 3, it was found that the replacement intercrop intercepted 33\% more radiation than sole wheat and $12 \%$ more than sole maize in 2013 , and $10 \%$ more radiation than sole wheat but $2 \%$ less than sole maize in 2014.

Zhu et al. (2015) investigated the changes in radiation interception due to the effects of plant plasticity and row configuration. In wheat-maize intercrop, plant plasticity refers to the changes in leaf number, leaf size and tiller number in the intercrop phenotype compared to the sole crop phenotype, while configuration refers to the planting patterns, e.g. strip width and row distances. Zhu et al. (2015) found that wheat plasticity was the main reason for increased light interception and maize plasticity resulted in decreased light interception. Chapter 3 presented that intercropped wheat intercepted $23 \%$ more radiation per plant than sole wheat in 2013 , and $25 \%$ more in 2014 ; intercropped maize intercepted $17 \%$ more radiation per plant than sole maize in 2013 , but $9 \%$ less in 2014. The increased radiation interception for intercropped wheat comes from positive effects of wheat plasticity, i.e. more tillers per plant 


\section{Chapter 7}

and larger flag leaves than in sole wheat, and from the strip configuration. The decreased radiation interception of intercropped maize in 2014 was due to the negative effect of maize plasticity, i.e. lower leaf number and smaller leaf size in high leaf ranks (Zhu et al., 2014). And the positive effect of row configuration was not enough to compensate for the negative effect of maize plasticity in 2014. The comparatively low LER in the 2014 may therefore be diagnosed as a failure of effective recovery growth following wheat harvest, resulting in relatively low radiation interception.

\subsubsection{Changes in radiation use efficiency in intercrop}

The changes of radiation interception were not proportional to the changes in biomass (or yield), indicating the radiation use efficiencies (RUE) were different in sole crop and in intercrop. For example, the biomass of wheat was $12 \mathrm{t} \mathrm{ha}^{-1}$ in sole crop and $6 \mathrm{tha}^{-1}$ in intercrop in 2013 (Chapter 2), and the radiation interception was $597 \mathrm{MJ} \mathrm{m}^{-2} \mathrm{PAR}$ in sole wheat and $244 \mathrm{MJ} \mathrm{m}^{-2} \mathrm{PAR}$ in intercropped wheat. While the intercropped wheat captured only $41 \%$ as much radiation as sole wheat it produced $50 \%$ as much biomass, indicating an increase in radiation use efficiency.

In Chapters 3 and 4, it was found that intercropped wheat had a higher RUE than sole wheat, while skip-row wheat had the same RUE as sole wheat. The increase of wheat RUE in intercrop treatments, but not in skip-row wheat, suggests that the RUE changes are related to interactions with maize, i.e. shading or competition for water or nutrients. At the same time, intercropped maize showed a lower RUE than sole maize, while skip-row maize had the same RUE as sole maize. The decrease of maize RUE in intercrop, but not in skip-row maize, could indicate that the changes in RUE are related to interactions with wheat during seedling stages, e.g. shading or competition for water or nutrients. Shading provides both lower light intensity and a higher ratio of diffuse light to direct light. Previous studies showed that crop RUE increased with the fraction of diffuse radiation (Norman and Arkebauer, 1991; Sinclair et al., 1992; Hammer and Wright, 1994). In addition, in C3 crops, photosynthetic rate increases less than proportionally as the light intensity increases (Ögren and Evans, 1993), indicating a higher radiation use efficiency at low as compared to high light intensity in C3 crops. These two factors can explain the RUE increase in intercropped wheat. C4 species such as maize show an approximately linear increase in photosynthetic rate as the light intensity increases (Ögren and Evans, 1993). Thus maize tends to use light with the same efficiency under high and low light intensity. One factor that could have provided a positive response to the maize 
RUE in intercrop is a higher proportion of diffuse radiation due to shading by wheat in the early growth stage. Hence, RUE of intercropped maize would be expected to increase as a result of higher diffuse light fraction radiation compared to sole maize, but this was not observed. Therefore leaf nitrogen content and leaf photosynthetic rate were studied in Chapter 5.

Leaf nitrogen content and water availability have strong effects on radiation use efficiency under actual growing conditions (Sinclair and Muchow, 1999). For example, Sinclair and Horie (1989) showed hyperbolic relationships between leaf specific nitrogen (LSN) and radiation use efficiency (RUE) in maize, rice and soybean, i.e. RUE increases faster at low LSN than at high LSN. In Chapter 5, maize in add-row intercrops had a significantly lower specific leaf nitrogen $\left(0.50 \mathrm{~g} \mathrm{~N} \mathrm{~m}^{-2}\right.$ leaf) than sole maize $\left(0.66 \mathrm{~g} \mathrm{~N} \mathrm{~m}^{-2}\right.$ leaf). Strong competition for nitrogen may decrease radiation use efficiency in intercropped maize. In Chapter 6, higher RUE was found for intercropped maize than sole maize in Wuwei; in that experiment the nitrogen fertilizer was $338 \mathrm{~kg} \mathrm{~N} \mathrm{ha}^{-1}$ in the intercrop, which was much higher than in the experiment in Wageningen $\left(200 \mathrm{~kg} \mathrm{~N} \mathrm{ha}^{-1}\right)$. Thus the decrease of RUE in intercropped maize in the Wageningen experiments may relate to insufficient supply of nitrogen fertilizer to intercropped maize.

Although intercropped maize had a lower leaf nitrogen content than sole maize, its photosynthetic rate was found to be higher than that of sole maize for the ear leaf during flowering (Chapter 5). The high photosynthetic rate in intercropped maize may relate to better water availability and improved canopy structure than in sole maize, differences in leaf nitrogen allocation to chlorophyll and Rubisco, and differences between intercropped maize an sole maize in the importance of the ear leaf with respect to the supply of assimilates to the growing ear. (Chapter 5). However, this may not be true for all the leaves and throughout the entire growing season, since intercropped maize had a smaller biomass per plant and a lower RUE in this experiment than sole maize. At the same time, the higher photosynthetic rate in intercropped maize showed the potential for recovery growth after wheat harvest, and the possibilities to achieve a higher yield per plant and higher RUE than sole maize under favourable growing conditions (Section 7.3). 


\subsection{Are those findings in wheat-maize intercrop true for other intercrop systems?}

There are three main characteristics of wheat-maize intercrop that support the high productivity. The first is gap filling response or plasticity of wheat (i.e. the border row effect), the second is "recovery" growth for maize, and the third is high input requirement. And these characteristics are different from those of intercrops with the same growing period (TND is zero). Relay intercropping allows the intercropped species to use space and resources at different moments in the growing season, providing the possibility to capture more resources and to minimize interspecific competition between species. This temporal complementary effect does not exist for intercropping with the same growing period of the component species, for example wheat-pea intercrop (Ghaley et al., 2005) and vetch-cereal (wheat, triticale, barley and oat) intercrop (Dhima et al., 2007). In these systems, yield advantages come from complementarity and facilitation in nitrogen use (Bedoussac et al., 2015). Though relay intercropping is often used in the region where the thermal time is not enough to grow two sequential crops, it can also be applied in conditions allowing double cropping systems. For example, Huang et al. (2015) reported that in North China Plain, farmers developed a wheatmaize/watermelon cropping system to increase productivity and income. In this system, watermelon is grown partly intercropped with wheat and partly intercropped with maize. While the wheat-maize/watermelon system yielded only $74 \%$ of wheat and $81 \%$ of maize as compared to double cropping, it yielded watermelon in addition, which is $79 \%$ of the yield of sole watermelon.

In a relay intercrop, the late sown crop is initially growing under unfavourable growing conditions due to the shading by the first crop. Under actual growing conditions, it may also suffer stress from water limitation or nutrient deficiency because it is a weaker competitor compared to the early sown crop. Thus the recovery growth after the harvest of the first crop is important for the late sown crop. However, in some intercropping systems, the recovery growth is not reported. For example, in a meta-analysis for cereal-legume intercropping systems, Yu (2016) showed that the partial LER of the early sown crop increased with a relatively early sowing, but the partial LER of late sown crop decreased with a relatively later sowing. The positive effect of TND on the early sown crop and the negative effect of TND on the late sown crop jointly resulted in no significant effects of TND on total LER for cereallegume intercrop systems, indicating no "recovery" growth or a very limited "recovery" 
growth for the second sown crop. This may relate to the low input in cereal-legume intercropping, where the depletion of water and/or nutrients by the first crop may negatively affect the growth of the second crop.

Bedoussac et al. (2015) stated that "intercropping is particularly suited for low-nitrogen availability systems". This may be true for cereal-legume intercrops, because the yield advantage (LER) decreases with the increase of $\mathrm{N}$ input (Rao et al., 1987; Jensen, 1996). Legumes can fix nitrogen from air, and when intercropped with cereals, the competition for nitrogen triggered legumes to fix more nitrogen than in sole crop (Xiao et al., 2004). By contrast, in wheat-maize intercrop, sufficient nutrients inputs are required to achieve high yield advantages, especially for the recovery growth of maize during the late growing season.

\subsection{Other aspects of wheat-maize intercropping}

In this thesis, I mainly focused on the aboveground competition, i.e. the intercropped species competition for solar radiation. However, the below ground interaction cannot be ignored in intercrops as discussed in Section 7.5. Mu et al. (2013) found that when a plastic root barrier was put between wheat and maize strips, the intercropping yield advantage decreased. They furthermore estimated that belowground interspecies interactions made up $32 \sim 40 \%$ of the increased yield in three years. This positive belowground interspecific interaction may be due to the improved root distribution and more root biomass. For example, Li et al. (2006) found that intercropped wheat spread the roots under the neighbouring maize plants, while intercropped maize proliferated its roots more deeply than sole maize, and both intercropped wheat and maize had a greater root length density (root length per unit soil volume) than the sole crops. Cong et al. (2015b) found that the root biomass in the intercrop was higher than in sole crops.

Although the wheat-maize intercrop provided significant advantages in land use efficiency, some literatures reported it decreased water use efficiency. For example, Gao et al. (2009) showed wheat-maize intercrop used water $23 \%$ less efficiently than sole maize, and $\mathrm{Hu}$ et al. (2015) also showed wheat-maize intercrop used more water than sole crops. But the water use efficiency of the intercrop can be improved by alternative irrigation practices (Yang et al., 2011) or straw mulching (Yin et al., 2015; Hu et al., 2016). In addition, the reduced tillage and straw mulching management in intercrop were found to reduce soil carbon emission compared to the conventional sole crops (Hu et al., 2015; Hu et al., 2016). However, such 


\section{Chapter 7}

practices maybe equally effective in sole crops. Furthermore, after seven years of intercropping, the soil organic $\mathrm{C}$ and soil organic $\mathrm{N}$ had increased in the top $20 \mathrm{~cm}$ soil compared to sole crops (Cong et al., 2015b). Those findings suggest that wheat-maize intercropping may not only improve the land use efficiency, but also has the potential to improve water use efficiency and mitigate greenhouse gas emission.

\subsection{The current state and future of wheat-maize intercropping}

The area of wheat-maize intercropping was 75,100 ha in Ningxia and 200,000 ha in Gansu in 1995 ( $\mathrm{Li}$ et al., 2001b), but it decreased during the past decades presumably due to three socioeconomic reasons. First, with the economic growth in China and the change of food diet, farmers may choose to grow more profitable crops, such as vegetables and fruits rather than wheat and maize. This is happening in the many parts of China, especially in the suburban villages. And there is a transformation of land use towards cooperation between farmers and agricultural companies. For example, Zhang et al. (2014) reported that in Minle county, Zhangye city, farmers changed from grain production to potato production for a potato processing company. And Shi et al. (2014) showed that the proportion of land used for grain production is currently much less than for cash crops in Zhangye city. Secondly, with increasing job opportunities in cities, the agricultural sector lost labourers (Feike et al., 2012), and this particularly affected wheat-maize intercropping because it is labour intensive. The third reason is the governmental policy on water use. For example, the local government banned wheat-maize intercrop in Wuwei city, because the policy makers believe that intercrops use more water than sole crops.

Although the above reasons caused a large decrease of wheat-maize intercropping in Gansu province, a considerable proportion of farmers is still using wheat-maize intercropping in the five surveyed villages, i.e. 238 farms out of 360 farms (Chapter 6). Cash crops do not take a large share of land in these villages because they are far from the city (the closest city Gaotai is about $50 \mathrm{~km}$ ). In Chapter 6, the land use scenario analysis showed that if all farmers would stop using wheat-maize intercropping and switch to sole wheat and sole maize, the wheat yield would decrease $33 \%$ and the maize yield would decrease $29 \%$ compared to the current grain production. Meanwhile, large yield gaps (relative to potential yields) were found in farmers' fields, i.e. the yield gap was $33 \%$ for sole wheat and $15 \%$ for intercropped wheat, while it was $49 \%$ for sole maize and $51 \%$ for intercropped maize. Though the poor control of 
weeds, diseases and pests were diagnosed to be factors leading to yield gaps, the main problem in this region is water shortage.

In future, wheat-maize intercropping may not prevail in northwest China as in the 1990s due to the competition for water and land from cash crops and labour migration from rural areas. However, wheat-maize intercrop may establish in other regions with its advantages in land use efficiency, for example in Europe. In Chapter 2, the experiments showed that the LER of wheat-maize intercropping under Dutch growing conditions was up to 1.3, indicating wheatmaize intercropping has the potential to outperform sole crops in Europe. However, a yearly variation in intercropping productivity was also observed, and it is presumably caused by climatic factors and agronomic management, i.e. low temperature, low light intensity and insufficient nitrogen fertilizer supply. As maize is a C4 crop, it favours high temperature and high light intensity. As noted before, the recovery growth of intercropped maize after wheat harvest is crucial to maintain high productivity of maize in intercrop. Thus a wheat-maize intercrop may benefit from new maize cultivars which are better adapted to cool growing conditions. In addition, as European agriculture is highly mechanized, another challenge of using wheat-maize intercropping is to design suitable machines for different sowing and harvesting times of the two species and for their strip configurations. There are several examples showing that machines are occasionally used in intercropping cultivation. In Henan province, north China, wheat can be harvested by combine harvester in wheat-cotton relay intercropping because cotton plants are relatively small at the time of wheat harvest. Bulson et al. (1997) also demonstrated that wheat and field bean could be sown in alternative rows and harvested by a combiner. In our field experiments, small machines ( $1.5 \mathrm{~m}$ wide) were used to sow maize between wheat strips and harvest wheat between maize strip (Fig. 2.2 a and c), while large machines ( $3 \mathrm{~m}$ wide) were used to sow wheat and harvest maize as in sole crops. More intercrop-specific machines will become available in the market only if the farmers have interest in intercropping, e.g. for economic reasons. Thus an engagement between researchers and other actors in the value chain will be required to enable an environment in which intercropping will become a feasible option for farmers in the future.

\subsection{Concluding remarks and opportunities for future research}

In this thesis, I studied the growth and productivity of wheat-maize intercropping at organ, plant and cropping system level, and also assessed its contribution to grain production at a regional level. From previous studies and the field experiments in this thesis, we know that 


\section{Chapter 7}

wheat is easy to maintain the advantages in intercropping compared to the sole crop, due to reduced competition during early stages of the intercrop compared to the sole crop. But we know less about intercropped maize, e.g. why does intercropped maize hold advantages in some locations but not in other locations. Factors such as temperature, radiation and nitrogen levels after wheat harvest are assumed to explain the variation in different locations (Section 7.2). Those assumptions can only be tested with more field experiments at different locations and with different input levels. In Chapter 5, intercropped maize was found to have a higher photosynthetic rate with a lower specific leaf nitrogen compared to sole maize during flowering stage. On the one hand, this finding is exciting and more research is needed to explain this unusual phenomenon from a physiological perspective. On the other hand, Chapter 5 only studied the nitrogen concentration and photosynthesis of the ear leaf for three weeks, and it is uncertain how well these measurements represent the whole plant and the whole growing season for intercropped maize. Measurements must be done for different leaves and during the entire growing season to allow for proper upscaling. Therefore, the growth of intercropped maize under different climatic conditions and different input levels are interesting to study.

In Chapter 6, I only focused on the yields in farmers' fields, and there are many more questions that need to be answered, such as what factors affect farmers to make decisions on using or stopping wheat-maize intercropping; do they invest more labour and/or fertilizer in intercrops than in sole crops, and does intercropping use resources more efficiently than sole crops? In northwest China, though wheat-maize intercrop can provide high yields, the concern for water resources needs to be taken into account. There are some experiments showing that different agronomic management practices, e.g. straw mulching or alternative irrigation methods could save water and improve water use efficiency in Wuwei (Hu et al., 2016; Yin et al., 2015). More work must be done to provide evidence to farmers and policy makers to use the limited land and water more efficiently and to produce more food. For example, targetoriented analysis can be conducted for different land use criteria, e.g. to maximize grain production or economic profit, or to minimize environmental impact or labour input (van Ittersum et al., 1998; Lu et al., 2003; Lu et al., 2004; Dogliotti et al., 2005). Furthermore, land use analysis can be conducted in the regions where wheat-maize intercropping is feasible but not being used, to assess the potential increase in grain production if all or partly the current sole wheat and sole maize land is used for wheat-maize intercropping. 


\section{References}

A

Abbad, H., Jaafari, S.E.L., Bort, J., Araus, J.L., 2004. Comparison of flag leaf and the ear photosynthesis with biomass and grain yield of durum wheat under various water conditions and genotypes. Agronomie 24, 19-28.

Adu-Gyamfi, J.J., Myaka, F.A., Sakala, W.D., Odgaard, R., Vesterager, J.M., Høgh-Jensen, H., 2007. Biological nitrogen fixation and nitrogen and phosphorus budgets in farmer-managed intercrops of maize-pigeonpea in semi-arid southern and eastern Africa. Plant and soil 295, 127-136.

Alexandratos, N., Bruinsma, J., 2012. World agriculture towards 2030/2050: the 2012 revision. ESA Working Paper No. 12-03. Food and Agriculture Organization of the United Nations.

Andersen, M.K., Hauggaard-Nielsen, H., Ambus, P., Jensen, E.S., 2005. Biomass production, symbiotic nitrogen fixation and inorganic $\mathrm{N}$ use in dual and tri-component annual intercrops. Plant and Soil 266, 273-287.

Andow, D.A., 1991. Vegetational diversity and arthropod population response. Annual review of entomology $36,561-586$.

Andrade, F.H., Uhart, S.A., Cirilo, A., 1993. Temperature affects radiation use efficiency in maize. Field Crops Research 32, 17-25.

Angulo, C., Rötter, R., Lock, R., Enders, A., Fronzek, S., Ewert, F., 2013. Implication of crop model calibration strategies for assessing regional impacts of climate change in Europe. Agricultural and Forest Meteorology 170, 32-46.

Araus, J.L., Brown, H.R., Febrero, A., Bort, J., Serret, M.D., 1993. Ear photosynthesis, carbon isotope discrimination and the contribution of respiratory $\mathrm{CO}_{2}$ to differences in grain mass in durum wheat. Plant, Cell and Environment 16, 383-392.

Arlauskienė, A., Maikštėnienė, S., Šarūnaitè, L., Kadžiulienė, Ž., Deveikytė, I., Žèkaitė, V., Česnulevičienè, R., 2011. Competitiveness and productivity of organically grown pea and spring cereal intercrops. Žemdirbystè = Agriculture 98, 339-348. 
Baumann, D.T., Bastiaans, L., Goudriaan, J., van Laar, H.H., Kropff, M.J., 2002. Analysing crop yield and plant quality in an intercropping system using an eco-physiological model for interplant competition. Agricultural Systems 73, 173-203.

Baumann, D.T., Kropff, M.J., Bastiaans, L., 2000. Intercropping leeks to suppress weeds. Weed research 40, 359-374.

Bedoussac, L., Journet, E.-P., Hauggaard-Nielsen, H., Naudin, C., Corre-Hellou, G., Jensen, E.S., Prieur, L., Justes, E., 2015. Ecological principles underlying the increase of productivity achieved by cereal-grain legume intercrops in organic farming. A review. Agronomy for Sustainable Development 35, 911-935.

Bell, M.A., Fischer, R.A., Byerlee, D., Sayre, K., 1995. Genetic and agronomic contributions to yield gains: A case study for wheat. Field Crops Research 44, 55-65.

Björkman, O., 1981. Responses to different quantum flux densities. Physiological plant ecology I. Springer, pp. 57-107.

Boling, A.A., Tuong, T.P., van Keulen, H., Bouman, B.A.M., Suganda, H., Spiertz, J.H.J., 2010. Yield gap of rainfed rice in farmers' fields in Central Java, Indonesia. Agricultural systems 103, 307-315.

Bolker, B.M., 2008. Ecological models and data in R. Princeton University Press.

Bouman, B.A.M., van Keulen, H., van Laar, H.H., Rabbinge, R., 1996. The 'School of de Wit'crop growth simulation models: a pedigree and historical overview. Agricultural systems 52, 171-198.

Brisson, N., Bussiere, F., Ozier-Lafontaine, H., Tournebize, R., Sinoquet, H., 2004. Adaptation of the crop model STICS to intercropping. Theoretical basis and parameterisation. Agronomie 24, 409-421.

Brooker, R.W., Bennett, A.E., Cong, W.-F., Daniell, T.J., George, T.S., Hallett, P.D., Hawes, C., Iannetta, P.P., Jones, H.G., Karley, A.J., Li, L., McKenzie, B.M., Pakeman, R.J., Paterson, E., Schöb, C., Shen, J., Squire, G., Watson, C.A., Zhang, C., Zhang, F., Zhang, J., White, P.J., 2015. Improving intercropping: a synthesis of research in agronomy, plant physiology and ecology. New Phytologist 206, 107-117.

Bulson, H.A.J., Snaydon, R.W., Stopes, C.E., 1997. Effects of plant density on intercropped wheat and field beans in an organic farming system. The Journal of Agricultural Science 128, 59-71. 
Carr, P.M., Horsley, R.D., Poland, W.W., 2004. Barley, oat, and cereal-pea mixtures as dryland forages in the Northern Great Plains. Agronomy Journal 96, 677-684.

Cassman, K.G., 1999. Ecological intensification of cereal production systems: yield potential, soil quality, and precision agriculture. Proceedings of the National Academy of Sciences 96, 5952-5959.

Cassman, K.G., Dobermann, A., Walters, D.T., Yang, H., 2003. Meeting cereal demand while protecting natural resources and improving environmental quality. Annual Review of Environment and Resources 28, 315-358.

Cenpukdee, U., Fukai, S., 1992. Cassava/legume intercropping with contrasting cassava cultivars. 1. Competition between component crops under three intercropping conditions. Field Crops Research 29, 113-133.

Clawson, D.L., 1985. Harvest security and intraspecific diversity in traditional tropical agriculture. Economic Botany 39, 56-67.

Cong, W.-F., Hoffland, E., Li, L., Janssen, B.H., van der Werf, W., 2015a. Intercropping affects the rate of decomposition of soil organic matter and root litter. Plant and Soil 391, 399-411.

Cong, W.-F., Hoffland, E., Li, L., Six, J., Sun, J.-H., Bao, X.-G., Zhang, F.-S., van der Werf, W., 2015b. Intercropping enhances soil carbon and nitrogen. Global change biology $21,1715-1726$.

Corre-Hellou, G., Faure, M., Launay, M., Brisson, N., Crozat, Y., 2009. Adaptation of the STICS intercrop model to simulate crop growth and $\mathrm{N}$ accumulation in pea-barley intercrops. Field Crops Research 113, 72-81.

Corre-Hellou, G., Fustec, J., Crozat, Y., 2006. Interspecific competition for soil N and its interaction with N2 fixation, leaf expansion and crop growth in pea-barley intercrops. Plant and Soil 282, 195-208.

Crawley, M.J., 2012. The R book. John Wiley \& Sons.

\section{D}

Dai, X., Ouyang, Z., Li, Y., Wang, H., 2013. Variation in yield gap induced by nitrogen, phosphorus and potassium fertilizer in north China plain. PloS one 8, e82147. 
Dale, J.E., 1988. The Control of Leaf Expansion. Annual Review of Plant Physiology and Plant Molecular Biology 39, 267-295.

De Koeijer, K.d., van der Werf, W., 1995. Effect of beet yellowing viruses on light interception and light use efficiency of the sugarbeet crop. Crop Protection 14, 291297.

De Wit, C., 1959. Potential photosynthesis of crop surfaces. Neth. J. Agric. Sci 7, 141-149.

Dhima, K.V., Lithourgidis, A.S., Vasilakoglou, I.B., Dordas, C.A., 2007. Competition indices of common vetch and cereal intercrops in two seeding ratio. Field Crops Research 100, 249-256.

Dogliotti, S., van Ittersum, M.K., Rossing, W.A.H., 2005. A method for exploring sustainable development options at farm scale: a case study for vegetable farms in South Uruguay. Agricultural Systems 86, 29-51.

$\mathbf{E}$

Entz, M.H., Guilford, R., Gulden, R., 2001. Productivity of organic crop production in the eastern region of the Northern Great Plains: A survey of 14 farms. Can J Plant Sci 81, 351-354.

Evans, L.T., 1993. Crop Evolution, Adaptation and Yield Cambridge Univ. Press, Cambridge, UK.

$\mathbf{F}$

Fan, Z., Chai, Q., Huang, G., Yu, A., Huang, P., Yang, C., Tao, Z., Liu, H., 2013. Yield and water consumption characteristics of wheat/maize intercropping with reduced tillage in an Oasis region. European Journal of Agronomy 45, 52-58.

FAO, 2009. How to Feed the World in 2050. Rome: High-Level Expert Forum.

Farré, I., van Oijen, M., Leffelaar, P.A., Faci, J.M., 2000. Analysis of maize growth for different irrigation strategies in northeastern Spain. European Journal of Agronomy $12,225-238$.

Feike, T., Doluschitz, R., Chen, Q., Graeff-Hönninger, S., Claupein, W., 2012. How to overcome the slow death of intercropping in the North China Plain. Sustainability 4, 2550-2565.

Field, C., 1983. Allocating leaf nitrogen for the maximization of carbon gain: leaf age as a control on the allocation program. Oecologia 56, 341-347. 
Fischer, R.A., Byerlee, D., Edmeades, G.O., 2012. Crop yields and global food security. Canberra: Australian Center for International Agricultural Research.

Fukai, S., Trenbath, B., 1993. Processes determining intercrop productivity and yields of component crops. Field Crops Research 34, 247-271.

\section{G}

Gallagher, J.N., Biscoe, P.V., 1978. Radiation absorption, growth and yield of cereals. J. Agric. Sci. 91, 47-60.

Gao, Y., Duan, A., Sun, J., Li, F., Liu, Z., Liu, H., Liu, Z., 2009. Crop coefficient and wateruse efficiency of winter wheat/spring maize strip intercropping. Field Crops Research 111, 65-73.

Gao, Y., Wu, P., Zhao, X., Wang, Z., 2014. Growth, yield, and nitrogen use in the wheat/maize intercropping system in an arid region of northwestern China. Field Crops Research 167, 19-30.

Gelman, A., Hwang, J., Vehtari, A., 2014. Understanding predictive information criteria for Bayesian models. Statistics and Computing 24, 997-1016.

Ghaley, B.B., Hauggaard-Nielsen, H., Høgh-Jensen, H., Jensen, E.S., 2005. Intercropping of wheat and pea as influenced by nitrogen fertilization. Nutrient Cycling in Agroecosystems 73, 201-212.

Ghanbari, A., Dahmardeh, M., Siahsar, B.A., Ramroudi, M., 2010. Effect of maize (Zea mays L.) - Cowpea (Vigna unguiculata L.) intercropping on light distribution, soil temperature and soil moisture in arid environment. Journal of Food, Agriculture and Environment 8, 102-108.

Gosse, G., Varlet-Grancher, C., Bonhomme, R., Chartier, M., Allirand, J., Lemaire, G., 1986. Maximum dry matter production and solar radiation intercepted by a canopy. Agronomie (France) 6, 47-56.

Goudriaan, J., 1977. Crop micrometeorology: a simulation study. Pudoc, Center for Agricultural Publishing and Documentation.

Gregory, P.J., Ingram, J.S.I., Andersson, R., Betts, R.A., Brovkin, V., Chase, T.N., Grace, P.R., Gray, A.J., Hamilton, N., Hardy, T.B., 2002. Environmental consequences of alternative practices for intensifying crop production. Agriculture, ecosystems \& environment 88, 279-290. 


\section{H}

Ha, N., Feike, T., Angenendt, E., Xiao, H., Bahrs, E., 2015. Impact of farm management diversity on the environmental and economic performance of the wheat-maize cropping system in the North China Plain. International Journal of Agricultural Sustainability $13,350-366$.

Hammer, G.L., Wright, G.C., 1994. A theoretical analysis of nitrogen and radiation effects on radiation use efficiency in peanut. Crop and Pasture Science 45, 575-589.

Harris, D., Natarajan, M., Willey, R., 1987. Physiological basis for yield advantage in a sorghum/groundnut intercrop exposed to drought 1: dry-matter production, yield, and light interception. Field Crops Research 17, 259-272.

Hauggaard-Nielsen, H., Ambus, P., Jensen, E.S., 2003. The comparison of nitrogen use and leaching in sole cropped versus intercropped pea and barley. Nutrient Cycling in Agroecosystems 65, 289-300.

Hauggaard-Nielsen, H., Jensen, E.S., 2001. Evaluating pea and barley cultivars for complementarity in intercropping at different levels of soil $\mathrm{N}$ availability. Field Crops Research 72, 185-196.

Haverkort, A.J., Bicamumpaka, M., 1986. Correlation between intercepted radiation and yield of potato crops infested by phytophora-infestans in central-Africa. Netherlands Journal of Plant Pathology 92, 239-247.

Hawkins, A., 1982. Light interception, photosynthesis and crop productivity. Outlook on Agriculture 11, 104-113.

Hochman, Z., Gobbett, D., Holzworth, D., McClelland, T., van Rees, H., Marinoni, O., Garcia, J.N., Horan, H., 2012. Quantifying yield gaps in rainfed cropping systems: A case study of wheat in Australia. Field Crops Research 136, 85-96.

Horie, T., De Wit, C.T., Goudriaan, J., Bensink, J., 1979. A formal template for the development of cucumber in its vegetative stage (I, II and III). Proceedings of the Koninklijke Nederlandse Akademie van Wetenschappen. Serie C: Biological and medical sciences $82,433-479$.

Horwith, B., 1985. A role for intercropping in modern agriculture. BioScience 35, 286-291.

Hu, F., Chai, Q., Yu, A., Yin, W., Cui, H., Gan, Y., 2015. Less carbon emissions of wheatmaize intercropping under reduced tillage in arid areas. Agronomy for Sustainable Development 35, 701-711. 
Hu, F., Gan, Y., Cui, H., Zhao, C., Feng, F., Yin, W., Chai, Q., 2016. Intercropping maize and wheat with conservation agriculture principles improves water harvesting and reduces carbon emissions in dry areas. European Journal of Agronomy 74, 9-17.

Huang, C., Liu, Q., Heerink, N., Stomph, T., Li, B., Liu, R., Zhang, H., Wang, C., Li, X., Zhang, C., van der Werf, W., Zhang, F., 2015. Economic Performance and Sustainability of a Novel Intercropping System on the North China Plain. PloS one $10, \mathrm{e} 0135518$.

\section{J}

Jackson, J.E., Palmer, J.W., 1979. A simple model of light transmission and interception by discontinuous canopies. Annals of botany 44, 381-383.

Jamieson, P.D., Semenov, M.A., Brooking, I.R., Francis, G.S., 1998. Sirius: a mechanistic model of wheat response to environmental variation. European Journal of Agronomy $8,161-179$.

Jensen, E.S., 1996. Grain yield, symbiotic N2 fixation and interspecific competition for inorganic $\mathrm{N}$ in pea-barley intercrops. Plant and Soil 182, 25-38.

Johnson, I.R., Parsons, A.J., Ludlow, M.M., 1989. Modelling photosynthesis in monocultures and mixtures. Functional Plant Biology 16, 501-516.

\section{$\mathbf{K}$}

Keating, B.A., Carberry, P.S., 1993. Resource capture and use in intercropping: solar radiation. Field Crops Research 34, 273-301.

Keating, B.A., Carberry, P.S., Hammer, G.L., Probert, M.E., Robertson, M.J., Holzworth, D., Huth, N.I., Hargreaves, J.N.G., Meinke, H., Hochman, Z., 2003. An overview of APSIM, a model designed for farming systems simulation. European Journal of Agronomy 18, 267-288.

Knörzer, H., Graeff-Hönninger, S., Guo, B., Wang, P., Claupein, W., 2009. The rediscovery of intercropping in China: a traditional cropping system for future Chinese agriculture-a review. Climate Change, Intercropping, Pest Control and Beneficial Microorganisms. Springer, pp. 13-44.

Kontturi, M., Laine, A., Niskanen, M., Hurme, T., Hyövelä, M., Peltonen-Sainio, P., 2011. Pea-oat intercrops to sustain lodging resistance and yield formation in northern 
European conditions. Acta Agriculturae Scandinavica, Section B-Soil \& Plant Science 61, 612-621.

Kooman, P.L., Haverkort, A.J., 1995. Modelling development and growth of the potato crop influenced by temperature and daylength: LINTUL-POTATO. Potato ecology and modelling of crops under conditions limiting growth. Springer, pp. 41-59.

Kropff, M.J., van Laar, H.H., 1993. Modelling crop-weed interactions. CAB International Wallingford, UK.

Kropff, M.J., Vossen, F.J.H., Spitters, C.J.T., Groot, W.d., 1984. Competition between a maize crop and a natural population of Echinochloa crus-galli (L.) PB. Netherlands Journal of Agricultural Science 32, 324-327.

Kyamanywa, S., Tukahirwa, E.M., 1988. Effect of mixed cropping beans, cowpeas and maize on population densities of bean flower thrips, Megalurothrips sjostedti (Trybom)(Thripidae). International Journal of Tropical Insect Science 9, 255-259.

\section{L}

Laborte, A.G., de Bie, K.C.A.J.M., Smaling, E.M.A., Moya, P.F., Boling, A.A., van Ittersum, M.K., 2012. Rice yields and yield gaps in Southeast Asia: Past trends and future outlook. European Journal of Agronomy 36, 9-20.

Lafolie, F., Bruckler, L., Ozier-Lafontaine, H., Tournebize, R., Mollier, A., 1999. Modeling soil-root water transport and competition for single and mixed crops. Plant and soil 210, 127-143.

Lantinga, E.A., Nassiri, M., Kropff, M.J., 1999. Modelling and measuring vertical light absorption within grass-clover mixtures. Agricultural and Forest Meteorology 96, 7184.

Leong, T.Y., Anderson, J.M., 1986. Light-quality and irradiance adaptation of the composition and function of pea-thylakoid membranes. Biochimica et Biophysica Acta (BBA)-Bioenergetics 850, 57-63.

Li, K., Yang, X., Liu, Z., Zhang, T., Lu, S., Liu, Y., 2014. Low yield gap of winter wheat in the North China Plain. European Journal of Agronomy 59, 1-12.

Li, L., Li, S.M., Sun, J.H., Zhou, L.L, Bao, X.G., Zhang, H.G., Zhang, F., 2007. Diversity enhances agricultural productivity via rhizosphere phosphorus facilitation on phosphorus deficient soils. Proceedings of the National Academy of Science 104, 1192-1196. 
Li, L., Sun, J., Zhang, F., 2011. Intercropping with wheat leads to greater root weight density and larger below-ground space of irrigated maize at late growth stages. Soil Science and Plant Nutrition 57, 61-67.

Li, L., Sun, J., Zhang, F., Guo, T., Bao, X., Smith, F.A., Smith, S.E., 2006. Root distribution and interactions between intercropped species. Oecologia 147, 280-290.

Li, L., Sun, J., Zhang, F., Li, X., Rengel, Z., Yang, S., 2001a. Wheat/maize or wheat/soybean strip intercropping: II. Recovery or compensation of maize and soybean after wheat harvesting. Field Crops Research 71, 173-181.

Li, L., Sun, J., Zhang, F., Li, X., Yang, S., Rengel, Z., 2001b. Wheat/maize or wheat/soybean strip intercropping: I. Yield advantage and interspecific interactions on nutrients. Field Crops Research 71, 123-137.

Li, L., Zhang, L., Zhang, F., 2013. Crop mixtures and the mechanisms of overyielding. Encyclopedia of Biodiversity, 2nd edn (ed. Levin SA). Academic Press, Waltham.

Li, N., Wang, X., Shi, M., Yang, H., 2015. Economic Impacts of Total Water Use Control in the Heihe River Basin in Northwestern China-An Integrated CGE-BEM Modeling Approach. Sustainability 7, 3460-3478.

Liang, W., Carberry, P., Wang, G., Lü, R., Lü, H., Xia, A., 2011. Quantifying the yield gap in wheat-maize cropping systems of the Hebei Plain, China. Field Crops Research 124, 180-185.

Liang, W., Lu, H., Xia, A., Wang, G., Qin, F., Yang, Z., Lu, Y., 2006. A preliminary analysis on the yield gap of winter wheat between demonstration plots and farmers' fields. Journal of Food Agriculture and Environment 4, 143.

Liu, T., Song, F., Liu, S., Zhu, X., 2011. Canopy structure, light interception, and photosynthetic characteristics under different narrow-wide planting patterns in maize at silking stage. Spanish Journal of Agricultural Research 9, 1249-1261.

Lithourgidis, A.S., Dhima, K.V., Vasilakoglou, I.B., Dordas, C.A., Yiakoulaki, M.D., 2007. Sustainable production of barley and wheat by intercropping common vetch. Agronomy for Sustainable Development 27, 95-99.

Lithourgidis, A.S., Dordas, C.A., 2010. Forage yield, growth rate, and nitrogen uptake of faba bean intercrops with wheat, barley, and rye in three seeding ratios. Crop Science 50, 2148-2158. 
Lithourgidis, A.S., Dordas, C.A., Damalas, C.A., Vlachostergios, D.N., 2011a. Annual intercrops: an alternative pathway for sustainable agriculture. Australian Journal of Crop Science 5, 396-410.

Lithourgidis, A.S., Vasilakoglou, I.B., Dhima, K.V., Dordas, C.A., Yiakoulaki, M.D., 2006. Forage yield and quality of common vetch mixtures with oat and triticale in two seeding ratios. Field Crops Research 99, 106-113.

Lithourgidis, A.S., Vlachostergios, D.N., Dordas, C.A., Damalas, C.A., 2011b. Dry matter yield, nitrogen content, and competition in pea-cereal intercropping systems. European Journal of Agronomy 34, 287-294.

Liu, X., He, P., Jin, J., Zhou, W., Sulewski, G., Phillips, S., 2011. Yield gaps, indigenous nutrient supply, and nutrient use efficiency of wheat in China. Agronomy journal 103, 1452-1463.

Liu, X.H., Chen, F., 2005. Farming System in China. China Agriculture Press, Beijing.

Liu, Z., Yang, X., Hubbard, K.G., Lin, X., 2012. Maize potential yields and yield gaps in the changing climate of northeast China. Global change biology 18, 3441-3454.

Lobell, D.B., Cassman, K.G., Field, C.B., 2009. Crop yield gaps: their importance, magnitudes, and causes. Annual Review of Environment and Resources 34, 179.

Loomis, R.S., Williams, W.A., 1963. Maximum crop productivity: an extimate. Crop Science $3,67-72$.

Lu, C., Fan, L., 2013. Winter wheat yield potentials and yield gaps in the North China Plain. Field crops research 143, 98-105.

Lu, C.H., van Ittersum, M.K., Rabbinge, R., 2003. Quantitative assessment of resource-use efficient cropping systems: a case study for Ansai in the Loess Plateau of China. European Journal of Agronomy 19, 311-326.

Lu, C.H., van Ittersum, M.K., Rabbinge, R., 2004. A scenario exploration of strategic land use options for the Loess Plateau in northern China. Agricultural Systems 79, 145-170.

Lunnan, T., 1989. Barley-pea mixtures for whole crop forage. Effects of different cultural practices on yield and quality. Norwegian Journal of Agricultural Sciences 3, 57-71.

\section{M}

Machado, S., 2009. Does intercropping have a role in modern agriculture? Journal of Soil and Water Conservation 64, 55A-57A. 
Mahallati, M.N., Koocheki, A., Mondani, F., Feizi, H., Amirmoradi, S., 2015. Determination of optimal strip width in strip intercropping of maize (Zea mays L.) and bean (Phaseolus vulgaris L.) in Northeast Iran. Journal of Cleaner Production 106, 343350.

Malézieux, E., Crozat, Y., Dupraz, C., Laurans, M., Makowski, D., Ozier-Lafontaine, H., Rapidel, B., De Tourdonnet, S., Valantin-Morison, M., 2009. Mixing plant species in cropping systems: concepts, tools and models. A review. Agronomy Sustainable Development 29, 43-62.

Mao, L., Zhang, L., Zhao, X., Liu, S., van der Werf, W., Zhang, S., Spiertz, H., Li, Z., 2014. Crop growth, light utilization and yield of relay intercropped cotton as affected by plant density and a plant growth regulator. Field Crops Research 155, 67-76.

Marshall, B., Willey, R.W., 1983. Radiation interception and growth in an intercrop of pearl millet/groundnut. Field Crops Research 7, 141-160.

Masclaux-Daubresse, C., Reisdorf - Cren, M., Orsel, M., 2008. Leaf nitrogen remobilisation for plant development and grain filling. Plant Biology 10, 23-36.

Massignam, A.M., Chapman, S.C., Hammer, G.L., Fukai, S., 2009. Physiological determinants of maize and sunflower grain yield as affected by nitrogen supply. Field Crops Research 113, 256-267.

Matson, P.A., Parton, W.J., Power, A.G., Swift, M.J., 1997. Agricultural intensification and ecosystem properties. Science 277, 504-509.

Mead, R., Willey, R.W., 1980. The concept of a 'land equivalent ratio'and advantages in yields from intercropping. Experimental Agriculture 16, 217-228.

Meng, Q., Hou, P., Wu, L., Chen, X., Cui, Z., Zhang, F., 2013. Understanding production potentials and yield gaps in intensive maize production in China. Field crops research 143, 91-97.

Miralles, D.J., Slafer, G.A., 1991. A simple model for non-destructive estimates of leaf area in wheat. Cereal Research Communications, 439-444.

Monsi, M., Saeki, T., 1953. The light factor in plant communities and its significance for dry matter production. Japanese Journal of Botany 14, 22-52.

Monteith, J.L., 1977. Climate and the Efficiency of Crop Production in Britain. Royal Society of London Philosophical Transactions Series B 281, 277-294. 
Mu, Y., Chai, Q., Yu, A., Yang, C., Qi, W., Feng, F., Kong, X., 2013. Performance of wheat/maize intercropping is a function of belowground interspecies interactions. Crop Science 53, 2186-2194.

Mucheru-Muna, M., Pypers, P., Mugendi, D., Kung'u, J., Mugwe, J., Merckx, R., Vanlauwe, B., 2010. A staggered maize-legume intercrop arrangement robustly increases crop yields and economic returns in the highlands of Central Kenya. Field Crops Research $115,132-139$.

Muchow, R.C., Davis, R., 1988. Effect of nitrogen supply on the comparative productivity of maize and sorghum in a semi-arid tropical environment II. Radiation interception and biomass accumulation. Field Crops Research 18, 17-30.

Muchow, R.C., Sinclair, T.R., 1994. Nitrogen response of leaf photosynthesis and canopy radiation use efficiency in field-grown maize and sorghum. Crop Science 34, 721727.

Mueller, N.D., Gerber, J.S., Johnston, M., Ray, D.K., Ramankutty, N., Foley, J.A., 2012. Closing yield gaps through nutrient and water management. Nature 490, 254-257.

\section{$\mathbf{N}$}

Nash, J.E., Sutcliffe, J.V., 1970. River flow forecasting through conceptual models part I-A discussion of principles. Journal of hydrology 10, 282-290.

Natarajan, M., Willey, R.W., 1980. Sorghum-pigeonpea intercropping and the effects of plant population density. 2. Resource use. The Journal of Agricultural Science 95, 59-65.

Natarajan, M., Willey, R.W., 1986. The effects of water stress on yield advantages of intercropping systems. Field Crops Research 13, 117-131.

Neumann, K., Verburg, P.H., Stehfest, E., Müller, C., 2010. The yield gap of global grain production: A spatial analysis. Agricultural Systems 103, 316-326.

Norman, J.M., Arkebauer, T.J., 1991. Predicting canopy light-use efficiency from leaf characteristics. Modeling plant and soil systems, 125-143.

Novozamsky, I., Houba, V.J.G., van Eck, R., van Vark, W., 1983. A novel digestion technique for multi- element plant analysis. Communications in Soil Science \& Plant Analysis 14, 239-248.

\section{O}

Ögren, E., Evans, J.R., 1993. Photosynthetic light-response curves. Planta 189, 182-190. 
Osman, A.M., Milthorpe, F.L., 1971. Photosynthesis of wheat leaves in relation to age, illuminance and nutrient supply. II. Results. Photosynthetica 5, 61-70.

Ozier-Lafontaine, H., Vercambre, G., Tournebize, R., 1997. Radiation and transpiration partitioning in a maize-sorghum intercrop: test and evaluation of two models. Field crops research $49,127-145$.

\section{$\mathbf{P}$}

Plummer, M., Best, N., Cowles, K., Vines, K., 2006. CODA: Convergence diagnosis and output analysis for MCMC. R news 6, 7-11.

Pommel, B., Gallais, A., Coque, M., Quilleré, I., Hirel, B., Prioul, J., Andrieu, B., Floriot, M., 2006. Carbon and nitrogen allocation and grain filling in three maize hybrids differing in leaf senescence. European Journal of Agronomy 24, 203-211.

Pronk, A., Goudriaan, J., Stilma, E., Challa, H., 2003. A simple method to estimate radiation interception by nursery stock conifers: a case study of eastern white cedar. NJASWageningen Journal of Life Sciences 51, 279-295.

\section{$\mathbf{R}$}

R Core Team, 2015. R: A language and environment for statistical computing. R Foundation for Statistical Computing, Vienna. URL http://www.R-project.org/.

Rahman, M.M., Amano, T., Shiraiwa, T., 2009. Nitrogen use efficiency and recovery from N fertilizer under rice-based cropping systems. Australian Journal of Crop Science 3, 336.

Rao, M.R., Willey, R.W., 1980. Evaluation of yield stability in intercropping: studies on sorghum/pigeonpea. Experimental Agriculture 16, 105-116.

Rao, M.R., Rego, T.J., Willey, R.W., 1987. Response of cereals to nitrogen in sole cropping and intercropping with different legumes. Plant and Soil 101, 167-177.

Rawson, H.M., Hackett, C., 1974. An exploration of the carbon economy of the tobacco plant. III. Gas exchange of leaves in relation to position on the stem, ontogeny and nitrogen content. Functional Plant Biology 1, 551-560.

Risch, S.J., 1983. Intercropping as cultural pest control: prospects and limitations. Environmental Management 7, 9-14. 


\section{$\mathbf{S}$}

Shi, M., Wang, X., Yang, H., Wang, T., 2014. Pricing or quota? A solution to water scarcity in oasis regions in China: A case study in the Heihe River Basin. Sustainability 6, 7601-7620.

Simane, B., van Keulen, H., Stol, W., Struik, P.C., 1994. Application of a crop growth model (SUCROS-87) to assess the effect of moisture stress on yield potential of durum wheat in Ethiopia. Agricultural Systems 44, 337-353.

Sinclair, T.R., Horie, T., 1989. Leaf nitrogen, photosynthesis, and crop radiation use efficiency: a review. Crop science 29, 90-98.

Sinclair, T.R., Muchow, R.C., 1999. Radiation use efficiency. Advances in agronomy 65, 215-265.

Sinclair, T.R., Shiraiwa, T., Hammer, G.L., 1992. Variation in crop radiation-use efficiency with increased diffuse radiation. Crop Science 32, 1281-1284.

Sinoquet, H., Bonhomme, R., 1992. Modeling radiative transfer in mixed and row intercropping systems. Agricultural and Forest Meteorology 62, 219-240.

Sivakumar, M.V.K., Virmani, S.M., 1980. Growth and resource use of maize, pigeonpea and maize/pigeonpea intercrop in an operational research watershed. Experimental Agriculture 16, 377-386.

Sivakumar, M.V.K., Virmani, S.M., 1984. Crop productivity in relation to interception of photosynthetically active radiation. Agricultural and Forest Meteorology 31, 131-141.

Slafer, G.A., Rawson, H.M., 1994. Sensitivity of wheat phasic development to major environmental factors: a re-examination of some assumptions made by physiologists and modellers. Functional Plant Biology 21, 393-426.

Song, Y.N., Zhang, F.S., Marschner, P., Fan, F.L., Gao, H.M., Bao, X.G., Sun, J.H., Li, L., 2006. Effect of intercropping on crop yield and chemical and microbiological properties in rhizosphere of wheat (Triticum aestivum L.), maize (Zea mays L.), and faba bean (Vicia faba L.). Biology and Fertility of Soils 43, 565-574.

Spiertz, H., 2013. Challenges for crop production research in improving land use, productivity and sustainability. Sustainability 5, 1632-1644.

Spitters, C.J.T., Schapendonk, A.H.C.M., 1990. Evaluation of breeding strategies for drought tolerance in potato by means of crop growth simulation. Genetic Aspects of Plant Mineral Nutrition. Springer, pp. 151-161. 
Stitt, M., Schulze, D., 1994. Does Rubisco control the rate of photosynthesis and plant growth? An exercise in molecular ecophysiology. Plant, cell \& environment 17, 465-487.

Szumigalski, A., van Acker, R., 2005. Weed suppression and crop production in annual intercrops. Weed Science 53, 813-825.

\section{$\mathbf{T}$}

Terashima, I., Evans, J.R., 1988. Effects of light and nitrogen nutrition on the organization of the photosynthetic apparatus in spinach. Plant and Cell Physiology 29, 143-155.

Tilman, D., Cassman, K.G., Matson, P.A., Naylor, R., Polasky, S., 2002. Agricultural sustainability and intensive production practices. Nature 418, 671-677.

Tottman, D.R., 1987. The decimal code for the growth stages of cereals, with illustrations. Annals of Applied Biology 110, 441-454.

Trenbath, B., Francis, C., 1986. Resource use by intercrops. Multiple cropping systems, 57-81.

Tsubo, M., Walker, S., 2002. A model of radiation interception and use by a maize-bean intercrop canopy. Agricultural and Forest Meteorology 110, 203-215.

Tsubo, M., Walker, S., Ogindo, H.O., 2005. A simulation model of cereal-legume intercropping systems for semi-arid regions I. Model development. Field Crops Research 93, 10-22.

Turchin, P., 2003. Complex population dynamics: a theoretical/empirical synthesis. Princeton University Press.

\section{V}

Valipour, M., Ziatabar Ahmadi, M., Raeini-Sarjaz, M., Gholami Sefidkouhi, M.A., Shahnazari, A., Fazlola, R., Darzi-Naftchali, A., 2015. Agricultural water management in the world during past half century. Archives of Agronomy and Soil Science 61, 657-678.

van Delden, A., 2001. Yielding ability and weed suppression of potato and wheat under organic nitrogen management. Doctoral Thesis. Wageningen University, the Netherlands.

van Delden, A., Kropff, M.J., Haverkort, A.J., 2001. Modeling temperature-and radiationdriven leaf area expansion in the contrasting crops potato and wheat. Field Crops Research 72, 119-141. 
van Ittersum, M.K., Cassman, K.G., Grassini, P., Wolf, J., Tittonell, P., Hochman, Z., 2013. Yield gap analysis with local to global relevance-a review. Field Crops Research 143, 4-17.

van Ittersum, M.K., Leffelaar, P.A., van Keulen, H., Kropff, M.J., Bastiaans, L., Goudriaan, J., 2003. On approaches and applications of the Wageningen crop models. European Journal of Agronomy 18, 201-234.

van Ittersum, M.K., Rabbinge, R., 1997. Concepts in production ecology for analysis and quantification of agricultural input-output combinations. Field Crops Research 52, 197-208.

van Ittersum, M.K., Rabbinge, R., van Latesteijn, H.C., 1998. Exploratory land use studies and their role in strategic policy making. Agricultural Systems 58, 309-330.

van Oort, P.A.J., Saito, K., Tanaka, A., Amovin-Assagba, E., van Bussel, L.G.J., van Wart, J., de Groot, H., van Ittersum, M.K., Cassman, K.G., Wopereis, M.C.S., 2015. Assessment of rice self-sufficiency in 2025 in eight African countries. Global Food Security 5, 39-49.

Vandermeer, J., 1989. The Ecology of Intercropping. Cambridge: Cambridge University Press. Vilich-Meller, V., 1992. Mixed cropping of cereals to suppress plant diseases and omit pesticide applications. Biological Agriculture \& Horticulture 8, 299-308.

\section{W}

Wallach, D., Makowski, D., Jones, J.W., Brun, F., 2013. Working with Dynamic Crop Models: Methods, Tools and Examples for Agriculture and Environment. Academic Press.

Wang, Z., Zhao, X., Wu, P., He, J., Chen, X., Gao, Y., Cao, X., 2015. Radiation interception and utilization by wheat/maize strip intercropping systems. Agricultural and Forest Meteorology 204, 58-66.

Willey, R.W., 1979. Intercropping, its importance and research need I. Competition and yield advantages. Field Crops Abstracts 32, 1-10.

Willey, R.W., 1990. Resource use in intercropping systems. Agricultural water management $17,215-231$. 
Xiao, Y., Li, L., Zhang, F., 2004. Effect of root contact on interspecific competition and N transfer between wheat and fababean using direct and indirect $15 \mathrm{~N}$ techniques. Plant and Soil 262, 45-54.

$\mathbf{Y}$

Yang, C., Huang, G., Chai, Q., Luo, Z., 2011. Water use and yield of wheat/maize intercropping under alternate irrigation in the oasis field of northwest China. Field Crops Research 124, 426-432.

Yin, W., Yu, A., Chai, Q., Hu, F., Feng, F., Gan, Y., 2015. Wheat and maize relay-planting with straw covering increases water use efficiency up to $46 \%$. Agronomy for Sustainable Development 35, 815-825.

Yoshida, S., Coronel, V., 1976. Nitrogen nutrition, leaf resistance, and leaf photosynthetic rate of the rice plant. Soil Science and Plant Nutrition 22, 207-211.

Yu, Y., 2016. Crop yields in intercropping: meta-analysis and virtual plant modelling. Doctoral Thesis. Wageningen Univeristy, Wageningen, the Netherlands.

Yu, Y., Stomph, T.-J., Makowski, D., van der Werf, W., 2015. Temporal niche differentiation increases the land equivalent ratio of annual intercrops: A meta-analysis. Field Crops Research 184, 133-144.

\section{$\mathbf{Z}$}

Zadoks, J.C., Chang, T.T., Konzak, C.F., 1974. A decimal code for the growth stages of cereals. Weed research 14, 415-421.

Zhang, F., Li, L., 2003. Using competitive and facilitative interactions in intercropping systems enhances crop productivity and nutrient-use efficiency. Plant and Soil 248, 305-312.

Zhang, L., van der Werf, W., Zhang, S., Li, B., Spiertz, J.H.J., 2007. Growth, yield and quality of wheat and cotton in relay strip intercropping systems. Field Crops Research 103, 178-188.

Zhang, L., van der Werf, W., Bastiaans, L., Zhang, S., Li, B., Spiertz, J., 2008. Light interception and utilization in relay intercrops of wheat and cotton. Field Crops Research 107, 29-42. 
Zhang, L., Zhu, X., Heerink, N., Shi, X., 2014. Does output market development affect irrigation water institutions? Insights from a case study in northern China. Agricultural Water Management 131, 70-78.

Zhu, J., van der Werf, W., Anten, N.P.R., Vos, J., Evers, J.B., 2015. The contribution of phenotypic plasticity to complementary light capture in plant mixtures. New Phytologist 207, 1213-1222.

Zhu, J., van der Werf, W., Vos, J., Anten, N.P.R., van der Putten, P.E.L., Evers, J.B., 2016. High productivity of wheat intercropped with maize is associated with plant architectural responses. Annals of Applied Biology, 357-372.

Zhu, J., Vos, J., van der Werf, W., van der Putten, P.E.L., Evers, J.B., 2014. Early competition shapes maize whole-plant development in mixed stands. Journal of experimental botany 65, 641-653.

Zhu, Y., Chen, H., Fan, J., Wang, Y., Li, Y., Chen, J., Fan, J., Yang, S., Hu, L., Leung, H., 2000. Genetic diversity and disease control in rice. Nature 406, 718-722. 


\section{Appendix A}

Yield and yield components of wheat and maize in wheat-maize intercropping in the Netherlands

Table A1 Fertilizer and pesticides application time and amount

Table A2 Wheat yield components in border and inner rows, in different treatments and years

Table A3 Wheat biomass, grain yield and HI in border and inner rows, in different treatments and years

Table A4 Monthly mean temperature, total precipitation and total sunshine duration for Wuwei (Gansu, China) condition in 2013 and 2014 


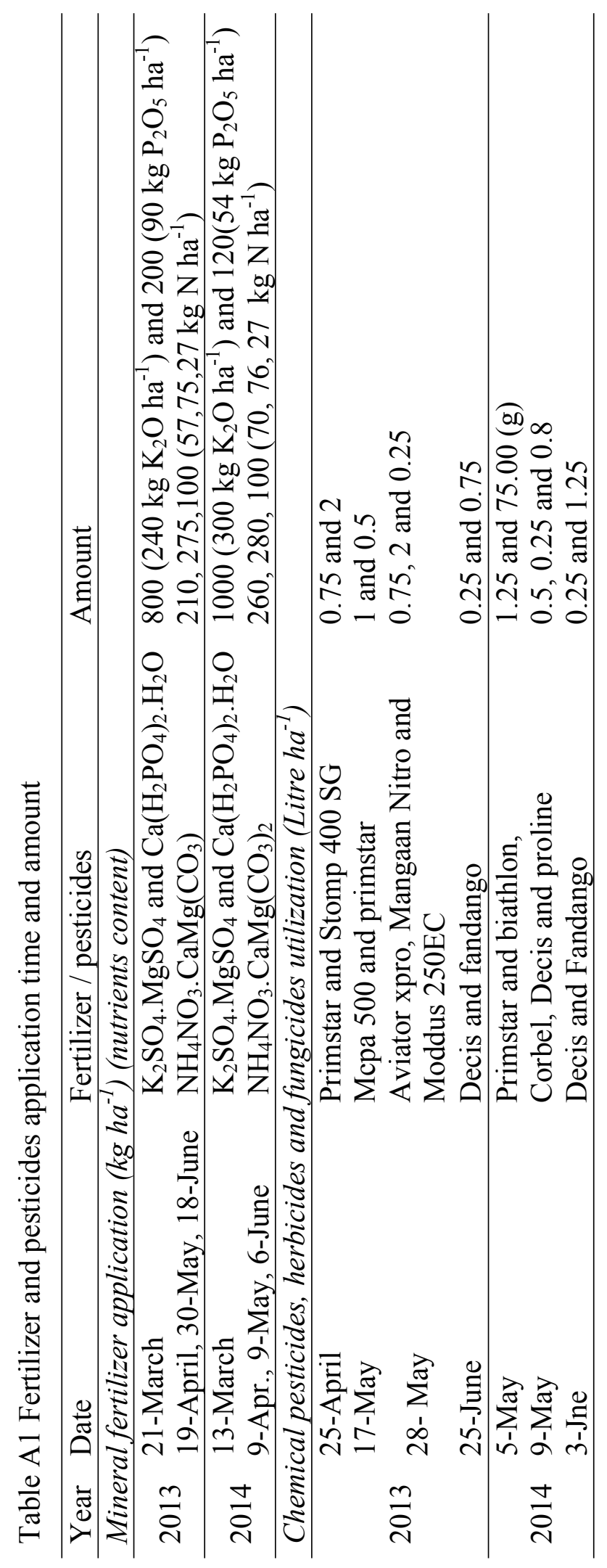




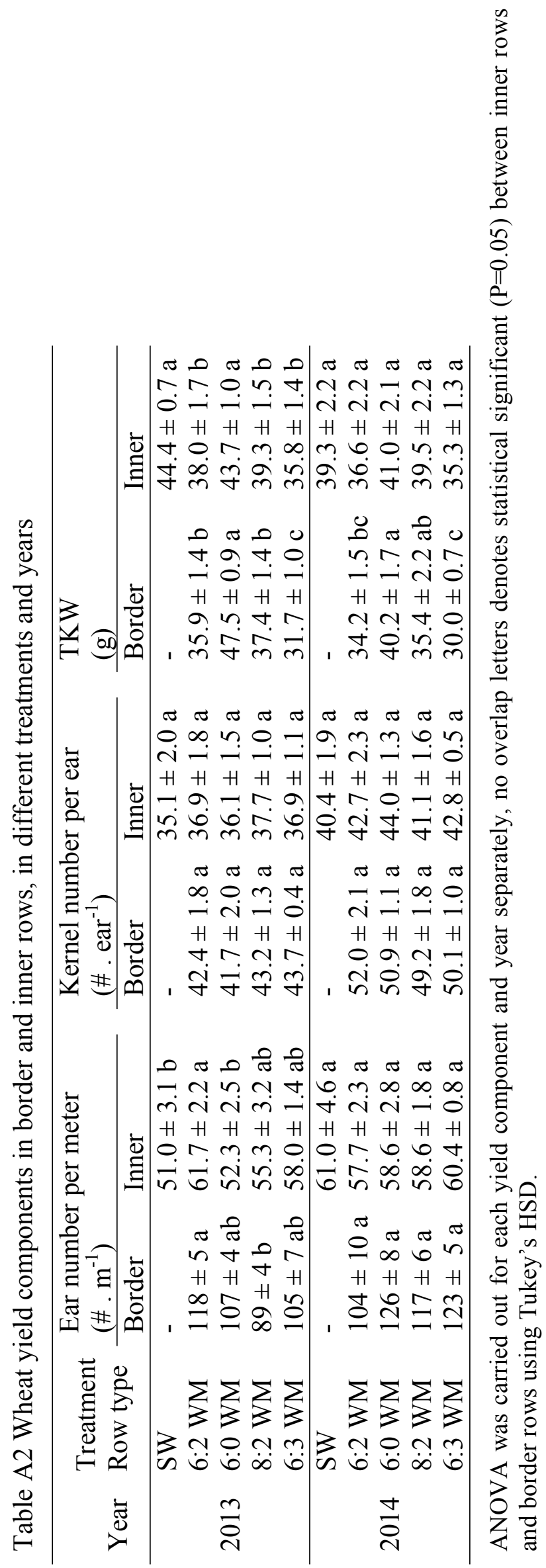




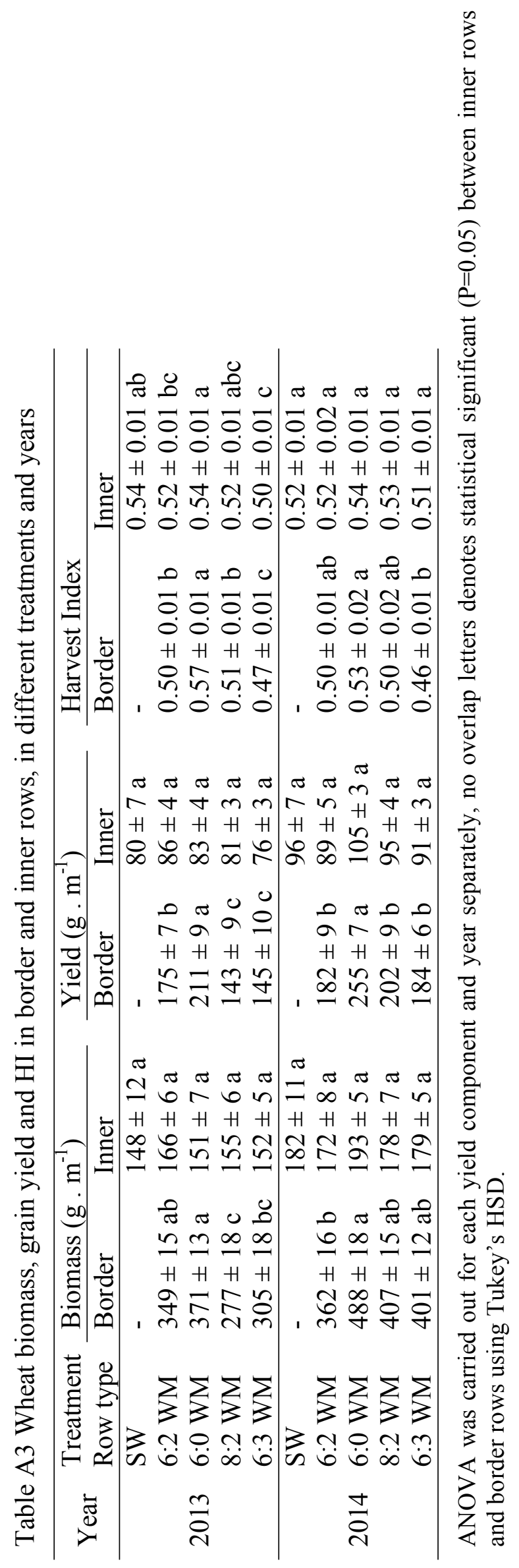




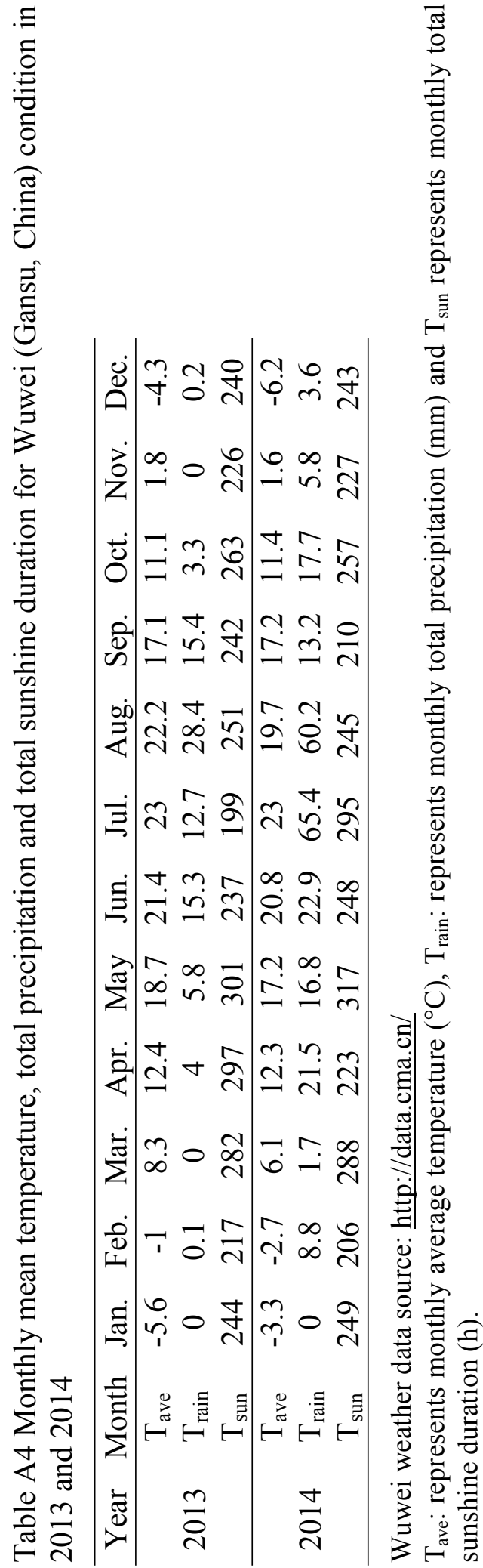





\section{Appendix B}

Simulating potential growth in a relay-strip intercropping system: model description, calibration and testing

Fig. B1 Wheat and maize tip and collar emergence time (thermal time) in sole crops and 6:2WM intercrop.

Fig. B2 Wheat tiller dynamics and maize leaf senescence with thermal time.

Fig. B3 Biomass partitioning fractions to leaves, stems and organs for wheat and maize in different systems across two years.

Fig. B4 Tiller number per plant and leaf area per meter row in inner rows and border rows in replacement intercrop (6:2WM) in 2013 and 2014. 

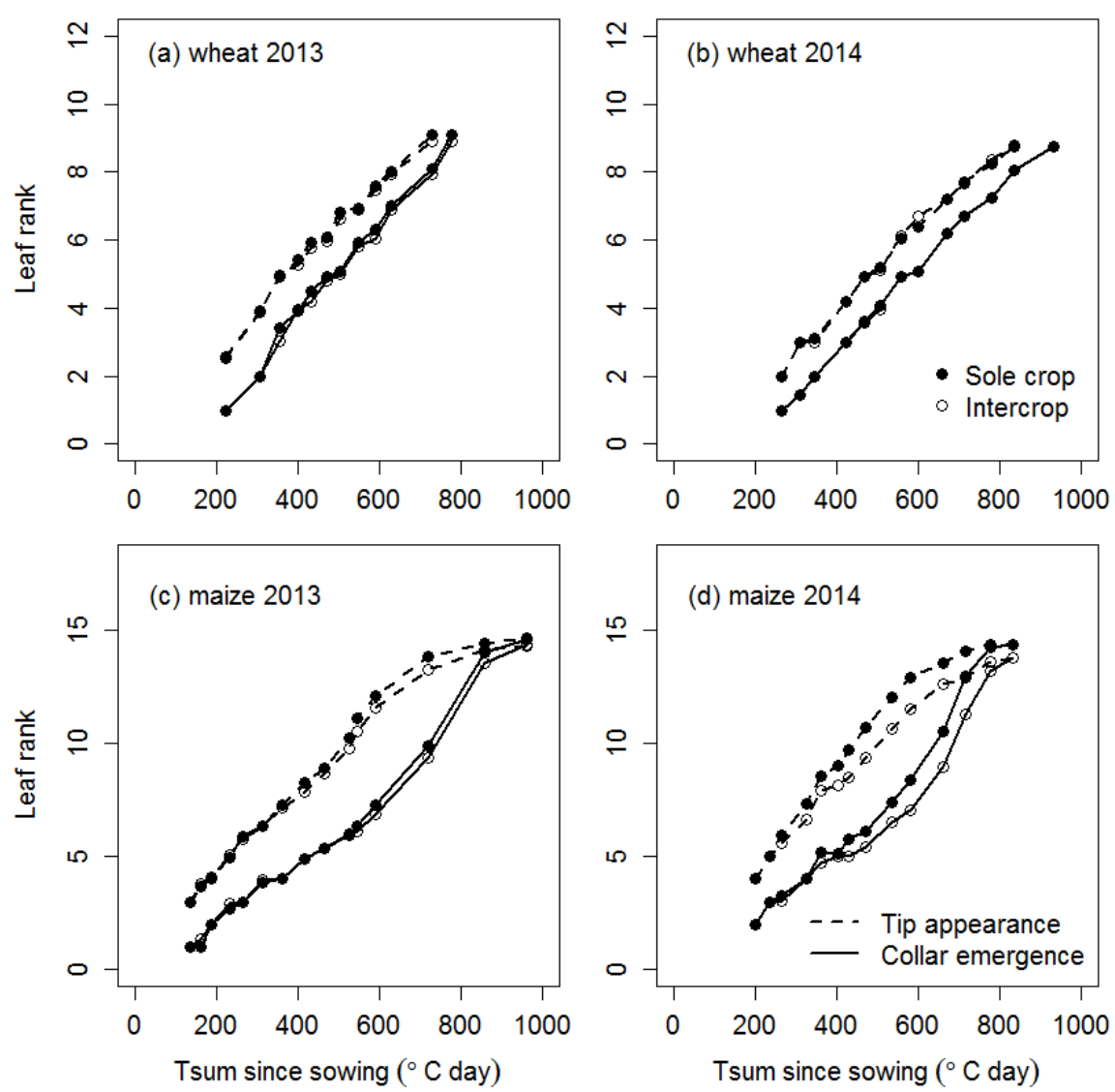

Fig. B1 Wheat and maize tip and collar emergence time (thermal time) in sole crops and 6:2WM intercrop. In each block (3 blocks in 2013 and 4 blocks in 2014), six wheat/maize plants in sole crops and twelve wheat/maize plants in intercrop were randomly selected and regularly observed. For each crop, the tip and collar emergence was monitored twice a week, from one week after emergence until the collar of flag leaf appearance. 

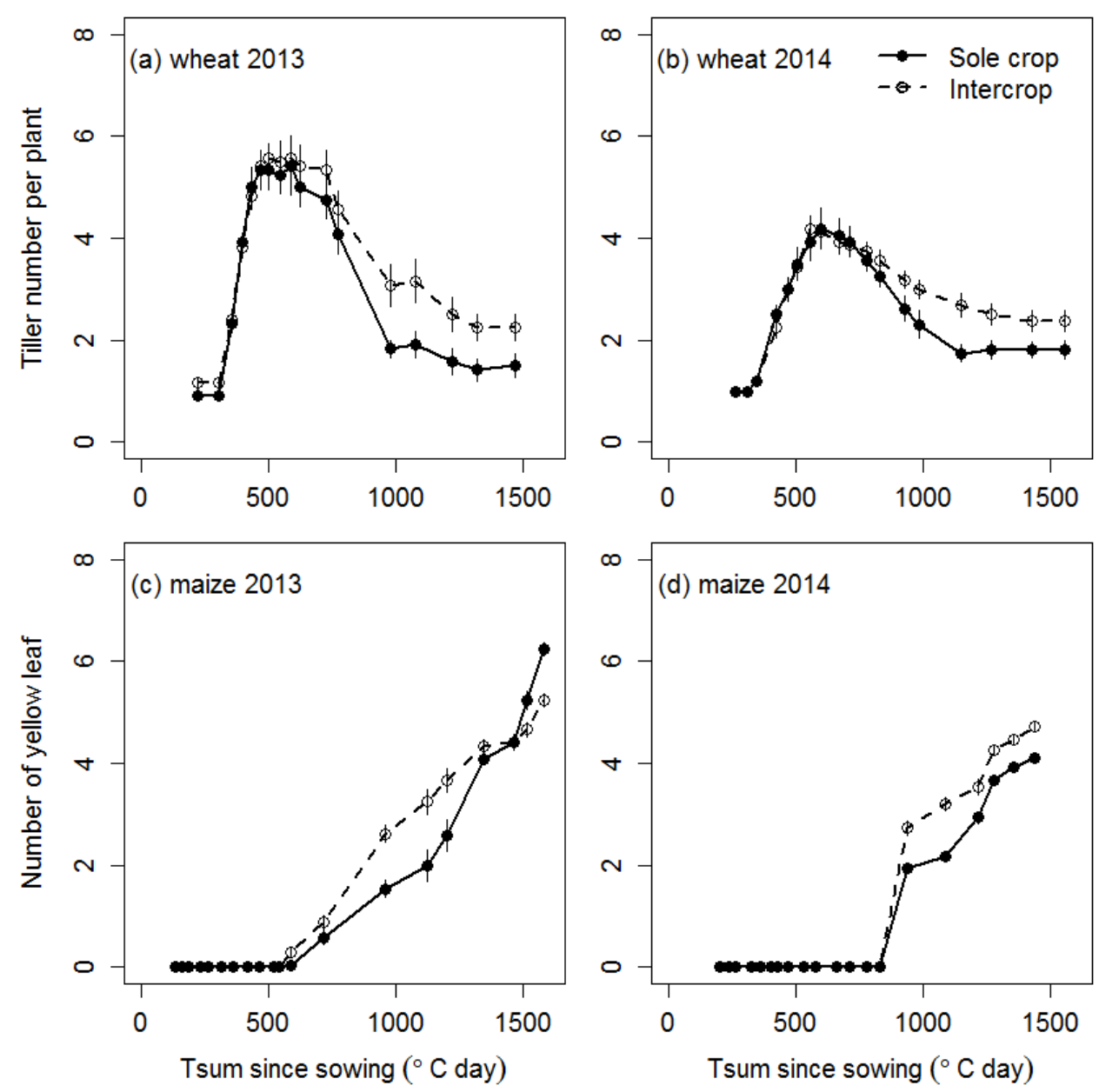

Fig. B2 Wheat tiller dynamics and maize leaf senescence with thermal time. In each block (3 blocks in 2013 and 4 blocks in 2014), six wheat/maize plants in sole crops and twelve wheat/maize plants in intercrop were randomly selected and regularly observed. For wheat, the number of tillers of target plant was counted twice a week from the first tiller appearance (growth stage 21) until the tiller number stayed constant (about late milk, growth stage 77 (Tottman, 1987)), the number of tillers showed here are all from inner rows. For maize, the number of yellow leaves was monitored twice a week, from the first yellow leaf appearance until ripening. 

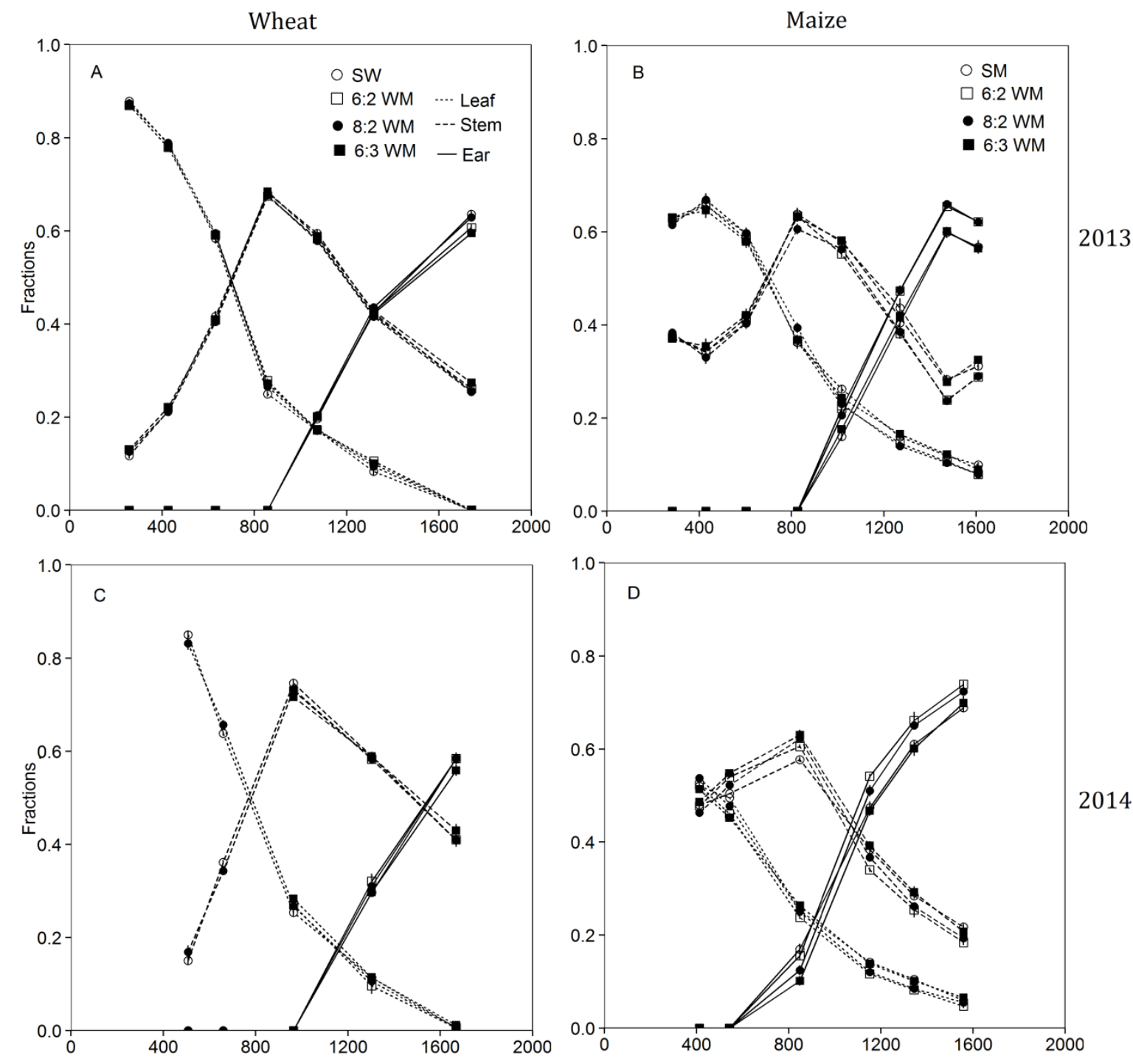

Temperature sum since sowing $\left({ }^{\circ} \mathrm{C}\right.$ day)

Fig. B3 Biomass partitioning fractions to leaves, stems and organs for wheat and maize in different systems across two years. The left panels are for wheat and the right panels are for maize. A and B are for 2013, and C and D are for 2014. 

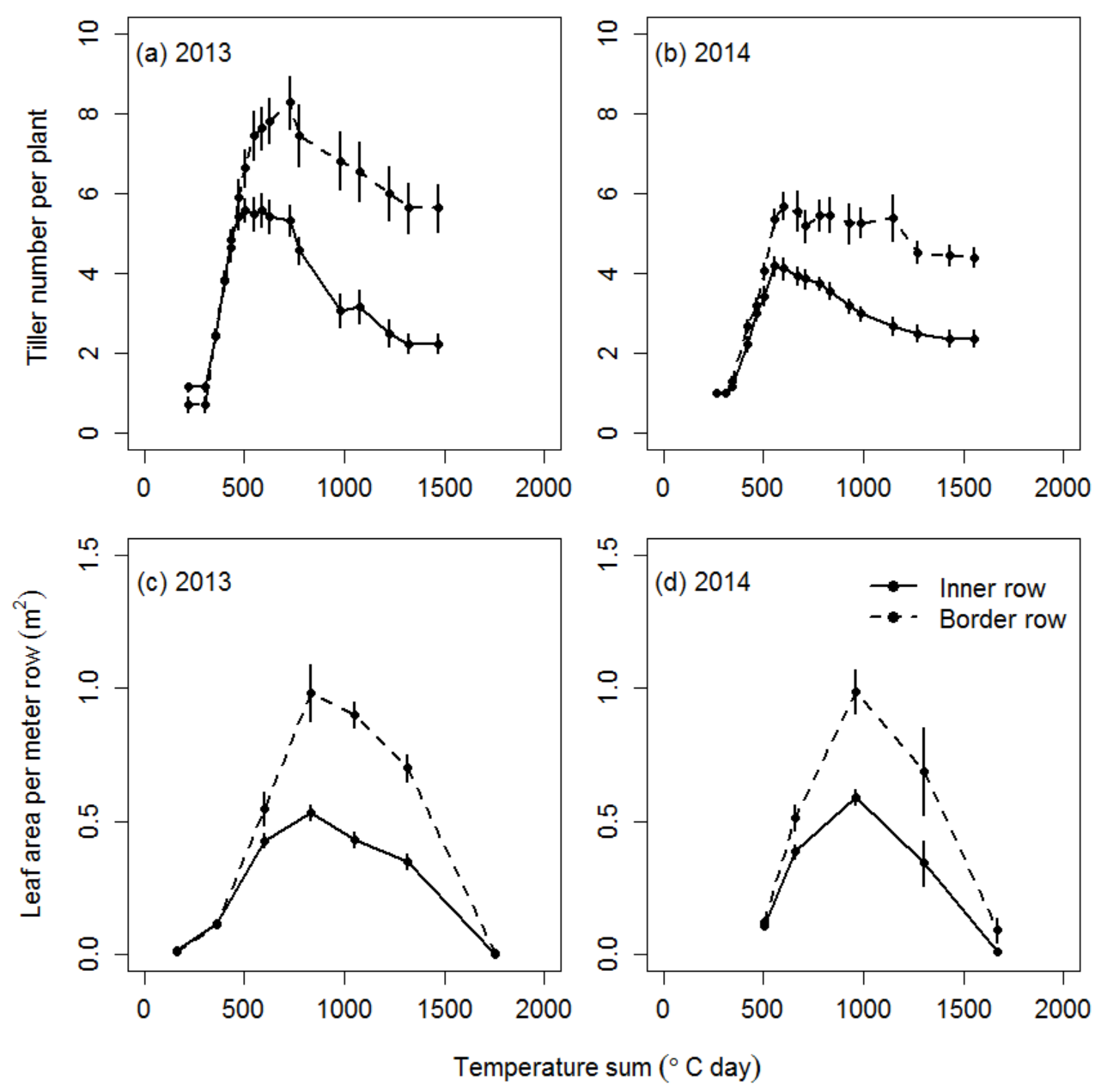

Fig. B4 Tiller number per plant and leaf area per meter row in inner rows and border rows in replacement intercrop (6:2WM) in 2013 and 2014. 



\section{Appendix C}

On yield gains and yield gaps in intercropping: opportunities for increasing grain production in northwest China

Table C1 Irrigation schedule ( $\mathrm{mm}$ ) for different cropping systems

Table C2 Fertilizer application schedule for different crop systems

Table C3 Model inputs related to planting configurations in intercrops

Table C4 Description of parameters and their values

Table C5. Summary of biomass partitioning fractions to leaves, stems and storage organs as a function of $T_{\text {sum }}$

Table C6 Mean RUE from calibration

Fig. C1 Simulated values versus observed values for LAI.

Fig. C2 Simulated values versus observed values for biomass

Table C7 LER of wheat-maize intercrop by model simulations from year 2010 to 2014 
Table C1 Irrigation schedule ( $\mathrm{mm}$ ) for different cropping systems

\begin{tabular}{|c|c|c|c|c|c|c|c|c|}
\hline \multirow[b]{2}{*}{ Treatment } & \multirow{2}{*}{$\begin{array}{l}\text { Winter } \\
\text { irrigation }\end{array}$} & \multicolumn{3}{|c|}{ Wheat } & \multirow{2}{*}{$\begin{array}{l}\text { Wheat } \\
\text { harvest }\end{array}$} & \multicolumn{2}{|c|}{ Maize } & \multirow[b]{2}{*}{ Total } \\
\hline & & Seedling & Shooting ${ }^{*}$ & $\begin{array}{l}\text { Grain } \\
\text { filling }\end{array}$ & & flowering & $\begin{array}{l}\text { Grain } \\
\text { filling }\end{array}$ & \\
\hline SW & 120 & 75 & 90 & 75 & - & - & - & 360 \\
\hline SM & 120 & - & 90 & 75 & 90 & 75 & 75 & 525 \\
\hline $6: 2 \mathrm{WM}$ & 120 & 75 & 90 & 75 & 90 & 75 & 75 & 600 \\
\hline
\end{tabular}

${ }^{*}$ At wheat shooting, maize is at seedling stage, at wheat grain filling stage, maize is at shooting stage, at wheat harvest, maize is at silking stage.

Table C2 fertilizer application schedule for different crop systems

\begin{tabular}{|c|c|c|c|c|}
\hline \multirow[t]{2}{*}{ Treatment } & \multirow{2}{*}{$\begin{array}{c}\text { wheat } \\
\text { Before sowing }\end{array}$} & \multicolumn{3}{|c|}{ Maize } \\
\hline & & Before sowing & Seven leaf mature & Grain filling \\
\hline SW & $225 \mathrm{~kg} \mathrm{~N} \mathrm{ha}^{-1}$ & & & \\
\hline SM & $150 \mathrm{~kg} \mathrm{P}_{2} \mathrm{O}_{5} \mathrm{ha}^{-1}$ & $\begin{array}{l}135 \mathrm{~kg} \mathrm{~N} \mathrm{ha}^{-1} \\
150 \mathrm{~kg} \mathrm{P}_{2} \mathrm{O}_{5} \mathrm{ha}^{-1}\end{array}$ & $270 \mathrm{~kg} \mathrm{~N} \mathrm{ha}{ }^{-1}$ & $45 \mathrm{~kg} \mathrm{~N} \mathrm{ha}^{-1}$ \\
\hline $6: 2 \mathrm{WM}$ & $\begin{array}{l}112.5 \mathrm{~kg} \mathrm{~N} \mathrm{ha}^{-1} \\
75 \mathrm{~kg} \mathrm{P}_{2} \mathrm{O}_{5} \mathrm{ha}^{-1}\end{array}$ & $\begin{array}{l}67.5 \mathrm{~kg} \mathrm{~N} \mathrm{ha}^{-1} \\
75 \mathrm{~kg} \mathrm{P}_{2} \mathrm{O}_{5} \mathrm{ha}^{-1}\end{array}$ & $135 \mathrm{~kg} \mathrm{~N} \mathrm{ha}^{-1}$ & $22.5 \mathrm{~kg} \mathrm{~N} \mathrm{ha}^{-1}$ \\
\hline
\end{tabular}

Note: in intercrop the fertilizer was given for wheat and maize strip separately.

Table C3 Model inputs related to planting configurations in intercrops

\begin{tabular}{llllllllll}
\hline Treatment & $\begin{array}{l}S_{1} \\
(\mathrm{~cm})\end{array}$ & $\begin{array}{l}P_{1} \\
(\mathrm{~cm})\end{array}$ & $\begin{array}{l}S_{2} \\
(\mathrm{~cm})\end{array}$ & $\begin{array}{l}P_{2} \\
(\mathrm{~cm})\end{array}$ & LAIS $_{1}$ & LAIIS $_{2}$ & LAII $_{1}$ & LAII $_{2}$ & $\begin{array}{l}\text { Relative } \\
\text { density total }\end{array}$ \\
\hline $\mathrm{SW}$ & - & - & - & - & 0.01 & - & - & - & 1 \\
$\mathrm{SM}$ & - & - & - & - & - & 0.01 & - & - & 1 \\
$6: 2 \mathrm{WM}$ & 80 & 80 & 80 & 80 & - & - & 0.0056 & 0.0064 & 1.19 \\
\hline
\end{tabular}




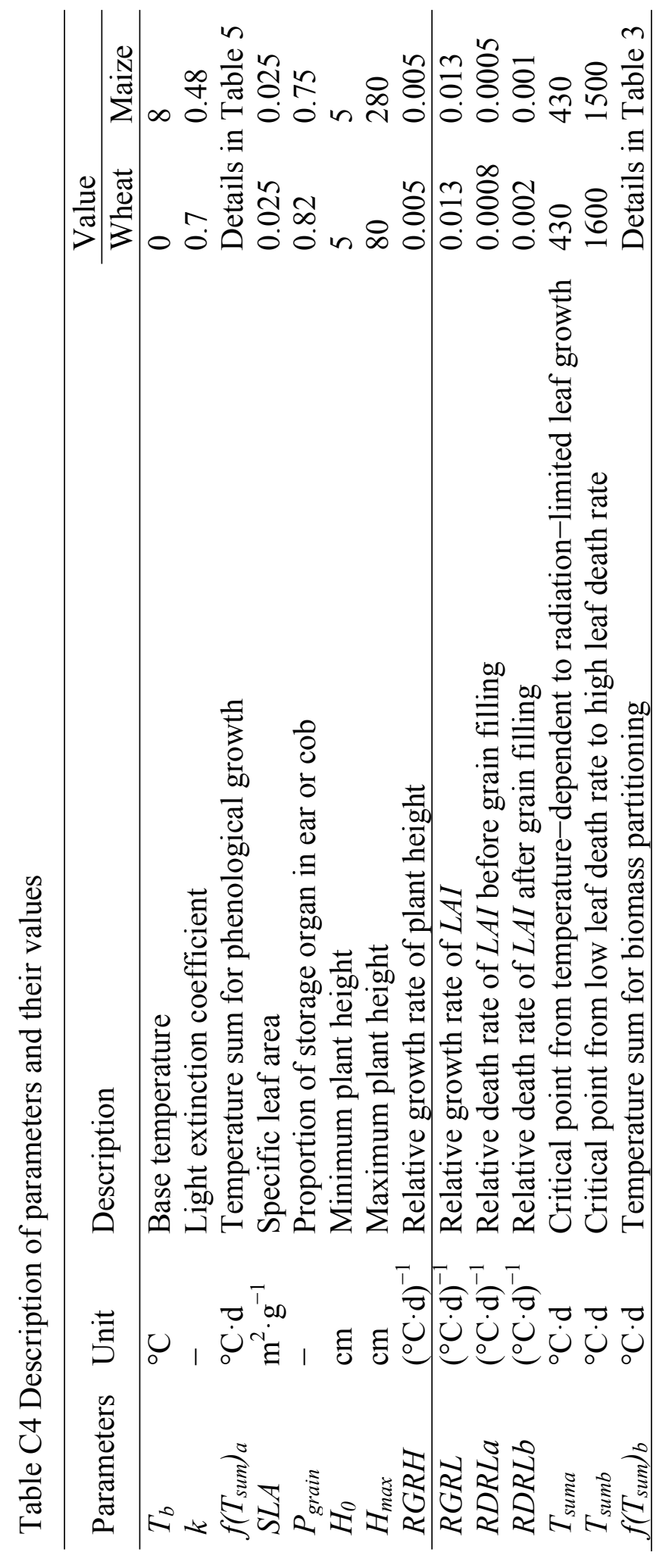


Table C5 Summary of biomass partitioning fractions to leaves, stems and storage organs as a function of $T_{\text {sum }}$

\begin{tabular}{lcccc}
\hline \multicolumn{1}{c}{ Growth stage } & $T_{\text {sum }}\left({ }^{\circ} \mathrm{C}\right.$ day) & Leaf & Stem & Storage \\
\hline Wheat & & & & \\
\hline Emergence (10) & 90 & 0.7 & 0.3 & 0 \\
Main shoot and five tillers (25) & 300 & 0.5 & 0.5 & 0 \\
Stem elongation (31) & 850 & 0.3 & 0.7 & 0 \\
Ear emergence(55) & 1100 & 0.1 & 0.5 & 0.4 \\
Beginning of anthesis (61) & 1350 & 0 & 0.3 & 0.7 \\
Milking (73) & 1560 & 0 & 0 & 1 \\
Ripening (92) & 2000 & 0 & 0 & 1 \\
\hline Maize & & & & \\
\hline Emergence (10) & 50 & 0.75 & 0.25 & 0 \\
5 leaves unfolded (15) & 200 & 0.6 & 0.4 & 0 \\
7 leaves unfolded (17) & 300 & 0.3 & 0.7 & 0 \\
Flag leaf unfolded (39) & 880 & 0.15 & 0.55 & 0.3 \\
Beginning of anthesis (61) & 1300 & 0 & 0.4 & 0.6 \\
Milking (73) & 1400 & 0 & 0 & 1 \\
Ripening (92) & 1900 & 0 & 0 & 1 \\
\hline
\end{tabular}

Numbers in brackets represent growth stages according to (Tottman, 1987).

Table C6 Mean RUE from calibration

\begin{tabular}{clcc}
\hline Year & Treatment & $\begin{array}{c}\text { Wheat RUE } \\
\left(\mathrm{g} \mathrm{MJ}^{-1} \mathrm{PAR}\right)\end{array}$ & $\begin{array}{c}\text { Maize RUE } \\
\left.\mathrm{g} \mathrm{MJ}^{-1} \text { PAR }\right)\end{array}$ \\
\hline \multirow{2}{*}{2010} & sole crop & 2.55 & 3.18 \\
& intercrop & 3.40 & 3.54 \\
\hline \multirow{2}{*}{2011} & sole crop & 2.27 & 3.25 \\
& intercrop & 2.98 & 3.61 \\
\hline \multirow{2}{*}{2012} & sole crop & 2.31 & 3.20 \\
& intercrop & 2.83 & 3.52 \\
\hline \multirow{2}{*}{ Mean } & sole crop & 2.38 & 3.21 \\
& intercrop & 3.07 & 3.56 \\
\hline
\end{tabular}



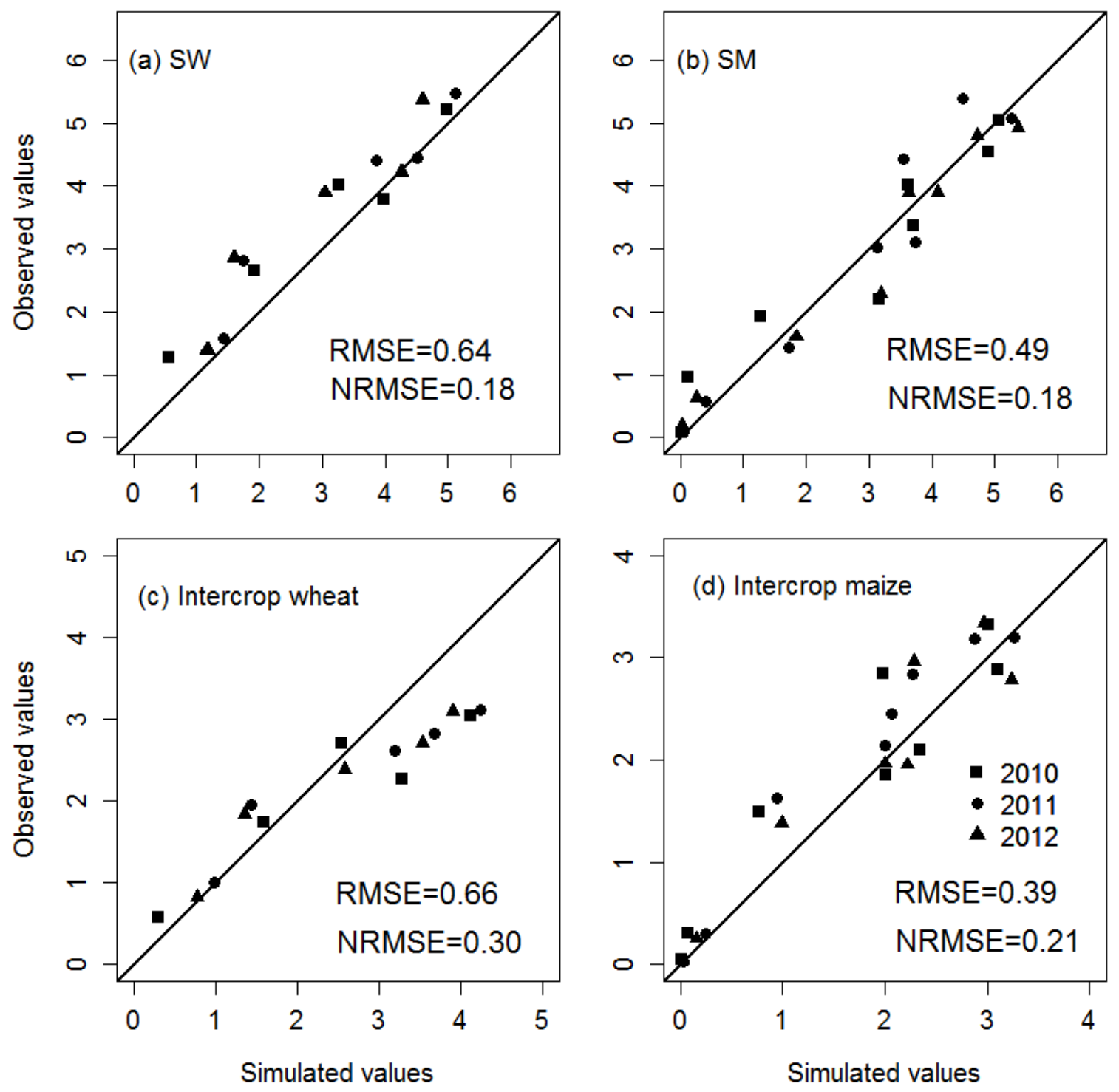

Fig. C1 Simulated values versus observed values for LAI. 

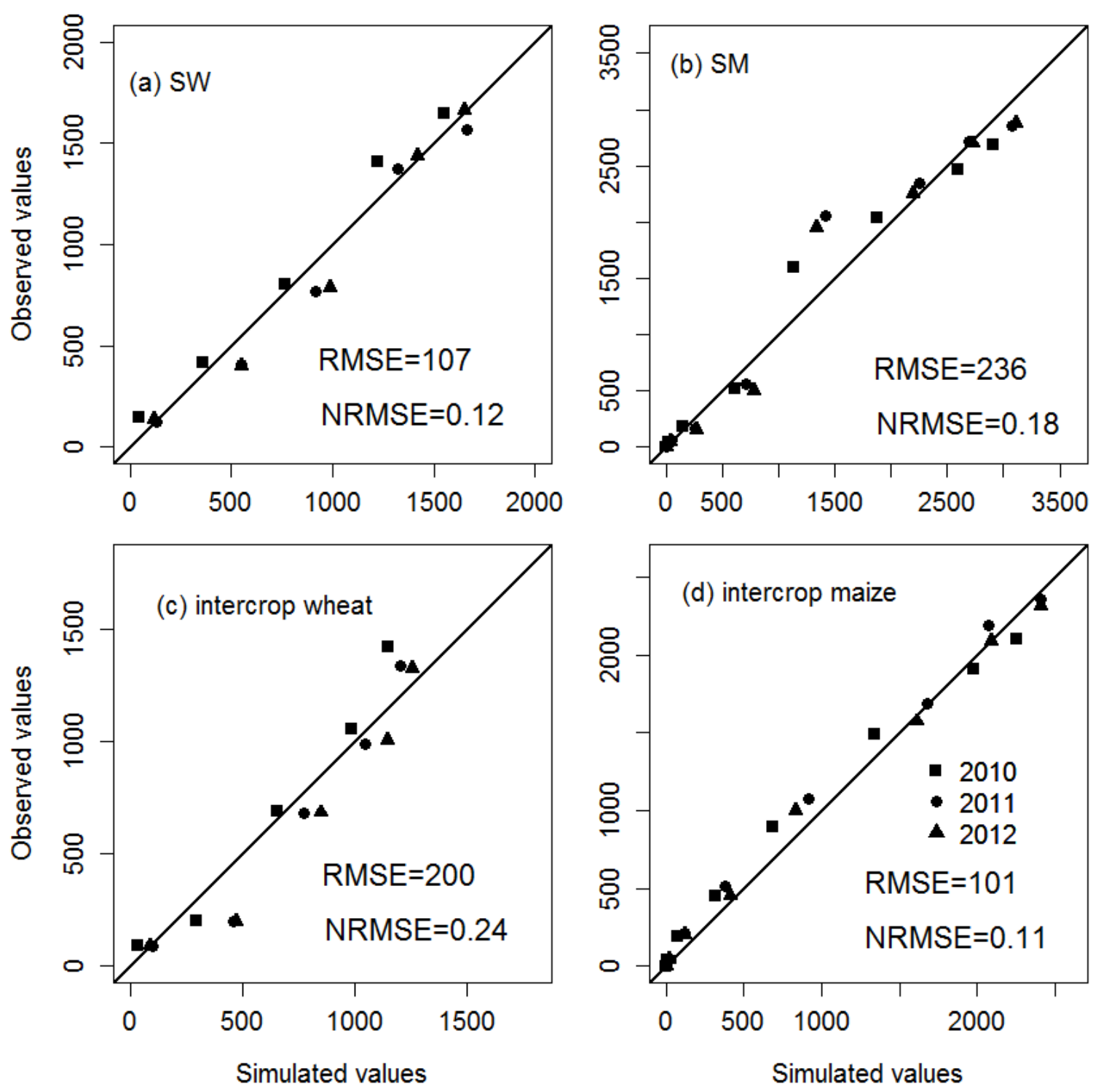

Fig. C2 Simulated values versus observed values for biomass

Table C7 LER of wheat-maize intercrop by model simulations from year 2010 to 2014

\begin{tabular}{cccccccc}
\hline \multirow{2}{*}{ Year } & \multirow{2}{*}{ Treatment } & \multicolumn{3}{c}{ Biomass } & \multicolumn{3}{c}{ Yield } \\
& & PLER $_{\mathrm{W}}$ & PLER $_{\mathrm{M}}$ & LER & PLER $_{\mathrm{W}}$ & PLER $_{\mathrm{M}}$ & LER \\
\hline 2010 & $6: 2 \mathrm{WM}$ & 0.71 & 0.77 & 1.48 & 0.62 & 0.83 & 1.45 \\
2011 & $6: 2 \mathrm{WM}$ & 0.74 & 0.78 & 1.52 & 0.66 & 0.84 & 1.50 \\
2012 & $6: 2 \mathrm{WM}$ & 0.74 & 0.79 & 1.52 & 0.65 & 0.85 & 1.50 \\
2013 & $6: 2 \mathrm{WM}$ & 0.76 & 0.77 & 1.53 & 0.68 & 0.83 & 1.52 \\
2014 & $6: 2 \mathrm{WM}$ & 0.79 & 0.79 & 1.57 & 0.71 & 0.86 & 1.57 \\
Mean & $6: 2 \mathrm{WM}$ & 0.75 & 0.78 & 1.53 & 0.66 & 0.84 & 1.51 \\
\hline
\end{tabular}

PLER $_{\mathrm{w}}$ is the partial land equivalent for wheat in intercrop, PLER $\mathrm{m}$ is the partial land equivalent for maize. 


\section{Summary}

It has been estimated that global grain production must increase by ca. $60-70 \%$ to meet food demand in 2050, when the global population will have grown beyond 9 billion. Meanwhile, modern agriculture has caused substantial environmental impacts, including soil degradation, desertification and water pollution. Thus, the development of more sustainable practices for intensification is urgent. One potential strategy is intercropping.

Intercropping is the cultivation of two or more crop species simultaneously in the same field. Intercropping has many potential advantages such as higher overall productivity, better pest and disease control and enhanced ecological services. Wheat-maize intercropping is widely used by farmers in northwest China since the 1960s due to the substantial yield advantages (i.e. a land equivalent ratio substantially larger than one). In this region, the thermal time is not sufficient to grow wheat and maize after each other, but the temperature sum allows to grow the two species with partially overlapping growing periods as a relay strip intercrop. In this system, wheat is sown in strips of approximately six rows wide in spring and harvested in July. Empty space is left between the wheat strips to sow maize in May and harvest it in September. The land equivalent ratio (LER) of this intercropping system is up to 1.6. Grain production would increase enormously if this high productivity system could be more widely used. Another approach to increase yields is to improve crop management and close the gap between the yields that are potentially possible and those that are realized in practice. Yield gaps have been quantified in monoculture grain production, but so far not in intercrops. However, yield gaps are likely to exist in intercropping and they need to be quantified. Changing from sole crops to intercropping and closing yield gaps together may contribute substantially to increased food production in future.

This thesis studied the growth and productivity of wheat-maize intercropping at organ, plant and cropping system level, and also assessed its contribution to grain production at a regional level. The aims of this thesis were to 1) test whether wheat-maize intercropping has yield advantages under west European growing conditions (i.c. in the Netherlands); 2) study the mechanisms of intercropping performance from an agronomic and physiological perspective; 3) to develop an intercrop model for potential growing conditions; and 4) to perform a preliminary explorative land use study for northwest China. To achieve the first two objectives, two years (2013 and 2014) of field experiments were conducted in Wageningen, 
the Netherlands. Treatments included sole wheat (SW) and sole maize (SM), a replacement intercrop consisting of strips of six wheat rows alternating with two maize rows ( $6: 2 \mathrm{WM})$, as well as subtractive or augmentative designs, based on skip-row (6:0WM, 0:2WM) and addrow (8:2WM, 6:3WM) configurations.

Chapter 2 determines how spatial heterogeneity in planting patterns in the intercrop (e.g. border rows vs inner rows in strips of one species) results in spatial heterogeneity in plant performance and yield. The yield components were determined to obtain more insight in crop physiological responses underlying the yield response in different planting configurations. The results showed that there is a potential for high productivity in wheat-maize intercropping under west European growing conditions, but the conditions in the Netherlands seems less favourable for this system than those in the regions in northwest China where this system is used by farmers. More specifically: due to a lower temperature sum and solar radiation in the Netherlands as compared to northern China, maize under Dutch growing conditions has less time and less suitable conditions for recovery growth after wheat harvest. Intercropping increased the ear number per meter row and the kernel number per ear for wheat in border rows, but decreased the thousand kernel weight and harvest index, indicating reduced competition in early growing period but intensified competition over time as the maize plants grew taller. Augmentative designs did not provide greater yield advantages than replacement intercrop, indicating plant plasticity in border rows was sufficient to intercept resources in the replacement intercrop. Performance of maize in the intercrop might be optimized by using adapted varieties with a short growth cycle.

Row configurations in intercrops determine which crop rows interact with the same species and which interact with the other species, shaping the expression of interspecific competition for resources, plastic resource capture, and plant growth. Chapter 3 determines how row configuration influences radiation interception and productivity in wheat-maize intercropping in the Netherlands. Light interception was derived from a geometric model for light distribution in the intercrop, in combination with measurements of plant height, width of crop strips and space between the strips. Radiation use efficiency (RUE) was determined by regressing biomass, determined in periodic harvests, on cumulative light interception. The results showed that intercrops often had greater total light interception than sole crops. RUE was higher in intercropped wheat than in sole wheat, whereas RUE was lower in intercropped maize than in sole maize. These changes reflect competitive relationships in the intercrop, 
with wheat producing extra tillers in intercrop and depleting soil nutrients, competitively suppressing and constraining maize growth.

Chapter 4 presents, calibrates and tests a crop model for potential growth and production in relay-strip intercrops. The model was developed by combining principles of a sole crop model using the radiation use efficiency concept with a strip intercrop light partitioning model. The integrated model allows simulating the growth and the yield of two intercropped species in relay-strip intercropping under potential growing conditions with competition for light only, while other resources are assumed to be non-limiting. Bayesian analysis was applied to calibrate RUE of wheat and maize in sole crops and replacement intercrop. The results also showed that intercropped wheat had a greater RUE than sole wheat while intercropped maize had a lower RUE than sole maize. The intercrop model was further tested with two add-row intercrops. The simulated LAI and biomass showed good agreement with observations, and the intercrop model accounted satisfactorily for the border row effects on total crop productivity in the intercrop. The intercrop model is easy to calibrate, and applicable to a wide range of intercrops, e.g. different crop combinations and planting configurations. It can thus be used to explore alternative land use options with sole and intercrops.

The field experiments showed that intercropped maize had a lower crop radiation use efficiency than sole maize (Chapters 3 and 4). Therefore potential physiological mechanisms underlying this change were investigated in Chapter 5. In 2014, the maize leaf traits, including specific leaf area, specific leaf nitrogen, and chlorophyll content were determined during three weeks at flowering stage, and the photosynthetic rate of the leaves was measured. Intercropped maize had less favourable leaf traits (i.c. a smaller leaf nitrogen content, lower chlorophyll content and thinner leaves) than sole maize, but the leaves in the intercrop did not show a lower but a higher photosynthetic rate than leaves in sole maize. These surprising results can have multiple underlying causes, including differences in the spatial pattern of water distribution and water acquisition in intercropped maize as compared to sole maize, improved (more open) canopy structure in the intercrop with better penetration of light to the level of the cob, a changed nitrogen allocation within the leaf (to chlorophyll and Rubisco), and a different importance of the ear leaf with respect to the supply of assimilates to the growing cob. The low RUE in intercropped maize may be related to nitrogen (or other nutrients) deficiency during grain filling. Overall, these findings demonstrate the complexity of competitive relationships and plasticity in intercrops. 
In Chapter 6, the concepts of potential yield, yield gain and yield gap in intercropping are defined and applied to wheat-maize relay intercropping in Zhangye city, northwest China. The potential yields were estimated for five years (2010-2014) by crop modelling (sole crop and intercrop model, Chapter 4). The models were calibrated with data from a three years' field experiment in Wuwei city (2010-2012). The actual yields were determined by surveys of 310 farm households in 2013. The results showed that the farm and regional level yields are greater when integrating wheat-maize intercropping into the land use than when only using sole wheat or sole maize. Production can be further improved by closing the yield gap in intercropping. Water shortage and inadequate pest and disease control are the likely main factors for yield gaps in this region. A land use scenario analysis showed that substituting all wheat-maize intercropping by sole crops will substantially decrease grain production compared to the current land use.

In Chapter 7, I compared the wheat-maize intercrop performance in different growing conditions combining the findings in this thesis and data from literature. The productivity of wheat-maize strip intercropping is higher and more stable in northwest China than in the Netherlands. This may relate to better climatic conditions and more nitrogen input in China. In future, wheat-maize intercropping may not be as prevalent in northwest China as in the 1990s, due to the competition for water and land from cash crops and labour migration from rural areas to cities. At the same time, intercropping may have potential in other regions where it has yield advantages, for example in Europe. There are several challenges to widely apply wheat-maize strip intercropping in Europe, e.g. breeding new maize cultivars that can outperform sole maize under cool climatic conditions, and designing new machines allowing mechanization of strip intercropping. Future intercropping research on the one hand has to understand the mechanisms of intercropping performance, e.g. plant plasticity at plant level and biochemical level. On the other hand, it has to explore the opportunities that intercropping can provide for modern agriculture and future food security. 


\section{Acknowledgements}

I am very grateful to have this opportunity to study in Wageningen, and to work with so many nice people from all over the world. Now it is the time to recall the memories of the past four years and to express my appreciation to those people who have helped me, encouraged me, inspired me and brought me lots of happiness. Without you I would never finish this thesis nor have such a nice experience in Wageningen.

Firstly, I would like to express my sincere gratitude to my supervisors, Prof. Martin K. van Ittersum and Dr Wopke van der Werf. Thank you for finding financial support to allow me conducting field experiments in Wageningen, and thank you for encouraging me to take courses which helped me a lot in data analysis, crop modelling and paper writing. Thank you for your encouragements and compliments which made me confident. Martin, your "goaloriented" thinking and project management style taught me how to focus on the main objectives and set the priorities. This not only helped me finish this thesis within four years, but is also very useful for my future in time and project management. Wopke, I should say that I am very lucky to be one of your students. You know the strength and weakness of each student, and supervised us differently. I admire that you are always energetic, enthusiastic and patient. I would also like to thank your wife, Saskia Beverloo, for her hospitality and nice dinners.

Secondly, I would like to express my earnest thanks to Ing. Peter E.L. van der Putten. Peter, thank you very much for your support in my field experiments. You provided me great help in arranging the experimental equipment, in communicating with the Unifarm people, in field management and data collection, and also in supervising master students. We had a great time working in fields and labs. Meanwhile, I would like to thank other experimental team members: Dr Hiroe Yoshida and Mr. Marcelo Labra Fernandez. It was very lucky that three of us had experiments in the same year (2013) and built a cooperation team. We helped each other during the busy experiment period and learned experimental techniques from each other. We also shared our stories during coffee breaks and organized many parties together. Besides, I would like to thank many colleagues who helped me a lot in my field experiments: $\mathrm{Dr} \mathrm{Yu}$ Yang, Mr. Georgios Angelopoulos, Dr Chen Bin, Dr Li Guohua and Mr. Hong Yu. I also would like to thank the Unifarm staff, especially Mr. John van der Lippe, Mr. Wim van der 
Slikke, Mr. Herman Meurs, Mr. Frans Bakker, Mr. Evert-Jan van Laar and Mr. Gerrit Huisman, for their professional field management and data collection in my experiments.

Thirdly, I would like to thank all the master students who joined my project: Mr. Niel Verhoog, Miss Elisabeth Simon, Mr. Antoine Couëdel, Miss Wang Guoyu and Miss Tan Mexiu. Thank you for believing in me and choosing to join my project, and your great help in conducting field experiments. From supervising, I also learned to change my position from a student to a supervisor, and change the way of behavior and thinking.

Next, I would like to thank many important collaborators of this thesis: Prof. Zhang Lizhen, Prof. Chai Qiang, Dr Nico Heerink, Dr Peter A. Leffelaar, Dr Wang Yajun, Mr. Hong Yu, Miss Zhang Yue and Mr. Yin Wen. Lizhen, thank you very much for encouraging me to learn English and to apply for this $\mathrm{PhD}$ position in Wageningen, for your great suggestions in shaping some chapters of this thesis, and for your substantial support in data analysis. Peter, thank you very much for your great support in supervising Elisabeth, and your considerable efforts in improving the manuscript of Chapter 3. Prof. Chai Qiang, Nico, Hong Yu and Yin Wen, thank you very much for your generosity in sharing experimental and surveyed data, and for your great inputs in revising the manuscript. Without you I would not be able to finish Chapter 6 nor complete this thesis. Zhang Yue, thank you very much for measuring and analyzing the leaf nitrogen concentration. You are very dedicated and responsible. I believe you will be very successful in your own study and your future career.

Besides, I am very greatful to Prof. Jan Goudriaan and Dr David Makowski for helpful discussion and suggestions for crop model development and calibration, and to Dr Yin Xinyou and Dr Herman Berghuijs for nice and helpful discussion on photosynthesis. I would also like to thank Dr Tjeerd Jan Stomph and Dr Pepijn van Oort, for nice discussions and suggestions on supervising master students and improving my manuscripts. I would also like to thank some Chinese visiting researchers for their nice suggestions on my thesis: Prof. Zhang Fusuo, Prof. Tao Fulu, Dr Dong Yan, Dr Zhang Chaochun, Dr Huang Chengdong, Dr Tang Xiaoyan.

Furthermore, I would like to thank the excellent secretaries and financial officer in CSA and PPS, Ms. Sjanie van Wetten, Ms. Nicole Wolffensperger, Ms. Linda Kaster and Mr. Alex-Jan de Leeuw. You are very professional and efficient. It's great to have you around. Sjanie, thank you very much for your great help and arrangements for my arriving, staying and 
leaving Wageningen. You also helped me a lot in reading Dutch letters and dealing with the housing subsidy and tax affairs. Nicole, thank you very much for giving me a tutorial in thesis formatting and your great help in thesis printing. I would also like to express my appreciation to all other CSA and PPS colleagues, especially to Prof. Paul Struik, Prof. Niels Anten, Dr Aad van Ast, Dr Lammert Bastiaans, Dr Bob Douma, Dr Steven Driever, Dr Jochem Evers, Dr Cor Langeveld, Dr Willemien Lommen, Dr Peter Vermeulen, Dr Jan Vos, Dr Willemien Geertsema, Dr Zou Yi, Ing. Bert Rijk, Prof. Ken Giller, Mink Zijlstra, Dr Maja Slingerland, Dr Tom Schut, Dr Joost van Heerwaarden, Dr Katrien Descheemaeker and Dr Pytrik Reidsma. Thank you very much for your nice tips during coffee time and great comments and suggestions during lunch seminars.

I would also like to thank many $\mathrm{PhD}$ fellows: Luuk van Dijk, Gu Shenghao, Herman Berghuijs, Ali Elhakeem, Ouyang Wenjing, Marcelo Labra Fernandez, Uta Priegnitz, Martin Sikma, Tang Kailei, Giovani Theisen, Dennis Tippe, Marloes van Loon, Jorad de Vries, Yu Yang, Ioannis Baltzakis, Chen Bin, André Braga Junqueira, Marcia de Melo Carvalho, Franca Bongers, Li Guohua, Merel Jansen, Cong Wenfeng, Stella Kabiri, Niteen Kadam, Catherine Kiwuka, Alejandro Morales Sierra, Cyprian Mwale, Joao Unyes Vieira da Silva and Wang Na. Thank you very much for organizing or joining the scientific seminars, $\mathrm{PhD}$ meetings, lunch discussions, international dinners, Thursday drinks, or outdoor activities. You brought me great happiness and good memories in Wageningen. Luuk and Gu Shenghao, thank you very much for willing to be my paranymphs and your great help in thesis printing and organizing my defense ceremony and party.

I would also like to thank all my Chinese friends in Wageningen: Wang Zhaojun, Gu Shenghao, Yu Yang, Liu Chuchu, Li Guohua, Wu Liansun, Zou Yi, Wu Jia, Tan Meixiu, Li Huayi, Zhang Hao, Zhang Ningyi, Qin Wei, Song Chunxu, Wang Jingmeng, Liu Qian, Hou Yong, Yan Dan, Yao Mingtian, Wang Xinxin, Zhang Peiyu, Xue Wei, Tang Kailei, Ouyang Wengjing, He Wei, Huang Chidu, Liu Xia, Ma Lin, Cheng Xu, Zhu Feng, Zeng Tian, Yang Peipei, Zhang Lu, Li Chunjie, Bai Zhaohai, Guo Weijie, Hong Yu, Cong Wenfeng, Jing Jingying, Lu Yue, Huang Zheng, Chen Bin, Gu Junfei, Pan Yunyu and Cai Chuang. Thank you very much for organizing the fantastic travels and great parties, which colored my life in Wageningen. Zhaojun, I am very lucky having you during the lasts two years in Wageningen, as a "good Chinese neighbor" and as my best friend. Thank you very much for preparing delicious dinners for me when I was very busy writing the thesis. Thank you for sharing great 
stories from your hometown and your office. I wish you great success in your $\mathrm{PhD}$ study and your future career, and wish you could find your right person and have a colourful life.

Finally, I would like to express my deepest gratitude to my parents, my brother, my parentsin-law, my husband Zhu Junqi and other relatives. Thanks very much for your support, understanding and encouragement. Junqi, you not only support me in life but also helped me a lot in doing field experiments, in data analysis in $\mathrm{R}$ and giving suggestions to improve the manuscripts. It is my greatest happiness to have you with me in the past ten years, and thank you very much for loving me and accompanying me.

Fang Gou

Chongqing, China,

$26^{\text {th }}$ October, 2016 


\section{Publication list}

Gou, F., van Ittersum, M.K., Wang, G., van der Putten, P.E.L., van der Werf, W., 2016. Yield and yield components of wheat and maize in wheat-maize intercropping in the Netherlands. European Journal of Agronomy 76, 17-27.

Gou, F., van Ittersum, M.K., van der Werf, W., 2017. Simulating potential growth in a relaystrip intercropping system: model description, calibration and testing. Field Crops Research $200,122-142$.

Gou, F., van Ittersum, M.K., Simon, E., Leffelaar, P.A., van der Putten, P.E.L., Zhang, L., van der Werf, W., 2016. Intercropping wheat and maize increases total radiation interception and wheat RUE but lowers maize RUE (accepted by European Journal of Agronomy).

Gou, F., Yin, W., Hong, Y., van der Werf, W., Chai, Q., Heerink N., van Ittersum M.K., 2016. On yield gaps and yield gains in intercropping: opportunities for increasing grain production in northwest China (under revision for publication in Agricultural systems).

Gou, F., van Ittersum, M.K., Couëdel A., Zhang, Y., Wang, Y., van der Putten, P.E.L., Zhang, L., van der Werf, W., 2016. Wheat-maize intercropping lowers leaf nitrogen but increases leaf photosynthesis in maize: a puzzle of plant plasticity and competitive resource acquisition (submitted to Annals of Botany).

Gou, F., Zhang, L., Dong, W., Yu, Y., Di, W., Shen, J., 2012. Simulation model for crop development stages in sunflower and potato intercropping. Chinese Journal of Applied Ecology 10, 2773-2778 (in Chinese with English abstract).

Gou, F., Zhang, L., Dong, W., Yu, Y., Di, W., Zhao, P., Tuo, D., Pan X., 2013. Biomass Accumulations and Crop Yields Difference Research in a Couple of Strip Intercropping Systems in Agro-pastoral Ecotone. Scientia Agricultura Sinica 6, 129-141 (in Chinese with English abstract).

Yuan, M., Zhang, L., Gou, F., Su, Z., Spiertz, J.H.J., van der Werf, W., 2013. Assessment of crop growth and water productivity for five $\mathrm{C} 3$ species in semi-arid Inner Mongolia. Agricultural Water Management 122: 28-38.

Huang, C., Liu, Q., Gou, F., Xiaolin Li a, Zhang, C., van der Werf, W., Zhang, F., 2017. Plant growth patterns in a tripartite strip relay intercrop are shaped by asymmetric aboveground competition. Field Crops Research 201, 41-51. 



\section{PE\&RC Training and Education Statement}

With the training and education activities listed below the $\mathrm{PhD}$ candidate has complied with the requirements set by the C.T. de Wit Graduate School for Production Ecology and Resource Conservation (PE\&RC) which comprises of a minimum total of 32 ECTS (= 22 weeks of activities)

\section{Review of literature (4.5 ECTS)}

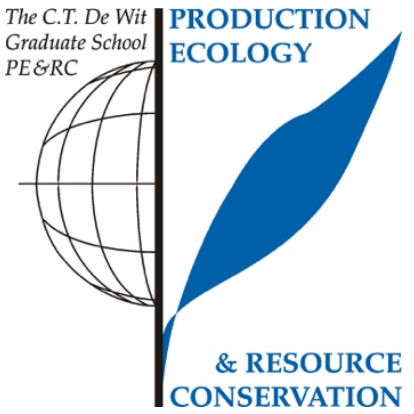

- Modelling resource use efficiency in intercropping systems

\section{Writing of project proposal (3 ECTS)}

- Explorative modelling and yield gap analysis of grain production in mixed cropping systems

\section{Post-graduate courses (7.2 ECTS)}

- The art of crop modelling; PE\&RC (2013)

- Introduction to R for statistical analysis; PE\&RC (2013)

- Zero-inflated models \& GLMM using R; PE\&RC (2014)

- Bayesian statistics; PE\&RC (2015)

- Modelling plant form and function using GroIMP; PE\&RC (2016)

\section{Invited review of (unpublished) journal manuscript (2 ECTS)}

- Field Crops Research: comparing agricultural practices and yields of low-input, organic and conventional systems (2015)

- Crop Science: intercropping pea with wheat under different planting dates and mineral nitrogen fertilizer rates (2015)

\section{Deficiency, refresh, brush-up courses (24 ECTS)}

- Systems analysis, simulation and systems management; PE\&RC (2012)

- Advanced statistics; PE\&RC (2012)

- Ecological modelling and data analysis in R; PE\&RC (2013)

- Quantitative analysis land use systems; PE\&RC (2014)

\section{Competence strengthening / skills courses (2 ECTS)}

- Workshop scientific integrity; WGS (2013)

- PhD Workshop carousel; WGS $(2014,2016)$

- The essentials of scientific writing and presenting; WGS (2015) 
PE\&RC Annual meetings, seminars and the PE\&RC weekend (1.2 ECTS)

- PE\&RC Weekend (2013)

- PE\&RC Day $(2014,2015)$

\section{Discussion groups / local seminars / other scientific meetings (6.3 ECTS)}

- $\quad$ Lunch seminar CSA \& PPS (2013-2016)

- Sustainable Intensification of Agricultural Systems (SIAS) (2014-2016)

- $\quad$ R Users meeting (2015)

\section{International symposia, workshops and conferences (6.3 ECTS)}

- Netherlands Annual Ecology Meeting; oral presentation; the Netherlands (2015)

- Intercropping workshop and field trip; oral presentation; China (2015)

- International crop modelling symposium; poster presentation; Germany (2016)

\section{Lecturing / supervision of practical's / tutorials (6.6 ECTS)}

- Population \& systems ecology $(2013,2014)$

- Ecological modelling and data analysis in R (2015)

\section{Supervision of MSc student}

- Plant growth and development of wheat and maize in intercrop

- Light interception and utilization of wheat and maize in intercrop

- Maize leaf traits and photosynthesis for maize in intercrop

- Yield and yield components of wheat and maize in intercrop

- Modelling water use efficiency in wheat-maize intercrop 


\section{Curriculum vitae}

Fang Gou was born on July $10^{\text {th }}, 1985$ in Chongqing city, southwest China. In 2004, she left her hometown and studied Agro-meteorology at China Agricultural University in Beijing. After her Bachelor studies, she worked as an assistant engineer in a wind power company in Beijing. In 2010, she started her Master studies in the Department of Applied Agrometeorology, China Agricultural University. During her MSc study, she worked on several intercropping systems in Inner Mongolia for sustainable food production and soil protection from wind erosion. In 2012, she completed her Master degree and obtained a four-year scholarship from the China Scholarship Council. In September 2012, she moved to the Netherlands and started her $\mathrm{PhD}$ research at Wageningen University in the Centre for Crop Systems Analysis and Plant Production Systems group. During her PhD research, she studied the growth and productivity of wheat-maize intercropping at organ, plant and cropping system level, and assessed its contribution to grain production at a regional level. 


\section{Funding}

The research described in this thesis was financially supported by the National Key Research and Development Program of China (2016YFD0300202), the China Scholarship Council (CSC), the Key Sino-Dutch Joint Research Project of NSFC (grant number: 31210103906) and the International Cooperation and Exchange of the National Science Foundation of China (31461143025).

Cover design Fang Gou

Printing GVO drukkers \& vormgevers B.V., Ede 